\title{
Targeting PPARs in metabolic risk management: A pharmacological and nutritional approach
}

Citation for published version (APA):

Bragt-van Wijngaarden, M. C. E. (2011). Targeting PPARs in metabolic risk management: $A$ pharmacological and nutritional approach. [Doctoral Thesis, Maastricht University]. Datawyse / Universitaire Pers Maastricht. https://doi.org/10.26481/dis.20111214mb

Document status and date:

Published: 01/01/2011

DOI:

10.26481/dis.20111214mb

Document Version:

Publisher's PDF, also known as Version of record

\section{Please check the document version of this publication:}

- A submitted manuscript is the version of the article upon submission and before peer-review. There can be important differences between the submitted version and the official published version of record. People interested in the research are advised to contact the author for the final version of the publication, or visit the DOI to the publisher's website.

- The final author version and the galley proof are versions of the publication after peer review.

- The final published version features the final layout of the paper including the volume, issue and page numbers.

Link to publication

\footnotetext{
General rights rights.

- You may freely distribute the URL identifying the publication in the public portal. please follow below link for the End User Agreement:

www.umlib.nl/taverne-license

Take down policy

If you believe that this document breaches copyright please contact us at:

repository@maastrichtuniversity.nl

providing details and we will investigate your claim.
}

Copyright and moral rights for the publications made accessible in the public portal are retained by the authors and/or other copyright owners and it is a condition of accessing publications that users recognise and abide by the legal requirements associated with these

- Users may download and print one copy of any publication from the public portal for the purpose of private study or research.

- You may not further distribute the material or use it for any profit-making activity or commercial gain

If the publication is distributed under the terms of Article $25 \mathrm{fa}$ of the Dutch Copyright Act, indicated by the "Taverne" license above, 


\section{Targeting PPARs in metabolic}

risk management: a pharmacological and nutritional approach 


\section{ilutín}

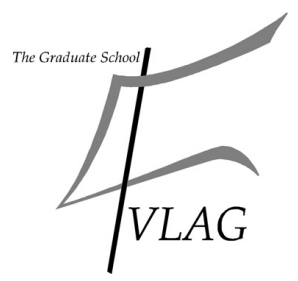

The studies in this theses werd performed within the Nutrition and Toxicology Research Institute Maastricht (NUTRIM), which participates in the Graduate School VLAG (Food Technology, Agrobiotechnology, Nutrition and Health Sciences), accredited by the Foyal Netherlands Academy of Arts and Sciences.

Cover design: Menno Oosterhuis (mnno.nl)

Styling: Anneke Boringa, FrieslandCampina

Print: Datawyse bv / Universitaire Pers Maastricht

ISBN nr. 9789461591029 


\title{
Targeting PPARs for metabolic risk management: a pharmacological and nutritional approach
}

\author{
Proefschrift \\ Ter verkrijging van de graad van doctor aan de Universiteit Maastricht, \\ op gezag van de Rector Magnificus, Prof. mr. G.P.M.F. Mols, \\ volgens het besluit van het College van Decanen, \\ in het openbaar te verdedigen \\ op woensdag 14 december 2011 om 14.00 uur \\ door \\ Marjolijn C.E. Bragt-van Wijngaarden \\ Geboren op 10 januari 1981 te Roosendaal en Nispen
}

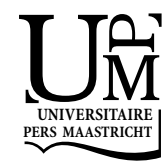




\section{Promotor}

Prof. dr. ir. R.P. Mensink

\section{Beoordelingscommissie}

Prof. dr. E.C.M. Mariman (voorzitter)

Prof. dr. E.E. Blaak

Prof. dr. M.K.C. Hesselink

Prof. dr. ir. A.H. Kersten, Wageningen University

Prof. dr. ir. A.M.W.J. Schols 
“Let als je naar een doel reist goed op de weg.

Want de weg verrijkt ons terwijl we hem bewandelen".

"When you travel toward an objective, be sure to pay attention to the road. It is the road that enriches us as we walk its length."

(Paulo Coelho)

Aan mijn ouders 



\section{Content}

\section{Chapter 1}

General introduction

\section{Chapter 2}

Blood-based gene expression analysis as a tool for biomarker discovery

\section{Chapter 3}

Anti-inflammatory effect of rosiglitazone is not reflected in expression of $\mathrm{NF} \kappa \mathrm{B}$-related genes in peripheral blood mononuclear cells of patients

with type 2 diabetes mellitus

\section{Chapter 4}

Comparison of the effects of n-3 long chain polyunsaturated fatty acids and fenofibrate on markers of inflammation and vascular function, and on the serum lipoprotein profile in overweight and obese subjects

\section{Chapter 5}

Effects of fenofibrate and fish oil on gene expression in peripheral blood mononuclear cells, muscle, and adipose tissue from overweight and obese individuals

\section{Chapter 6}

Differential effects of fenofibrate and fatty acids on NFאB activity in HepG2 cells 99

\section{Chapter 7}

General discussion

Summary

Samenvatting

Dankwoord 151 



\section{СнартеR 1}

\section{General introduction}



The global epidemic of obesity is clearly associated with the increasing incidence of diet-related diseases, such as cardiovascular diseases (CVD) and type II diabetes mellitus (T2D)1. Obesity is often associated with various metabolic disturbances, such as abnormal lipid and carbohydrate metabolism and a pro-inflammatory state of the body. These lipid and non-lipid risk factors of metabolic origin predispose to the development of the metabolic syndrome (figure 1). The metabolic syndrome in clinical practice is most frequently diagnosed according to the guidelines of the National Cholesterol Education Program Third Adult Treatment Panel (NCEP ATPIII) ${ }^{2}$. It defines the metabolic syndrome when 3 of the following criteria are present: waist circumference $\geq 102 \mathrm{~cm}$ in men and $\geq 88 \mathrm{~cm}$ in women, $\mathrm{HDL}$ cholesterol $\leq 1.03 \mathrm{mmol} / \mathrm{L}$ in men and $\leq 1.3 \mathrm{mmol} / \mathrm{L}$ in women, triglycerides $\geq 1.7 \mathrm{mmol} / \mathrm{L}$ and elevated blood pressure (systolic blood pressure $\geq 130$ $\mathrm{mmHg}$ or diastolic blood pressure $\geq 85 \mathrm{mmHg}$ ). These conditions increases the risk of developing CVD and T2D³.

The exact mechanisms underlying the metabolic syndrome are still unknown, but potential molecular targets to treat and prevent this metabolic disturbance are peroxisome proliferator-activated receptors (PPARs). PPARs are one of the central regulators of nutrient-gene interactions and involved in various metabolic processes. Understanding the physiological and molecular effects of PPARs in these processes will therefore provide insight in potential targets for the prevention of the metabolic syndrome

This chapter will give a general introduction to the metabolic processes involved in the metabolic syndrome and the role of PPARs herein and provides the outline of this thesis.

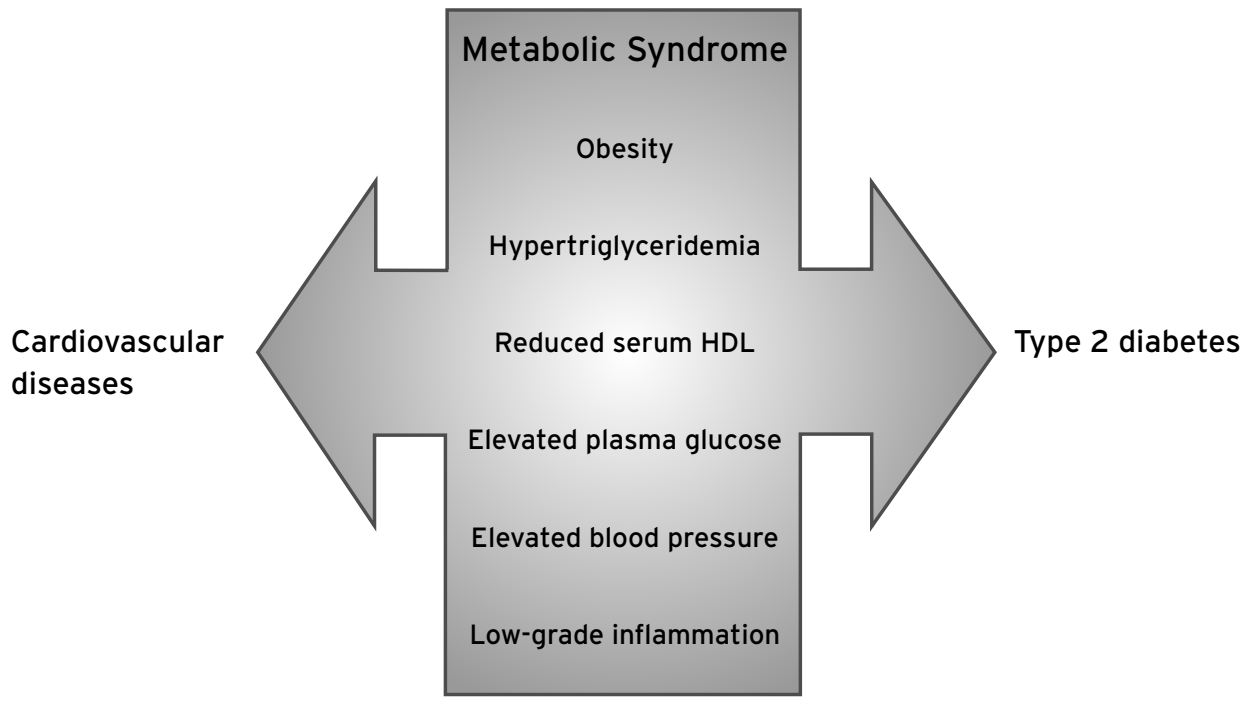

Figure 1. Metabolic disturbances and diseases associated with the metabolic syndrome. 


\section{Regulation and deregulation of lipid and lipoprotein metabolism}

A large part of morbidity and mortality in the Western population is related to disturbances in lipid metabolism. Therefore, many attempts have been made in human studies and animal studies to modulate specific lipids and constituents of lipoprotein particles in order to understand and to prevent the consequences of these disturbances. This paragraph will briefly describe the regulation of lipid and lipoprotein metabolism.

\subsection{Lipoproteins}

Lipoproteins are particles found in plasma that transport the fat-soluble cholesterol and triglycerides. There are various lipoprotein classes: chylomicrons, very low density lipoprotein (VLDL), intermediate dense lipoproteins (IDL), low density lipoproteins and high density lipoproteins (HDL). Each class varies in size, weight, lipid composition, density and apolipoprotein content (table 1). Lipoproteins consist of a hydrophobic core containing esterified cholesterol and triglycerides, surrounded by a monolayer of phospholipids. The polar phospholipid surface allows the lipoproteins to travel in the aqueous blood plasma. The lipoprotein membrane also contains apolipoproteins, the major protein components of lipoproteins. Apolipoproteins are among others responsible for the recognition of the lipoprotein particle by a specific receptor. Importantly, within their class, lipoproteins are in a constant flux following a continuum of decreasing size and density. This means that within each class, lipoproteins can be further divided into subclasses ${ }^{4}$. For example, LDL can be divided in the subclasses light (LDL1 and 2), intermediate (LDL3), or dense (LDL4 and 5).

Table 1. Composition and properties of lipoprotein classes.

\begin{tabular}{lcccccc}
$\begin{array}{l}\text { Lipoprotein } \\
\text { class }\end{array}$ & $\begin{array}{c}\text { Density }(\mathrm{g} / \\
\mathrm{mL})\end{array}$ & $\begin{array}{c}\text { Diameter } \\
(\mathrm{nm})\end{array}$ & Protein $(\%)$ & $\begin{array}{c}\text { Cholesterol } \\
(\%)\end{array}$ & $\begin{array}{c}\text { Phospho- Triglycerides } \\
\text { lipid(\%) }\end{array}$ & $\begin{array}{c}(\%) \\
\text { Chylomicron }\end{array}$ \\
\hline 0.95 & $100-500$ & $1-2$ & 8 & 7 & 84 \\
VLDL & $0.95-1.006$ & $30-80$ & 10 & 22 & 18 & 50 \\
LDL & $1.006-1.019$ & $25-50$ & 18 & 29 & 22 & 31 \\
IDL & $1.019-1.063$ & $18-28$ & 25 & 50 & 21 & 4 \\
HDL & $1.063-1.21$ & $5-15$ & 33 & 30 & 29 & 8 \\
\hline
\end{tabular}

\subsection{Lipid and lipoprotein metabolism}

The digestion and absorption of dietary fat are part of the so-called exogenous pathway (figure 2). Dietary fat consists mainly of triglycerides (TG), which are insoluble in the aqueous environment of the gut. Due to the action of bile salts, fat is emulsified yielding mixed micelles to transport dietary lipids to the 
intestinal cells and to make these lipids more vulnerable to be attacked by water soluble enzymes. By the action of pancreatic lipase (PL) in the intestine, TG are hydrolyzed to free fatty acids (FFA) and monoacylglycerol. Short chain fatty acids ( $\leq 12$ carbons) will enter the circulation directly. Other fatty acids will be first esterified back to TG after absorption in the enterocyte. Then, TG will enter the circulation as chylomicrons containing apoB48, A-I and A-IV via the lymphatic system. In the circulation, apoCll becomes attached and serves as a cofactor for lipoprotein lipase (LPL) to hydrolyze TG into FFA in the capillary endothelium. The resulting FFA will be taken up by peripheral tissues to be stored as fat, oxidized to provide energy, or re-esterified to TG in the liver and transported back into the circulation as very low density lipoproteins (VLDL). After depletion of TG, chylomicron remnant particles will be taken up by the apoE receptor in the liver and removed from the circulation.

The synthesis and secretion of TG and cholesterol by the liver is defined as the endogenous pathway (figure 2). Free fatty acids bound to albumin in blood plasma are taken up by the liver and packaged as TG into VLDL particles together with apoB100, CII and E. TG and VLDL can also be synthesized from a surplus of glucose and amino acids in the fed state. VLDL undergoes hydrolysis by the action of LPL together with cofactor apoCII, resulting in a smaller IDL particle. Part of the IDL particles is converted to LDL by the action of hepatic lipase $(\mathrm{HL})$ and another part will be taken up again by the liver via the apoE or LDL receptor (LDLR). LDL particles containing apoB account for the majority of serum cholesterol and can be taken up via LDL receptors in the liver or in other peripheral tissues. There is a large heterogeneity in LDL particles, due to differences in the amount of cholesterol per particle. In this respect, a differentiation can be made between the highly atherogenic small dense particles and the less atherogenic buoyant LDL particles. Especially small dense LDL particles are considered to be atherogenic, since they can more easily cross the capillary endothelium ${ }^{5}$ and are more susceptible to oxidation ${ }^{6}$. In the endothelium, cholesteryl esters from these particles can be taken up and accumulate in macrophages, resulting in the formation of foam cells. Together with an increase in inflammation, this contributes to an increased risk to develop atherosclerosis.

$\mathrm{HDL}$ is involved in reverse cholesterol transport (figure 2). It receives excess cholesterol from peripheral tissues to transport it back to the liver. Cholesterol and phospholipids are transferred to apolipoprotein A1 (apoA1), a process catalyzed by ATP binding cassette transporter A1 (ABCA1). This results in the formation of a nascent HDL particle, also called pre- $\beta$-HDL. Then, the transporter ABCG1 and the enzyme lysolecithin cholesterol acyltransferase (LCAT) increase the capacity of $\mathrm{HDL}$ to receive and esterify cholesterol, leading to a mature and more dense HDL particle. HDL cholesteryl esters will be taken up by scavenger receptor B1 (SR-BI) in the liver and used for the synthesis of bile acids. HDL cholesteryl esters can also be shuttled to other lipoproteins by the action of cholesteryl ester transfer protein (CETP). 


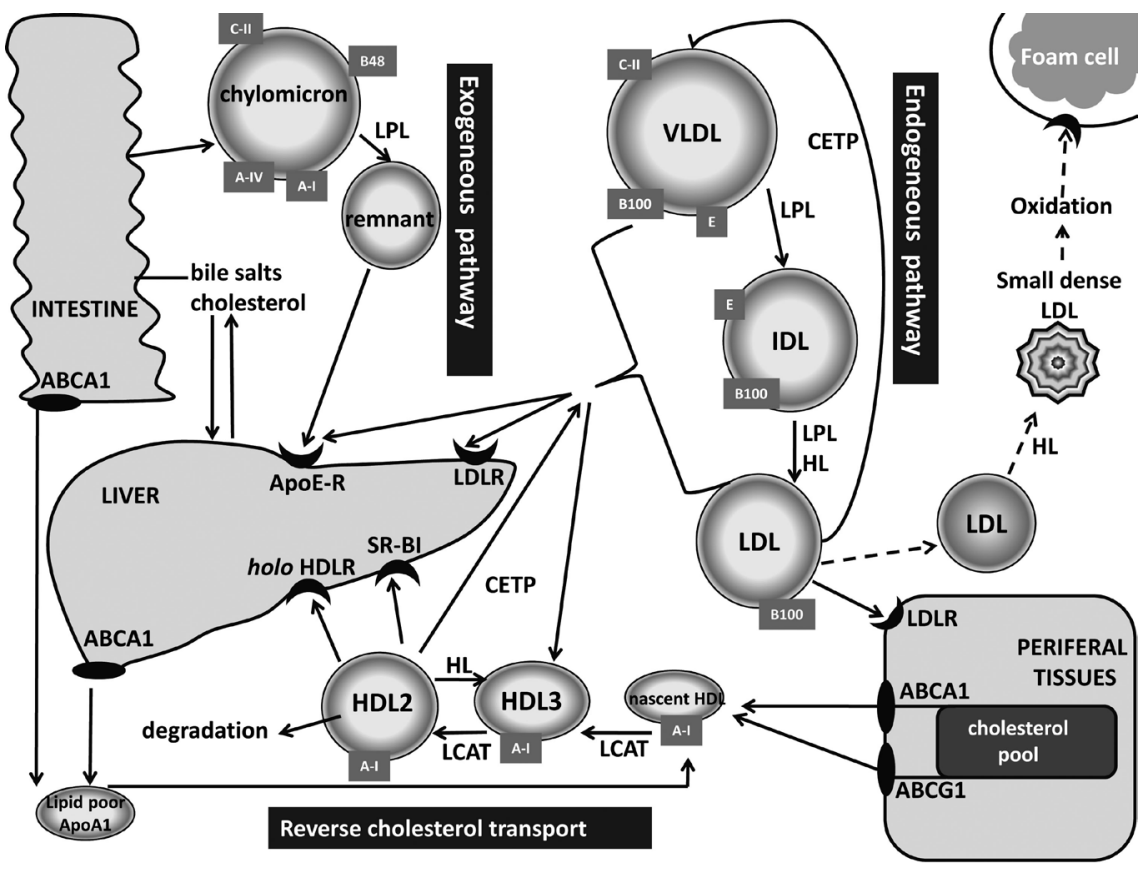

Figure 2. Schematic overview of lipoprotein metabolism.

ABC: ATP binding cassette transporter, Apo: apolipoprotein, CETP: cholesteryl ester transfer protein, FFA: free fatty acids, HDL: high density lipoprotein, HDLR: HDL receptor, HL: hepatic lipase, HSL: hormone sensitive lipase, IDL: intermediate density lipoprotein, LCAT: Iysolecithin cholesterol acyltransferase, LDL: low density lipoprotein, LDLR: LDL receptor, LPL: lipoprotein lipase, PL: pancreatic lipase, SR-BI: scavenger receptor class B member 1 , TG: triglycerides, VLDL: very low density lipoproteins.

\subsection{Dyslipidemia in the metabolic syndrome}

A feature of the metabolic syndrome is a deregulation of lipid and lipoprotein metabolism, resulting in an atherogenic lipoprotein profile characterized by small dense $L D L$, decreased high density $H D L$, and increased TG7. The lipid overflow in the metabolic syndrome can lead to the accumulation of fat in non-adipose tissues, such as muscle, heart and liver, which contributes to the development of insulin resistance ${ }^{8}$. Normally, in response to a meal, our body will produce insulin. Insulin stimulates LPL and inhibits hormone-sensitive lipase (HSL) ${ }^{9}$ (figure 3). This will result in an increased triglyceride and fatty acid synthesis in adipose tissue and liver. The metabolic syndrome, however, is often associated with an insulin-resistant state. Insulin is overproduced, but tissues do not adequately respond to insulin anymore. This leads to lipid metabolic disturbances (figure 3 ). In the insulin resistant state, the inhibitory effect of insulin on HSL is diminished or lost, leading to increased activity of HSL. This results in an increased release of FFA from the adipose tissue ${ }^{9}$. Also, LPL will be inhibited in the insulin resistant 
state resulting in the accumulation of TG-rich VLDL particles. TG from these VLDL particles can be transported via CETP to HDL, resulting in smaller TGrich HDL particles. Small HDL a better substrate for HSL and therefore quickly cleared from the circulation ${ }^{10}$. As a consequence, less HDL particles are available for the reverse cholesterol transport. All together, this will ultimately lead to dyslipidemia, an important characteristic of the metabolic syndrome.

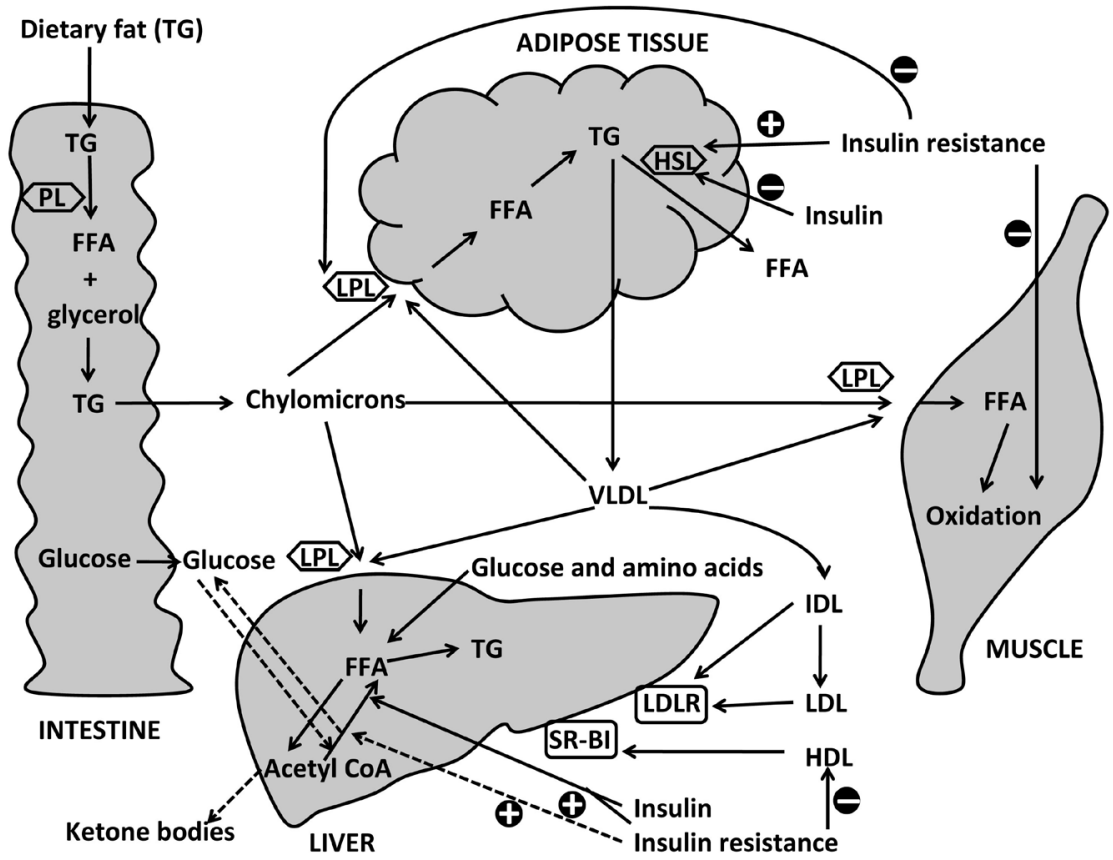

Figure 3. Schematic overview of lipid metabolism and disturbances in the metabolic syndrome.

FFA: free fatty acids, HDL: high density lipoprotein, HL: hepatic lipase, HSL: hormone sensitive lipase, IDL: intermediate density lipoprotein, LDL: Iow density lipoprotein, LDLR: LDL receptor, LPL: lipoprotein lipase, PL: pancreatic lipase, SR-BI: scavenger receptor class member 1, TG: triglycerides, VLDL: very low density lipoproteins.

\section{Regulation and deregulation of glucose metabolism}

Disturbances in lipid and glucose metabolism in the metabolic syndrome are inter-related. Excess of adipose tissue is associated with an increased secretion of insulin, leading to hyperinsulinemia. Insulin plays an important role in lipid metabolism, but is also the predominant regulator of glucose metabolism. Insulin lowers blood glucose by suppression of gluconeogenesis in the liver and stimulation of glucose uptake by peripheral tissues, mainly muscle and adipose 
tissue. The metabolic syndrome is associated with resistance to insulin-mediated glucose uptake, and one of the diagnostic criteria of the metabolic syndrome is an elevated fasting plasma glucose level. As tissues become less sensitive to insulin, glucose and FFA levels will strongly increase after a meal, but the extra amount of insulin produced by the pancreatic $\beta$ cells is still sufficient to maintain normoglycemia. However, at a certain moment, the pancreas will not be able to produce enough insulin to overcome the insulin resistance. In this case, gluconeogenesis in the liver will be strongly increased. Also, the inhibitory effect of insulin on adipose tissue HSL will disappear and causes FFA levels to further increase. In this way, hyperglycemia can develop, leading to the progression of metabolic syndrome into T2D or CVD.

\section{Low-grade systemic inflammation}

Metabolism and immunity are tightly linked, as many hormones, cytokines, signaling proteins, transcription factors, and bioactive lipids play a role in both metabolism and immunity ${ }^{11}$. The metabolic syndrome is associated with a lowgrade inflammation state ${ }^{12}$, which plays a critical role in the development of insulin resistance, T2D ${ }^{11}$ and CVD ${ }^{13}$. Body fat, especially visceral fat, is seen as a key regulator of inflammation. Adipose tissue is not merely a passive fat depot, but acts more as an active endocrine organ capable of secreting numerous cytokines. Adipocytes secrete a variety of pro-inflammatory proteins, such as MMP9, TNF $\alpha$ and IL6". It is also possible that these inflammatory proteins are secreted by macrophages, since these cells co-localize with adipocytes in adipose tissue and have overlapping metabolic and inflammatory signaling and sensing pathways ${ }^{11}$. These secreted proteins contribute to a state of low-grade systemic inflammation. The increased level of pro-inflammatory cytokines together with elevated FFA levels in the plasma of obese subjects also stimulate the liver to secrete $\mathrm{C}$-reactive protein $(\mathrm{CRP})^{14,15}$. This even worsens the state of low-grade inflammation, because CRP is an acute phase protein involved in various inflammatory processes. As a result, the risk of developing T2D and CVD increases, as inflammation has been shown to be one of the underlying causes of atherosclerosis and insulin resistance ${ }^{16,17}$. However, it should be noted that body fat is not exclusively responsible for the state of low-grade inflammation. Other suggested contributors to the development of a low-grade inflammatory state are increases in nonesterified plasma fatty acids due to a decreased fat storage capacity in adipose tissue ${ }^{12,18}$, insensitivity to the anti-inflammatory effects of insulin ${ }^{12}, 19$, or reduced anti-inflammatory molecules, such as adiponectin and IL10 12 .

\section{PPARs}

A common denominator to link all metabolic and inflammation processes as described in the previous chapters is the involvement of peroxisome proliferator- 
activated receptors (PPARs). PPARs are one of the central regulators of nutrientgene interactions and are able to regulate lipid, carbohydrate, and inflammatory pathways, hereby maintaining homeostasis ${ }^{20-22}$. So far, three PPAR isotypes have been identified in vertebrates: PPAR $\alpha$, PPAR $\delta$, and PPAR $\gamma$ PPAR $\alpha$ and PPAR $\gamma$ are within the focus of this thesis and will be discussed in this paragraph. PPAR $\alpha$ is abundantly expressed in the liver and to a lesser extent in the kidney, testes, heart, small intestine, pancreas, smooth muscle and adipose tissue ${ }^{23}$. PPAR $\gamma$ mRNA is specifically expressed at high levels in adipose tissue, but is also detected in the intestine (colon), skeletal muscle, liver and bone marrow stromal cells ${ }^{23}$. PPARs are ligand-activated transcription factors and activate transcription of their target genes as a heterodimer with their DNA binding partner retinoid $X$ receptor $(R X R)^{24}$. The PPAR:RXR complex initiates gene transcription after binding to the PPAR response elements (PPRE) in enhancer sites of regulated genes (left part of figure 4 ).

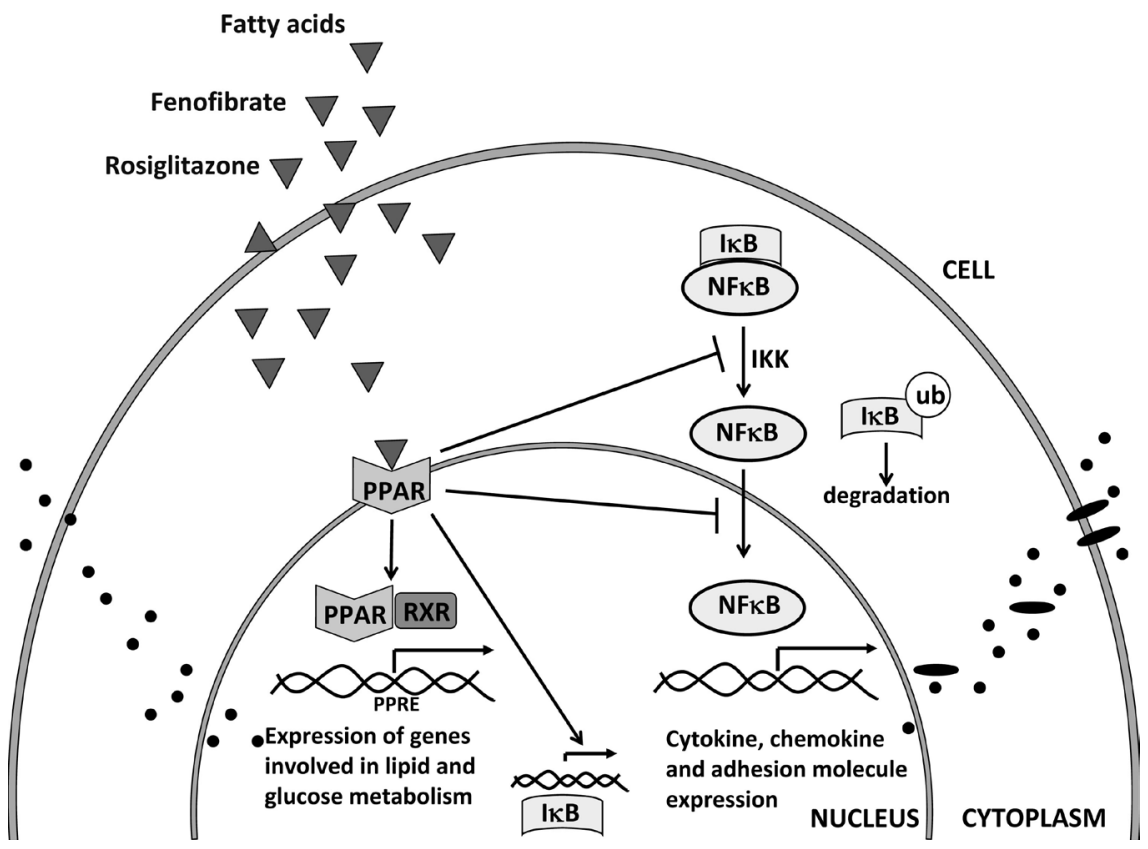

Figure 4. PPAR signaling (left) and interference with NF $\kappa B$ signaling (right).

$I \kappa B$ : inhibitor $\kappa B$, IKK: I $\mid \kappa B$ kinase, NF $\kappa B$ : nuclear factor $\kappa B$, PPAR: peroxisome proliferatoractivated receptor, PPRE: PPAR response element, $R X R$ : retinoid $X$ receptor, ub: ubiquitination

\subsection{PPAR ligands}

The activity of PPARs can be modulated by synthetic ligands, such as the hypolipidemic drug fenofibrate (activates PPAR $\alpha$ ) or the insulin-sensitizing drug rosiglitazone (activates PPAR $\gamma$ ). In addition, PPARs are able to sense the presence 
of fatty acids ${ }^{25}$. The types of fatty acids differ in their ability to activate PPARs, as has been demonstrated in studies using almost exclusively ligand-binding assays $^{24}$. In this respect, polyunsaturated fatty acids deserve attention as they have been shown to be very potent natural activators of PPARs ${ }^{26,27}$. There is a large overlap in ligand recognition between the PPAR isotypes ${ }^{28}$, but regardless of this overlap, there will remain a functional difference between the isotypes due to differences in binding affinity of the ligands and the tissue distribution of PPARs $^{28}$.

\subsection{Metabolic role of PPAR $\alpha$}

PPAR $\alpha$ is mainly involved in lipid metabolic processes to maintain lipid homeostasis. Increased plasma free fatty acid levels are thought to stimulate PPAR $\alpha$ target genes, resulting in an increased cellular uptake, intracellular esterification, and mitochondrial $\beta$-oxidation of fatty acids ${ }^{29-32}$. PPAR agonists, like fibrates, improve the lipid profile by decreasing triglyceride levels and LDL cholesterol levels ${ }^{33}, 34$. This hypotriglyceridemic effect is mediated by an increased lipoprotein lipase activity by PPAR $\alpha^{33}$. Additionally, a modification of plasma lipoproteins was observed after fibrate treatment, namely a reduction in the triglyceride content of VLDL particles and a reduction of small dense LDL particles ${ }^{35}$. HDL cholesterol levels increase upon PPAR $\alpha$ activation, possibility via the induction of ATP binding cassette transporter A1 (ABCA1) or enhanced apolipoprotein A1 (ApoA1) mRNA expression ${ }^{36,37}$. In this way, PPAR $\alpha$ stimulates cholesterol efflux from peripheral tissues and subsequent uptake of cholesterol by the liver, as well as the release of new HDL particles into the circulation. All together, PPAR $\alpha$ activation is thought to contribute to a less atherogenic lipid profile and favors a healthier lipid homeostasis.

\subsection{Metabolic role of PPAR}

PPAR $\gamma$ is mainly involved in glucose metabolism, but also exerts a potential beneficial effect on lipid metabolism ${ }^{38}$. Studies with tissue-specific PPAR knockout mice, demonstrated that PPAR $\gamma$ agonists exert their effects primarily by influencing skeletal muscle ${ }^{39,40}$. PPAR $\gamma$ activation increases the expression of genes involved in glucose uptake and synthesis by skeletal muscle. Modulation of gene expression in liver will result in a reduced hepatic glucose production and subsequent release due to a decreased gluconeogenesis ${ }^{39-41}$. PPAR $\gamma$ also is a key regulator of adipocyte differentiation and adipogenesis. Stimulation of adipocyte differentiation via PPAR $\gamma$ leads to the formation of an increased number of small adipocytes, which are able to take up free fatty acids more easily ${ }^{42}$. Consequently, the flux of free fatty acids to the liver and muscle will be decreased and reverses the insulin resistance of the muscle. This could ameliorate the effect of metabolic syndrome. In general, human intervention studies with PPAR $\gamma$ agonists report reduced fasting insulin concentrations, glucose concentrations, and improved whole body insulin sensitivity ${ }^{38}$. Like PPAR $\alpha$ agonists, PPAR $\gamma$ agonists can reduce plasma free fatty acid concentration, mainly by increasing fatty acid 
uptake and storage ${ }^{43}$. Generally, HDL levels are increased upon treatment with a PPAR $\gamma$ agonist ${ }^{44}$. Differential effects have been observed for triglyceride and LDL cholesterol levels, depending on the type of PPAR $\gamma$ agonist ${ }^{45-48}$. PPAR $\gamma$ agonists are able to increase the size of LDL particles and decrease the number of atherogenic small dense LDL particles ${ }^{38}$.

\subsection{PPARs in inflammation}

It thought that PPAR $\alpha$ and PPAR $\gamma$ represses inflammation by a physical interaction and forming inactive complexes with proinflammatory transcription factors, such as Nuclear Factor $\kappa \mathrm{B}(\mathrm{NF} \kappa \mathrm{B})$ (figure 4$)^{20,49}$. This transcription factor normally induce the transcription of pro-inflammatory genes, such as cytokines (IL6, TNF $\alpha$ ), chemokines (IL8, MCP1), and cellular adhesion molecules (VCAM1, ICAM1 $)^{50}$. Another way in which PPAR $\alpha$ and PPAR $\gamma$ control inflammation is more indirectly by influencing transcription of genes that inhibit NFKB signaling, such as Inhibitor $\kappa B\left(I_{\kappa} B\right)$ and $I_{\kappa} B$ kinase (IKK) (figure 4). For example, ligandactivated PPAR $\alpha$ is able to induce the expression of $I_{\kappa} B^{49}$. This is a protein that binds to $N F \kappa B$ and prevents the translocation of $N F \kappa B$ to the cell nucleus and, subsequent, the transcription of pro-inflammatory genes. Therefore, induction of I $\mathrm{B}$ via PPAR $\alpha$ is correlated with a decrease in inflammation. Another example is the inhibition of IKK upon activation of PPAR $\gamma^{20}$. Inhibition of IKK prevents the degradation of $I_{\kappa} B$. In this way NFKB stays bound to its inhibitor, retains in the cytoplasm, and is unable to activate gene transcription of pro-inflammatory genes. Due to this NFאB inhibitory effect, targeting inflammation via PPARs may provide an interesting way to ameliorate the state of low-grade inflammation and reduce the risk of T2D and CVD.

\section{Peripheral blood mononuclear cells as surrogate to study gene expression}

Gene expression profiling is an interesting way to explore the effects of pharmacological or nutritional challenges on the metabolic state or condition of different target tissues. However, this is complicated in humans due to the relative inaccessibility of target tissues. Therefore, it would be advantageous to use blood cells, since blood is more readily accessible in contrast to muscle and adipose tissue for example. From a technical point of view, peripheral blood mononuclear cells (PBMCs) are very suitable to isolate from whole blood and for RNA extraction for the purpose of gene expression studies. PBMCs are cells with a round nucleus and consist of Iymphocytes (T-cells, B-cells and NK-cells) and monocytes, which play an important role in immune responses.

Blood cells circulate through the body and may serve as sentinels, which pick up physiological and pathological changes and capture these changes by altering their transcriptome ${ }^{51}$. Gene expression studies have shown that PBMCs respond to nutritional-52, pharmacological-53 and toxicological stimuli54 and exercise $^{55}$. Furthermore, PBMCs have been used for diagnostic, mechanistic 
and therapeutic assessments of different disease states ${ }^{56}$. PBMCs also express PPARs, which makes PBMCs also interesting to study the molecular effects of these transcription factors. Altogether, studying gene expression in PBMCs can give more insight in the mechanisms behind the nutritional and pharmacological effects on several metabolic processes. This will contribute to the identification of early transcriptional biomarkers for the prevention of metabolic disturbances. However, more information is needed if PBMCs indeed give a good reflection of the metabolic condition of specific target tissues.

\section{Outline of this thesis}

This thesis provides insight in the physiological and molecular effects of PPARs in various metabolic processes and the role that nutrition can play in modulating these transcription factors. In this light, the suitability of PBMCs to study gene expression will be addressed. Chapter 2 provides and extensive overview of the use of gene expression profiles in blood cells, with emphasis on the use of PBMCs, and discusses the applicability of these expression profiles to detect gene expression changes reflecting the condition of specific target tissues and metabolic changes. The role of PPAR $\gamma$ in inflammation control is addressed in chapter 3. For this, we studied the effect of rosiglitazone on plasma inflammatory markers in T2D patients in the fasted and hyperinsulinemic state. In addition, we examined if changes in plasma inflammatory markers were also reflected by inflammation-related gene expression changes in PBMCs. In chapters 4 and 5 , a comparison is made between a pharmacological (fenofibrate) and dietary (fish oil) approach to target PPAR $\alpha$ in a double-blind, randomized, placebo controlled, cross-over study in twenty overweight and obese subjects. First, the physiological effects of fenofibrate and fish oil on plasma and serum metabolic risk markers will be described (chapter 4). Secondly, the effects of fish oil and fenofibrate on gene expression profiles in PBMCs, muscle and adipose tissue are addressed (chapter 5). Chapter 6 describes a mechanistic in vitro study to elucidate the role of PPAR $\alpha$ in mediating the effects of different fatty acids and fenofibrate on NFKB activity in a human liver cell model. Chapter 7 briefly summarizes the findings of the different studies that have been described. In this last chapter, the main results are discussed in depth and put into a broader perspective. 


\section{References}

1 James PT. Obesity: the worldwide epidemic. Clin Dermatol, 2004; 22: 276-280.

2 Executive Summary of The Third Report of The National Cholesterol Education Program (NCEP) Expert Panel on Detection, Evaluation, And Treatment of High Blood Cholesterol In Adults (Adult Treatment Panel III). Jama, 2001; 285: 2486-2497.

3 Salmenniemi U, Ruotsalainen E, Pihlajamaki J, et al. Multiple abnormalities in glucose and energy metabolism and coordinated changes in levels of adiponectin, cytokines, and adhesion molecules in subjects with metabolic syndrome. Circulation, 2004; 110: 3842-3848.

4 Otvos JD, Jeyarajah EJ, Bennett DW, et al. Development of a proton nuclear magnetic resonance spectroscopic method for determining plasma lipoprotein concentrations and subspecies distributions from a single, rapid measurement. Clin Chem, 1992; 38: 1632-1638.

5 Bjornheden T, Babyi A, Bondjers G, et al. Accumulation of lipoprotein fractions and subfractions in the arterial wall, determined in an in vitro perfusion system. Atherosclerosis, 1996; 123: 43-56.

6 Tribble DL, Rizzo M, Chait A, et al. Enhanced oxidative susceptibility and reduced antioxidant content of metabolic precursors of small, dense low-density lipoproteins. Am J Med, 2001; 110: 103-110.

7 Berneis K and Rizzo M. LDL size: does it matter? Swiss Med Wkly, 2004; 134: 720-724.

8 Bergman RN, Kim SP, Hsu IR, et al. Abdominal obesity: role in the pathophysiology of metabolic disease and cardiovascular risk. Am J Med, 2007; 120: S3-8; discussion S29-32.

9 Lewis GF, Carpentier A, Adeli K, et al. Disordered fat storage and mobilization in the pathogenesis of insulin resistance and type 2 diabetes. Endocr Rev, 2002; 23: 201-229.

10 Lewis GF and Rader DJ. New insights into the regulation of HDL metabolism and reverse cholesterol transport. Circ Res, 2005; 96: 1221-1232.

11 Wellen KE and Hotamisligil GS. Inflammation, stress, and diabetes. J Clin Invest, 2005; 115: 1111-1119.

12 Esposito $\mathrm{K}$ and Giugliano D. The metabolic syndrome and inflammation: association or causation? Nutr Metab Cardiovasc Dis, 2004; 14: 228-232.

13 Libby P. Inflammation and cardiovascular disease mechanisms. The American journal of clinical nutrition, 2006; 83: 456S-460S.

14 Frohlich M, Imhof A, Berg G, et al. Association between C-reactive protein and features of the metabolic syndrome: a population-based study. Diabetes Care, 2000; 23: 1835-1839.

15 Visser M, Bouter LM, McQuillan GM, et al. Elevated C-reactive protein levels in overweight and obese adults. Jama, 1999; 282: 2131-2135.

16 Haffner SM. Insulin resistance, inflammation, and the prediabetic state. Am J Cardiol, 2003; 92: 18J-26J.

17 Ross R. Atherosclerosis is an inflammatory disease. Am Heart J, 1999; 138: S419-420.

18 Smith J, Al-Amri M, Dorairaj P, et al. The adipocyte life cycle hypothesis. Clin Sci (Lond), 2006; 110: 1-9.

19 Dandona P, Aljada A and Mohanty P. The anti-inflammatory and potential anti-atherogenic effect of insulin: a new paradigm. Diabetologia, 2002; 45: 924-930.

20 Delerive P, Fruchart J and Staels B. Peroxisome proliferator-activated receptors in inflammation control. J Endocrinol, 2001; 169: 453-459.

21 Evans RM, Barish GD and Wang YX. PPARs and the complex journey to obesity. Nat Med, 2004; 10: 355-361.

22 Martens FM, Visseren FL, Lemay J, et al. Metabolic and additional vascular effects of thiazolidinediones. Drugs, 2002; 62: 1463-1480.

23 Auboeuf $D$, Rieusset J, Fajas $L$, et al. Tissue distribution and quantification of the expression of mRNAs of peroxisome proliferator-activated receptors and liver $X$ receptor-alpha in humans: no alteration in adipose tissue of obese and NIDDM patients. Diabetes, 1997; 46: 1319-1327.

24 Desvergne B and Wahli W. Peroxisome proliferator-activated receptors: nuclear control of metabolism. Endocr Rev, 1999; 20: 649-688.

25 Grimaldi PA. Lipid sensing and lipid sensors : Peroxisome Proliferator-Activated Receptors as sensors of fatty acids and derivatives. Cell Mol Life Sci, 2007; 64: 2459-2464.

26 Forman BM, Chen $\mathrm{J}$ and Evans RM. Hypolipidemic drugs, polyunsaturated fatty acids, and eicosanoids are ligands for peroxisome proliferator-activated receptors alpha and delta. Proc Natl Acad Sci U S A, 1997; 94 : 4312-4317. 
27 Kliewer SA, Sundseth SS, Jones SA, et al. Fatty acids and eicosanoids regulate gene expression through direct interactions with peroxisome proliferator-activated receptors alpha and gamma. Proc Natl Acad Sci U S A, 1997; 94: 4318-4323.

28 Krey G, Braissant O, L'Horset F, et al. Fatty acids, eicosanoids, and hypolipidemic agents identified as ligands of peroxisome proliferator-activated receptors by coactivator-dependent receptor ligand assay. Mol Endocrinol, 1997; 11: 779-791.

29 Fruchart JC. Peroxisome proliferator-activated receptor-alpha activation and high-density lipoprotein metabolism. Am J Cardiol, 2001; 88: 24N-29N.

30 Schoonjans K, Staels B and Auwerx J. Role of the peroxisome proliferator-activated receptor (PPAR) in mediating the effects of fibrates and fatty acids on gene expression. J Lipid Res, 1996; 37: 907-925.

31 Schoonjans $\mathrm{K}$, Watanabe $\mathrm{M}$, Suzuki $\mathrm{H}$, et al. Induction of the acyl-coenzyme A synthetase gene by fibrates and fatty acids is mediated by a peroxisome proliferator response element in the $\mathrm{C}$ promoter. The Journal of biological chemistry, 1995; 270: 19269-19276.

32 Staels B, Dallongeville J, Auwerx J, et al. Mechanism of action of fibrates on lipid and lipoprotein metabolism. Circulation, 1998; 98: 2088-2093.

33 Heller $F$ and Harvengt $C$. Effects of clofibrate, bezafibrate, fenofibrate and probucol on plasma lipolytic enzymes in normolipaemic subjects. Eur J Clin Pharmacol, 1983; 25: 57-63.

34 van Raalte $\mathrm{DH}$, Li M, Pritchard $\mathrm{PH}$, et al. Peroxisome proliferator-activated receptor (PPAR)alpha: a pharmacological target with a promising future. Pharm Res, 2004; 21: 1531-1538.

35 Bruckert E, Dejager S and Chapman MJ. Ciprofibrate therapy normalises the atherogenic low-density lipoprotein subspecies profile in combined hyperlipidemia. Atherosclerosis, 1993; 100: 91-102.

36 Chinetti G, Lestavel S, Bocher V, et al. PPAR-alpha and PPAR-gamma activators induce cholesterol removal from human macrophage foam cells through stimulation of the ABCA1 pathway. Nat Med, 2001; 7: 53-58.

37 Staels B and Auwerx J. Regulation of apo A-I gene expression by fibrates. Atherosclerosis, 1998; 137 Suppl: S19-23.

38 Carey DG, Cowin GJ, Galloway GJ, et al. Effect of rosiglitazone on insulin sensitivity and body composition in type 2 diabetic patients [corrected]. Obes Res, 2002; 10: 1008-1015.

39 Kersten S. Peroxisome proliferator activated receptors and obesity. Eur J Pharmacol, 2002; 440: $223-234$.

40 Zierath JR, Ryder JW, Doebber T, et al. Role of skeletal muscle in thiazolidinedione insulin sensitizer (PPARgamma agonist) action. Endocrinology, 1998; 139: 5034-5041.

41 Raman $\mathrm{P}$ and Judd RL. Role of glucose and insulin in thiazolidinedione-induced alterations in hepatic gluconeogenesis. Eur J Pharmacol, 2000; 409: 19-29.

42 Ye JM, Dzamko N, Cleasby ME, et al. Direct demonstration of lipid sequestration as a mechanism by which rosiglitazone prevents fatty-acid-induced insulin resistance in the rat: comparison with metformin. Diabetologia, 2004; 47: 1306-1313.

43 Feige JN, Gelman L, Michalik L, et al. From molecular action to physiological outputs: peroxisome proliferatoractivated receptors are nuclear receptors at the crossroads of key cellular functions. Prog Lipid Res, 2006; 45: 120-159.

44 Esteve E, Ricart W and Fernandez-Real J. Dyslipidemia and inflammation: an evolutionary conserved mechanism. Clin Nutr, 2005; 24: 16-31.

45 Aronoff S, Rosenblatt S, Braithwaite S, et al. Pioglitazone hydrochloride monotherapy improves glycemic control in the treatment of patients with type 2 diabetes: a 6-month randomized placebo-controlled doseresponse study. The Pioglitazone 001 Study Group. Diabetes Care, 2000; 23: 1605-1611.

46 Fonseca V, Rosenstock J, Patwardhan R, et al. Effect of metformin and rosiglitazone combination therapy in patients with type 2 diabetes mellitus: a randomized controlled trial. Jama, 2000; 283: 1695-1702.

47 Kipnes MS, Krosnick A, Rendell MS, et al. Pioglitazone hydrochloride in combination with sulfonylurea therapy improves glycemic control in patients with type 2 diabetes mellitus: a randomized, placebo-controlled study. Am J Med, 2001; 111: 10-17.

48 Lebovitz $\mathrm{H}$, Dole J, Patwardhan $\mathrm{R}$, et al. Rosiglitazone monotherapy is effective in patients with type 2 diabetes. J Clin Endocrinol Metab, 2001; 86: 280-288.

49 Delerive P, Gervois P, Fruchart JC, et al. Induction of IkappaBalpha expression as a mechanism contributing to the anti-inflammatory activities of peroxisome proliferator-activated receptor-alpha activators. The Journal of biological chemistry, 2000; 275: 36703-36707. 
50 Ergas D, Eilat E, Mendlovic S, et al. N-3 fatty acids and the immune system in autoimmunity. IMAJ, 2002; 4: 34-38.

51 Liew C-C, Ma J, Tang H, et al. The peripheral blood transcriptome dynamically reflects system wide biology: a potential diagnostic tool. J Lab Clin Med, 2006; 147: 126-132.

52 van Erk MJ, Blom WA, van Ommen B, et al. High-protein and high-carbohydrate breakfasts differentially change the transcriptome of human blood cells. The American journal of clinical nutrition, 2006; 84: 12331241.

53 Wibaut-Berlaimont V, Randi AM, Mandryko V, et al. Atorvastatin affects leukocyte gene expression in dyslipidemia patients: in vivo regulation of hemostasis, inflammation and apoptosis. J Thromb Haemost, 2005; 3: 677-685.

54 van Leeuwen DM, Gottschalk RW, van Herwijnen MH, et al. Differential gene expression in human peripheral blood mononuclear cells induced by cigarette smoke and its constituents. Toxicol Sci, 2005; 86: 200-210.

55 Connolly $\mathrm{PH}$, Caiozzo VJ, Zaldivar $\mathrm{F}$, et al. Effects of exercise on gene expression in human peripheral blood mononuclear cells. J Appl Physiol, 2004; 97: 1461-1469.

56 Achiron A and Gurevich M. Peripheral blood gene expression signature mirrors central nervous system disease: The model of multiple sclerosis. Autoimmun Rev, 2006; 5: 517-522. 



\section{Chapter 2}

\section{Blood-based gene expression analysis as a tool for biomarker discovery}

Marjolijn C.E. Bragt-van Wijngaarden ${ }^{1,2}$, Ronald P. Mensink $k^{1,2}$

1 Dutch Nutrigenomics Consortium, Top Institute Food and Nutrition, Wageningen, The Netherlands

2 NUTRIM School for Nutrition, Toxicology and Metabolism, Department of Human Biology, Maastricht University Medical Centre+, Maastricht, The Netherlands 


\section{Abstract}

Gene expression profiling can be used to understand the effects of external factors on the metabolic state or condition of specific target tissues. In humans, such studies are complicated by the inaccessibility of these tissues. Therefore, blood cells are used as a surrogate, because blood is more readily accessible. Blood cells circulate through the body and may serve as sentinels, which pick up physiological and pathological changes and capture these changes by altering their transcriptome. This characteristic of blood cells is interesting to understand underlying mechanisms and to identify transcriptional biomarkers of responses to external stimuli, such as nutrition, pharma, toxicological agents, and exercise. In this way, it may be possible to detect metabolic disturbances before a clinical event occurs. Furthermore, gene expression profiling in blood cells may also provide biomarkers for disease diagnosis, disease progression and survival, and the effectiveness of disease treatment. However, more information is needed before it will be possible to widely implement the use of gene expression profiling in blood cells into clinical practice. Little is known, for example, about inter- and intraindividual variation in blood cell gene expression. Furthermore, sample processing and the resulting complex mixture of cell types affect the gene expression profile, independent of the research question. The purpose of this review is to provide an overview of the use of gene expression profiles in blood cells, with emphasis on the use of Peripheral Blood Mononuclear Cells (PBMCs), and to discuss the applicability of these expression profiles to detect gene expression changes reflecting the condition of specific target tissues and metabolic changes. 


\section{Introduction}

Gene expression profiling can be used to understand the effects of external factors, such as diet, on the metabolic state or condition of specific target tissues (figure 1). In humans, such studies are complicated by the inaccessibility of these tissues. Therefore, blood cells have been suggested as a surrogate, because blood is more readily accessible in humans. To be used as a surrogate, it is important that for the processes studied a relationship exists between the gene expression profiles in blood cells and those in the target tissues. More specifically, when studying changes in gene expression profiles as induced by an intervention, it is of importance that at the given dose and duration of exposure, the changes in gene expression profiles in blood cells correlate with those in the target tissue. Over $80 \%$ of the genes expressed in human blood cells are found in the brain, colon, heart, kidney, liver, lung, prostate, spleen or stomach. In addition, many of these genes are responsive to environmental changes'. These findings contributed to the formulation of the so-called "Sentinel Principle", in which blood cells circulate as "sentinels" that respond to changes in the macro and micro environment of organs".

Gene expression profiling of surrogate cells or tissues can be very useful, not only to understand underlying molecular mechanisms, but also in the search for biomarkers that reflect early changes in gene expression caused by exposure to external stimuli. In this way, by using genetic biomarkers, it may be possible to already detect metabolic disturbances before a clinical event occurs. Surrogate tissue can also be useful for disease diagnosis, or for the prediction of disease progression and survival, or the effectiveness of disease treatment.

This review will give an overview of the use of gene expression profiles in blood cells in different settings, specifically focussing on Peripheral Blood Mononuclear Cells (PBMCs). In addition, the applicability of these blood cells as surrogate cells to detect gene expression changes reflecting the condition of specific target tissues will be discussed. 


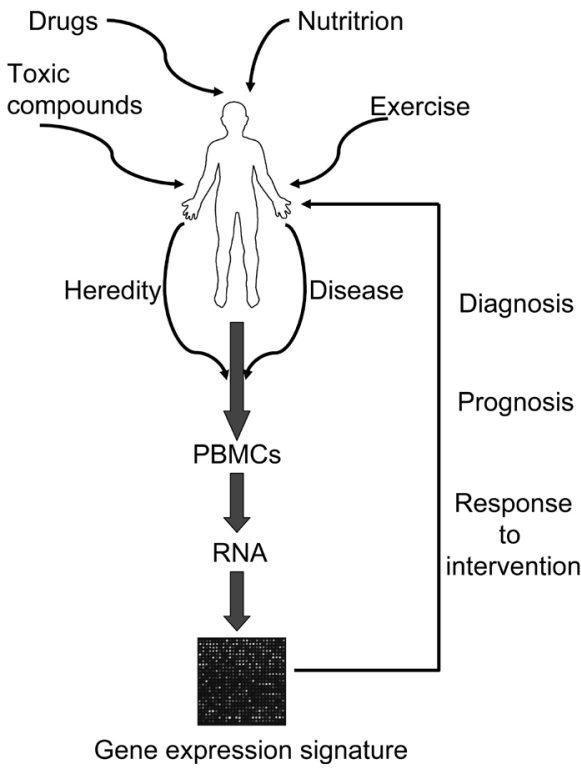

Figure 1. Gene expression profiling of PBMCs.

PBMCs circulate through the human body and are in close contact with human tissues, nutrients, toxic compounds and drugs. External and internal factors can thereby influence gene transcription in PBMCs. The use of RNA-based microarray experiments to obtain gene expression signatures can be a promising tool for disease diagnosis, predicting disease progression and response to an intervention.

\section{Blood cells and gene expression profiling}

\subsection{Blood cell composition and blood processing}

PBMCs are blood cells with a round nucleus and consist of lymphocytes (T-cells, B-cells and NK-cells) and monocytes. Other cells, present in whole blood, include red blood cells, platelets, reticulocytes, and granulocytes (neutrophils, eosinophils, basophils).

Blood cells for gene expression analysis can be isolated in different ways. RNA from whole blood can be isolated directly using the PAXgene ${ }^{\mathrm{TM}}$ (Becton Dickinson Company, Franklin lakes, NJ, USA) or QIAamp (Qiagen Benelux B.V., Venlo, the Netherlands) method. Ficoll-Hypaque density centrifugation and BDCPT vacutainer tubes (Becton Dickinson Company, Franklin lakes, NJ, USA) can be used to isolate directly PBMCs from whole blood. It is important to realize that results can be affected by technical aspects, such as blood sampling, cell isolation procedures, time to analysis, and temperature during processing. Debey et al. investigated the influence of most of these technical aspects on gene expression profiles as determined with oligonucleotide microarrays in peripheral blood samples from 29 healthy blood donors ${ }^{2}$. The choice of cell and RNA isolation technique (PAX, QIAamp, Ficoll-hypaque, BD-CPT) resulted in variable gene expression signatures. Significantly lower numbers of transcripts were found in PAX-isolated RNA samples from whole blood, which was likely due to the disturbing impact of reticulo-derived globin transcripts ${ }^{3}$. These transcripts are present in the red blood cells, which contribute to a large part to the amount of RNA isolated with this system. This suggests that the use of PBMCs is preferred 
above the use of whole blood for gene expression profiling.

Temperature during processing had only a minor effect on the expression profile. The effect of temperature was reflected in the change in expression of mainly stress responsive genes, as confirmation with RT-PCR showed an increase in the expression of interleukin (IL) 8 and dual specificity phosphatase 1 (DUSP1) in Ficoll isolated samples at room temperature compared with samples processed at $8^{\circ} \mathrm{C}^{2}$. Time delay (20-24h) to PBMC isolation and subsequent RNA extraction, however, had the largest impact on gene expression profiles, as evidenced by increased expression levels of early response and stress genes involved in the cell survival machinery ${ }^{2}$. In addition, Molina et al. have demonstrated increased mRNA expression of cytokines in whole blood and PBMCs after delayed isolation of PBMCs from whole blood at room temperature 4 . Thus, these studies show that a rapid isolation of PBMCs is required to prevent changes in gene expression

Not only isolation procedures, but also the relative proportions of cell types in blood determine gene expression profiles. The number of T cells, B-cells, NK cells, monocytes and granulocytes can vary greatly among individuals, depending on states of health and disease, and in response to stimuli5. In PBMCs, the proportion of monocytes can vary between $2-10 \%{ }^{6}$, NK cells between $6-29 \%$, T-lymphocytes from $61-85 \%$ and B-lymphocytes from $7-23 \% 7$. Palmer et al. investigated cell-type specific gene expression signatures for the major constituents of blood with DNA microarrays ${ }^{5}$. Clustering analysis could separate the samples in T-cells, B-cells, whole blood, and PBMCs, indicating cell-specific gene expression. Expression profiles of purified monocytes and NK-cells were not investigated. From the total T-cell population, profiles for CD4+ T cells and CD8+ T-cells could not be distinguished. In addition, genes characteristic for each cell sub-type were investigated. For the B-cell population, 427 genes were identified, that were mainly related to antigen binding, processing and presentation, and to $\mathrm{MHC}$ Class II receptor activity 5 . For T-cells, 222 specific genes were identified, which were related to their cell surface receptors and involved in T-cell receptor complex, signal transduction, and receptor activity ${ }^{5}$. Lymphocytes could be distinguished from granulocytes by the characteristic expression of 67 genes related to macromolecule biosynthesis and ribosomal proteins in lymphocytes, while cell surface and were mainly characteristic for granulocytes ${ }^{5}$.

To summarize, gene expression patterns are influenced by the choice of the cell isolation method and cell processing. It is crucial to rapidly process blood for RNA isolation, and to perform cell isolation preferentially at lower temperature to avoid effects on inflammatory and stress-related genes. Furthermore, one should also keep in mind that the proportion of subsets of cells can be influenced by the condition (health or disease) of a subject or by an intervention, which can influence the outcome of gene expression analysis. 


\subsection{Variation of gene expression in blood cells}

To obtain insight into the normal variation between and within subjects, the variation in gene expression over time and variation associated with specific subject characteristics (such as age, BMI and gender), it is fundamental to understand the extent, nature and sources of variation in gene expression. To validate the use of blood cells as surrogate to detect potential changes in inaccessible tissues, information on the degree of variation in gene expression and responsiveness to environmental factors is essential. Independent of the research question, temporal variation, together with intra- and inter-individual variability, are important factors contributing to differences in gene expression patterns in blood cells. These sources of variation are especially important, when only small changes in gene expression are expected, such as in nutritional intervention studies in healthy subjects.

At least three studies have addressed inter- and/or intra-individual variation in expression profiles of blood cells from healthy volunteers ${ }^{8-10}$. Although these studies resulted in variable outcomes possibly due to differences in array platforms, genes represented on arrays, analytical procedures, and variation in leukocyte subsets, some important general conclusions can be drawn. Gene expression patterns in samples from the same individual were very consistent ${ }^{8-10}$. Eady et al. showed that intra-individual differences were relatively small, that is $<20 \%$ for $80 \%$ of the 8489 genes examined ${ }^{8}$. This was confirmed by clustering analysis, in which samples from the same subject clustered together ${ }^{8}$. A cluster of 25 immunoglobulin genes showed the highest intra-individual variation. Differences in gene expression profiles between individuals were much larger compared to intra-individual differences ${ }^{8-10} .39 \%$ of the genes examined by Eady et al. differed significantly between sample sets from different donors and thus contributed to inter-individual differences in gene expression levels ${ }^{8}$. Individual specific gene sets, which overlapped between the studies of Eady et al. ${ }^{8}$, Radich et al. ${ }^{9}$, and Whitney et al. ${ }^{10}$, contained genes encoding for MHC class II molecules and interferon regulated genes. There were marked differences in gene expression between whole blood and PBMCs, at least partly due to differences in cellular composition of the samples ${ }^{10}$. Therefore, it is better to use PBMCs than whole blood to minimize variation between samples caused by differences in cellular composition. Other factors that can contribute to inter-individual variation are gender, age and $\mathrm{BMI}^{8-10}$.

Inter- and intra-individual variations are common in biological research and this information is, for example, needed for power calculations during the design phase of a study. The consistency of gene expression profiles in PBMCs over time within individuals is very promising for the application of microarray technology in intervention studies. 


\section{Blood cells as surrogate cells to monitor gene expression alteration in inaccessible target tissues}

\subsection{Blood cells and liver}

In humans, the liver has an important role in coordinating and regulating lipid metabolism"1. There are several human and animal studies that have compared the expression of genes, involved in lipid metabolism, between PBMCs and the liver ${ }^{12-18}$.

As the LDL receptor and HMG CoA reductase play an important role in cholesterol metabolism, these two genes have been studied extensively. The LDL receptor is responsible for the uptake of LDL particles and HMG CoA reductase is the rate-limiting enzyme in endogenous cholesterol synthesis. Harwood et al. have suggested that in healthy men, the regulatory mechanisms in PBMCs controlling HMG CoA reductase activity are similar to those in the liver ${ }^{13}$. In that study, HMG CoA reductase activity in PBMCs was decreased during fasting or after a highcholesterol meal and was increased by lowering circulating cholesterol levels. Similar changes in liver HMGCoA reductase activity have been demonstrated in animal studies ${ }^{12,16,18}$. This was also confirmed at the transcriptome level by Powel and Kroon, who compared LDL receptor and HMG CoA reductase gene expression in livers and PBMCs of 13 patients who underwent cholecystectomy for symptomatic gallstones ${ }^{15}$. The number of LDL receptor mRNA copies per $\mu \mathrm{g}$ mRNA was equal between the liver and PBMCs, while in liver tissue the number of HMG CoA reductase molecules was less as compared to that in PBMCs. However, expression levels of both the LDL receptor and HMG CoA reductase in PBMCs closely paralleled expression in human liver, consistent with a coordinate regulation.

Other proteins involved in lipid metabolism are ATP binding cassette (ABC) proteins transmembrane transporter proteins, which facilitate the transport of lipids, sterols, drugs and large polypeptides. Expression levels of ABC transporter genes in PBMCs and liver were investigated by Moshen et al. in patients with hepatocellular carcinoma ${ }^{14}$. They found positive correlations for ABCA2, C1 and G1 between PBMCs and non-cancerous parts of the liver. ABCA2 and $\mathrm{G} 1$ are involved in cholesterol efflux, whereas ABCC1 plays a role in the development of multi-drug resistance by increased excretion of a drug out of the cell.

Vermunt et al. investigated the expression of various desaturases, which are important in the conversion of fatty acids, in the liver and in PBMCs of subjects undergoing a surgical operation ${ }^{17}$. The mRNA levels of $\Delta 6$ and $\Delta 9$ desaturase in PBMCs correlated negatively with those in the liver. However, no correlation was observed for $\Delta 5$ desaturase. These results indicate that $\Delta 6$ and $\Delta 9$ desaturase mRNA levels in PBMCs may predict those in the liver, although these genes may not be similarly regulated in both cell types.

Overall, it seems that for the limited number of genes studied, expression levels in PBMCs of genes involved in lipid homeostasis correlate with those in the liver. 


\subsection{Blood cells and tissues relevant in toxicant exposure}

PBMCs could also play an important role as surrogate cells to measure toxicant exposure. The effect of toxicant exposure partly depends on the oxidative metabolism of toxic compounds, mediated by cytochromes P450 (CYPs) in the liver. These proteins are involved in detoxification, elimination, and activation of a wide variety of compounds. Furukawa et al. compared gene expression levels of CYPs in PBMCs and liver tissue from patients with hepatocellular carcinoma ${ }^{19}$. From the 19 CYPs measured, 6 genes could be detected in both PBMCs and non-tumour tissue from liver. From these genes, only the expression of CYP4B1 correlated between PBMCs and liver tissue, which indicate that PBMCs are no appropriate to study CYP expression in liver.

The relationship between the expression of early onco suppressor genes (c-myc, Ha-ras and p53) in rat PBMCs and potential target tissues (lung, liver, lymph nodes, kidneys and spleen) was investigated by Ember et al., 24 and 48 hours after intraperitoneal exposure to the carcinogen 1-nytropene ${ }^{20}$. The c-myc oncogene could not be used as biomarker, because of its low expression level in all tissues studied. Similar changes in gene expression patterns were only found between PBMCs and spleen, where early changes in Ha-ras and p53 expression matched. No associations between gene expression changes with the other tissues were reported.

In view of the limited number of studies, in different species and with different research questions, it is not possible to conclude if genes in PBMCs could be useful as a molecular biomarker to study toxicological exposure in target tissues. More research in this area is certainly warranted.

\section{$4 \quad$ Reflection of gene expression changes by blood cells}

\subsection{Blood cell gene expression in nutrigenomics}

Gene expression profiling in blood cells has already been used as a tool to study the effects of dietary exposure in human intervention studies. Van Erk et al. evaluated the potential of this tool in a cross-over study investigating the effects of a high carbohydrate and a high protein breakfast in RNA from whole blood of 8 healthy men'1. There were 176 differentially expressed genes in response to the high carbohydrate breakfast and 778 genes were changed after the high protein breakfast. The high carbohydrate intake resulted in lower expression of genes involved in glycogen metabolism, whereas the high protein intake resulted in lower expression of genes involved in protein biosynthesis. Furthermore, the high protein breakfast downregulated PGC1-related coactivator (PPRC1) and Lipin, genes involved in energy homeostasis and lipid metabolism. Fasting has also a pronounced influence on gene expression in blood cells. Bouwens et al. studied gene expression changes after 24 and $48 \mathrm{~h}$ fasting in PBMCs of four healthy males ${ }^{22}$. A number of 1200 genes were changed after $24 \mathrm{~h}$ fasting and 1386 genes after $48 \mathrm{~h}$ fasting, with an overlap of $>74 \%$ between both time-points. Pathway 
analysis at these time-points revealed that fatty acid $\beta$-oxidation, pyruvate metabolism, and RNA-DNA metabolism pathways were upregulated, whereas the tricarboxylic acid cycle was downregulated. Fasting will increase plasma free fatty acid levels, because of the breakdown of triglycerides in the adipose tissue ${ }^{23}$. These free fatty acids are able to activate nuclear receptor PPAR $\alpha$, which can account for the observed effects, as expression of specific PPAR $\alpha$ target genes was strongly upregulated. The functionality of PPAR $\alpha$ in PBMCs was further demonstrated in vitro ${ }^{24}$. From a physiological point of view, diet-induced changes in gene expression profiles can expected to be much smaller compared to changes induced by drugs or disease. Though differences in gene expression profiles in PBMCs were not specifically related to those in other tissues, these studies clearly show the potential of using gene expression profiles in blood cells to understand diet-induced metabolic effects at the molecular level.

Most nutritional intervention studies have focussed on the transcriptional regulation of genes involved in cholesterol metabolism in vivo, in particular on LDL receptor ${ }^{25-28}$ and HMG CoA reductase ${ }^{13,27,28}$ mRNA expression in response to dietary changes. Boucher et al. showed that 7-day dietary cholesterol

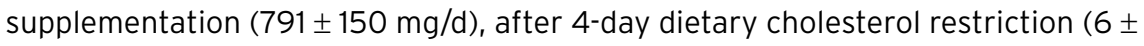
$4 \mathrm{mg} / \mathrm{d}$ ), downregulated the expression of these genes in PBMCs of healthy human in vivo ${ }^{27}$. They also measured LDL receptor-related protein (LRP), a receptor for the uptake of cholesterol-rich lipoprotein which plays a role in the regulation of serum lipoprotein levels ${ }^{29}$. Upon cholesterol supplementation, the mRNA level of this receptor increased, which suggested a role of LRP for the protection against increased blood cholesterol levels. However, the exact function of LRP remains speculative. During cholesterol supplementation that followed the 4-day dietary fat restriction, there was a positive correlation between changes in LDL receptor and HMG CoA reductase expression. A study by Appelbaum-Bowden et al. also showed a downregulation of LDL receptor expression upon a high cholesterol diet $(1034 \pm 25 \mathrm{mg} / \mathrm{d})$ versus a low cholesterol diet $(137 \pm 25 \mathrm{mg} / \mathrm{d})$ in PBMCs of healthy individuals ${ }^{25}$. Besides a response on gene expression, it has also been shown that PBMCs respond very quickly to changes in plasma and dietary cholesterol levels in term of enzyme activity. As shown by Harwood et al., a single, high cholesterol meal decreased HMG CoA reductase activity within two hours, whereas cholesterol depletion by plasma pheresis led to a two-fold elevation in enzyme activity within 90 minutes of treatment ${ }^{13}$.

Functional foods, which influence cholesterol metabolism, have also been shown to reflect their effects on gene expression in PMBCs. Plant stanol ester consumption is known to inhibit intestinal cholesterol absorption and to lower plasma cholesterol in humans. Plat and Mensink showed that plant stanol ester consumption $(3.8-4 \mathrm{~g} / \mathrm{d}$ ) increased LDL receptor mRNA levels in PBMCs from healthy men and women ${ }^{28}$. HMGCoA reductase mRNA levels did not significantly change. However, mRNA levels of these two genes correlated positively in PBMCs, illustrating a coordinate expression of both genes. Another dietary component that may lower cholesterol levels is soy protein. The exact mechanism is unclear, 
but effects may be due to the binding of isoflavones from soy protein to the oestrogen receptor. Baum et al. investigated the effects of soy consumption providing moderate $(56 \mathrm{mg} / \mathrm{d})$ and high $(90 \mathrm{mg} / \mathrm{d})$ amounts of isoflavones versus consumption of a control diet with casein and non-fat dry milk on lipoproteins and LDL receptor mRNA levels in hypercholesterolemic, postmenopausal women ${ }^{26}$. Irrespective of the amount of isoflavones, serum total cholesterol levels did not change after soy consumption, but the LDL/HDL ratio decreased and LDL receptor mRNA increased in PBMCs.

To summarize, PBMCs respond to changes in plasma cholesterol by changing gene expression of LDL receptor and HMGCoA reductase. It appears that mechanisms underlying cellular cholesterol homeostasis overlap between the liver and PBMCs. This has frequently been demonstrated for the genes that regulate cholesterol uptake (LDL receptor) and cholesterol synthesis (HMG CoA reductase). In addition, these genes are regulated coordinately in PBMCs. Therefore, PBMCs are suitable biosensors to study diet-induced changes in LDL receptor and HMGCoA reductase expression in the liver.

\subsection{Blood cell gene expression in pharmacogenomics}

Gene expression profiles in blood cells can also be relevant to study the effectiveness of a specific treatment or to identify patients who respond most effectively to a treatment.

Atorvastatin, is a medicine used to treat dyslipidemia by lowering cholesterol synthesis via the inhibition of HMG CoA reductase activity in the liver. However, atorvastatin exerts also anti-inflammatory effects that may reduce the risk for cardiovascular, independent of its cholesterol-lowering effect. Wibaut-Berlaimont et al. investigated early and late effects of atorvastatin treatment on PBMC gene expression in dyslipidemic patients. For this, human microarrays containing 12,650 genes were used ${ }^{30}$. The expression of 240 genes was changed upon atorvastatin treatment. Compared with baseline, 48 genes were differentially expressed after 12h, 75 genes after 36h, 58 genes after 1 week and 121 genes after 4 weeks. Many of these genes were involved in inflammation, hemostasis, or apoptosis, indicating the pleiotropic effects of this drug. Surprisingly, at the early time points (12h and/or 36h), expression of genes linked to the IFN $\alpha$ pathway, such as STAT1 (key signalling molecule downstream IFN $\alpha$ and IFN $\gamma$ ) and IL15 (monocyte cytokine) was increased. At these early time points, LDL receptor expression was also upregulated, although no significant effects on serum lipids levels were evident. There were also a number of downregulated pro-thrombotic genes, such as prostaglandin $\mathrm{G} / \mathrm{H}$ synthase and the thromboxane $\mathrm{A} 2$ receptor. At late time-points ( 1 and/or 4 weeks), when serum total and LDL cholesterol levels were decreased, in particular expression of genes involved in apoptosis, such as the pro-apoptotic genes Bax and XIAP (apoptosis inhibitor) was downregulated. In conclusion, the difference in response on gene expression over time indicated both lipid-dependent and lipid-independent effects of atorvastatin treatment on gene expression. These results also indicate that PBMCs can be used as surrogate 
to study drug response, which can lead to new insights into the mechanism of action of atorvastatin.

Transcriptional profiling of blood cells can also contribute to the process of drug development, for example to the development of Liver X Receptor (LXR) agonists. These agonists are of interest due to their anti-atherosclerotic effect, because they increase the expression of $A B C A 1$ and $A B C G 1$ resulting in an increased cholesterol transport. Peripheral blood cells express LXR $\alpha$ and LXR $\beta$ and respond to LXR agonists by increasing the expression of these target genes in a time- and dose-dependent manner ${ }^{31}$. Therefore, these relevant target genes may be useful biological indicators for clinical development of LXR modulators ${ }^{31}$.

In cancer research it is important to find gene expression changes that can serve as biomarkers of drug activity. DePrimo et al. conducted a study with PBMC samples from 2 randomised, open-label, multi-centre phase III clinical trial to examine gene expression changes after treatment with standard chemotherapy or standard chemotherapy plus SU5416 (a vascular endothelial growth factor receptor kinase inhibitor) in patients with advanced colorectal cancer ${ }^{32}$. Expression profiling using Affimetrix microarrays revealed that 13 transcripts were specific to patients receiving SU5416 treatment. Of these transcripts, 6 were further tested in 62 additional samples. This confirmed that 4 of these genes, CD24, lactoferrin, lipocalin and MMP-9, consistently correlated with SU5416 treatment. Using the expression of these genes, it was possible to predict if the patient belonged to the SU5416 or control treatment arm. However, these four transcripts may merely represent biomarkers of SU5416 administration rather than a response to changes in disease status ${ }^{32}$.

A study by Hakonarson et al. is a good example of a pharmacological study that used gene expression profiles for identification of biomarkers of therapeutic benefit ${ }^{33}$. Gene expression profiling in PBMCs of asthma patients was performed to identify genes that could predict responders and non-responders to inhaled glucocorticosteroids. Gene expression analyses revealed 15 genes that could predict response to glucocorticosteroids with 85\% accuracy. Of these 15 genes, 11 genes could be confirmed and detected with Real Time PCR. Interestingly, the downregulation of the $N F \kappa B$ gene predicted the response with $81 \%$ accuracy. Downregulation of NFKB activation results in the reduced expression of inflammatory mediators, such as cytokines and chemokines, which play an important role in asthma. In addition to NFKB, STAT4 and IL4R were also strong predictor genes. Whether this panel of genes are only reactive to the glucocorticoid treatment itself or also play a regulatory role in mediating the effects of glucocorticoid treatment in asthma remains to be established.

In conclusion, these encouraging results form a good basis to further explore the use of PBMCs as a surrogate system for biomarker analysis in pharmacology studies. However, future studies should not only focus on biomarkers of solely drug exposure, but more importantly, biomarkers should also reflect the mechanism of action of the drug and change in disease status upon drug treatment. 


\subsection{Blood cell gene expression in toxicogenomics}

To study the early effects of exposure to a xenobiotic on gene expression, Van Leeuwen et al. exposed PBMCs from different donors ex vivo to cigarette smoke and its constituents for $18 \mathrm{~h}^{34}$. After exposure, gene expression was measured using a microarray containing 600 toxicologically relevant genes. Many genes involved in immune and stress responses were changed upon exposure. Other studies also showed gene expression changes in these processes after exposure to cigarette smoke, ionizing radiation, arsenic exposure and benzene exposure ${ }^{35-38}$. Surprisingly, Van Leeuwen et al. found no regulation of genes involved in DNA damage response and only a few involved in DNA repair ${ }^{34}$. The gene that showed the largest effect was SERPINB2, a primary regulator of plasminogen activation, which inhibits apoptosis. In addition, in vivo research by Lampe et al. identified predictive signatures in PBMCs, which could specifically and sensitively distinguish smoking from non-smoking individuals ${ }^{36}$. A subset of predictive genes (e.g. CYP1B1, IL1ß) also correlated with plasma levels of cotinine, the primary metabolite of nicotine. Thus, these results indicate that PBMCs are able to reflect toxicological relevant gene expression changes in response to cigarette smoke.

Cytochrome P450 1A1 and 1B1 (CYP1A1 and CYP1B1, respectively) are phase I enzymes, which are involved in the metabolic activation of dioxin-like compounds and the oxidative metabolism of estrogens. These enzymes can be found in many tissues, including PBMCs. Van Duursen et al. exposed PBMCs from 10 non-smoking healthy women ex vivo to dioxin-like compounds, 2,3,7,8-tetrachlorodibenzop-dioxin (TCDD), and the less potent dioxin-like polychlorinated biphenyl 126 $(P C B 126)^{39}$. However, there was a large inter-individual variability in constitutive and induced CYP1A1 and CYP1B1 expression in Iymphocytes $^{39}$. In addition, concentrations of dioxin(-like) compounds at which significant effects on gene expression were observed in PBMCs in vitro, were 10-fold higher as compared with levels found in human blood ${ }^{39}$. Therefore, CYP1A1 and CYP1B1 might not be applicable as biomarkers of exposure to dioxin and dioxin-like compounds.

Rockett et al. compared gene expression changes in rat PBMCs and uteri following $17 \beta$-estradiol exposure ${ }^{40}$. They showed that of the 1185 genes measured, 193 genes were detectable in both tissues and 18 of these genes were significantly altered in both tissues. Of these 18 genes, 8 genes (e.g. jun-D, phospholipase A2, thymidine kinase) appeared to be treatment specific and not tissue specific, because gene expression changed in a similar degree and in a similar direction in both tissues ${ }^{41}$.

Studies describing the effects of different toxic compounds on gene expression changes in PBMCs did not suggest that a common set of genes can be used as a generic biomarker to measure exposure to toxic compounds. Furthermore, as also holds for pharmacogenomic research, it is important that future gene expression studies in PBMCs not solely searches for profiles and genes that reflect exposure, but also for profiles that reflect a biological response to the exposure. 


\subsection{Gene expression in blood cells in response to exercise}

Exercise leads to an increase in circulating PBMCs and to an increase of both circulating pro-inflammatory and anti-inflammatory mediators ${ }^{42}$. Connolly et al. examined if these changes were paralleled by alterations in gene expression in PBMCs after an acute bout of exercise ${ }^{43}$. For this, 15 healthy adult men (18$30 y)$ performed 30 minutes of constant work rate cycle ergometry $(\sim 80 \%$ peak $\mathrm{O}_{2}$ uptake). Gene expression was analysed pre-exercise, end-exercise and 60 minutes in recovery. Comparing the pre- and end-exercise gene expression profiles, revealed (mainly upregulated) changes in 311 genes, related to stress and inflammation. The expression of these genes returned to baseline after 60 minutes of recovery. Furthermore, IL1 receptor antagonist and IL6 inhibitor, both anti-inflammatory mediators, increased when comparing end-exercise and recovery profiles. Besides genes involved in inflammation, exercise also caused an upregulation of genes involved in growth and repair. However, it cannot be excluded that some of these gene expression changes in PBMC were due to alterations in the proportions of lymphocytes and monocytes in the circulation due to the exercise intervention ${ }^{43}$. Comparable exercise-responsive genes were identified in a study conducted by Zieker et al. (CD14, chemokine ligand 4 , CSF3R, HDPB1, IL1 receptor type 2, IL1 receptor antagonist, IL2 receptor beta) ${ }^{44}$. In this study, gene expression was analysed in whole blood obtained from 8 halfmarathon runners, before (to), immediately after ( $\mathrm{t} 1$ ) and 24 hours after exercise (t2). The genes represented on the custom-made microarray (384 cDNAs in triplicate) were selected based on their role in inflammation, apoptosis and stress responses. Cluster analysis revealed that 36 genes were changed comparing t1 with to, and 21 genes were changed when $\mathrm{t} 2$ was compared with to. All changes were in the same direction in all 8 half-marathon runners. This study showed that (exhaustive) physical activity is associated with a different pattern of gene expression at each time-point in response to a half-marathon.

Endurance training leads to adaptation in oxidative metabolism in skeletal muscle, as shown by a relative decrease in carbohydrate utilisation and increase in fatty acid oxidation ${ }^{45}$. Zeibig et al. investigated whether these adaptive changes in skeletal muscle were also reflected in PBMCs ${ }^{46}$. They studied the expression levels of carnitine palmitoyl transferases 1 and 2 , which transport fatty acids into the mitochondria, and expression levels of carnitine acetyl transferase (CRAT), human specific microsomal carnitine acyltransferase (GRP58), and the organic cation transporter OCTN2, which are all involved in the uptake of L-carnitine across the plasma membrane in muscle and blood cells. Gene expression analysis was conducted in muscle and PBMCs of 6 endurance-trained subjects, before and after a 6-months training period with an average low-intensity training of $12 \mathrm{~h}$ per week, consisting of running, cycling and skating. There was a concordant stimulation of CPT1, CPT2, CRAT, GRP58 and OCTN2 in PBMCs and muscle tissue. In addition, CPT1A, the liver isoform of CPT1, which is not expressed in adult skeletal muscle, was also increased to the same extent as the muscle isoform CPT1B in PBMCs. Thus, PBMCs can mimic gene expression changes that occur in muscle as a result 
of endurance training.

Overall, examining the genomic response of blood cells to exercise could reveal mechanisms that can explain the metabolic effects of different forms of training. Furthermore, gene expression fingerprints might serve as an interesting research tool for monitoring exercise and training loads and for diagnosis and treatment of exercise related stress.

\section{Gene expression profiles in blood cells for disease diagnose and prediction of disease progression}

Variation of PBMC gene expression signatures observed in healthy subjects is markedly smaller than that observed among patients, and thus provides robust support for using gene expression patterns for characterisation and diagnosis of disease states ${ }^{47}$. Research to identify specific genes in PBMCs, which reflect physiological and pathological state of different tissues of the body, will help the clinical practice in disease diagnosis and prediction of disease progression of patients. Tang et al. conducted one of the first studies in rats to demonstrate that gene expression profiles in blood cells could serve as fingerprint of different disease states, such as stroke, seizures, hypoglycaemia and hypoxia ${ }^{48}$. Their results suggested that gene expression profiles in PBMCs had potential to be used for diagnostic, mechanistic and therapeutic assessment of different disease states. This approach has now also been implemented in human studies.

Blood cells can be representative surrogate cells to study multifactorial diseases, such as cardiovascular diseases (CVD) or type II diabetes. Gene expression analysis has been shown to discriminate patients with hypertension ${ }^{49}$, ${ }^{50}$, atherosclerosis ${ }^{51}$, and coronary artery disease patients ${ }^{52}$ from healthy controls. Another study with type II diabetic subjects showing the diagnostic potential of gene expression analysis in PBMCs, revealed that genes involved in the JNK pathway may be candidate markers for hyperglycemia-induced stress, whereas genes from the OXPHOS pathway may be markers of morbidity of type II diabetes ${ }^{53}$. Gene expression analysis in PBMCs is not only useful for disease diagnosis, but may also help to unravel the aetiology of a disease. For example, PBMCs respond to changes in plasma lipid levels by regulating genes involved in lipid and fatty acid synthesis and inflammation, which can shed more light on the relation between plasma lipids and the development of diseases, such as atherosclerosis and CVD ${ }^{54}$.

In the field of oncology, gene expression profiling in target tissues revealed differences between signatures from normal and malignant tissues ${ }^{55,56}$. In search for markers in surrogate tissue, Twine et al. identified a set of eight mainly inflammatory related genes, which distinguished PBMCs from advanced renal cell carcinoma patients and healthy volunteers ${ }^{57}$. In addition, later research in this field even showed that gene expression patterns in PBMCs of patients with renal cell carcinoma correlated with disease prognosis ${ }^{58}$. Not only gene expression target tissue, but also in blood cells, as surrogate cells, can be influenced by the early stages of breast cancer development. Using gene expression analysis of 
1368 genes in women with breast cancer and women with no signs of the disease, Sharma et al. identified a gene set of 37 genes in RNA from whole blood, which predicted the existence of breast cancer in more that $80 \%$ of the cases ${ }^{59}$. Distinct transcriptional profiles in blood cells were also identified for other types of cancer, such as bladder, colorectal and prostate cancer ${ }^{60}$.

For many other diseases, the use of gene expression profiling may have potential for disease diagnosis, prognosis and progression, as has been suggested for haematological diseases, neurological disorders, psychiatric disorders and auto-immune diseases ${ }^{60}$. The clinical applicability of gene expression profiles in blood cells as surrogate cells in predicting disease prognosis and progression was illustrated by Deng et al. ${ }^{61}$. They demonstrated the clinical potential of gene expression profiles in PBMCs by the use of a predictive gene panel to identify recipients with moderate or severe rejection of an allograft transplant from patients who tolerated the transplant ${ }^{61,62}$. Thus, the development of geneexpression based tests seem promising, although subsequent additional research is warranted for thorough validation and evaluation of cost-effectiveness of these assays in clinical practice.

\section{Conclusion and future perspectives}

At this moment, the application of blood transcriptomics is still in its infancy, although more and more studies are performed to identify biomarker genes related to responses to interventions, disease diagnosis, and prediction of disease progression. Overall, as sentinels that serve as an individual's health sensor, gene expression profiles in blood cells are able to reflect changes caused by diet, medicine intake, toxicant exposure and exercise. When studying gene expression in blood cells, standardisation of study procedures is important, including the choice of blood cells and RNA isolation technique and a strict control of blood handling time and temperature. Furthermore, the use of (specific) PBMC cells is preferred above the use of whole blood, to prevent the disturbing impact of reticulo-derived globin transcripts and granulocytes on gene expression. Challenges in future will be a) the selection of the most responsive cell population, as variation in amounts of specific cell types can influence gene expression profiles regardless of the question studied, b) well-controlled gene expression studies with well-characterised populations to decrease variation due to confounding variables (e.g. environmental factors) c) large trials specifically designed to validate the use of possible biomarkers, d) translation of gene expression profiles to the clinical practice, which include the study of associations between gene expression with relevant and objective clinical endpoints, the clinical applicability of expression assay, and the evaluation of cost-effectiveness. In future, analysis of candidate genes selected from microarray studies in PBMCs can potentially provide an efficient and sensitive tool to be implemented for routine use in the clinical practice and may provide additional information beyond already existing traditional biomarkers. 


\section{Acknowledgements}

This study was funded by the Nutrigenomics Consortium (NGC) of Top Institute Food and Nutrition (TIFN) and the National Genomics Initiative (BSIK program).

\section{References}

1 Liew C-C, Ma J, Tang H, et al. The peripheral blood transcriptome dynamically reflects system wide biology: a potential diagnostic tool. J Lab Clin Med, 2006; 147: 126-132.

2 Debey S, Schoenbeck U, Hellmich M, et al. Comparison of different isolation techniques prior gene expression profiling of blood derived cells: impact on physiological responses, on overall expression and the role of different cell types. The pharmacogenomics journal, 2004; 4: 193-207.

3 Wu K, Miyada G, Martin J, et al. Globin reduction protocol: a method for processing whole blood RNA samples for improved array results. http://www.affymetrix.com/support/technical/technotes/blood2_technote.pdf, 2003.

4 Molina MA, Gamboa EM, Tello PC, et al. Spontaneous inflammatory cytokine gene expression in normal human peripheral blood mononuclear cells. Lymphatic research and biology, 2006; 4: 34-40.

5 Palmer C, Diehn M, Alizadeh AA, et al. Cell-type specific gene expression profiles of leukocytes in human peripheral blood. BMC genomics, 2006; 7 : 115.

6 Kasper D and Randolph T, Harrison's principles of internal medicine, New York, McGraw-Hill, Medical pub. Division, 2005.

7 Reichert $\mathrm{T}$, DeBruyere $\mathrm{M}$, Deneys $\mathrm{V}$, et al. Lymphocyte sub-set reference ranges in adult caucasians. Clin Immunol Immunopathol, 1991; 60: 190-208.

8 Eady JJ, Wortley GM, Wormstone YM, et al. Variation in gene expression profiles of peripheral blood mononuclear cells from healthy volunteers. Physiol Genomics, 2005; 22: 402-411.

9 Radich JP, Mao M, Stepaniants S, et al. Individual-specific variation of gene expression in peripheral blood leukocytes. Genomics, 2004; 83: 980-988.

10 Whitney AR, Diehn M, Popper SJ, et al. Individuality and variation in gene expression patterns in human blood. Proc Natl Acad Sci U S A, 2003; 100: 1896-1901.

11 Brown MS and Goldstein JL. Lipoprotein receptors in the liver. Control signals for plasma cholesterol traffic. J Clin Invest, 1983; 72: 743-747.

12 Clarke CF, Fogelman AM and Edwards PA. Diurnal rhythm of rat liver mRNAs encoding 3-hydroxy-3methylglutaryl coenzyme A reductase. Correlation of functional and total mRNA levels with enzyme activity and protein. The Journal of biological chemistry, 1984; 259: 10439-10447.

13 Harwood $\mathrm{H}$, Bridge D and Stracpoole P. In vivo regulation of human mononuclear leukocyte 3-hydroxy-3methylglutaryl coenzyme A reductase. J Clin Invest, 1987; 79: 1125-1132.

14 Moustafa MA, Ogino D, Nishimura M, et al. Comparative analysis of ATP-binding cassette (ABC) transporter gene expression levels in peripheral blood leukocytes and in liver with hepatocellular carcinoma. Cancer Sci, 2004; 95: 530-536.

15 Powell E and Kroon P. Low density lipoprotein receptor and 3-hydroxy-3-methylglutaryl coenzyme A reductase gene expression in human mononuclear leukocytes is regulated coodinately and parallels gene expression in human liver. J Clin Invest, 1994; 93: 2168-2174.

16 Rodwell VW, Nordstrom JL and Mitschelen JJ. Regulation of HMG-CoA reductase. Advances in lipid research, $1976 ; 14: 1-74$.

17 Vermunt SHF, Greve J-W, Hornstra G, et al. Relationship between mRNA levels for delta 5, delta 6 and delta 9 desaturases in mononuclear blood cells and liver tissue in man. PhD Thesis, 2001: 67-77.

18 Young $\mathrm{N}$ and Rodwell V. Regulation of hydroxymethylglytaryl CoA reductase in rat leukocytes. J Lipid Res, 1977; 18: 572-580.

19 Furukawa M, Nishimura M, Ogino D, et al. Cytochrome p450 gene expression levels in peripheral blood mononuclear cells in comparison with the liver. Cancer Sci, 2004; 95: 520-529.

20 Ember I, Kiss I, Gyongyi Z, et al. Comparison of early onco/suppressor gene expressions in peripheral leukocytes and potential target organs of rats exposed to the carcinogen 1-nitropyrene. Eur J Cancer Prev, 2000; 9: 439-442. 
21 van Erk MJ, Blom WA, van Ommen B, et al. High-protein and high-carbohydrate breakfasts differentially change the transcriptome of human blood cells. The American journal of clinical nutrition, 2006; 84: 12331241.

22 Bouwens M, Afman LA and Muller M. Fasting induces changes in peripheral blood mononuclear cell gene expression profiles related to increases in fatty acid beta-oxidation: functional role of peroxisome proliferator activated receptor alpha in human peripheral blood mononuclear cells. The American journal of clinical nutrition, 2007; 86: 1515-1523.

23 Cahill GF, Jr. Starvation in man. N Engl J Med, 1970; 282: 668-675.

24 Bouwens M, Afman LA and Muller M. Activation of peroxisome proliferator-activated receptor alpha in human peripheral blood mononuclear cells reveals an individual gene expression profile response. BMC genomics, 2008; 9: 262.

25 Applebaum-Bowden D, Haffner S, Hartsook E, et al. Down-regulation of the low-density lipoprotein receptor bu dietary cholesterol. Am J Clin Nutr, 1984; 39: 360-367.

26 Baum JA, Teng H, Erdman JW, Jr., et al. Long-term intake of soy protein improves blood lipid profiles and increases mononuclear cell low-density-lipoprotein receptor messenger RNA in hypercholesterolemic, postmenopausal women. The American journal of clinical nutrition, 1998; 68: 545-551.

27 Boucher $\mathrm{P}$, de Lorgeril M, Salen $\mathrm{P}$, et al. Effect of dietary cholesterol on low density lipoprotein-receptor, 3-hydroxy-3-methylglutaryl-CoA reductase, and low density lipoprotein receptor-related protein mRNA expression in healthy humans. Lipids, 1998; 33: 1177-1186.

28 Plat $\mathrm{J}$ and Mensink RP. Effects of plant stanol esters on LDL receptor protein expression and on LDL receptor and HMG-CoA reductase mRNA expression in mononuclear blood cells of healthy men and women. FASEB J, 2002; 16: 258-260.

29 Hussain MM, Maxfield FR, Mas-Oliva J, et al. Clearance of chylomicron remnants by the low density lipoprotein receptor-related protein/alpha 2-macroglobulin receptor. The Journal of biological chemistry, 1991; 266: 13936-13940.

30 Wibaut-Berlaimont V, Randi AM, Mandryko V, et al. Atorvastatin affects leukocyte gene expression in dyslipidemia patients: in vivo regulation of hemostasis, inflammation and apoptosis. J Thromb Haemost, 2005; 3: 677-685.

31 DiBlasio-Smith EA, Arai M, Quinet EM, et al. Discovery and implementation of transcriptional biomarkers of synthetic LXR agonists in peripheral blood cells. Journal of translational medicine, 2008; 6: 59.

32 DePrimo SE, Wong LM, Khatry DB, et al. Expression profiling of blood samples from an SU5416 Phase III metastatic colorectal cancer clinical trial: a novel strategy for biomarker identification. BMC Cancer, 2003; 3: 3.

33 Hakonarson $\mathrm{H}$, Bjornsdottir US, Halapi E, et al. Profiling of genes expressed in peripheral blood mononuclear cells predicts glucocorticoid sensitivity in asthma patients. Proc Natl Acad Sci U S A, 2005; 102: 14789-14794.

34 van Leeuwen DM, Gottschalk RW, van Herwijnen MH, et al. Differential gene expression in human peripheral blood mononuclear cells induced by cigarette smoke and its constituents. Toxicol Sci, 2005; 86: 200-210.

35 Amundson SA, Do KT, Shahab S, et al. Identification of potential mRNA biomarkers in peripheral blood Iymphocytes for human exposure to ionizing radiation. Radiation research, 2000; 154: 342-346.

36 Lampe JW, Stepaniants SB, Mao M, et al. Signatures of environmental exposures using peripheral leukocyte gene expression: tobacco smoke. Cancer Epidemiol Biomarkers Prev, 2004; 13: 445-453.

37 Ryder MI, Hyun W, Loomer $\mathrm{P}$, et al. Alteration of gene expression profiles of peripheral mononuclear blood cells by tobacco smoke: implications for periodontal diseases. Oral microbiology and immunology, 2004; 19 : 39-49.

38 Wu MM, Chiou HY, Ho IC, et al. Gene expression of inflammatory molecules in circulating lymphocytes from arsenic-exposed human subjects. Environmental health perspectives, 2003; 111: 1429-1438.

39 van Duursen MB, Sanderson JT and van den Berg M. Cytochrome P450 1A1 and 1B1 in human blood lymphocytes are not suitable as biomarkers of exposure to dioxin-like compounds: polymorphisms and interindividual variation in expression and inducibility. Toxicol Sci, 2005; 85: 703-712.

40 Rockett JC, Kavlock RJ, Lambright CR, et al. DNA arrays to monitor gene expression in rat blood and uterus following 17beta-estradiol exposure: biomonitoring environmental effects using surrogate tissues. Toxicol Sci, 2002; 69: 49-59. 
41 Rockett JC, Burczynski ME, Fornace AJ, et al. Surrogate tissue analysis: monitoring toxicant exposure and health status of inaccessible tissues through the analysis of accessible tissues and cells. Toxicol Appl Pharmacol, 2004; 194: 189-199.

42 Ostrowski K, Rohde T, Asp S, et al. Pro- and anti-inflammatory cytokine balance in strenuous exercise in humans. The Journal of physiology, 1999; 515 ( Pt 1): 287-291.

43 Connolly PH, Caiozzo VJ, Zaldivar F, et al. Effects of exercise on gene expression in human peripheral blood mononuclear cells. J Appl Physiol, 2004; 97: 1461-1469.

44 Zieker D, Zieker J, Dietzsh J, et al. cDNA-microarray analysis as research tool for expression profiling in human peripheral blood following exercise. 86-96.

45 Jeukendrup A. Regulation of fat metabolism in skeletal muscle. Ann N Y Acad Sci, 2002; 967: 217-235.

46 Zeibig J, Karlic H, Lohninger A, et al. Do blood cells mimic gene espression profile alterations known to occur in muscular adaptation to endurance training? Eur J Appl Physiol, 2005; 95: 96-104.

47 Achiron A and Gurevich M. Peripheral blood gene expression signature mirrors central nervous system disease: The model of multiple sclerosis. Autoimmun Rev, 2006; 5: 517-522.

48 Tang Y, Lu A, Aronow BJ, et al. Blood genomic responses differ after stroke, seizures, hypoglycemia, and hypoxia: blood genomic fingerprints of disease. Ann Neurol, 2001; 50: 699-707.

49 Chon H, Gaillard CA, van der Meijden BB, et al. Broadly altered gene expression in blood leukocytes in essential hypertension is absent during treatment. Hypertension, 2004; 43: 947-951.

50 Visvikis-Siest S, Marteau JB, Samara A, et al. Peripheral blood mononuclear cells (PBMCs): a possible model for studying cardiovascular biology systems. Clin Chem Lab Med, 2007; 45: 1154-1168.

51 Patino WD, Mian OY, Kang JG, et al. Circulating transcriptome reveals markers of atherosclerosis. Proc Natl Acad Sci U S A, 2005; 102: 3423-3428.

$52 \mathrm{Ma} J$ and Liew CC. Gene profiling identifies secreted protein transcripts from peripheral blood cells in coronary artery disease. Journal of molecular and cellular cardiology, 2003; 35: 993-998.

53 Takamura T, Honda M, Sakai Y, et al. Gene expression profiles in peripheral blood mononuclear cells reflect the pathophysiology of type 2 diabetes. Biochem Biophys Res Commun, 2007; 361: 379-384.

54 Ma J, Dempsey AA, Stamatiou D, et al. Identifying leukocyte gene expression patterns associated with plasma lipid levels in human subjects. Atherosclerosis, 2007; 191: 63-72.

55 Ramaswamy S, Tamayo P, Rifkin R, et al. Multiclass cancer diagnosis using tumor gene expression signatures. Proc Natl Acad Sci U S A, 2001; 98: 15149-15154.

$56 \mathrm{Su}$ Al, Welsh JB, Sapinoso LM, et al. Molecular classification of human carcinomas by use of gene expression signatures. Cancer research, 2001; 61: 7388-7393.

57 Twine NC, Stover JA, Marshall B, et al. Disease-associated expression profiles in peripheral blood mononuclear cells from patients with advanced renal cell carcinoma. Cancer research, 2003; 63: 6069-6075.

58 Burczynski M, Twine N, Dukart G, et al. Transcriptional profiles in peripheral blood mononuclear cells prognostic of clinical outcomes in patients with advanced renal cell carcinoma Clin Cancer Res, 2005; 11: 1181-1189.

59 Sharma P, Sahni NS, Tibshirani R, et al. Early detection of breast cancer based on gene-expression patterns in peripheral blood cells. Breast Cancer Res, 2005; 7: R634-644.

60 Mohr S and Liew CC. The peripheral-blood transcriptome: new insights into disease and risk assessment. Trends in molecular medicine, 2007; 13: 422-432.

61 Deng MC, Eisen HJ, Mehra MR, et al. Noninvasive discrimination of rejection in cardiac allograft recipients using gene expression profiling. Am J Transplant, 2006; 6: 150-160.

62 Evans RW, Williams GE, Baron HM, et al. The economic implications of noninvasive molecular testing for cardiac allograft rejection. Am J Transplant, 2005; 5: 1553-1558. 


\section{Chapter 3}

\section{Anti-inflammatory effect of rosiglitazone is not reflected in expression of $\mathrm{NF} \kappa \mathrm{B}$-related genes in peripheral blood mononuclear cells of patients with type 2 diabetes mellitus}

Marjolijn C.E. Bragt-van Wijngaarden 1,2, Jogchum Plat², Marco Mensink², Patrick Schrauwen², Ronald P. Mensink, ${ }^{12}$

1 Dutch Nutrigenomics Consortium, Top Institute Food and Nutrition, Wageningen, The Netherlands

2 NUTRIM School for Nutrition, Toxicology and Metabolism, Department of Human Biology, Maastricht University Medical Centre+, Maastricht, The Netherlands

Based on BMC Endocrine Disorders 2009;9:8 


\section{Abstract}

Rosiglitazone not only improves insulin-sensitivity, but also exerts antiinflammatory effects. We have now examined in type 2 diabetic patients if these effects are reflected by changes in mRNA expression in peripheral blood mononuclear cells (PBMCs) to see if these cells can be used to study these antiinflammatory effects at the molecular level in vivo. Eleven obese type 2 diabetic patients received rosiglitazone $(2 \times 4 \mathrm{mg} / \mathrm{d})$ for 8 weeks. Fasting blood samples were obtained before and after treatment. Ten obese control subjects served as reference group. The expression of NFKB-related genes and PPAR $\gamma$ target genes in PBMCs, plasma TNF $\alpha$, IL6, MCP1 and hsCRP concentrations were measured. In addition, blood samples were obtained after a hyperinsulinemic-euglycemic clamp. Rosiglitazone reduced plasma MCP1 and hsCRP concentrations in diabetic patients $(-9.5 \pm 5.3 \mathrm{pg} / \mathrm{mL}, p=0.043$ and $-1.1 \pm 0.3 \mathrm{mg} / \mathrm{L} p=0.003)$, respectively). For hsCRP, the concentration became comparable with the non-diabetic reference group. However, of the $84 \mathrm{NF \kappa B}$-related genes that were measured in PBMCs from type 2 diabetic subjects, only RELA, SLC20A1, INF $\gamma$ and IL1R1 changed significantly $(p<0.05)$. In addition, PPAR $\gamma$ and its target genes (CD36 and LPL) did not change. During the clamp, insulin reduced plasma MCP1 concentration in the diabetic and reference groups $(-9.1 \pm 1.8 \%, p=0.001$ and $-11.1 \pm 4.1 \%, p=0.023$, respectively) and increased IL6 concentration in the reference group only $(23.5 \pm 9.0 \%, p=0.028)$. In type 2 diabetic patients, the anti-inflammatory effect of rosiglitazone is not reflected by changes in NFKB and PPAR $\gamma$ target genes in PBMCs in vivo. Furthermore, our results do not support that high insulin concentrations contribute to the proinflammatory profile in type 2 diabetic patients. 


\section{Introduction}

Rosiglitazone, an agonist for the nuclear receptor peroxisome proliferatoractivated receptor gamma (PPAR $\gamma$ ), is a widely used drug for the treatment of type 2 diabetes mellitus. It belongs to the group of thiazolidinediones (TZD) and increases insulin sensitivity of peripheral tissues. In addition, there is evidence that rosiglitazone has anti-inflammatory effects ${ }^{1-3}$. It has been postulated that rosiglitazone exerts its anti-inflammatory effect through inhibition of

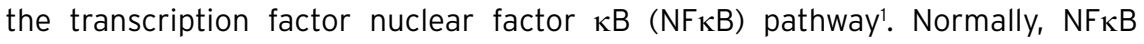
is bound in the cytosol to its inhibitor $\kappa \mathrm{B}\left(I_{\kappa \mathrm{B}}\right)$ to prevent activation of $\mathrm{NF \kappa B}$. Inflammatory signals can cause phosphorylation of $I \kappa B$, thereby releasing and activating $\mathrm{NF \kappa B}$, followed by translocation of $\mathrm{NF \kappa B}$ to the nucleus and activation of genes involved in the pro-inflammatory response, such as TNF $\alpha$ and matrix metalloproteinases ${ }^{4}$. To further understand in humans the in vivo (anti-inflammatory) effects of rosiglitazone treatment at the molecular level, it would be advantageous that Peripheral Blood Mononuclear Cells (PBMCs) could be used. These cells are readily accessible in humans compared to the relatively inaccessible target tissues of PPAR $\gamma$ ligands, namely adipose tissue and liver ${ }^{5}$. It has already been demonstrated that monocytes respond to PPAR $\gamma$ ligands by reducing the expression of inflammatory cytokines ex vivo, such as TNF $\alpha$, IL- 6 and IL $1 b^{6}$. In addition, Mohanty et al. ${ }^{3}$ have shown that rosiglitazone inhibits the binding of NFKB to DNA in the nucleus of PBMCs from obese and obese diabetic patients. This was accompanied by an anti-inflammatory effect, as indicated by reduced plasma hsCRP and MCP-1 concentrations ${ }^{3}$. However, it is not known if rosiglitazone's anti-inflammatory effect changes the transcription of NF $\kappa B$ related genes in PBMCs in vivo. Therefore, the first aim of our study was to examine if anti-inflammatory properties of rosiglitazone are reflected in changes in expression of genes involved in the $N F \kappa B$ signaling pathway in PBMCs. Furthermore, the role of an increased insulin concentration in lowgrade systemic inflammation, as often seen in type 2 diabetic patients, is not completely understood ${ }^{7}$. Therefore, the second aim of this study was to examine plasma inflammatory markers in the fasted (hyperglycaemic) state and during hyperinsulinemia using a hyperinsulinemic-euglycemic clamp.

\section{Methods}

\subsection{Subjects}

Twelve middle-aged obese men with well-controlled type 2 diabetes mellitus participated in this study. Due to extreme changes in serum cholesterol concentrations and gene expression profiles, one subject was excluded from the statistical analyses. The characteristics of the 11 remaining (age, $62 \pm 5 \mathrm{y}$; body mass index (BMI), $31 \pm 3 \mathrm{~kg} / \mathrm{m}^{2}$ ) type 2 diabetic subjects and $10 \mathrm{BMI}$ and age matched normoglycemic controls (age, $57 \pm 8 \mathrm{y}$; BMl, $30 \pm 4 \mathrm{~kg} / \mathrm{m}^{2}$ ) are shown in 
table 1. Type 2 diabetes mellitus was diagnosed at least 1 year before the study, and most patients were treated with sulphonylurea $(n=3)$ or metformin $(n=5)$ or both $(n=1)$ as anti-diabetic medication. Control subjects had normal glucose homeostasis, as determined with a standard oral glucose tolerance test, and had no family history of diabetes. The Medical Ethical Review Board of Maastricht University had approved the study and written, informed consent was obtained from all volunteers.

\subsection{Study design}

Details of this study have been described previously ${ }^{8,9}$. In short, diabetic patients stopped any anti-diabetic medication 14 days before the start of the study. Subjects were asked not to participate in (exhaustive) physical activity the last three days preceeding the measurements, and to consume a diet according to the Dutch guidelines for a healthy diet. After a baseline hyperinsulinemiceuglycemic clamp, diabetic patients were treated with rosiglitazone (Avandia ${ }^{\circledR}$, GlaxoSmithKline, Zeist, the Netherlands), $8 \mathrm{mg} /$ day ( $2 \times 4 \mathrm{mg}$ ) for 8 weeks. After rosiglitazone treatment, subjects underwent a second clamp. Blood samples were drawn before and after the clamp, thereby providing fasting and insulinstimulated blood samples before and after rosiglitazone treatment. The nondiabetic patients served as baseline controls to the diabetic patients. They also underwent a hyperinsulinemic-euglycemic clamp, but were not treated with rosiglitazone.

\subsection{Hyperinsulinemic-euglycemic clamp}

After an overnight fast, subjects came to the laboratory at 8 AM. A cannula was inserted into each antecubital vein for the infusion of tracer, insulin and glucose. A third cannula was inserted retrogradely into a superficial dorsal hand vein for arterialized blood sampling. After taking fasting blood samples, a primed constant infusion of $[6,6]^{-2} \mathrm{H}_{2}$-glucose was initiated $(0.04 \mathrm{mg} / \mathrm{kg} \cdot \mathrm{min})$ for 300 minutes. At $\mathrm{t}=120 \mathrm{~min}$, a 3-hour primed constant infusion of insulin (Actrapid, Novo Nordisk, Bagsvaerd, Denmark) was started $\left(40 \mathrm{mU} / \mathrm{m}^{2} \cdot \mathrm{min}\right)$, and glucose was clamped by a variable co-infusion of $20 \%$ glucose with tracer added. Blood samples taken at $\mathrm{t}=0 \mathrm{~min}$ and $\mathrm{t}=300 \mathrm{~min}$ were used for further analysis.

\subsection{Plasma measurements}

EDTA plasma was obtained by 10 minutes of centrifugation at $3000 \mathrm{rpm}$ immediately after sampling, and stored at $-80^{\circ} \mathrm{C}$ for later analysis. Concentrations of total cholesterol (ABX Diagnostics, Montpelier, France), HDL cholesterol (precipitation method; Roche Diagnostics Corporation, Indianapolis, IN), and triglycerides corrected for free glycerol (Sigma-Aldrich Chemie, Steinheim, Germany) were analysed enzymatically. Serum LDL cholesterol concentrations were calculated by using the formula of Friedewald et al. ${ }^{10}$. Insulin concentrations were measured using a RIA (Linco Research. St. Charles, MO, USA). Free fatty acids (FFA) were determined using the Wako Nefa $C$ test kit (Wako Chemicals, 
Neuss, Germany) and plasma glucose was determined by using the hexokinase method (LaRoche, Basel, Switzerland). The glucose infusion rate (GIR) was used as a measure of insulin sensitivity. For the inflammation markers, high sensitive CRP (hsCRP) was measured on Cobas Mira with a commercial available kit (Kamiya Biomedical Company, Seattle, WA, USA) and TNF $\alpha$, IL6 and MCP1 were measured with an ELISA kit from R\&D systems. All samples from one subject were analysed in the same analytical run. Samples were corrected for plasma albumin concentrations to correct for changes in blood volume due to fluid infusion during the hyperinsulinemic-euglycemic clamp ${ }^{11}$.

\subsection{PBMC isolation and total RNA isolation}

PBMCs were isolated from an EDTA anti-coagulated peripheral fasted blood sample of diabetic patients only, directly after blood sampling through gradient centrifugation using lymphoprep (Nycomed, Oslo, Norway) according to the instructions from the manufacturer. The obtained PBMCs were immediately lysed and homogenised in $1.5 \mathrm{ml}$ Trizol (Invitrogen Life Technologies, Breda, The Netherlands) for RNA stabilisation and subsequent RNA isolation according a standardized protocol as described by the manufacturer. Next, RNA was purified using the RNeasy mini kit (Qiagen Benelux B.V., Venlo, the Netherlands) followed by dissolving the RNA in RNAse and DNAse free water (Invitrogen Life Technologies, Breda, The Netherlands). RNA purity was measured on the NanoDrop 1000 (NanoDrop Technologies, Wilmington, DE, USA), and considered suitable for further processing at 260/280 and 260/230 ratios of $>1.7$. Integrity was evaluated using the BioAnalyzer (Agilent, Palo Alto CA, USA) and considered to be intact with an RNA integrity number $>7.0$.

\subsection{Real time PCR}

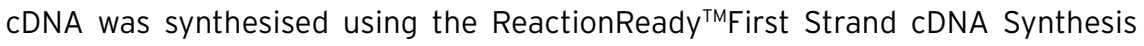
Kit (SuperArray Bioscience corporation, Frederick, MD, USA). The total amount of RNA used in the reaction varied from $800 \mathrm{ng}$ to $1 \mu \mathrm{g}$. Equal amounts of RNA were used for samples before and after treatment of the same subject.

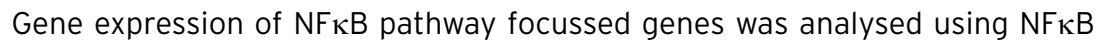
$\mathrm{RT}^{2}$ Profiler PCR arrays, according to the manufacturer's instructions (SuperArray Bioscience Corporation, Frederick, MD, USA). The PCR array consisted of a 96-well plate including primer sets of $84 \mathrm{NF \kappa B}$ related genes (see additional file 1), plus 5 housekeeping genes and 2 negative controls. The primer sets were optimised for real time detection using $\mathrm{RT}^{2}$ Real Time ${ }^{\mathrm{TM}}$ SYBR Green PCR master mix (SuperArray Bioscience Corporation, Frederick, MD, USA). In addition, the relative expression levels of PPAR $\gamma, C D 36$ and LPL, were also determined with real time PCR, using assays-on-demand and Taqman Universal Mastermix (Applied Biosystems, Foster City, CA, USA). All gene expression analyses were performed on the ABI PISM 7000 system (Applied Biosystems, Foster City, CA, USA). 


\subsection{Data analysis of real time PCR data}

The No Template Control tested for DNA contamination in the PCR system and the No Reverse Transcription Control tested for contamination of the original RNA with genomic DNA. Those threshold cycles were above 35, which indicates that there was no contamination. The average $C_{t}$ values of the housekeeping genes, $\beta$-actin and 18srRNA, were used for normalisation of each individual sample. To express the difference in expression before and after rosiglitazone treatment in diabetic patients, the $\Delta \Delta C_{t}$ value was calculated for each gene according to the comparative $\mathrm{Ct}$ method, and was used for statistical analysis.

\subsection{Statistics}

Fasting plasma parameters are presented as mean \pm SEM. Gene expression levels were not normally distributed and are therefore expressed as median $\Delta \Delta C_{t}$ values together with corresponding ranges. An independent Student's t-test was used to compare diabetic patients before or after rosiglitazone with control subjects. Results of plasma parameters before and after rosiglitazone treatment in type 2 diabetic patients were analysed using a paired Student's t-test. The effect of rosiglitazone on gene expression levels in type 2 diabetic patients was analysed with the non-parametric Wilcoxon signed rank test. Changes (\%) in plasma parameters during the hyperinsulinemic-euglycemic clamp (TO vs. T300) were tested with a one sample t-test. In addition, using the Student's t-test, the changes in plasma parameters induced by the hyperinsulinemic-euglycemic clamp before rosiglitazone treatment were compared to the clamp-induced changes after rosiglitazone treatment.

All statistical analyses were performed with SPSS 14.0 for Windows (SPSS Inc., Chicago, IL, USA). 
Table 1. BMI and plasma parameters of type 2 diabetic patients before and after rosiglitazone treatment and of non-diabetic controls.

\begin{tabular}{|c|c|c|c|c|c|c|c|c|c|}
\hline \multirow[b]{3}{*}{ BMI (kg/m2) } & \multicolumn{6}{|c|}{ Diabetic patients $(n=11)$} & \multicolumn{3}{|c|}{ Controls $(n=10)$} \\
\hline & \multicolumn{3}{|c|}{ Before treatment } & \multicolumn{3}{|c|}{ After treatment } & \multirow[b]{2}{*}{31} & \multirow[b]{2}{*}{ \pm} & \multirow[b]{2}{*}{1.3} \\
\hline & 30 & \pm & 1.0 & 31 & \pm & 1.0 & & & \\
\hline Glucose (mmol/L) & 9.2 & \pm & $0.5^{\mathrm{a}}$ & 8.1 & \pm & $0.5^{b, c}$ & 5.8 & \pm & 0.1 \\
\hline Insulin (mU/L) & 24.1 & \pm & $3.1^{a}$ & 17.2 & \pm & $1.7^{\mathrm{b}, \mathrm{c}}$ & 12.3 & \pm & 0.9 \\
\hline $\operatorname{GIR}(\mu \mathrm{mol} / \mathrm{kg} / \mathrm{min})$ & 12.8 & \pm & $1.3^{\mathrm{a}}$ & 20.6 & \pm & $1.7^{\mathrm{b}}$ & 24.6 & \pm & 2.4 \\
\hline Total cholesterol $(\mathrm{mmol} / \mathrm{L})$ & 5.4 & \pm & 0.3 & 5.7 & \pm & 0.4 & 5.2 & \pm & 0.3 \\
\hline LDL cholesterol (mmol/L) & 3.5 & \pm & 0.2 & 3.8 & \pm & 0.4 & 3.4 & \pm & 0.3 \\
\hline HDL cholesterol (mmol/L) & 0.93 & \pm & 0.1 & $1.10^{\mathrm{b}}$ & \pm & $0.1^{\mathrm{b}}$ & 1.14 & \pm & 0.1 \\
\hline $\mathrm{TCH} / \mathrm{HDL}$ ratio & 6.9 & \pm & 1.1 & 5.5 & \pm & 1.0 & 5.5 & \pm & 1.1 \\
\hline Triglycerides (mmol/L) & 2.0 & \pm & 0.3 & $1.5^{\mathrm{b}}$ & \pm & $0.2^{\mathrm{b}}$ & 1.5 & \pm & 0.4 \\
\hline $\mathrm{FFA}(\mu \mathrm{mol} / \mathrm{L})$ & 509 & \pm & 47 & 400 & \pm & $37 b$ & 513 & \pm & 45.6 \\
\hline
\end{tabular}

a Significantly different $(\mathrm{P}<0.05)$ between diabetic patients and non-diabetic controls

b Significant effect $(P<0.05)$ of rosiglitazone treatment in diabetic patients

c Significantly different $(P<0.05)$ between diabetic patients after rosiglitazone treatment and non-diabetic controls

\section{Results}

\subsection{Body weight}

There was no difference in body weight between diabetic patients and the BMl-matched controls $(94.3 \pm 4.1 \mathrm{~kg}$ and $92.7 \pm 4.1 \mathrm{~kg}$, respectively $(p=0.778)$ ). Rosiglitazone treatment resulted in a slight, but non-significant increase in body weight during the 8 weeks follow-up period in the diabetic patients $(1.3 \pm 1.0 \mathrm{~kg}$, $p=0.21$.

\subsection{Plasma glucose and insulin concentrations and insulin sensitivity}

As expected, diabetic patients were less insulin-sensitive and had higher fasting plasma glucose and insulin concentrations compared with non-diabetic controls (table 1). Fasting glucose and insulin were significantly decreased in the diabetic patients after rosiglitazone treatment $(-1.0 \pm 0.5 \mathrm{mmol} / \mathrm{L}, p=0.044)$ and $(-6.9 \pm$ $2.3 \mathrm{mU} / \mathrm{L}, p=0.013$, respectively), while insulin sensitivity increased (change in GIR: $+7.8 \pm 1.9 \mu \mathrm{mol} / \mathrm{kg} / \mathrm{min}, p=0.002$ ) (table 1 ). 


\subsection{Plasma lipid concentrations}

As shown in table 1, there were no significant differences in plasma total cholesterol, LDL cholesterol, HDL cholesterol, TCH/HDL ratio, triglycerides and free fatty acids (FFA) between diabetic patients and non-diabetic controls. Fasting $\mathrm{HDL}$ cholesterol increased significantly $(+0.21 \pm 0.07 \mu \mathrm{mol} / \mathrm{L}, p=0.013)$, while triglyceride and FFA concentrations decreased $(-0.48 \pm 0.21 \mu \mathrm{mol} / \mathrm{L}, p=0.042$ and $-109 \pm 38 \mathrm{mmol} / \mathrm{L}, p=0.018$ respectively) upon rosiglitazone treatment in diabetic patients. Total cholesterol and LDL cholesterol concentrations were not significantly affected by rosiglitazone treatment $(+0.30 \pm 0.20 \mathrm{mmol} / \mathrm{L}, p=0.152$ and $+0.30 \pm 0.20 \mathrm{mmol} / \mathrm{L}, p=0.160$, respectively). The $\mathrm{TCH} / \mathrm{HDL}$ ratio tended to improve after treatment $(-1.3 \pm 0.7)$, but this did not reach statistically significance $(p=0.09)$.

\subsection{Plasma hsCRP, TNF $\alpha$, IL6 and MCP1 concentrations}

As shown in figure 1, the basal plasma concentration of hsCRP in the diabetic patients was $2.2 \pm 0.4 \mathrm{mg} / \mathrm{L}$, which was significantly higher than that of the nondiabetic controls $(1.0 \pm 0.2 \mathrm{mg} / \mathrm{L}, p=0.027)$. There were no differences in TNF $\alpha$, IL6 and MCP1 concentrations between diabetic patients and control subjects. As a result of rosiglitazone treatment, basal hsCRP and MCP1 concentrations significantly decreased $(-1.1 \pm 0.3 \mathrm{mg} / \mathrm{L}, p=0.003$ and $-9.5 \pm 5.3 \mathrm{pg} / \mathrm{mL}, p=0.043$, respectively) and, paradoxically, TNF $\alpha$ concentrations increased $(+0.22 \pm 0.1$ $\mathrm{pg} / \mathrm{mL}, p=0.037$ ) in type 2 diabetic patients. After rosiglitazone treatment, hsCRP $(1.0 \pm 0.16 \mathrm{mg} / \mathrm{L})$ and $\mathrm{MCP} 1$ concentrations $(132 \pm 7 \mathrm{pg} / \mathrm{mL})$ in diabetic patients were comparable with those measured in non-diabetic controls.
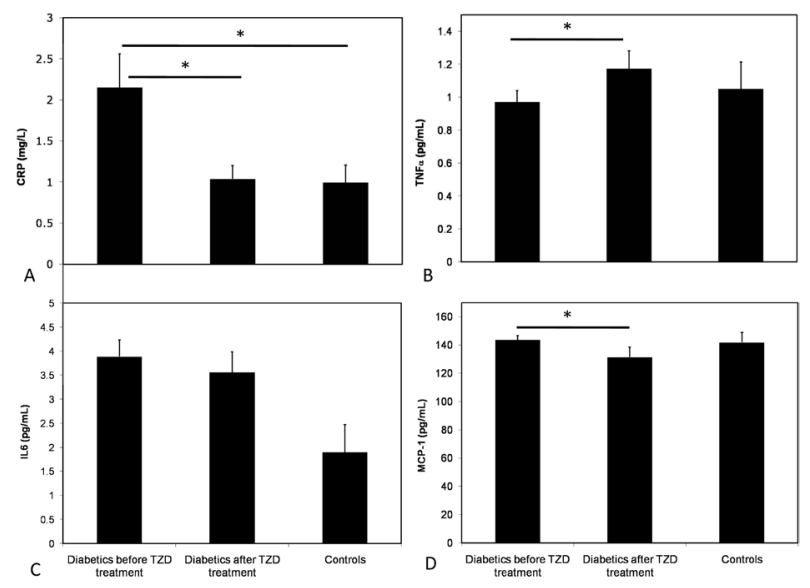

Figure 1. Concentrations of plasma inflammation markers in controls and in diabetics before and after rosiglitazone treatment.

Baseline concentrations of plasma inflammatory markers, A) hsCRP, B) TNF $\alpha$, C) IL6 and D) $M C P 1$, in type 2 diabetic and control subjects and levels after rosiglitazone treatment in type 2 diabetic patients. $*=p$-value $<0.05$ 


\subsection{Expression of PPAR $\gamma, P P A R \gamma$ responsive genes and $N F K B$ related genes}

Of the 84 genes measured, 75 were detectable in PBMCs and only the expression of genes encoding for IFN $\gamma$ (interferon gamma), ILIR1 (interleukin 1 receptor 1), RELB ( $V$-rel reticuloendotheliosis viral oncogene homolog $B$, nuclear factor of kappa light polypeptide gene enhancer in B-cells 3 (avian)) and SLC20A1 (solute carrier family 20 (phosphate transporter) member 1) changed significantly in the diabetic patients upon rosiglitazone treatment (table 2).

The expression level of PPAR $\gamma$ itself was not changed by its ligand rosiglitazone. Also expression levels of CD36 (thrombospondin receptor) and LPL (lipoprotein lipase), which are known PPAR $\gamma$ target genes ${ }^{12-14}$, did not change (table 2).

Table 2. Effect of rosiglitazone treatment on expression levels $\left(\Delta C_{t}\right)$ of PPAR, PPAR $\gamma$ responsive genes and $\mathrm{NF} \kappa \mathrm{B}$ related genes in type 2 diabetic patients ${ }^{1}$.

\begin{tabular}{lcc} 
Gene & $\Delta \Delta C_{t}$ (after - before treatment) & $p$ - value ${ }^{3}$ \\
PPAR $\gamma$ & $0.31(-0.70-1.29)$ & 0.213 \\
CD36 & $0.37(-0.93-0.90)$ & 0.248 \\
LPL & $-0.39(-0.90-1.26)$ & 0.248 \\
INF $\gamma$ & $-0.53(-3.04-0.62)$ & 0.045 \\
IL1R1 & $0.37(-1.16-1.51)$ & 0.041 \\
RELB & $0.31(-0.23-2.27)$ & 0.016 \\
SLC20A1 & $0.41(-1.03-1.93)$ & 0.033 \\
\hline
\end{tabular}

1 The expression of 84 genes related to $N F \kappa B$ was profiles using the $\mathrm{RT}^{2}{ }^{2}$ Profiler ${ }^{\mathrm{TM}} \mathrm{PCR}$ Array; $\mathrm{n}=11$

2 Values are reported as $\Delta \Delta C_{t}$ values and presented as medians with ranges. A negative $\Delta \Delta C_{t}$ value corresponds with an upregulation and a positive $\Delta \Delta C_{t}$ value with a downregulation of the gene after rosiglitazone treatment.

3 Gene expression levels ( $\Delta C_{t}$ values) were analysed with the non-parametric Wilcoxon signed rank test. Differences were considered significant at a $p$-value $<0.05$ 
Table 3. Relative changes in plasma parameters upon insulin-stimulation during the hyperinsulinemic-euglycemic clamp.

\begin{tabular}{|c|c|c|c|c|c|c|c|c|c|}
\hline \multirow[b]{3}{*}{ Albumin (\%) } & \multicolumn{6}{|c|}{ Diabetic patients $(n=11)$} & \multicolumn{3}{|c|}{ Controls $(n=10)$} \\
\hline & \multicolumn{3}{|c|}{ Before treatment } & \multicolumn{3}{|c|}{ After treatment } & \multirow[b]{2}{*}{-6.0} & \multirow[b]{2}{*}{ \pm} & \multirow[b]{2}{*}{$0.8^{\#}$} \\
\hline & -3.4 & \pm & $0.9 \#$ & -3.1 & \pm & $1.1^{\#}$ & & & \\
\hline Total cholesterol (\%) & 0.4 & \pm & 0.8 & -1.7 & \pm & 1.4 & 0.4 & \pm & 0.7 \\
\hline LDL cholesterol (\%) & 2.5 & \pm & 2.1 & -0.5 & \pm & 1.3 & 2.3 & \pm & 1.1 \\
\hline HDL cholesterol (\%) & 1.3 & \pm & 2.7 & 0.8 & \pm & 1.6 & 2.7 & \pm & 1.3 \\
\hline Triglycerides (\%) & -5.2 & \pm & 6.4 & -14.3 & \pm & $5.5^{a, c}$ & -16.7 & \pm & $4.5^{a}$ \\
\hline FFA (\%) & -58.9 & \pm & $3.4^{a, b}$ & -65.0 & \pm & $4.1^{\mathrm{a}, \mathrm{c}}$ & -80.1 & \pm & $2.6^{a}$ \\
\hline hsCRP (\%) & -4.7 & \pm & 2.7 & -4.9 & \pm & 2.4 & 5.5 & \pm & 4.5 \\
\hline TNF $\alpha(\%)$ & 12.0 & \pm & 6.6 & -9.1 & \pm & $7.9^{c}$ & 12.1 & \pm & 14.2 \\
\hline IL6 (\%) & 13.7 & \pm & 6.7 & 16.4 & \pm & 7.9 & 23.5 & \pm & $9.0^{a}$ \\
\hline MCP1 (\%) & -9.1 & \pm & $1.8^{\mathrm{a}}$ & -3.7 & \pm & 4.0 & -11.1 & \pm & $4.1^{\mathrm{a}}$ \\
\hline
\end{tabular}

\# Plasma albumin changed $(p<0.05)$ during the clamp because of increase in blood volume due to fluid infusion. Therefore, all plasma parameters are corrected for changes in plasma albumin concentration and presented as mean \pm SEM

a Significant change $(P<0.05)$ in response to insulin

b Significant difference between type 2 diabetic patients and BMI-matched controls in response to insulin

c Significant change $(P<0.05)$ effect of rosiglitazone treatment on the response to insulin in type 2 diabetic patients

\subsection{Changes in plasma parameters during the clamp}

Before rosiglitazone treatment, plasma albumin concentrations were $38.1 \pm$ $0.6 \mathrm{~g} / \mathrm{L}$ before the clamp and $36.8 \pm 0.5 \mathrm{~g} / \mathrm{L}$ after the clamp $(p=0.005)$. These concentrations were comparable after rosiglitazone treatment. For the control subjects, these values were before and after the clamp respectively $38.7 \pm 0.6$ $\mathrm{g} / \mathrm{L}$ and $36.4 \pm 0.7 \mathrm{~g} / \mathrm{L}(p<0.001)$. The observed reductions in plasma albumin concentration indicate that due to the glucose infusion, the plasma volume had changed during the clamp. Therefore, levels of the plasma parameters were related to those of albumin. It is known that plasma albumin concentrations are stable during the day ${ }^{11}$.

Before treatment, serum total, LDL, and HDL cholesterol levels did not change in response to insulin during the hyperinsulinemic-euglycemic clamp in both type 2 diabetic patients and control subjects (table 3 ). Triglycerides levels decreased 
in control subjects $(-16.7 \pm 4,5 \%, p=0.007)$ and also in diabetic patients after rosiglitazone treatment $(-14.3 \pm 5.5 \%, p=0.027)$. FFA levels decreased significantly in type 2 diabetic patients $(-58.9 \pm 3.4 \%, p<0.001)$ in response to insulin. In control subjects the reduction in FFA was even more pronounced $(-80.1 \pm 2.6 \%, p<0.001)$. Rosiglitazone improved the insulin-induced decrease in FFA (from -58.9 $\pm 3.4 \%$ to $-65.0 \pm 4.1 \%, p=0.045$ ).

Insulin significantly decreased MCP1 levels in type 2 diabetic patients before rosiglitazone treatment $(-9.1 \pm 1.8 \%, p=0.001)$ and control subjects $(-11.1 \pm 4.1 \%$, $p=0.023$ ) (table 3 ). Control subjects also showed a significant increase in IL6 levels $(23.5 \pm 9.0 \%, p=0.028)$ Changes in TNF $\alpha$ levels upon insulin stimulation differed significantly before and after rosiglitazone treatment in diabetic patients. Levels of TNF $\alpha$ increased during the clamp before rosiglitazone treatment $(+12.0$ $\pm 6.6 \%)$, but decreased after rosiglitazone treatment $(-9.1 \pm 7.9 \%, p=0.006)$.

\section{Discussion}

In this study, 8 weeks of rosiglitazone treatment $(2 \times 4 \mathrm{mg} / \mathrm{d})$ not only improved insulin sensitivity and plasma lipids, but also lowered fasting plasma concentrations of hsCRP and MCP1. After rosiglitazone, fasting concentrations of hsCRP and MCP1 in diabetic patients were even comparable to those of nondiabetic controls. These anti-inflammatory changes were not reflected in the expression of $\mathrm{NF} \kappa \mathrm{B}$-related genes in PBMCs.

Reductions in fasting triglyceride concentrations have been reported for other TZDs, such as pioglitazone, troglitazone and darglitazone. We have now shown that these results can be extended to rosiglitazone. Furthermore, FFA concentrations were also reduced after rosiglitazone treatment. These reductions may be explained by an increased clearance of TG and FFA, as shown by Dhindsa et al. ${ }^{15}$. Rosiglitazone treatment further significantly increased serum HDL cholesterol concentrations and total cholesterol and LDL cholesterol tended to increase. Generally, the effects of rosiglitazone on serum lipid concentrations were comparable to those of other TZDs ${ }^{16}$.

Rosiglitazone treatment in type 2 diabetic patients decreased hsCRP and MCP1 concentrations, indicating a reduced inflammatory state. Mohanty et al. also observed a significant reduction in MCP1 and hSCRP concentrations after 6 weeks of rosiglitazone treatment $(4 \mathrm{mg} / \mathrm{d})$ in non-diabetic obese subjects and obese diabetic patients ${ }^{3}$. In accordance with previous studies ${ }^{2}, 17,18$, we did not observe an effect of rosiglitazone on plasma IL6 concentrations. The increase we observed in TNF $\alpha$ concentrations is unexpected, although studies on the effects of TZDs on plasma TNF $\alpha$ concentrations are inconsistent. Some studies have shown that plasma concentrations of this cytokine are increased in subjects with insulin resistance or type 2 diabetes ${ }^{19,20}$. A number of other studies, however, showed reduced TNF $\alpha$ concentrations ${ }^{21,22}$ after rosiglitazone treatment in type 2 diabetic patients, whereas others found no effect ${ }^{18}$. In line with our observations, Goldstein et al. ${ }^{23}$ showed that TNF $\alpha$ concentrations were significantly increased 
when rosiglitazone was added to metformin treatment in type 2 diabetic patients. Due to these inconsistent results, a clear explanation is lacking.

Despite the rosiglitazone-induced reductions in fasting plasma CRP and MCP1, which are under control of $\mathrm{NF}_{\kappa} \mathrm{B}^{24,25}$, expression of $\mathrm{NF} \kappa \mathrm{B}$-related genes in PBMCs hardly changed upon rosiglitazone treatment. Of the 75 detectable NF $\kappa B$-related genes in PBMCs, only 4 genes were significantly altered. The gene encoding for interferon gamma (INF $\gamma$ ) was significantly upregulated, whereas ILR1, RELB and SLC20A1 were significantly downregulated by rosiglitazone treatment. These changes would indicate an inhibition of the NFKB signalling cascade ${ }^{4,26-}$ 28. The significant reduction in MCP1 and hSCRP concentrations after 6 weeks of rosiglitazone treatment $(4 \mathrm{mg} / \mathrm{d}$ ) in non-diabetic obese subjects and obese diabetic patients as described by Mohanty et al., was accompanied by a significant fall in intranuclear $\mathrm{NF} \kappa \mathrm{B}$ levels in $\mathrm{PBMCs}^{3}$. This suggests a direct interference of PPAR $\gamma$ in the binding of $N F \kappa B$ to the promotor regions of proinflammatory genes. However, these reduced intranuclear $N F \kappa B$ levels were not accompanied by a changed expression of the NFKB-related genes IkB and p65 (REL A) after rosiglitazone treatment ${ }^{3,29}$. For troglitazone, another PPAR $\gamma$ agonist, it has also been demonstrated that intranuclear and cellular levels of NFKB were decreased in mononuclear cells of obese subjects ${ }^{30}$. Unfortunately, these studies did not examine if the fall in intranuclear $N F \kappa B$ levels was accompanied by a reduced expression of inflammatory NFKB target genes. In our study, the lack of effect on $\mathrm{NF} \kappa \mathrm{B}$ related genes by rosiglitazone in PBMCs suggests that PBMCs are insensitive to rosiglitazone.

To further substantiate whether PBMCs were non-responsive to rosiglitazone treatment, we evaluated if rosiglitazone influenced gene expression of specific PPAR $\gamma$ dependent genes in PBMCs in vivo, i.e., PPAR $\gamma$ itself, CD36 and lipoprotein lipase (LPL). In vitro and ex vivo studies have shown that expression of CD36 ${ }^{31}$, 32 and $\mathrm{LPL}^{33}$ in macrophages increased after activation of PPAR $\gamma$. In our study, however, the in vivo expression of PPAR $\gamma$, CD36 and LPL in PBMCs was not altered by rosiglitazone treatment, which suggests that PBMCs are non-responsive to rosiglitazone. In contrast to most other studies, we used PBMCs, a mixed population of white blood cells, and studied the in vivo effects. Most studies that did observe anti-inflammatory effects of rosiglitazone focussed on in vitro effects in a specific subpopulation of blood cells, namely monocytes or macrophages. These studies showed an increased expression of PPAR $\gamma$ and PPAR $\gamma$ responsive genes when these cells were cultured ex vivo or in vitro, and/or were given extra cytokine stimulation ${ }^{31,34,35}$. In vivo, Bouhlel et al. ${ }^{34}$ showed a significant upregulation of PPAR $\gamma$ expression in PBMCs of subjects after 2 months of $45 \mathrm{mg} /$ day pioglitazone (TZD) treatment in patients with severe atherosclerosis, although expression of the PPAR $\gamma$ dependent genes, CD136 and mannose receptor, did not change. Combining these finding with our results suggests that gene expression profiles in PBMCs are not suitable to use as a biomarker to study in vivo the effects of rosiglitazone intervention at a molecular level. Whether specific subpopulations of cells within PBMCs are suitable, warrant further investigation. In this respect, 
study of monocytes, preferably isolated from blood via for example cell sorter techniques, warrants attention as especially the monocytes play an important role in the inflammation process and insulin resistance. Arkan et al ${ }^{36}$, for example, showed that deletion of $\mathrm{IKK} \beta$, required for the activation of $\mathrm{NF \kappa B}$, in myeloid precursor cells protected animals from diet-induced obesity-related insulin resistance.

To investigate the acute effect of insulin on the low-grade pro-inflammatory profile in type 2 diabetic patients at constant glucose concentrations, plasma inflammation parameters were analysed before and after the hyperinsulinemiceuglycemic clamp. Results, however, were not conclusive. MCP1 level decreased in both diabetic and control subjects, IL 6 level increased only in control subjects, while hsCRP and TNF $\alpha$ levels did not significantly change. The reduced MCP1 level after insulin stimulation can, however, also be an indirect effect of insulin and explained for example by the insulin-mediated reduction in FFA ${ }^{37}$. The causal role of IL 6 in the development of insulin resistance and type 2 diabetes is not clear. Infusion with a physiological concentration of IL6 in humans increased the uptake of glucose in subcutaneous adipose tissue in vivo ${ }^{38}$. On the other hand, IL6 levels are increased in type 2 diabetic subjects. Like in our study, Krogh-Madsen et al. found an increase in plasma IL6 concentrations during a hyperinsulinemiceuglycemic clamp in healthy human males ${ }^{39}$. This increase was accompanied by an elevated insulin-stimulated increase in IL 6 gene expression in adipose tissue. Also, they found no change in plasma concentrations of TNF $\alpha$, which expression was increased in adipose tissue and reduced in muscle tissue ${ }^{39}$. The reason that we did not find a reduction in hSCRP concentration may have been due to the relative short time of insulin infusion in our study, as previous studies demonstrated decreased hsCRP concentrations after 10 or more hours of insulin infusion ${ }^{40-42}$. It also needs to be mentioned that during the hyperinsulinemiceuglycemic clamp, not only insulin infusion can exerts biological effects, but also the amount of glucose infused to maintain euglycemia ${ }^{43}$. However, Dandona et al. have demonstrated an acute anti-inflammatory effect of insulin infusion at a physiological concentration, infusing insulin (2.0-2.5 IU/h) - dextrose(5\%) and in obese non-diabetic subjects, while maintaining glucose levels as close to basal levels as possible ${ }^{41}$. This anti-inflammatory effect was reflected by reduced intranuclear levels of $\mathrm{NF} \kappa \mathrm{B}$, increased $\mathrm{I}_{\kappa \mathrm{B}}$, decreased ROS generation and decreased p47phox subunit in PBMCs, decreased plasma intracellular adhesion molecule 1, plasminogen inhibitor 1 and MCP1 concentrations ${ }^{41}$. Infusion with only dextrose or saline had no effects on these parameters ${ }^{41}$. Taken together, a supraphysiological increase in insulin concentration does not per se contribute to the disturbances in inflammatory markers in type 2 diabetic patients.

In conclusion, 8 weeks of rosiglitazone treatment $(2 \times 4 \mathrm{mg} / \mathrm{d})$ resulted in improved insulin sensitivity and lipid profile and reduced concentrations of plasma inflammatory markers (MCP1 and hsCRP) in type 2 diabetic patients. Furthermore, plasma inflammatory parameters did not change consistently during the clamp in both diabetic and control patients, which does not suggest that high insulin levels 
contribute to the proinflammatory state in type 2 diabetic patients. Finally, the anti-inflammatory effect of rosiglitazone is not reflected by changes in NF $\kappa B$ and PPAR $\gamma$ target genes in PBMCs in vivo.

\section{Acknowledgements}

This study was funded by the Nutrigenomics Consortium (NGC) of Top Institute Food and Nutrition (TIFN), the Dutch BSIK fund, and GlaxoSmithKline. We would like to acknowledge Martine Hulsbosch from NGC of TIFN for the analysis of plasma lipids and her help with the immunoassays and gene expression analysis. 


\section{References}

1 Delerive $\mathrm{P}$, Fruchart $\mathrm{J}$ and Staels B. Peroxisome proliferator-activated receptors in inflammation control. J Endocrinol, 2001; 169: 453-459.

2 Haffner SM, Greenberg AS, Weston WM, et al. Effect of rosiglitazone treatment on nontraditional markers of cardiovascular disease in patients with type 2 diabetes mellitus. Circulation, 2002; 106: 679-684.

3 Mohanty P, Aljada A, Ghanim H, et al. Evidence for a potent antiinflammatory effect of rosiglitazone. J Clin Endocrinol Metab, 2004; 89: 2728-2735.

4 Hayden MS, West AP and Ghosh S. NF-kappaB and the immune response. Oncogene, 2006; 25: 6758-6780.

5 Semple RK, Chatterjee VK and O'Rahilly S. PPAR gamma and human metabolic disease. J Clin Invest, 2006; 116: 581-589.

6 Jiang C, Ting A and Seed B. PPAR-g agonists inhibit production of monocyte inflammatory cytokines. Nature, 1998; 39: 82-86.

7 Krogh-Madsen R, Moller K, Dela F, et al. Effect of hyperglycemia and hyperinsulinemia on the response of IL-6, TNF-alpha, and FFAs to low-dose endotoxemia in humans. American journal of physiology, 2004; 286: E766772.

8 Mensink M, Hesselink MK, Russell AP, et al. Improved skeletal muscle oxidative enzyme activity and restoration of PGC-1alpha and PPARbeta/delta gene expression upon rosiglitazone treatment in obese patients with type 2 diabetes mellitus. Int J Obes (Lond), 2007.

9 Schrauwen P, Mensink M, Schaart G, et al. Reduced skeletal muscle uncoupling protein-3 content in prediabetic subjects and type 2 diabetic patients: restoration by rosiglitazone treatment. J Clin Endocrinol Metab, 2006; 91: 1520-1525.

10 Friedewald WT, Levy RI and Fredrickson DS. Estimation of the concentration of low-density lipoprotein cholesterol in plasma, without use of the preparative ultracentrifuge. Clin Chem, 1972; 18: 499-502.

11 Margarson M and Soni N. Plasma volume measurement in septic patients using an albumin dilution technique: comparison with the standard radio-labelled albumin method. Intensice Care Med, 2005; 31: 289-295.

12 Heinaniemi M, Uski JO, Degenhardt T, et al. Meta-analysis of primary target genes of peroxisome proliferatoractivated receptors. Genome Biol, 2007; 8: R147.

13 Schoonjans K, Peinado-Onsurbe J, Lefebvre AM, et al. PPARalpha and PPARgamma activators direct a distinct tissue-specific transcriptional response via a PPRE in the lipoprotein lipase gene. The EMBO journal, 1996; 15: 5336-5348.

14 Tontonoz P, Nagy L, Alvarez JG, et al. PPARgamma promotes monocyte/macrophage differentiation and uptake of oxidized LDL. Cell, 1998; 93: 241-252.

15 Dhindsa S, Tripathy D, Sanalkumar N, et al. Free fatty acid-induced insulin resistance in the obese is not prevented by rosiglitazone treatment. J Clin Endocrinol Metab, 2005; 90: 5058-5063.

16 van Wijk JP, de Koning EJ, Martens EP, et al. Thiazolidinediones and blood lipids in type 2 diabetes. Arterioscler Thromb Vasc Biol, 2003; 23: 1744-1749.

17 Chu JW, Abbasi F, Lamendola C, et al. Effect of rosiglitazone treatment on circulating vascular and inflammatory markers in insulin-resistant subjects. Diab Vasc Dis Res, 2005; 2: 37-41.

18 Hetzel J, Balletshofer B, Rittig K, et al. Rapid effects of rosiglitazone treatment on endothelial function and inflammatory biomarkers. Arterioscler Thromb Vasc Biol, 2005; 25: 1804-1809.

19 Popa C, Netea MG, van Riel PL, et al. The role of TNF-\{alpha\} in chronic inflammatory conditions, intermediary metabolism, and cardiovascular risk. J Lipid Res, 2007; 48: 751-762.

20 Pradhan AD, Manson JE, Rifai N, et al. C-reactive protein, interleukin 6, and risk of developing type 2 diabetes mellitus. Jama, 2001; 286: 327-334.

21 Marx N, Imhof A, Froehlich J, et al. Effect of rosiglitazone treatment on soluble CD4OL in patients with type 2 diabetes and coronary artery disease. Circulation, 2003; 107: 1954-1957.

22 Varo N, Vicent D, Libby $\mathrm{P}$, et al. Elevated plasma levels of the atherogenic mediator soluble CD40 ligand in diabetic patients: a novel target of thiazolidinediones. Circulation, 2003; 107: 2664-2669.

23 Goldstein BJ, Weissman PN, Wooddell MJ, et al. Reductions in biomarkers of cardiovascular risk in type 2 diabetes with rosiglitazone added to metformin compared with dose escalation of metformin: an EMPIRE trial sub-study. Curr Med Res Opin, 2006; 22: 1715-1723. 
24 Agrawal A, Cha-Molstad H, Samols D, et al. Overexpressed nuclear factor-kappaB can participate in endogenous $\mathrm{C}$-reactive protein induction, and enhances the effects of C/EBPbeta and signal transducer and activator of transcription-3. Immunology, 2003; 108: 539-547.

25 Teferedegne B, Green MR, Guo Z, et al. Mechanism of action of a distal NF-kappaB-dependent enhancer. Mol Cell Biol, 2006; 26: 5759-5770.

26 Ghosh S, May MJ and Kopp EB. NF-kappa B and Rel proteins: evolutionarily conserved mediators of immune responses. Annu Rev Immunol, 1998; 16: 225-260.

27 Saklatvala $\mathrm{J}$ and Guesdon F. Interleukin 1 and tumor necrosis factor signal transduction mechanisms: potential targets for pharmacological control of inflammation. J Rheumatol Suppl, 1992; 32: 65-69; discussion 69-70.

28 Takayanagi $\mathrm{H}$, Ogasawara K, Hida S, et al. T-cell-mediated regulation of osteoclastogenesis by signalling crosstalk between RANKL and IFN-gamma. Nature, 2000; 408: 600-605.

29 Sun SC, Ganchi PA, Ballard DW, et al. NF-kappa B controls expression of inhibitor I kappa B alpha: evidence for an inducible autoregulatory pathway. Science, 1993; 259: 1912-1915.

30 Ghanim H, Garg R, Aljada A, et al. Suppression of nuclear factor-kappaB and stimulation of inhibitor kappaB by troglitazone: evidence for an anti-inflammatory effect and a potential antiatherosclerotic effect in the obese. J Clin Endocrinol Metab, 2001; 86: 1306-1312.

31 Chawla A, Barak Y, Nagy L, et al. PPAR-g dependent and independent effects on macrophage gene expression in lipid metabolism and inflammation. Nature Medicine, 2001; 7: 48-52.

32 Moore $\mathrm{KJ}$, Rosen ED, Fitzgerald ML, et al. The role of PPAR-gamma in macrophage differentiation and cholesterol uptake. Nat Med, 2001; 7: 41-47.

33 Li L, Beauchamp MC and Renier G. Peroxisome proliferator-activated receptor alpha and gamma agonists upregulate human macrophage lipoprotein lipase expression. Atherosclerosis, 2002; 165: 101-110.

34 Bouhlel M, Derudas B, Rigamonti $A E$, et al. PPARg activation primes human monocytes into alternative M2 macrophages with anti-inflammatory prpoerties. Cell Metab, 2007; 6: 137-143.

35 Hong G, Davis B, Khatoon N, et al. PPAR gamma-dependent anti-inflammatory action of rosiglitazone in human monocytes: suppression of TNF alpha secretion is not mediated by PTEN regulation. Biochem Biophys Res Commun, 2003; 303: 782-787.

36 Arkan MC, Hevener AL, Greten FR, et al. IKK-beta links inflammation to obesity-induced insulin resistance. Nat Med, 2005; 11: 191-198.

37 Tripathy $D$, Mohanty $P$, Dhindsa $S$, et al. Elevation of free fatty acids induces inflammation and impairs vascular reactivity in healthy subjects. Diabetes, 2003; 52: 2882-2887.

38 Lyngso D, Simonsen $L$ and Bulow J. Metabolic effects of interleukin- 6 in human splanchnic and adipose tissue. The Journal of physiology, 2002; 543: 379-386.

39 Krogh-Madsen R, Plomgaard P, Keller $\mathrm{P}$, et al. Insulin stimulates interleukin- 6 and tumor necrosis factor-alpha gene expression in human subcutaneous adipose tissue. American journal of physiology, 2004; 286: E234238.

40 Chaudhuri A, Janicke D, Wilson MF, et al. Anti-inflammatory and profibrinolytic effect of insulin in acute STsegment-elevation myocardial infarction. Circulation, 2004; 109: 849-854.

41 Dandona $\mathrm{P}$, Aljada A, Mohanty $\mathrm{P}$, et al. Insulin inhibits intranuclear nuclear factor kappaB and stimulates IkappaB in mononuclear cells in obese subjects: evidence for an anti-inflammatory effect? J Clin Endocrinol Metab, 2001; 86: 3257-3265.

42 Wong VW, McLean M, Boyages SC, et al. C-reactive protein levels following acute myocardial infarction: effect of insulin infusion and tight glycemic control. Diabetes Care, 2004; 27: 2971-2973.

43 Mohanty P, Hamouda W, Garg R, et al. Glucose challenge stimulates reactive oxygen species (ROS) generation by leucocytes. J Clin Endocrinol Metab, 2000; 85: 2970-2973. 


\title{
Chapter 4
}

\author{
Comparison of the effects of \\ n-3 long chain polyunsaturated \\ fatty acids and fenofibrate on \\ markers of inflammation and \\ vascular function, and on the \\ serum lipoprotein profile in \\ overweight and obese subjects
}

Marjolijn C.E. Bragt-van Wijngaarden ${ }^{1,2}$, Ronald P. Mensink ${ }^{1,2}$

1 Dutch Nutrigenomics Consortium, Top Institute Food and Nutrition, Wageningen, The Netherlands

2 NUTRIM School for Nutrition, Toxicology and Metabolism, Department of Human Biology, Maastricht University Medical Centre+, Maastricht, The Netherlands

Based on Nutr Metab Cardiovasc Dis 2011; doi:10.1016/j.numecd.2010.12.010 


\section{Abstract}

The aim of this study was to compare the effects of n-3 long chain polyunsaturated fatty acids ( $n-3$ LCPUFA) from fish oil, with those of fenofibrate, on markers of inflammation and vascular function, and on the serum lipoprotein profile in overweight and obese subjects. Twenty overweight and obese subjects participated in a randomized, double-blind, placebo-controlled intervention trial and received $3.7 \mathrm{~g} / \mathrm{d} \mathrm{n}-3$ fatty acids (providing $1.7 \mathrm{~g} / \mathrm{d}$ EPA and $1.2 \mathrm{~g} / \mathrm{d}$ DHA), $200 \mathrm{mg}$ fenofibrate or placebo treatment for 6 weeks separated by a 2-weeks wash-out period. Fish oil and fenofibrate treatment reduced triglyceride $(-0.61 \pm 0.81 \mathrm{mmol} / \mathrm{L}, P<0.001$, and $-0.34 \pm 0.85 \mathrm{mmol} / \mathrm{L}, P=0.048$, respectively) and increased $\mathrm{HDL}$ cholesterol concentrations $(0.13 \pm 0.21 \mathrm{mmol} / \mathrm{L}, P=0.013$, and $0.10 \pm 0.18 \mathrm{mmol} / \mathrm{L}, P=0.076)$, as reflected by a decrease of large very VLDL particles and increases of large $\mathrm{HDL}$ particles and medium size HDL particles. Fish oil increased serum LDL cholesterol concentrations $(0.34 \pm 0.59 \mathrm{mmol} / \mathrm{L}, P=0.013)$. Fenofibrate reduced concentrations of soluble endothelial selectin (sE-selectin) $(-4.1 \pm 7.5 \mathrm{ng} / \mathrm{mL}$, $P=0.032$ ), but increased those of macrophage chemoattractant protein 1 (MCP1) ( $28 \pm 55 \mathrm{ng} / \mathrm{mL}, P=0.034)$. Fish oil had no effects on these markers. Although $\mathrm{n}-3$ LCPUFA and fenofibrate can both activate PPAR $\alpha$, they have differential effects on cardiovascular risk markers. In overweight and obese subjects fenofibrate (200 $\mathrm{mg} / \mathrm{d}$ ) or n-3 LCPUFA (3.7 g/d) treatment for 6 weeks did not improve markers for low-grade systemic inflammation, while fenofibrate had more profound effects on plasma lipids and markers for vascular activity compared to fish oil. 


\section{Introduction}

Drugs of the fibrate class, such as fenofibrate, are potent activators of Peroxisome Proliferator Activated Receptor $\alpha$ (PPAR $\alpha)^{1}$. These lipid-lowering drugs effectively reduce triglyceride, moderately reduce low density lipoprotein (LDL) cholesterol, and elevate high density lipoprotein (HDL) cholesterol ${ }^{2}$. Furthermore, fibrates may exert anti-inflammatory effects and improve vascular function ${ }^{3}$. Therefore, targeting PPAR $\alpha$ can be an effective way to improve features belonging to the metabolic syndrome and to reduce cardiovascular risk. As PPARs can be seen as lipid sensors, dietary n-3 fatty acids deserve attention in this respect. Especially the marine $n-3$ long-chain polyunsaturated fatty acids ( $n-3$ LCPUFA) eicosapentaenoic acid (EPA) and docosahexaenoic acid (DHA) preferentially bind to and activate PPAR $\alpha$. However, these n-3 LCPUFA can also activate PPAR $\gamma$ and PPAR $\delta$, two other PPAR isoforms ${ }^{1}$. As fibrates, dietary n-3 LCPUFA have potent hypotriglyceridemic effects and can increase $\mathrm{HDL}$ cholesterol ${ }^{4}$. Furthermore, the suggested beneficial effects on inflammation and endothelial function may further contribute to a reduction in cardiovascular risk. Stalenhoef et al. have now compared in hypertriglyceridemic subjects gemfibrozil with n-3 LCPUFA and showed that both treatments had favorable effects on serum lipid concentrations and lipoprotein particle heterogeneity ${ }^{5}$. However, in that study markers reflecting low-grade systemic inflammation and endothelial function were not examined.

To establish the relevance of a dietary component as a subtle, PPAR agonist with that of a strong, synthetic PPAR $\alpha$ agonist, we decided to compare sideby-side the effects of n-3 LCPUFA with those of fenofibrate on inflammatory parameters, vascular function, and the serum lipoprotein profile in overweight and obese subjects, who are at increased risk to have or to develop the metabolic syndrome.

\section{Methods}

\subsection{Subjects}

Caucasian subjects with a BMI of at least $27 \mathrm{~kg} / \mathrm{m}^{2}$ were recruited between the end of March and the end of August of 2007 via posters in the university and hospital buildings, and via advertisements in local newspapers. Subjects came to the university for a screening visit. On this visit, fasting blood was sampled for analyses of serum lipids and lipoproteins. In addition, height and body weight were determined. Furthermore, subjects had to complete a medical and general questionnaire. Exclusion criteria were BMI below $27 \mathrm{~kg} / \mathrm{m}^{2}$, impairment of kidney (creatinine $>150 \mathrm{mmol} / \mathrm{L}$ ) and liver function (ALAT, ASAT, ALP, GGT or total bilirubine $>2$ times upper limit of normal), serum total cholesterol above $8 \mathrm{mmol} / \mathrm{L}$, serum triglycerides above $4 \mathrm{mmol} / \mathrm{L}$, taking medication that could influence the study outcome or could interfere with fenofibrate treatment, use of fish oil supplements, consumption of plant sterol or stanol-enriched food products, having donated blood within 1 month prior to the start of the 
study, having a diagnosis of any long-term medical condition (e.g. diabetes, cardiovascular diseases, epilepsy) or experiencing strong symptoms of allergy. Subjects received oral and written information about the nature and risk of the experimental procedures before their written informed consent before the start of the study. The study was approved by the Medical Ethical Committee of Maastricht University.

After the screening of 34 subjects, 26 subjects met all our inclusion criteria and started the study. After inclusion, 6 subjects dropped out (1 man underwent surgery for an aneurysm, 1 woman had complained about vapours during the placebo period, 1 man and 1 woman did not regularly attend appointments and were excluded, 1 man had a work-related reason, and 1 man had personal reasons). Thus, ten men and ten women completed the trial. Baseline characteristics are presented in table 1.

Table 1. Baseline characteristics of the participants.

\begin{tabular}{|c|c|c|c|c|c|c|c|c|c|}
\hline \multirow[b]{2}{*}{ Age (years) } & \multicolumn{3}{|c|}{ All $(n=20)$} & \multicolumn{3}{|c|}{ Females $(n=10)$} & \multicolumn{3}{|c|}{ Males $(n=10)$} \\
\hline & 52 & \pm & 12 & 51 & \pm & 14 & 54 & \pm & 10 \\
\hline $\mathrm{BMI}\left(\mathrm{kg} / \mathrm{m}^{2}\right)$ & 33 & \pm & 5 & 34 & \pm & 5 & 31 & \pm & 5 \\
\hline Waist circumference $(\mathrm{cm})$ & 117 & \pm & 12 & 116 & \pm & 11 & 118 & \pm & 13 \\
\hline Systolic blood pressure $(\mathrm{mmHg})$ & 131 & \pm & 14 & 122 & \pm & 9 & 141 & \pm & 10 \\
\hline Diastolic blood pressure $(\mathrm{mmHg})$ & 91 & \pm & 8 & 85 & \pm & 7 & 96 & \pm & 5 \\
\hline Total cholesterol (mmol/L) & 6.23 & \pm & 1.18 & 5.89 & \pm & 1.45 & 6.59 & \pm & 0.78 \\
\hline LDL cholesterol (mmol/L) & 3.97 & \pm & 1.09 & 3.54 & \pm & 1.23 & 4.41 & \pm & 0.75 \\
\hline HDL cholesterol (mmol/L) & 1.52 & \pm & 0.44 & 1.67 & \pm & 0.46 & 1.38 & \pm & 0.39 \\
\hline Triglycerides (mmol/L) & 1.63 & \pm & 0.59 & 1.51 & \pm & 0.52 & 1.76 & \pm & 0.65 \\
\hline Glucose $(\mathrm{mmol} / \mathrm{L})$ & 5.34 & \pm & 0.73 & 5.22 & \pm & 0.54 & 5.45 & \pm & 0.88 \\
\hline Criteria metabolic syndrome $(n)^{2}$ & 2.2 & \pm & 1.0 & 1.6 & \pm & 0.7 & 2.7 & \pm & 1.1 \\
\hline Diagnosis metabolic syndrome $(n)^{2}$ & 7 & & & 1 & & & 6 & & \\
\hline
\end{tabular}

\subsection{Study design}

The study had a randomized, double-blind, placebo-controlled, crossover design. Each subject enrolled in random order in a fish oil, a fenofibrate and a placebo 
period for 6 weeks with a wash-out period of at least 2 weeks between the intervention periods. During the fish oil intervention, subjects had to consume daily 8 fish oil capsules (Marinol C-38тм, Lipid Nutrition, Wormerveer, the Netherlands), providing approximately $3.7 \mathrm{~g} / \mathrm{d}$ n-3 LCPUFA (1.7 g/d EPA and 1.2 $\mathrm{g} / \mathrm{d}$ DHA, ) and 2 capsules placebo-matching fenofibrate $(200 \mathrm{mg} / \mathrm{d}$ cellulose). During the fenofibrate period, subjects consumed 2 capsules providing 200 $\mathrm{mg} / \mathrm{d}$ micronized fenofibrate (Lipanthyl®, Fournier Laboratories, Dijon, France) and 8 placebo-matching fish oil capsules (containing $80 \%$ High Oleic Sunflower Oil (HOSO)). During the placebo period, subjects received 8 HOSO capsules and 2 cellulose capsules. Subjects had to ingest half of the capsules before breakfast and the other half before dinner with a glass of water. Subjects were restricted in their fish consumption to a maximum of one portion a week. During the study, subjects recorded any symptom of illness, visits to physician, medication used, alcohol consumption, and any deviations from the protocol in diaries. Body weight was recorded at weeks 0,5 and 6 of each intervention period and blood pressure was monitored using a sphygmomanometer (Omron M7, CEMEX Medische Techniek BV, Nieuwegein, the Netherlands). At the end of each intervention period, energy and nutrient intakes of the previous 4 weeks were estimated using a food frequency questionnaire (FFQ) ${ }^{6}$.

\subsection{Blood sampling and analyses}

\subsubsection{Blood sampling}

In weeks 5 and 6 of each intervention period, subjects arrived in the morning after an overnight fast and after abstinence from drinking alcohol the preceding day. Venous blood was sampled in BD vacutainer ${ }^{\circledR}$ tubes (Becton Dickinson Company, NJ, USA). Serum was obtained by clotting the blood for 30 minutes, followed by 30 min centrifugation at $2000 \times g$. EDTA, NaF and heparin plasma were obtained by centrifugation at $2000 \times g$ for 30 minutes at $4^{\circ} \mathrm{C}$, directly after sampling. Serum and plasma aliquots were snap frozen and stored at $-80^{\circ} \mathrm{C}$ until analysis.

\subsubsection{Clinical safety parameters}

Serum concentrations of markers of liver and kidney function (total bilirubin, aspartate aminotransferase (ASAT), alanine-aminotransferase (ALAT), alkaline phosphatase (ALP), $\gamma$-glutamyl transpeptidase $(\gamma$-GT), ureum, and creatinine) from week 6 of each intervention period were determined at the department of Clinical Chemistry, University Hospital Maastricht (Beckman Synchron CX7 Clinical systems, Beckman).

\subsubsection{Plasma lipids, lipoproteins and glucose}

Plasma EDTA samples from weeks 5 and 6 were analysed separately for concentrations of serum total cholesterol (ABX Diagnostics, Montpelier, 
France), HDL cholesterol (precipitation method; Roche Diagnostics Corporation, Indianapolis, IN), and triglycerides corrected for free glycerol (Sigma-Aldrich Chemie, Steinheim, Germany). Serum LDL cholesterol concentrations were calculated with the formula of Friedewald et al ${ }^{7}$. After analysis, values of weeks 5 and 6 were averaged. The free EPA and DHA content in plasma as a compliance marker, was determined with LC-MS methodology (TNO, Zeist, the Netherlands) as described $^{8}$ in heparin plasma of week 6 from each period. The plasma lipoprofile (number and size op lipoprotein particles) was analysed by NMR (NMR LipoProfile test, Liposcience Inc., Raleigh, NC, USA) in a pooled sample from weeks 5 and 6 of each treatment period. NaF plasma samples from weeks 5 and 6 were analysed for free fatty acids (FFA) with the Wako Nefa C test kit (Wako Chemicals, Neuss, Germany) and plasma glucose with the hexokinase method (LaRoche, Basel, Switzerland), and values were averaged.

\subsubsection{Markers of inflammation and vascular activity}

Plasma EDTA samples from weeks 5 and 6 of each intervention period were pooled prior to the analysis of plasma markers of inflammation and vascular activity. High sensitive CRP (hsCRP) was measured with a immunoturbidimetric assay using commercially available kit (Kamiya Biomedical Company, Seattle, WA, USA). The MS2400 Human Vascular Injury II Assay (Meso Scale Discovery, MD, USA) was used for analysis of soluble Vascular Cell Adhesion Molecule-1 (sVCAM1) and soluble Intracellular Adhesion Molecule-1 (sICAM1). Tumor Necrosis Factor $\alpha$ Receptors (TNFR) 1 and 2 were measured with the MS2400 TNFR1 and TNFR2 ultrasensitive assay (Meso Scale Discovery, MD, USA). Plasma concentrations of Macrophage Chemo-attractant Protein 1 (MCP1) were measured with the MA2400 Human MCP1 ultrasensitive assay (Meso Scale Discovery, MD, USA). Soluble endothelial selectin (sE-selectin) concentrations were measured by enzymelinked immunosorbent assay (ELISA) as described ${ }^{9}$. Plasma Tumor Necrosis Factor $\alpha(T N F \alpha)$ and interleukin 6 (IL6) were measured with an ELISA kit from R\&D systems (Abingdon, UK). All samples from one subject were analysed in the same analytical run in duplicate. The intra- and inter-assay variation coefficients were below $10 \%$ for all measured parameters.

\subsection{Statistics}

The power to detect a true difference of $0.20 \mathrm{mmol} / \mathrm{L}$ in triglyceride concentrations between treatments after adjustment for multiple comparisons was $80 \%$. Normality was checked visually and tested with the Shapiro-Wilk test. Glucose and sE-selectin concentrations were log-transformed to achieve normality. Differences in fasting levels at the end of the intervention periods were compared with a General Linear Model for Univariate ANOVA with treatment as fixed factor and subject number as random factor. Since there were no significant interactions between treatment and gender, and treatment and body weight on the outcome parameters, these parameters were not included in the final model. To adjust for multiple comparisons, a Tukey Honestly Significantly Difference 
(HSD) procedure was carried out. A P<0.05 was considered to be statistically significant. Data are presented as mean \pm SD. Statistical analysis was performed using SPSS 15.0 for Windows.

\section{Results}

\subsection{Compliance, dietary intake, bodyweight and blood pressure}

The calculated main daily capsule intake was 93\% during the fish oil period, 95\% during the fenofibrate period and $95 \%$ during the placebo period, indicating a good compliance. This was confirmed for the fish oil period, as plasma free EPA and DHA concentrations increased by 358\% $(P<0.001)$ and $105 \%(P<0.001)$ compared to the placebo period, and by $463 \%(P<0.001)$ and $157 \%(P<0.001)$ compared to the fenofibrate period, respectively. Total energy intake and the proportions of energy from fat, carbohydrates and protein, and the amounts of fiber, alcohol and cholesterol in the diet did not differ between the treatment groups (data not shown). Furthermore, bodyweight and blood pressure did not change between the treatment periods (data not shown).

Table 2. Effects of fish oil and fenofibrate on serum lipid concentrations and plasma glucose concentrations'.

\begin{tabular}{lccccccccccc} 
& \multicolumn{3}{c}{ Placebo } & \multicolumn{3}{c}{ Fenofibrate } & \multicolumn{3}{c}{ Fish oil } \\
Total cholesterol (mmol/L) & 6.01 & \pm & 1.32 & 5.42 & \pm & $1.20 *$ & 6.29 & \pm & $1.42^{\#}$ \\
LDL cholesterol (mmol/L & 3.74 & \pm & 1.14 & 3.30 & \pm & $1.09 *$ & 4.08 & \pm & $1.24 * \#$ \\
HDL cholesterol $(\mathrm{mmol} / \mathrm{L})$ & 1.44 & \pm & 0.41 & 1.58 & \pm & $0.42^{*}$ & 1.54 & \pm & 0.48 \\
FFA $(\mu \mathrm{M} / \mathrm{L})$ & 396 & \pm & 236 & 368 & \pm & 237 & 357 & \pm & 209 \\
Glucose $(\mathrm{mmol} / \mathrm{L})^{2}$ & 5.3 & \pm & 0.7 & 5.4 & \pm & 0.7 & 5.6 & \pm & 0.7 \\
\hline
\end{tabular}

\footnotetext{
Values are expressed as mean \pm SD. $*$ P $<0.05$ versus placebo period, \# $\mathrm{P}<0.05$ versus fenofibrate period

2 Log transformed concentrations were used for statistical analysis
}

\subsection{Effects on serum lipids and lipoprofile and plasma glucose}

Compared to placebo, fenofibrate reduced serum total cholesterol and LDL cholesterol by respectively $9 \%(-0.59 \mathrm{mmol} / \mathrm{L}, P=0.001)$ and $11 \%(-0.45$ $\mathrm{mmol} / \mathrm{L}, P=0.004$; table 2$)$. Fish oil tended to increase the concentration of total cholesterol $(P=0.099)$ and increased that of LDL cholesterol by $10 \%(0.34$ $\mathrm{mmol} / \mathrm{L}, P=0.035$ ) compared to placebo. Both fenofibrate and fish oil effectively reduced serum triglyceride concentrations by respectively $27 \%(-0.61 \mathrm{mmol} / \mathrm{L}$, $P<0.001)$ and $13 \% \quad(-0.34 \mathrm{mmol} / \mathrm{L}, P=0.048)$ compared with placebo (figure 1$)$. 
HDL cholesterol concentrations increased by $11 \%(0.13 \mathrm{mmol} / \mathrm{L}, P=0.013)$ after fenofibrate treatment, whereas fish oil tended to increase HDL cholesterol $(P=0.076)$ compared to placebo. Compared with fenofibrate treatment, HDL cholesterol $(P=0.737)$ and triglyceride concentrations $(P=0.133)$ were comparable after fish oil intake, but total cholesterol $(0.91 \mathrm{mmol} / \mathrm{L}, P<0.001)$ and $\mathrm{LDL}$ cholesterol $(0.78 \mathrm{mmol} / \mathrm{L}, P<0.001)$ were increased. Concentrations of free fatty acids were not affected by either treatment.

Fish oil tended to raise fasting plasma glucose concentrations compared to placebo $(0.24 \mathrm{mmol} / \mathrm{L}, P=0.056)$ and fenofibrate treatment had no effect $(P=0.721)$ compared to placebo. At the end of the intervention period, glucose concentrations between fish oil and fenofibrate treatment $(P=0.250)$ did not differ.

Compared to placebo, fenofibrate significantly reduced total VLDL particle numbers $(-23 \mathrm{nmol} / \mathrm{L}, P=0.001)$, in particular large $(-2.4 \mathrm{nmol} / \mathrm{L}, P=0.003)$ and medium VLDL particles $(-14 \mathrm{nmol} / \mathrm{L}, P=0.001)$. Fish oil reduced the number of large VLDL particles $(-3.0 \mathrm{nmol} / \mathrm{L}, P<0.001)$, although the total number of VLDL particles was not affected. It increased however the total number of LDL particles (224 nmol/L, $P=0.005)$, but decreased the number of IDL particles (-28 $\mathrm{nmol} / \mathrm{L}, P=0.016)$. For $\mathrm{HDL}$, fenofibrate decreased HDL size $(-0.11 \mathrm{~nm}, P=0.025)$ and increased the number of medium $\mathrm{HDL}$ particles $(3.1 \mu \mathrm{mol} / \mathrm{L}, P=0.011)$. Fish oil had no overall effect on HDL size, but increased the number large HDL particles $(1.5 \mu \mathrm{mol} / \mathrm{L})$. Fish oil treatment resulted in higher particle numbers of total $\operatorname{VLDL}(16 \mathrm{nmol} / \mathrm{L}, P=0.02)$, medium VLDL (13 nmol/L, $P=0.002)$, total LDL (334 $\mathrm{nmol} / \mathrm{L}, P<0.001)$, large LDL (132 $\mathrm{nmol} / \mathrm{L}, P=0.006)$ and small LDL $(215 \mathrm{nmol} / \mathrm{L}$, $P=0.043$ ) compared to fenofibrate treatment (table 3 ). The number of large HDL particles and HDL size were larger $(1.8 \mathrm{nmol} / \mathrm{L}, P=0.004$ and $0.14 \mathrm{~nm}, P=0.004$, respectively). The number of medium HDL particles was smaller after fish oil treatment compared to fenofibrate treatment $(-4.8 \mathrm{nmol} / \mathrm{L}, P<0.001)$. 
Table 3. Effects of fenofibrate and fish oil consumption on plasma NMR lipoprofile1.

\section{Placebo}

Fish oil

Particle numbers

$\begin{array}{lccccccccc}\text { Total VLDL } & 63 & \pm & 28 & 40 & \pm & 24^{*} & 56 & \pm & 40^{\#} \\ \text { Large VLDL } & 4.9 & \pm & 3.7 & 2.4 & \pm & 2.6^{*} & 1.8 & \pm & 3.2^{*} \\ \text { Medium VLDL } & 26 & \pm & 17 & 12 & \pm & 9^{*} & 26 & \pm & 24^{\#} \\ \text { Small VLDL } & 32 & \pm & 18 & 26 & \pm & 15 & 28 & \pm & 18 \\ \text { Total LDL } & 1484 & \pm & 554 & 1374 & \pm & 548 & 1708 & \pm & 679^{* \#} \\ \text { IDL } & 55 & \pm & 62 & 40 & \pm & 47 & 27 & \pm & 43^{*} \\ \text { Large LDL } & 523 & \pm & 252 & 439 & \pm & 176 & 571 & \pm & 292^{\#} \\ \text { Small LDL } & 906 & \pm & 614 & 895 & \pm & 497 & 1110 & \pm & 727^{\#} \\ \text { Medium Small LDL } & 191 & \pm & 139 & 190 & \pm & 118 & 223 & \pm & 145 \\ \text { Very small LDL } & 714 & \pm & 496 & 705 & \pm & 382 & 887 & \pm & 586^{\#} \\ \text { Total HDL } & 36 & \pm & 8 & 38 & \pm & 6 & 36 & \pm & 8 \\ \text { Large HDL } & 7.1 & \pm & 4.4 & 6.7 & \pm & 3.9 & 8.6 & \pm & 5.3^{* \#} \\ \text { Medium HDL } & 4.5 & \pm & 5.4 & 7.6 & \pm & 6.0^{*} & 2.8 & \pm & 3.4^{\#} \\ \text { Small HDL } & 25 & \pm & 6 & 24 & \pm & 7 & 25 & \pm & 6\end{array}$

Particle sizes

$\begin{array}{lccccccccc}\text { VLDL } & 56 & \pm & 16 & 53 & \pm & 10 & 48 & \pm & 8^{*} \\ \text { LDL } & 21 & \pm & 1 & 21 & \pm & 1 & 21 & \pm & 1 \\ \text { HDL } & 8.9 & \pm & 0.5 & 8.7 & \pm & 0.4^{*} & 8.9 & \pm & 0.5^{\#}\end{array}$

1 Values are means $\pm S D(n=20)$. Particle numbers are expressed in $n m o l / L$, except for $H D L$ particles, which are expressed in $\mu \mathrm{mol} / \mathrm{L}$. Particle sizes are expressed in $\mathrm{nm}$.

* $\mathrm{P}<0.05$ versus placebo period,

\# $\mathrm{P}<0.05$ versus fenofibrate period 


\subsection{Effects on plasma makers of inflammation and vascular activity}

Concentrations of TNFR1, TNFR2 hsCRP, TNF $\alpha$, IL6, sICAM-1 and SVCAM-1 did not differ between the treatments (table 4). Compared with placebo, the chemokine MCP1, however, increased upon fenofibrate treatment (28 ng/mL, $P=0.034$ ), but remained unaffected after fish oil treatment $(P=0.204)$ (table 4$)$. Further, fenofibrate significantly lowered sE-selectin concentrations compared to both placebo $(-4.1 \mathrm{ng} / \mathrm{mL}, P=0.034)$ and fish oil $(-5.7 \mathrm{ng} / \mathrm{mL}, P=0.014)$, whereas fish oil treatment had no effect compared to placebo $(P=0.932)$.

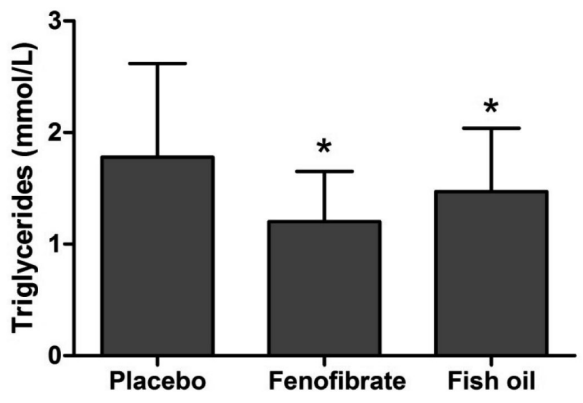

Figure 1. The effects of fish oil and fenofibrate treatment on serum triglyceride concentrations. Data are presented as mean \pm SD. An asterisk indicates a significant effect compared to placebo $(P<0.05)$

Table 4. Effects of fenofibrate and fish oil treatment on markers of inflammation and vascular function'.

\begin{tabular}{|c|c|c|c|c|c|c|c|c|c|}
\hline & \multicolumn{3}{|c|}{ Placebo } & \multicolumn{3}{|c|}{ Fenofibrate } & \multicolumn{3}{|c|}{ Fish oil } \\
\hline TNFR1 (ng/mL) & 3.4 & \pm & 0.8 & 3.5 & \pm & 0.7 & 3.4 & \pm & 0.6 \\
\hline TNFR2 (ng/mL) & 4.3 & \pm & 1.1 & 4.6 & \pm & 0.9 & 4.1 & \pm & 1.0 \\
\hline \multicolumn{10}{|l|}{ Acute phase protein } \\
\hline $\mathrm{CRP}(\mathrm{mg} / \mathrm{L})$ & 4.0 & \pm & 2.8 & 3.6 & \pm & 1.9 & 4.3 & \pm & 3.7 \\
\hline \multicolumn{10}{|l|}{ Cytokines } \\
\hline $\mathrm{TNF} \alpha(\mathrm{pg} / \mathrm{mL})$ & 2.0 & \pm & 0.8 & 2.0 & \pm & 0.6 & 2.0 & \pm & 0.7 \\
\hline IL6 (pg/mL) & 2.8 & \pm & 1.1 & 2.7 & \pm & 1.1 & 2.7 & \pm & 1.0 \\
\hline MCP1 (ng/mL) & 257 & \pm & 69 & 285 & \pm & $87^{*}$ & 267 & \pm & 64 \\
\hline \multicolumn{10}{|l|}{ Adhesion molecules } \\
\hline ICAM (ng/mL) & 275 & \pm & 50 & 304 & \pm & 105 & 267 & \pm & 48 \\
\hline $\operatorname{VCAM}(\mathrm{ng} / \mathrm{mL})$ & 440 & \pm & 102 & 451 & \pm & 95 & 425 & \pm & 86 \\
\hline E-selectin $(\mathrm{ng} / \mathrm{mL})^{2}$ & 76 & \pm & 32 & 72 & \pm & $32 *$ & 77 & \pm & $34^{\#}$ \\
\hline
\end{tabular}

1 Values are mean $\pm S D$. $* P<0.05$ versus placebo period, $\# P<0.05$ versus fenofibrate period

2 Log transformed concentrations were used for statistical analysis 


\subsection{Side effects}

Fish oil and micronized fenofibrate were well tolerated by all subjects. Fish oil had no significant effects on markers of liver and kidney function (table 5) compared to placebo. In contrast, fenofibrate slightly increased ALAT (22 IU/L, $P=0.043$ ). For 5 out of the 20 subjects values were above the normal range (Laboratory of Clinical Chemistry, University Hospital Maastricht, Maastricht, the Netherlands). Fenofibrate also increased ASAT (13 IU/L, $P=0.016 \mathrm{~L})$ and decreased ALP concentrations compared to placebo (-8 IU/L, $P=0.019)$. Creatinine concentrations were higher after fenofibrate treatment compared to placebo ( 9.8 $\mu \mathrm{mol} / \mathrm{L}, P<0.001)$ and fish oil treatment $(9.4 \mu \mathrm{mol} / \mathrm{L}, P<0.001)$. Although $\gamma$-GT did not change significantly $(P=0.979)$, it slightly exceeded the normal range upon fenofibrate treatment compared to placebo for 4 out of 20 subjects.

Table 5. Effects of fenofibrate and fish oil treatment on markers of kidney and liver function'.

\begin{tabular}{|c|c|c|c|c|c|c|c|c|c|c|c|c|}
\hline \multirow[b]{2}{*}{$\begin{array}{l}\text { Total bilirubin } \\
(\mu \mathrm{mol} / \mathrm{L})\end{array}$} & \multicolumn{3}{|c|}{ Placebo } & \multicolumn{3}{|c|}{ Fenofibrate } & \multicolumn{3}{|c|}{ Fish oil } & \multicolumn{3}{|c|}{$\begin{array}{l}\text { Reference } \\
\text { values }^{2}\end{array}$} \\
\hline & 14 & \pm & 7 & 12 & \pm & 3 & 14 & \pm & 5 & 0 & - & 17 \\
\hline ALAT (IU/L) & 28 & \pm & 8 & 50 & \pm & $52 *$ & 38 & \pm & 27 & 5 & - & 45 \\
\hline ASAT (IU/L) & 17 & \pm & 7 & 30 & \pm & $26 *$ & 22 & \pm & 10 & 5 & - & 35 \\
\hline $\operatorname{ALP}(I U / L)$ & 75 & \pm & 24 & 67 & \pm & $23 *$ & 73 & \pm & 21 & 30 & - & 140 \\
\hline$\gamma$-GT (IU/L) & 34 & \pm & 10 & 58 & \pm & 61 & 35 & \pm & 10 & 2 & - & 50 \\
\hline Ureum (mmo/L) & 5.0 & \pm & 0.9 & 5.4 & \pm & 1.3 & 4.8 & \pm & 0.9 & 3 & - & 7 \\
\hline Creatinine $(\mu \mathrm{mol} / \mathrm{L})$ & 78 & \pm & 12 & 88 & \pm & $16^{*}$ & 78 & \pm & $13^{\#}$ & 53 & - & 110 \\
\hline
\end{tabular}

1 Values are mean $\pm S D$. $* P<0.05$ versus placebo period, \# $P<0.05$ versus fenofibrate period

2 Reference values from the department of Clinical Chemistry, University Hospital Maastricht, Maastricht, the Netherlands

\section{Discussion}

Overweight and obese subjects are often characterized by a disturbed lipid and lipoprotein profile, low-grade systemic inflammation, and endothelial dysfunction. A way to improve these metabolic aberrations is by targeting PPAR $\alpha$. We hypothesized that a dietary intervention with n-3 LCPUFAs, as nonselective PPAR $\alpha$ agonists, could be an alternative for a strong medicinal agonist. Therefore, we directly compared the effects of these n-3 LCPUFAs with those of fenofibrate on a broad range of biomarkers for cardiovascular disease. However, we found that fenofibrate $(200 \mathrm{mg} / \mathrm{d})$ and $\mathrm{n}-3$ LCPUFA $(3.7 \mathrm{~g} / \mathrm{d})$ treatment for 
6 weeks did not improve markers for low-grade systemic inflammation and that fenofibrate had more profound effects on plasma lipids and vascular activity compared to fish oil in overweight and obese individuals.

Studies on fenofibrate have shown inconsistent results regarding effects on low-grade inflammation and vascular activity ${ }^{10-12}$. We found that fenofibrate reduced $\mathrm{SE}$-selectin concentration compared to placebo and fish oil treatment in overweight and obese subjects. This finding corresponds to that of Hogue et al., who found in type 2 diabetic patients, that micronized fenofibrate $(200 \mathrm{mg} / \mathrm{d})$ for 6 weeks reduced plasma sE-selectin, but did not affect concentrations of hsCRP, sICAM1 and SVCAM1". In contrast, Ryan et al. showed in an obese population, that fenofibrate reduced SVCAM1, sICAM1, TNF $\alpha$, IL6, IL1 $\beta$, but did not affect sE-selectin concentrations ${ }^{12}$. The reduced $\mathrm{sE-selectin} \mathrm{concentration} \mathrm{as} \mathrm{we} \mathrm{observed} \mathrm{suggests}$ beneficial effects of fenofibrate on vascular activity, since E-selectin is involved in the adherence of leukocytes in the process of atherosclerosis ${ }^{13}$. However, this seems to contradict the observed increase in MCP1 concentrations after fenofibrate treatment compared to placebo, since this chemokine is responsible for attracting monocytes to the injured endothelium ${ }^{13}$. For fish oil, human intervention studies using doses ranging between 1.1 and $6.6 \mathrm{~g} / \mathrm{d}$ n-3 LCPUFAs are inconsistent and do not often report beneficial effects on inflammatory markers and cellular adhesion molecules ${ }^{14-18}$. In that respect, our results agree with those of other studies in obese men ${ }^{17,18}$ and healthy middle-aged individuals ${ }^{19}$, although our sample size may have been too limited to detect statistically significant changes in IL6 and TNF $\alpha$.

The main well-established effects of fenofibrate and fish oil on plasma lipids are their hypotriglyceridemic effects ${ }^{4}{ }^{20}$. Indeed, we also found that both treatments similarly lowered serum triglyceride concentrations and the number of large triglyceride-rich VLDL particles. These effects have been ascribed to an increased hepatic lipolysis and decreased lipogenesis ${ }^{21,22}$, pathways which are under control of PPAR $\alpha^{2}$. We demonstrated a small increase in HDL cholesterol concentrations after fenofibrate and fish oil treatment, reflected by increases in medium size and large size HDL particles. The increased delivery of surface remnants from the catabolism of VLDL particles, together with a PPAR $\alpha$-induced expression of apoA1 and apoA2, the main apolipoproteins of $H D L$, may contribute to the raise in $H D L$ cholesterol ${ }^{23}$. Furthermore, PPAR $\alpha$ may stimulate reverse cholesterol transport via induction of ATP Binding Cassette protein A1 (ABCA1) ${ }^{24}$. Regarding the effects of fish oil and fenofibrate on triglycerides and HDL cholesterol, it is important to note that the degree of these effects largely depend on baseline plasma lipid levels ${ }^{4}$, 25,26 . In contrast to fenofibrate, fish oil increased LDL cholesterol concentrations. Others have also reported that high dose supplementation of EPA and DHA can raise LDL cholesterol by $5-10 \%^{26}$. In this respect, some groups of subjects may be more sensitive than other groups and it has been suggested that this variability in $\mathrm{LDL}$ cholesterol response is related to the apoE4 variant of apolipoprotein $\mathrm{E}^{27}$. For fenofibrate and fish oil treatments, it has been reported that the LDL particle size changes into a more buoyant type, which may be less atherogenic ${ }^{5}$. In our study, 
however, this could not be confirmed. Fish oil increased large, small and very small LDL compared to fenofibrate. These findings seem inconsistent in relation to our observed reduction in triglycerides and increase in large HDL particles. When plasma triglycerides are reduced, the proportion or concentration of small LDL particles is expected to be reduced and that of large HDL increased ${ }^{28}$. We do not have an explanation for these unexpected results.

Finally, we observed a non-significant increase of fasting plasma glucose after fish oil treatment. This agrees with a meta-analysis by Balk et al. ${ }^{26}$, who reported a very small and non-significant average net increase in fasting plasma glucose after treatment with $n-3$ LCPUFAs.

In summary, although n-3 LCPUFAs and fenofibrate can both activate PPAR $\alpha$, this study in overweight and obese subjects showed that both fenofibrate (200 $\mathrm{mg} / \mathrm{d}$ ) and fish oil ( $7.2 \mathrm{~g} / \mathrm{d}$, providing $1.7 \mathrm{~g} / \mathrm{d}$ EPA and $1.2 \mathrm{~g} / \mathrm{d} \mathrm{DHA}$ ) treatment for 6 weeks have different effects on cardiovascular risk markers. Both interventions equally lowered serum triglycerides and raised HDL cholesterol, which agrees with few other human studies that have compared side by side the effects of fibrates with those of n-3 LCPUFAs ${ }^{5,29,30}$ Also, as in several other studies ${ }^{26}$, fish oil treatment increased LDL cholesterol. Both treatments, however, did not improve markers for low-grade systemic inflammation, while fenofibrate had more profound, but apparently conflicting, effects on markers for vascular activity compared to fish oil. Still, like fenofibrate ${ }^{30}$, LCPUFAs may lower cardiovascular risk through beneficial effects on other cardiovascular risk factors such as blood pressure, arrhythmias and platelet function ${ }^{31,32}$.

\section{Acknowledgements}

This study was funded by the Nutrigenomics Consortium (NGC) of Top Institute Food and Nutrition (TIFN). We would like to thank Martine Hulsbosch, Carla Langejan and Vera Deckers for their assistance in executing the study and performing the laboratory analyses. 


\section{References}

1 Krey G, Braissant O, L'Horset F, et al. Fatty acids, eicosanoids, and hypolipidemic agents identified as ligands of peroxisome proliferator-activated receptors by coactivator-dependent receptor ligand assay. Mol Endocrinol, 1997; 11: 779-791.

2 Staels B, Dallongeville J, Auwerx J, et al. Mechanism of action of fibrates on lipid and lipoprotein metabolism. Circulation, 1998; 98: 2088-2093.

3 Delerive $\mathrm{P}$, Fruchart $\mathrm{J}$ and Staels B. Peroxisome proliferator-activated receptors in inflammation control. J Endocrinol, 2001; 169: 453-459.

4 Harris WS. n-3 fatty acids and serum lipoproteins: human studies. The American journal of clinical nutrition, 1997; 65: 1645S-1654S.

5 Stalenhoef $A F$, de Graaf J, Wittekoek ME, et al. The effect of concentrated n-3 fatty acids versus gemfibrozil on plasma lipoproteins, low density lipoprotein heterogeneity and oxidizability in patients with hypertriglyceridemia. Atherosclerosis, 2000; 153: 129-138.

6 Plat $\mathrm{J}$ and Mensink RP. Vegetable oil based versus wood based stanol ester mixtures: effects on serum lipids and hemostatic factors in non-hypercholesterolemic subjects. Atherosclerosis, 2000; 148: 101-112.

7 Friedewald WT, Levy RI and Fredrickson DS. Estimation of the concentration of low-density lipoprotein cholesterol in plasma, without use of the preparative ultracentrifuge. Clin Chem, 1972; 18: 499-502.

8 Wopereis S, Rubingh CM, van Erk MJ, et al. Metabolic profiling of the response to an oral glucose tolerance test detects subtle metabolic changes. PLoS ONE, 2009; 4: e4525.

9 Bouma M, Laan M, Deneter M, et al., Analysis of soluble adhesion molecules, In: Johnstone A and Turner M (eds), Immunohistochemistry: a practical approach, Oxford, Oxford University Press, 1997: 81-196.

10 Hiukka A, Westerbacka J, Leinonen ES, et al. Long-term effects of fenofibrate on carotid intima-media thickness and augmentation index in subjects with type 2 diabetes mellitus. J Am Coll Cardiol, 2008; 52: 21902197.

11 Hogue JC, Lamarche B, Tremblay AJ, et al. Differential effect of atorvastatin and fenofibrate on plasma oxidized low-density lipoprotein, inflammation markers, and cell adhesion molecules in patients with type 2 diabetes mellitus. Metabolism, 2008; 57: 380-386.

12 Ryan KE, McCance DR, Powell L, et al. Fenofibrate and pioglitazone improve endothelial function and reduce arterial stiffness in obese glucose tolerant men. Atherosclerosis, 2007; 194: e123-130.

13 Ross R. Atherosclerosis is an inflammatory disease. Am Heart J, 1999; 138: S419-420.

14 Chan DC, Watts GF, Barrett PH, et al. Effect of atorvastatin and fish oil on plasma high-sensitivity C-reactive protein concentrations in individuals with visceral obesity. Clin Chem, 2002; 48: 877-883.

15 Madsen T, Christensen JH, Blom M, et al. The effect of dietary n-3 fatty acids on serum concentrations of C-reactive protein: a dose-response study. Br J Nutr, 2003; 89: 517-522.

16 Yusof HM, Miles EA and Calder P. Influence of very long-chain n-3 fatty acids on plasma markers of inflammation in middle-aged men. Prostaglandins Leukot Essent Fatty Acids, 2008; 78: 219-228.

17 Jellema A, Plat J and Mensink RP. Weight reduction, but not a moderate intake of fish oil, lowers concentrations of inflammatory markers and PAI- 1 antigen in obese men during the fasting and postprandial state. European journal of clinical investigation, 2004; 34: 766-773.

18 Plat J, Jellema A, Ramakers J, et al. Weight loss, but not fish oil consumption, improves fasting and postprandial serum lipids, markers of endothelial function, and inflammatory signatures in moderately obese men. J Nutr, 2007; 137: 2635-2640.

19 Pot GK, Brouwer IA, Enneman A, et al. No effect of fish oil supplementation on serum inflammatory markers and their interrelationships: a randomized controlled trial in healthy, middle-aged individuals. Eur J Clin Nutr, 2009; 83: 1353-1359.

20 Grundy SM and Vega GL. Fibric acids: effects on lipids and lipoprotein metabolism. Am J Med, 1987; 83: 9-20.

21 Forcheron F, Cachefo A, Thevenon S, et al. Mechanisms of the triglyceride- and cholesterol-lowering effect of fenofibrate in hyperlipidemic type 2 diabetic patients. Diabetes, 2002; 51: 3486-3491.

22 Harris WS and Bulchandani D. Why do omega-3 fatty acids lower serum triglycerides? Curr Opin Lipidol, 2006; 17: 387-393.

23 Fruchart JC. Peroxisome proliferator-activated receptor-alpha activation and high-density lipoprotein metabolism. Am J Cardiol, 2001; 88: 24N-29N. 
24 Hossain MA, Tsujita M, Gonzalez FJ, et al. Effects of fibrate drugs on expression of ABCA1 and HDL biogenesis in hepatocytes. J Cardiovasc Pharmacol, 2008; 51: 258-266.

25 Despres JP, Lemieux I, Salomon $\mathrm{H}$, et al. Effects of micronized fenofibrate versus atorvastatin in the treatment of dyslipidaemic patients with low plasma HDL-cholesterol levels: a 12-week randomized trial. J Intern Med, 2002; 251: 490-499.

26 Balk EM, Lichtenstein AH, Chung M, et al. Effects of omega-3 fatty acids on serum markers of cardiovascular disease risk: A systematic review. Atherosclerosis, 2006.

27 Minihane AM. Fatty acid-genotype interactions and cardiovascular risk. Prostaglandins Leukot Essent Fatty Acids; 82: 259-264.

28 Deckelbaum RJ, Granot E, Oschry Y, et al. Plasma triglyceride determines structure-composition in low and high density lipoproteins. Arteriosclerosis, 1984; 4: 225-231.

29 Fasching $\mathrm{P}$, Rohac M, Liener K, et al. Fish oil supplementation versus gemfibrozil treatment in hyperlipidemic NIDDM. A randomized crossover study. Horm Metab Res, 1996; 28: 230-236.

30 Otto C, Ritter MM, Soennichsen AC, et al. Effects of n-3 fatty acids and fenofibrate on lipid and hemorrheological parameters in familial dysbetalipoproteinemia and familial hypertriglyceridemia. Metabolism, 1996; 45: 13051311.

31 Mozaffarian D. Fish, n-3 fatty acids, and cardiovascular haemodynamics. J Cardiovasc Med (Hagerstown), 2007; 8 Suppl 1: S23-26.

32 Richard D, Bausero P, Schneider C, et al. Polyunsaturated fatty acids and cardiovascular disease. Cell Mol Life Sci, 2009; 66: 3277-3288. 



\section{Chapter}

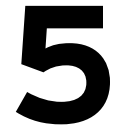

\section{Effects of fenofibrate and}

fish oil on gene expression in peripheral blood mononuclear cells, muscle, and adipose tissue from overweight and obese individuals

Marjolijn C.E. Bragt-van Wijngaarden ${ }^{1,2}$, Mark V. Boekschoten ${ }^{1,3}$, Michael Müller ${ }^{1,3}$, Ronald P. Mensink, ${ }^{12}$

1 Dutch Nutrigenomics Consortium, Top Institute Food and Nutrition, Wageningen, the Netherlands.

2 NUTRIM School for Nutrition, Toxicology and Metabolism, Department of Human Biology, Maastricht University Medical Centre+, Maastricht, the Netherlands.

3 Nutrition, Metabolism and Genomics group, Division of Human Nutrition, Wageningen University, Wageningen, the Netherlands 


\section{Abstract}

The molecular effects of the non-selective dietary PPAR $\alpha$ agonists n-3 LCPUFAs (fish oil) were compared side-by-side with those of the selective synthetic PPAR $\alpha$ agonist fenofibrate on whole-genome gene expression in peripheral blood mononuclear cells (PBMCs), white adipose tissue (WAT), and muscle in overweight and obese subjects. Eleven overweight and obese subjects participated in a randomized, double-blind, placebo-controlled intervention trial and received in random order $3.7 \mathrm{~g} / \mathrm{d} \mathrm{n}-3$ fatty acids (providing $1.7 \mathrm{~g} / \mathrm{d}$ EPA and $1.2 \mathrm{~g} / \mathrm{d}$ DHA), 200 $\mathrm{mg}$ fenofibrate or placebo treatment for 6 weeks separated by a wash-out period of at least 2-weeks. Fenofibrate changed 5 of the analysed 56 PPAR $\alpha$ target genes in PBMC, 4 in muscle, and 2 in WAT, whereas fish oil changed 2 genes in WAT only. Both treatments changed 17 out of 25 similar pathways in PBMCs, related to xenobiotic metabolism, biosynthesis of steroids, lipid metabolism, transcription, proteasome function, Th1 immunity, propanoate metabolism and nucleotide metabolism. The majority (18 out of 25 ) of downregulated pathways in WAT were similarly changed in PBMCs after fish oil and related to lipid metabolism and amino acid metabolism. Fenofibrate and fish oil hardly affected pathways in muscle. In PBMCs, fenofibrate and fish oil only regulated 9 similar genes in metabolic syndrome-related pathways, which were IL25, TICAM1, PRDX2, PTGS1, AGK, FDPS, LDLR, TNNI3, LMAN1 and PTGS1. Overall, 6-weeks treatment with n-3 LCPUFAs and fenofibrate hardly affected the expression of PPAR $\alpha$ target genes in overweight and obese subjects. Pathway analyses suggested that gene expression profiles in PBMCs can provide information about regulated metabolic processes by fish oil and fenofibrate in WAT, but not muscle. Expression of the individual genes, however, hardly overlapped between the tissues. 


\section{Introduction}

The incidence of diet-related diseases, such as cardiovascular diseases and diabetes mellitus type 2 , is increasing. These diseases are often linked to the metabolic syndrome, which refers to a cluster of metabolic disturbances related to an abnormal lipid and carbohydrate metabolism, and a pro-inflammatory state of the body. Potential molecular targets to prevent these metabolic disturbances are nuclear peroxisome proliferator-activated receptors (PPARs), which are one of the central regulators of nutrient-gene interactions ${ }^{1-3}$.

Activation of PPAR $\alpha$ showed that one of its functions is the regulation of genes involved in several aspects of lipid metabolism, including fatty acid uptake through membranes, fatty acid binding in cells, fatty acid oxidation, and lipoprotein assembly and transport ${ }^{4}$. Further, PPAR $\alpha$ may have a beneficial effect on genes involved in (vascular) inflammation and oxidative stress ${ }^{1,5}$. In fact, synthetic PPAR $\alpha$ agonists, such as fenofibrate, are already widely used as hypolipidemic drugs. As PPARs function as lipid sensors ${ }^{6}$, nutrition can play a pivotal role in the prevention and treatment of the metabolic syndrome. In this respect, longchain polyunsaturated fatty acids (LCPUFAs), such as eicosapenaenoic acid (EPA) and docosahexaenoic acid (DHA) deserve attention as effective, but nonselective PPAR activators ${ }^{7}$. Upon binding with fatty acids or a synthetic ligand (e.g. fenofibrate), PPAR bind as a heterodimer with the retinoid $X$ receptor to a PPAR responsive element (PPRE) in enhancer sites of regulated genes to regulate gene transcription 4 .

Comparing fenofibrate to fish oil side-by-side will show how effects on gene expression exerted by a drug relate to those than can be achieved with a dietary intervention. Furthermore, this may reveal important (PPAR $\alpha$-regulated) genes that reduce the risk of metabolic disturbances. PPAR $\alpha$ is predominantly expressed in the liver, followed by the muscle, intestine and adipose tissue ${ }^{8}$. Since these tissues contribute to the pathology of the metabolic syndrome ${ }^{9}$ and are relatively inaccessible in humans, information on the relationship between gene expression profiles in the easy accessible peripheral blood mononuclear cells (PBMCs) with those in other tissues is essential to monitor the effectiveness of an intervention and to unravel the underlying mechanisms of the metabolic syndrome in specific target tissues. Therefore, the effects of fish oil and fenofibrate on gene expression were investigated in PBMCs, muscle and white adipose tissue from overweight subjects by whole genome microarray analysis.

\section{Methods}

\subsection{Subjects}

Subjects with a BMI of at least $27 \mathrm{~kg} / \mathrm{m}^{2}$ were recruited via posters in the university and hospital buildings and via advertisements in local newspapers. Subjects came to the university for a screening visit. On this visit, fasting blood was sampled for analyses of serum lipids and lipoproteins. In addition, height and body weight 
were determined. Furthermore, subjects had to complete a medical and general questionnaire. Exclusion criteria were BMI below $27 \mathrm{~kg} / \mathrm{m}^{2}$, impairment of kidney and liver function, serum total cholesterol above $8 \mathrm{mmol} / \mathrm{L}$, serum triglycerides above $4 \mathrm{mmol} / \mathrm{L}$, taking medication that could influence the study outcome or could interfere with fenofibrate treatment, use of fish oil supplements, consumption of plant sterol or stanol-enriched food products, having donated blood within 1 month prior to the start of the study, having a diagnosis of any long-term medical condition (e.g. diabetes, cardiovascular diseases, epilepsy) or experiencing strong symptoms of allergy. After screening, twenty-six subjects met all our inclusion criteria and started this study. Subjects received oral and written information about the nature and risk of the experimental procedures before their written informed consent before the start of the study. The study was approved by the Medical Ethical Committee of Maastricht University.

After inclusion of 26 subjects, 6 subjects dropped out and were not included in the analysis ( 1 man underwent surgery for aneurism, 1 woman had complained about vapours during the placebo period, 1 man and 1 woman did not regularly attend appointments and were excluded, 1 man had a work-related reason, and 1 man had personal reasons). Ten men and ten women completed the trial. For this microarray experiment, the 11 subjects (six men and five women) were studied, who had a complete set at all time points for tissue and PBMC RNA. The baseline characteristics of these 11 subjects were comparable to the remaining 9 subjects who were not included in this sub-study. Subjects were $52 \pm 13$ y (mean \pm SD), with a bodyweight of $97 \pm 9 \mathrm{~kg}$ for men and $92 \pm 17 \mathrm{~kg}$ for women, a BMI of $31 \pm 3 \mathrm{~kg} / \mathrm{m}^{2}$ for men and $33 \pm 2 \mathrm{~kg} / \mathrm{m}^{2}$ for women, and a waist circumference of $117 \pm 9 \mathrm{~cm}$ for men and $114 \pm 8 \mathrm{~cm}$ for women. Serum concentrations of total cholesterol were $6.14 \pm 1.45 \mathrm{mmol} / \mathrm{L}$, of $\mathrm{LDL}$ cholesterol $3.97 \pm 1.28 \mathrm{mmol} / \mathrm{L}$, of HDL cholesterol 1.49 $\pm 0.48 \mathrm{mmol} / \mathrm{L}$, of triglycerides $1.48 \pm 0.38 \mathrm{mmol} / \mathrm{L}$, and of glucose $5.51 \pm 0.79$ $\mathrm{mmol} / \mathrm{L}$. Systolic blood pressure was $138 \pm 18 \mathrm{mmHg}$ and diastolic pressure was 94 $\pm 9 \mathrm{mmHg}$. On average, subjects exhibited $2.5 \pm 1.1$ components of the metabolic syndrome and 5 out of 11 subjects could be diagnosed as having the metabolic syndrome.

\subsection{Study design}

The study had a randomized, double-blind, placebo-controlled, crossover design. Each subject enrolled in random order in a fish oil, a fenofibrate and a placebo period for 6 weeks with a wash-out period of at least 2 weeks between the intervention periods. During the fish oil intervention, subjects had to consume 8 fish oil capsules (Marinol C-38 ${ }^{\mathrm{TM}}$, Lipid Nutrition, Wormerveer, the Netherlands), providing approximately $3.7 \mathrm{~g} / \mathrm{d}$ n-3 LCPUFA (1.7 g/d EPA and $1.2 \mathrm{~g} / \mathrm{d}$ DHA, corresponding to $160-240 \mathrm{~g}$ fatty fish/d), together with 2 capsules placebomatching fenofibrate ( $200 \mathrm{mg} / \mathrm{d}$ cellulose). During the fenofibrate period, subjects consumed 2 capsules providing $200 \mathrm{mg} / \mathrm{d}$ micronized fenofibrate (Lipanthyl®, Fournier Laboratories, Dijon, France), together with 8 placebo-matching fish oil capsules (containing $80 \%$ High Oleic Sunflower Oil (HOSO)). During the placebo 
period, subjects received 8 HOSO capsules together with 2 cellulose capsules. Subjects were instructed to ingest half of the capsules before breakfast and the other half before dinner with a glass of water. Subjects were restricted in their fish consumption to a maximum of one portion a week. During the study, subjects recorded any symptom of illness, visits to physician, medication used, alcohol consumption, and any deviations from the protocol in diaries. Body weight was recorded at weeks 0,5 and 6 of each intervention period and blood pressure was monitored using a sphygmomanometer (Omron M7, CEMEX Medische Techniek BV, Nieuwegein, the Netherlands). Venous blood samples collected in BD vacutainer ${ }^{\circledR}$ tubes (Becton Dickinson Company, NJ, USA) were collected at week 5 and 6 . Fasting serum samples were collected at weeks 5 and 6 to measure serum lipids. In week 6 of each intervention period, a fasting EDTA blood sample was collected for the isolation of PBMCs, and a muscle and adipose tissue biopsy was taken for gene expression analysis. At the end of the three intervention periods, energy and nutrient intakes were estimated for the previous 4 weeks using a food frequency questionnaire $(F F Q)^{10}$.

\subsection{Measurement of serum lipids}

Serum samples from weeks 5 and 6 were analysed separately for concentrations of serum total cholesterol (ABX Diagnostics, Montpelier, France), HDL cholesterol (precipitation method; Roche Diagnostics Corporation, Indianapolis, IN), and triglycerides corrected for free glycerol (Sigma-Aldrich Chemie, Steinheim, Germany). Serum LDL cholesterol concentrations were calculated using the formula of Friedewald et al. ${ }^{11}$. After analysis, values were averaged. The free EPA and DHA contents in plasma as a compliance marker, were determined with LCMS methodology (TNO, Zeist, the Netherlands) as described by Wopereis et al. ${ }^{12}$ in heparin plasma of week 6 from each period. NaF plasma samples from weeks 5 and 6 were analysed separately for free fatty acids (FFA) using the Wako Nefa C test kit (Wako Chemicals, Neuss, Germany). After analysis, values were averaged.

\subsection{PBMC isolation, muscle and adipose tissue biopsies}

After sampling, PBMCs were directly isolated from an EDTA anti-coagulated peripheral fasted blood sample at the end (week 6) of each intervention period, through gradient centrifugation using lymphoprep (Nycomed, Oslo, Norway) according to the instructions from the manufacturer. The PBMCs were immediately lysed and homogenised in $1.5 \mathrm{~mL}$ Trizol (Invitrogen Life Technologies, Breda, the Netherlands) for RNA stabilisation, immediately frozen in liquid nitrogen, and stored in sterile polypropylene tubes at $-80^{\circ} \mathrm{C}$ until further processing. During the same visit, a muscle and adipose tissue biopsy were taken by a physician. After local anaesthesia (Lidocaine HCL 1\%, B.Braun, Melsungen, Germany), a muscle biopsy from the vastus lateralis was taken by passing a 5-mm diameter side-cutting needle through a $7 \mathrm{~mm}$ skin incision according to the technique from Bergstrom et al. ${ }^{13}$. Following the muscle biopsy, a subcutaneous abdominal adipose tissue biopsy from the peri-umbillical region was taken. Under 
local anaesthesia (Lidocaine HCL 1\%, B.Braun, Melsungen, Germany), a biopsy was taken with a needle (Braun Medical Sterican needle $2.1^{*} 80 \mathrm{~mm}$, B.Braun) connected to a vacuum syringe (Hepafix Luerlock, B.Braun). The adipose tissue biopsy was washed with a sterile physiological saline solution to wash off blood and connective tissue. All tissue specimens were immediately frozen in liquid nitrogen and stored in sterile polypropylene tubes at $-80^{\circ} \mathrm{C}$ until further processing.

\subsection{RNA isolation}

Muscle and adipose tissue biopsies were homogenised in trizol using an ultrathurrax (IKA, Labortechnik, Staufen, Germany). Subsequently, RNA from PBMCs, muscle and adipose tissue was isolated from trizol according to a standardized protocol as described by the manufacturer (Invitrogen Life Technologies). Next, RNA was purified and treated with DNAse on RNeasy micro columns (Qiagen Benelux B.V., Venlo, the Netherlands), followed by dissolving the RNA in RNAse and DNAse free water (Invitrogen Life Technologies, Breda, the Netherlands). RNA yield was quantified using the NanoDrop 1000 (NanoDrop Technologies, Wilmington, DE, USA). RNA integrity was evaluated using the Agilent 2100 BioAnalyzer (Agilent, Palo Alto, CA, USA) with RNA 6000 nano chips (Agilent Technologies, South Queensferry, UK). Samples with a RIN score > 8.0 were considered to be acceptable for further processing.

\subsection{Microarray processing}

For 11 subjects, muscle, adipose tissue and PBMC RNA samples at the end of each intervention periods could be obtained and was used for microarray processing (99 microarrays in total). Total RNA (300 ng/sample) was labelled with 1-cycle cDNA labelling kit (MessageAmp ${ }^{\mathrm{TM}}$ II-Biotin Enhanced Kit, Ambion Inc. Austin TX, USA) and hybridized to human whole genome U133 plus 2.0 arrays (Affymetrix Inc, Santa Clara CA, USA). Sample labelling, hybridization to chips and image scanning were performed according to the manufacturer's Gene Chip Expression Analysis Technical Manual (Affymetrix Inc, Santa Clara CA, USA). Array data have been submitted to the Gene Expression Omnibus, accession number GSE27387.

\subsection{Data analysis and statistics}

Differences in fasting levels of serum lipids at the end of the intervention periods were compared with a General Linear Model for Univariate ANOVA with treatment as fixed factor and subject ID as random factor. Since there were no significant interactions between treatment and gender, and treatment and body weight on the outcome parameters, these parameters were not included in the final model. To adjust for multiple comparisons, a Tukey Honestly Significantly Difference (HSD) procedure was carried out. A $\mathrm{P}<0.05$ was considered to be statistically significant. Data are presented as mean \pm SD. Statistical analysis was performed using SPSS 15.0 for Windows.

Expression values were calculated using the Robust Multichip Average (RMA 
method). RMA signal value estimates are based on a robust average of background corrected perfect match intensities and normalisation was performed using quantile normalisation ${ }^{14,15}$. Genes with normalised signals below 20 on at least 6 out of 33 arrays from each tissue were excluded for further analyses. Genes were defined as significantly changed when comparison of the normal signal intensities showed a $\mathrm{p}$-value lower than 0.05 in a two-tailed paired t test with Bayesian correction (Intensity Based Modified t-statistics) ${ }^{16,17}$. Gene Set Enrichment Analysis was performed was used to focus on groups of genes that shared a biological function or regulation ${ }^{18,19}$. Microarray results were analyzed for the expression of 56 known PPAR target genes present on the array (see additional file 2), based on the KEGG PPAR signaling pathway (http://www.genome.jp/kegg/pathway/ hsa/hsa03320.html) and for the expression of genes belonging to key pathways involved in the metabolic syndrome ${ }^{20}$.

\section{Results}

\subsection{Compliance, dietary intake, body weight and blood pressure}

The calculated main daily capsule intake was 95\% during the fish oil period, $97 \%$ during the fenofibrate period and $96 \%$ during the placebo period, indicating a good compliance. This was further confirmed by analysis of plasma free EPA and DHA concentrations, which increased during the fish oil period by $310 \%(P<0.001)$ and $104 \%(P<0.001)$ compared to the placebo period, and by $427 \%(P<0.001)$ and $146 \%(P<0.001)$ compared to the fenofibrate period, respectively. Compared to placebo, fenofibrate did not change EPA and DHA concentrations ( $P=0.904$ and $P=0.920$, respectively). The proportions of energy from fat, carbohydrates and protein, and the amounts of fiber, alcohol and cholesterol in the diet did not differ between the treatments (data not shown). However, total energy intake was lower in the fish oil period compared to the fenofibrate period $(-1.2 \pm 1.4 \mathrm{MJ}, P=0.017)$. Bodyweight and blood pressure did not change between the treatment periods (data not shown).

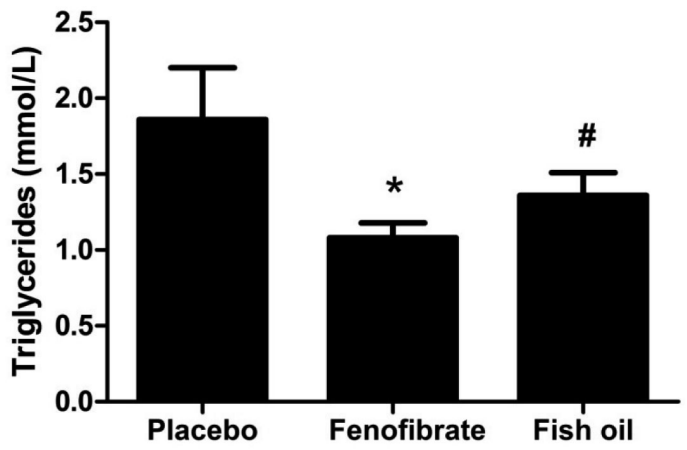

Figure 1. Fasting plasma triglyceride concentrations after the placebo, fenofibrate and fish oil period. Values are mean SEM $(n=11)$. Significant differences: * $P<0.05$ compared to placebo period, \# $P<0.05$ compared to fenofibrate period. 


\subsection{Effect of fenofibrate and fish oil treatment on plasma lipids}

As expected, fenofibrate treatment lowered fasting triglyceride concentrations compared to placebo $(-0.78 \pm 1.04 \mathrm{mmol} / \mathrm{L}, P<0.008)$ (figure 1). For fish oil, this effect nearly reached statistical significance $(-0.51 \pm 0.70 \mathrm{mmol} / \mathrm{L}, P=0.093)$. Furthermore, compared to placebo, fenofibrate significantly decreased fasting total cholesterol (from $5.86 \pm 1.57 \mathrm{mmol} / \mathrm{L}$ to $5.05 \pm 0.97 \mathrm{mmol} / \mathrm{L}, P=0.008$ ) and LDL cholesterol concentrations (from $3.64 \pm 1.33 \mathrm{mmol} / \mathrm{L}$ to $2.93 \pm 0.90$ $\mathrm{mmol} / \mathrm{L}, P=0.006$ ) and increased $\mathrm{HDL}$ cholesterol concentrations (from $1.32 \pm$ $0.36 \mathrm{mmol} / \mathrm{L}$ to $1.54 \pm 0.38 \mathrm{mmol} / \mathrm{L}, P=0.002$ ). Fish oil increased HDL cholesterol concentrations compared to placebo, but this effect just did not reach statistical significance (from $1.32 \pm 0.36 \mathrm{mmol} / \mathrm{L}$ to $1.45 \pm 0.45 \mathrm{mmol} / \mathrm{L}, P=0.057$ ). Total cholesterol and LDL cholesterol were non-significantly increased after fish oil treatment (from $5.86 \pm 1.57 \mathrm{mmol} / \mathrm{L}$ to $5.96 \pm 1.63 \mathrm{mmol} / \mathrm{L}, P=0.658$ and from $3.64 \pm 1.33$ to $3.73 \pm 1.34, P=0.473$ ). FFA concentrations were non-significantly decreased after fenofibrate and fish oil treatment (from $374 \pm 222 \mu \mathrm{M}$ to $342 \pm$ $262 \mu \mathrm{M}(P=0.500)$ and to $316 \pm 214 \mu \mathrm{M}(P=0.121)$, respectively $)$.

B) Muscle PBMC White adipose tissue $\begin{aligned} & \text { Figure 2. Venn diagrams } \\ & \text { of number of upregulated } \\ & \text { and downregulated genes in } \\ & \text { > subjects, which overlap } \\ & \text { between fenofibrate and } \\ & \text { fish oil treatment in PBMCs } \\ & \text { (A), muscle (B) and adipose } \\ & \text { tissue (C). Genes with a } P \\ & \text { value }<0.05 \text { were considered } \\ & \text { to be significantly regulated } \\ & \text { compared to the placebo } \\ & \text { period. }\end{aligned}$

\subsection{Differential expressed genes in PBMC, muscle and adipose tissue transcriptome}

In PBMCs, fish oil treatment significantly changed the expression of 537 genes and fenofibrate treatment that of 1445 genes with 106 overlapping genes. Of these overlapping genes, 84 changed into the same direction (figure 2). Compared with PBMCs, fewer genes were differentially expressed in muscle and adipose tissue. In muscle tissue, 486 genes were differentially regulated after fenofibrate treatment and 287 genes after fish oil treatment, while all 48 overlapping genes changed into the same direction. In contrast to PBMCs and muscle tissue, fish oil had a more pronounced effect on gene expression in adipose tissue. Fish oil consumption resulted in the differential expression of 441 genes compared to 259 genes after fenofibrate treatment. The large majority of overlapping genes ( 25 out of 29 ) between both treatments changed into the same direction. Overall, there was relatively little overlap in regulated genes between fish oil and 
fenofibrate treatment in any of the tissues. There was also very little overlap in regulated genes between tissues upon fenofibrate and fish oil treatment and the expression of none of the genes were similarly changed in all three tissues for either treatment (figure 3 ).

A) Fenofibrate

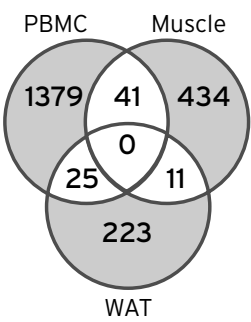

B) Fish oil

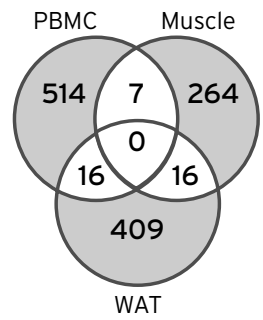

Figure 3. Venn diagrams of overlap in regulated genes between the tissues after fenofibrate (A) and fish oil (B) treatment. Genes with a $P$ value $<0.05$ were considered to be significantly regulated compared to the placebo period.

\subsection{Pathway analysis}

A summary of regulated processes in PBMCs is given in figures 4 and 5 . Fish oil and fenofibrate treatment regulated 25 common pathways in PBMCs, of which 17 were showed shared downregulation and 15 were regulated in opposite directions (data only partly shown in figure 4 and 5 ). Fenofibrate and fish oil overlapped in the downregulation of pathways involved in xenobiotic metabolism, biosynthesis of steroids, cholesterol biosynthesis cell cycle, transcription, oxidative phosphorylation, fatty acid synthesis, proteasome function, Th1 immunity, propanoate metabolism and nucleotide metabolism. Pathways related to integrinmediated cell adhesion, interleukin signaling, gap junction and roles of betaarrestin-dependent recruitment of src kinases in GPCR signalling, Interleukin 3 and interleukin 6 signaling were upregulated after fenofibrate treatment and downregulated after fish oil treatment. Fenofibrate (down)regulated only 3 pathways in WAT, which were related to FAS signaling (NES -1.74), intrinsic prothrombin activation (NES -1.68) and natural killer cell mediated cytotoxicity (NES -1.60). Fish oil treatment affected many more pathways in WAT compared to fenofibrate (figure 6). Predominantly immune and inflammatory processes were upregulated, while processes related to fatty acid metabolism and oxidative phosphorylation were downregulated. Of the 25 downregulated pathways in WAT, 18 pathways were similarly regulated in PBMCs after fish oil treatment (data partly shown in figure 6). Fenofibrate treatment had little effects on regulated pathways in muscle. Only genes related to statin pathway (NES -1.98), P53 signaling (NES -1.93), chondroitin sulphate biosynthesis (NES -1.88), ribosome (NES -1.87) and leukocyte transendothelial migration (NES -1.85) were downregulated. Also fish oil had only very minor effects on pathways in muscle. Upregulated GSEA processes were proteasome (NES 2.11), proteasome degradation (NES 1.89), integrin signaling and interleukin 9 signaling (NES 1.84), and downregulated processes were DNA replication reactome (NES -1.87), 0-glycan biosynthesis $(-1.85)$ and antigen processing and presentation (NES -1.76). 


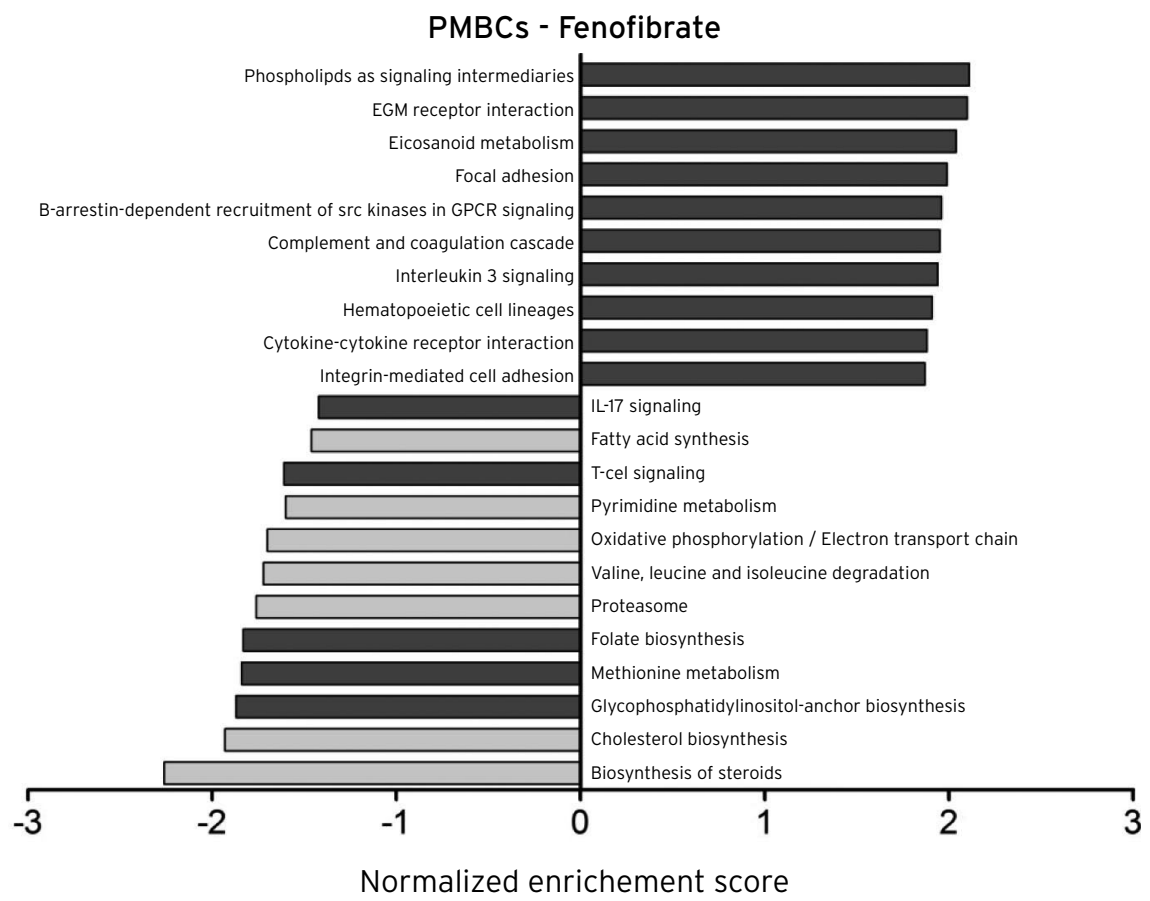

Figure 4. Selection of pathways regulated in PBMCs after fenofibrate treatment indentified by Gene Set Enrichment Analysis (FDR q-value $<0.25$, highest Normalized Enrichment sore $(\mathrm{NES})$ ). The NES reflects the degree to which a gene set is overrepresented the top (upregulated) or bottom (downregulated) of the ranked gene list and is corrected for gene set size. Light grey bars indicate an overlap of pathways regulated by fenofibrate and fish oil treatment in PBMCs. 


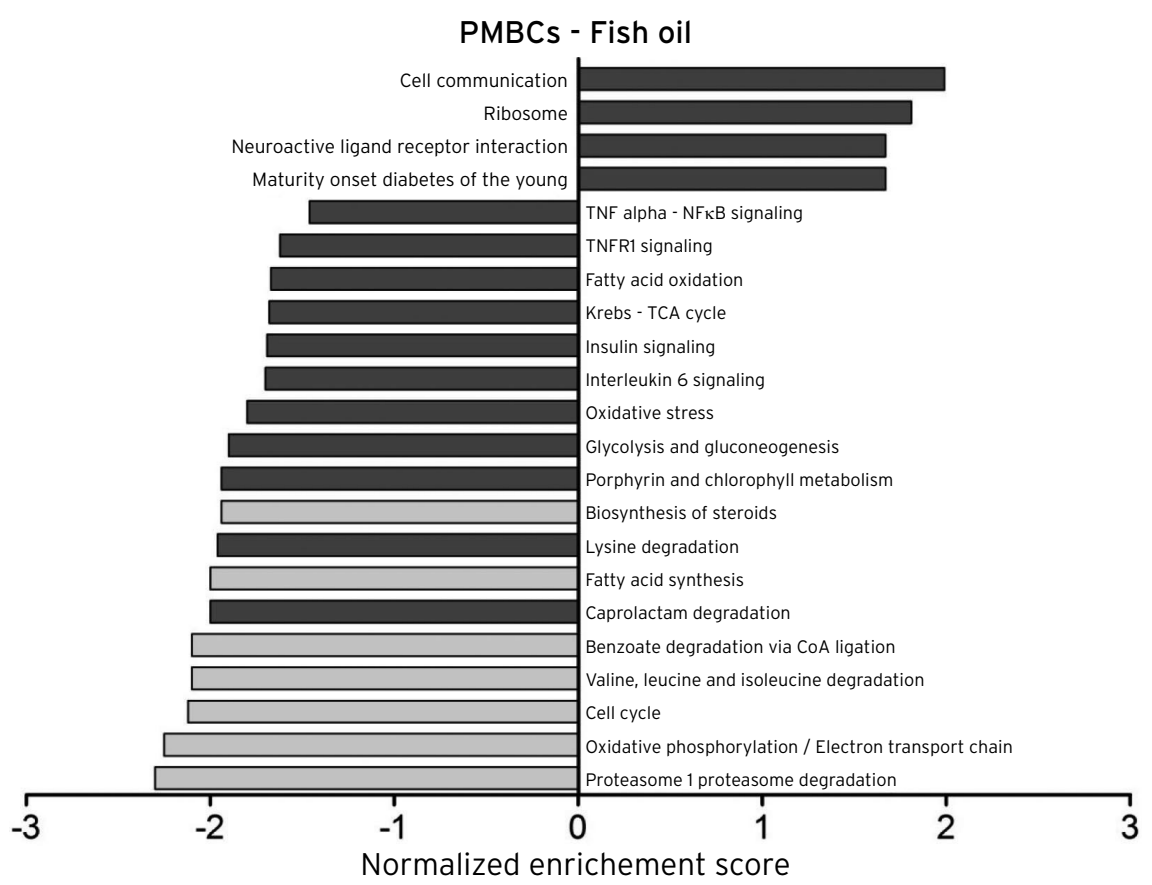

Figure 5. Selection of pathways regulated in PBMCs after fish oil treatment indentified by GSEA (FDR q-value $<0.25$, highest Normalized Enrichment sore (NES)). The NES reflects the degree to which a gene set is overrepresented at the top (upregulated) or bottom (downregulated) of the ranked gene list and is corrected for gene set size. Light grey bars indicate an overlap of regulated pathways regulated between fenofibrate and fish oil treatment in PBMCs.

\subsection{Expression of PPAR target genes and metabolic syndrome-related genes}

Fenofibrate significantly changed 5 of the analysed 56 PPAR target genes in PBMC, 4 genes in muscle, and 2 genes in WAT (table 1 and additional file 2). Fish oil did not change any of the known PPAR target genes in PBMC and muscle. In WAT, 2 PPAR target genes were significantly downregulated (table 1). PPAR $\alpha$ did not significantly change in any of the tissues due to the treatments. However, PPAR $\gamma$ was upregulated in muscle after fenofibrate treatment, while PPAR $\delta$ was downregulated in WAT after fish oil treatment. 


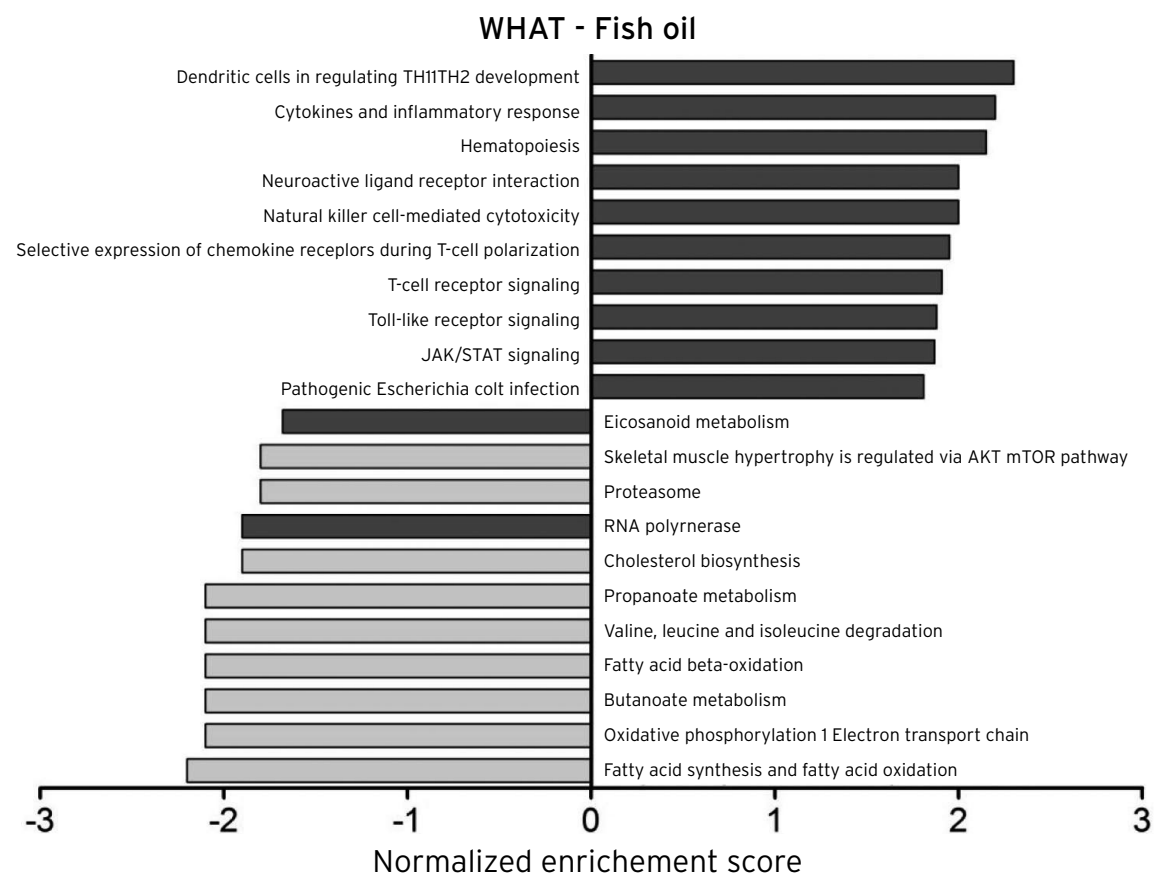

Figure 6. Selection of pathways regulated in WAT after fish oil treatment indentified by GSEA (FDR q-value $<0.25$, highest Normalized Enrichment sore (NES)). The NES reflects the degree to which a gene set is overrepresented at the top (upregulated) or bottom (downregulated) of the ranked gene list and is corrected for gene set size. Light grey bars represent processes similarly regulated in PBMCs after fish oil and fenofibrate treatment

Specific genes belonging to key pathways ${ }^{20}$ involved in the metabolic syndrome were regulated by fenofibrate and fish oil in PBMCs (tables 2 and 3), of which fenofibrate affected the expression of a larger number of those genes. Although both treatments regulated specific genes in these pathways, only the change in expression of 9 genes was shared. These genes were IL25, TICAM1, PRDX2, PTGS1, involved in inflammation and/or oxidative stress; AGK, FDPS and LDLR involved in lipid metabolism and transport; and TNNI3, LMAN1 and PTGS1 involved in vascular function and coagulation. Except for PTGS1, all these genes changed into the same direction. 
Table 1. Significantly changed genes from a set of 64 known PPAR target genes' in PBMC, WAT and muscle upon fenofibrate and fish oil treatment.

Gene name Entrez ID Description

FC $P$-value

\section{PBMC}

\section{Fenofibrate}

$\begin{array}{lclll}\text { NR1H2 } & 10062 & \text { nuclear receptor subfamily 1, group H, member 3 } & 1.11 & 0.01 \\ \text { CYP27A1 } & 1593 & \begin{array}{l}\text { cytochrome P450, family 27, subfamily A, polypeptide } \\ 1\end{array} & 1.09 & 0.04 \\ \text { ILK } & 3611 & \text { integrin-linked kinase } & 1.08 & 0.02 \\ \text { RXRA } & 6256 & \text { retinoid X receptor, alpha } & 1.07 & 0.04 \\ \text { ACSL5 } & 51703 & \text { acyl-CoA synthetase long-chain family member 5 } & -1.05 & 0.03 \\ \text { Fish oil } & & & & \end{array}$

- No change in expression of PPAR target genes -

\section{WAT}

\section{Fenofibrate}

$\begin{array}{lllrl}\text { APOCIII } & 345 & \text { apolipoprotein C-III } & 1.23 & 0.00 \\ \text { SORBS1 } & 10580 & \text { sorbin and SH3 domain containing 1 } & 1.07 & 0.02 \\ \text { Fish oil } & & & & \\ \text { RXRA } & 6256 & \text { retinoid X receptor, alpha } & -1.07 & 0.04 \\ \text { PPARD } & 5467 & \text { peroxisome proliferator-activated receptor delta } & -1.11 & 0.01 \\ \text { MUSCLE } & & & & \end{array}$

\section{Fenofibrate}

$\begin{array}{lllrl}\text { PPARG } & 5468 & \text { peroxisome proliferator-activated receptor gamma } & 1.14 & 0.03 \\ \text { PDPK1 } & 5170 & \text { 3-phosphoinositide dependent protein kinase-1 } & 1.06 & 0.04 \\ \text { ILK } & 3611 & \text { integrin-linked kinase } & -1.07 & 0.03 \\ \text { PLTP } & 5360 & \text { phospholipid transfer protein } & -1.18 & 0.01\end{array}$

Fish oil

- No change in expression of PPAR target genes -

1 See additional file 2 for the complete list of PPAR $\alpha$ target genes 
Table 2. Significantly changed genes $(P<0.05)$ in PBMCs after fish oil treatment in selected pathways adversely affected in the metabolic syndrome.

\begin{tabular}{|c|c|c|c|c|}
\hline \multicolumn{5}{|l|}{ Fish oil } \\
\hline Pathway & Gene name & Entrez ID & Description & FC \\
\hline Energy homeostasis & GHSR & 2693 & growth hormone secretagogue receptor & 1.10 \\
\hline \multirow{15}{*}{$\begin{array}{l}\text { Inflammation / } \\
\text { oxidative stress }\end{array}$} & CCL1 & 6346 & chemokine ( $\mathrm{C}-\mathrm{C}$ motif) ligand 1 & 1.14 \\
\hline & TLR9 & 54106 & toll like receptor 9 & 1.14 \\
\hline & IL19 & 29949 & interleukin 19 & 1.13 \\
\hline & IL6 & 3569 & interleukin 6 & 1.11 \\
\hline & TNFSF18 & 8995 & tumour necrosis factor ligand family member 18 & 1.11 \\
\hline & DEFB1 & 1672 & beta defensin 1 & 1.11 \\
\hline & BTLA & 151888 & $\mathrm{~B}$ and $\mathrm{T}$ Iymphocyte attenuator & 1.10 \\
\hline & $\mathrm{IL}_{25}$ & 64806 & interleukin 25 & 1.08 \\
\hline & $\mathrm{IL} 4 \mathrm{R}$ & 3566 & interleukin 4 receptor & 1.08 \\
\hline & TICAM1 1 & 148022 & toll like receptor adaptor molecule 1 & 1.08 \\
\hline & IL17RB & 55540 & interleukin 17 receptor B & 1.07 \\
\hline & MASP2 & 10747 & mannan-binding serine peptidase 2 & 1.07 \\
\hline & PRDX $2^{1}$ & 7001 & peroxiredoxin 2 & -1.08 \\
\hline & PTGS1 1 & 5742 & cyclooxygenase-1 & -1.11 \\
\hline & $\mathrm{ClQa}$ & 712 & complement Cq1 subcomponent subunit $\mathrm{A}$ & -1.21 \\
\hline \multirow{10}{*}{$\begin{array}{l}\text { Lipid metabolism / } \\
\text { Transport }\end{array}$} & ELA3A & 10136 & chymotrypsin-like elastase family member $3 \mathrm{~A}$ & 1.09 \\
\hline & APOM & 55937 & apolipoprotein M & 1.08 \\
\hline & ADIPOR1 & 51094 & adiponectin receptor 1 & 1.07 \\
\hline & $\mathrm{AGK}^{1}$ & 55750 & acylglycerol kinase & -1.06 \\
\hline & $\left.|N S| G\right|^{2}$ & 3638 & insulin-induced gene 1 & -1.08 \\
\hline & FDPS $^{1,2}$ & 2224 & farnesyl diphosphate synthetase & -1.08 \\
\hline & $\mathrm{LDLR}^{1}$ & 3949 & LDL receptor & -1.13 \\
\hline & FADS1 & 3992 & fatty acid desaturase 1 & -1.15 \\
\hline & DHCR24 & 1718 & 24-dehydrocholesterol reductase & -1.16 \\
\hline & CAV1 & 857 & caveolin 1 & -1.17 \\
\hline \multirow{4}{*}{$\begin{array}{l}\text { Glucose homeostasis / } \\
\text { insulin signalling }\end{array}$} & $\mathrm{SCT}$ & 6342 & Secretin & 1.17 \\
\hline & GHSR & 2693 & growth hormone secretagogue receptor & 1.10 \\
\hline & SLC37A4 & 2542 & glucose-6-phosphate translocase & 1.06 \\
\hline & ZFP106 & 64397 & zinc finger protein 106 & -1.06 \\
\hline \multirow{5}{*}{$\begin{array}{l}\text { Vascular function / } \\
\text { coagulation }\end{array}$} & TNNI3' & 7137 & troponin 13 & 1.14 \\
\hline & $\mathrm{F} 11$ & 2160 & coagulation factor $\mathrm{XI}$ & 1.14 \\
\hline & AGT & 183 & Angiotensinogen & 1.07 \\
\hline & LMAN11 & 3998 & lectin, mannose-binding, 1 & -1.08 \\
\hline & PTGS1 $^{1}$ & 5742 & prostaglandin endoperoxidase synthase 1 & -1.11 \\
\hline
\end{tabular}

1. Overlap between fenofibrate and fish oil treatment, ${ }^{2}$ Shared regulation with WAT 
Table 3. Significantly changed genes in PBMCs after fenofibrate treatment in selected pathways adversely affected in the metabolic syndrome.

\begin{tabular}{|c|c|c|c|c|}
\hline \multicolumn{5}{|l|}{ Fenofibrate } \\
\hline Pathway & Gene name & Entrez ID & Description & FC \\
\hline Energy homeostasis & LEPR & 3953 & Leptin receptor & 1.12 \\
\hline \multirow{20}{*}{$\begin{array}{l}\text { Inflammation / oxidative } \\
\text { stress }\end{array}$} & CXCL5 & 6374 & chemokine ( $\mathrm{C}-\mathrm{X}-\mathrm{C}$ motif) ligand 5 & 1.46 \\
\hline & CXCL9 & 4283 & chemokine ( $\mathrm{C}-\mathrm{X}-\mathrm{C}$ motif) ligand 9 & 1.26 \\
\hline & PTGS1' & 5742 & prostaglandin endoperoxidase synthase 1 & 1.24 \\
\hline & GPX3 & 2878 & glutathione peroxidase 3 & 1.23 \\
\hline & CXCL10 & 3627 & chemokine ( $\mathrm{C}-\mathrm{X}-\mathrm{C}$ motif) ligand 10 & 1.21 \\
\hline & SOD2 & 6648 & superoxide dismutase 2 & 1.14 \\
\hline & FPR1 & 2357 & formyl peptide receptor 1 & 1.13 \\
\hline & NFAM1 & 150372 & NFAT activating protein with ITAM motif 1 & 1.13 \\
\hline & SBNO2 & 22904 & strawberry notch homologue & 1.12 \\
\hline & TGFB1 & 7040 & transforming growth factor beta 1 & 1.11 \\
\hline & BDKRB1 & 623 & bradykinin receptor $\mathrm{B} 1$ & 1.11 \\
\hline & TICAM1 ${ }^{1}$ & 148022 & toll like adapter molecule & 1.10 \\
\hline & TICAM2 & 353376 & toll like adapter molecule 2 & 1.08 \\
\hline & $1125^{1}$ & 64806 & interleukin 25 & 1.07 \\
\hline & MSRA & 4482 & methionine sulphoxide reductase $\mathrm{A}$ & 1.07 \\
\hline & PRDX6 & 2071 & peroxiredoxin 6 & -1.05 \\
\hline & GCLC & 2729 & glutamate-cysteine ligase, catalytic subunit & -1.06 \\
\hline & MIF & 4282 & macrophage migration inhibitory factor & -1.08 \\
\hline & PRDX21 & 9588 & peroxiredoxin 2 & -1.10 \\
\hline & INFG & 3458 & interferon gamma & -1.25 \\
\hline \multirow{20}{*}{$\begin{array}{l}\text { Lipid metabolism / } \\
\text { transport }\end{array}$} & $\mathrm{ABCA} 1$ & 19 & ATP binding cassette transporter $\mathrm{A} 1$ & 1.24 \\
\hline & LIPC & 3990 & hepatic lipase & 1.24 \\
\hline & DGAT2L3 & 158833 & diacylglycerol-0-acetyltransferase-2 like 3 & 1.16 \\
\hline & MGLL & 11343 & monoacylglycerol lipase & 1.15 \\
\hline & LPLR1 & 4035 & low density lipoprotein receptor related protein 1 & 1.13 \\
\hline & APOE & 348 & apolipoprotein E & 1.12 \\
\hline & OSBP2 & 23762 & oxysteol binding protein 2 & 1.11 \\
\hline & CRAT & 1384 & carnitine-O-acetyltransferase & 1.09 \\
\hline & PLB1 & 151056 & phospholipase B1 & 1.08 \\
\hline & APOB48R & 55911 & apolipoprotein B48 receptor & 1.07 \\
\hline & SLC27A3 & 11000 & long chain fatty acid transport protein & 1.07 \\
\hline & FDFT1 & 2222 & farnesyldiphosphate farnesyltransferase 1 & -1.06 \\
\hline & ACSM3 & 6296 & acyl-CoA synthetase long-chain family member 3 & -1.07 \\
\hline & SC5DL & 6309 & sterol $\mathrm{C} 5$ desaturase & -1.07 \\
\hline & CROT & 54677 & carnitine octanoyltransferase & -1.08 \\
\hline & ACAT2 & 39 & acetyl-Coenzyme A acetyltransferase & -1.09 \\
\hline & FDPS $^{1}$ & 2224 & farnesyl diphosphate synthase & -1.09 \\
\hline & ACADSB & 36 & acyl-Coenzyme A dehydrogenase, short/branched chain & -1.11 \\
\hline & LDLR $^{1}$ & 3949 & low density lipoprotein receptor & -1.11 \\
\hline & $\mathrm{AGK}^{1}$ & 55750 & acylglycerol kinase & -1.13 \\
\hline
\end{tabular}




\begin{tabular}{llllr} 
Fenofibrate & & & & \\
Pathway & Gene name & Entrez ID & Description & FC \\
\hline & GK & 2710 & glucose kinase & 1.22 \\
Glucose homeostasis / & GAA & 2548 & glucosidase, alpha; acid & 1.11 \\
insulin signalling & SLC37A2 & 219855 & glycerol-3-phosphate transporter & 1.11 \\
& GRB10 & 2887 & growth-factor receptor bound protein 10 & 1.07 \\
& MGAT4A & 11320 & mannosyl (alpha-1,3-)-glycoprotein beta-1,4-N acetylglucos- & -1.06 \\
\hline & PTGS1 & 5742 & prostaglandin endoperoxidase synthase 1 & 1.24 \\
& GP1BA & 2811 & glycoprotein Ib (platelet), alpha polypeptide & 1.24 \\
& GP9 & 2815 & glycoprotein IX (platelet) & 1.21 \\
& F13A12 & 2162 & coagulation factor XIII, A1 polypeptide & 1.21 \\
& TBXAS1 & 6916 & thromboxane A synthase 1 (platelet) & 1.13 \\
Vascular function / & TNNI3' & 7137 & troponin I type 3 & 1.14 \\
& P2RX1 & 5023 & purinergic receptor P2X, ligand-gated ion channel, 1 & 1.14 \\
& SERPINE1 & 5054 & plasminogen activator inhibitor type I & 1.11 \\
& F12 & 2161 & coagulation factor XII (Hageman factor) & 1.11 \\
& F2RL1 & 2150 & coagulation factor II (thrombin) receptor-like 1 & 1.10 \\
& RENBP & 5973 & renin binding protein & 1.09 \\
& LMAN1 & 3998 & lectin, mannose-binding, 1 & -1.08 \\
\hline
\end{tabular}

1 Overlap between fenofibrate and fish oil treatment, ${ }^{2}$ Shared regulation with muscle

For WAT, fish oil also regulated genes in key pathways belonging to the metabolic syndrome and shared the upregulation of APOC3 and APOM with fenofibrate treatment (table 4). Furthermore, fenofibrate upregulated the VLDLR gene in WAT. In muscle, fish oil downregulated genes involved in inflammation, such as IL1R1, IL13, TICAM2 and CXCL14, and affected genes involved in glucose metabolism and insulin signaling, such as IRS2, PIK3R1. Compared to fish oil, fenofibrate treatment also downregulated CXCL14 in muscle. Fenofibrate downregulated genes involved in inflammation, such as MIF and C3. Genes in other pathways related to the metabolic syndrome were not affected. 
Table 4. Significantly changed genes in WAT after fish oil treatment in selected pathways adversely affected in the metabolic syndrome.

\begin{tabular}{|c|c|c|c|c|}
\hline \multicolumn{5}{|l|}{ Fish oil } \\
\hline Pathway & Gene name & Entrez ID & Description & $\mathrm{FC}$ \\
\hline \multirow[t]{2}{*}{ Energy homeostasis } & PPARD & 5467 & peroxisome proliferator activated receptor delta & -1.11 \\
\hline & NRIP1 & 8204 & nuclear receptor interacting protein 1 & -1.14 \\
\hline \multirow{9}{*}{$\begin{array}{l}\text { Inflammation / } \\
\text { oxidative stress }\end{array}$} & CXCL10 & 3627 & chemokine ( $C-X-C$ motif) ligand 10 & 1.53 \\
\hline & CD180 & 4064 & CD180 molecule & 1.53 \\
\hline & TNFSF4 & 7292 & tumour necrosis factor ligand family member 4 & 1.42 \\
\hline & FCER1G & 2207 & $\begin{array}{l}\text { Fc fragment of IgE, high affinity I, receptor for; gamma } \\
\text { polypeptide }\end{array}$ & 1.25 \\
\hline & SAMHD1 & 25939 & SAM domain and HD domain 1 & 1.17 \\
\hline & CD4 & 920 & CD4 molecule & 1.09 \\
\hline & TIRAP & 114609 & $\begin{array}{l}\text { toll-interleukin } 1 \text { receptor (TIR) domain containing adaptor } \\
\text { protein }\end{array}$ & 1.05 \\
\hline & CXCL12 & & chemokine (C-X-C motif) ligand 12 & -1.10 \\
\hline & $\mathrm{C} 3$ & 718 & complement component 3 & -1.11 \\
\hline \multirow{14}{*}{$\begin{array}{l}\text { Lipid metabolism / } \\
\text { Transport }\end{array}$} & APOC $3^{1}$ & 345 & apolipoprotein CIII & 1.11 \\
\hline & ACAD8 & 27034 & acyl-Coenzyme A dehydrogenase family, member 8 & -1.08 \\
\hline & HMGCS1 & & 3-hydroxy-3-methylglutaryl-Coenzyme A synthase 1 (soluble) & -1.10 \\
\hline & PPARD & 5467 & peroxisome proliferator activated receptor delta & -1.11 \\
\hline & ACADSB & 36 & acyl-Coenzyme A dehydrogenase, short/branched chain & -1.11 \\
\hline & $\mathrm{APOD}^{2}$ & 347 & apolipoprotein D & -1.12 \\
\hline & FDPS $^{3}$ & 2224 & farnesyl diphosphate synthase & -1.13 \\
\hline & NSDHL & 50814 & NAD(P) dependent steroid dehydrogenase-like & -1.14 \\
\hline & $\mathrm{DCl}$ & 1632 & dodecenoyl-Coenzyme A delta isomerase & -1.16 \\
\hline & SCARB1 & 949 & scavenger receptor class $B$, member 1 & -1.16 \\
\hline & ACSS2 & 55902 & acyl-CoA synthetase short-chain family member 2 & -1.24 \\
\hline & INSIG1 & 3638 & insulin-induced gene 1 & -1.25 \\
\hline & PNPLA3 & 80339 & patatin-like phospholipase domain containing 3 & -1.31 \\
\hline & AACS & 65985 & acetoacetyl-CoA synthetase & -1.38 \\
\hline \multirow{4}{*}{$\begin{array}{l}\text { Glucose homeostasis / } \\
\text { insulin signalling }\end{array}$} & PDK3 & 5165 & pyruvate dehydrogenase kinase, isozyme & 1.14 \\
\hline & INSR & 3643 & Insulin receptor & -1.07 \\
\hline & PPARD & 5467 & peroxisome proliferator activated receptor delta & -1.11 \\
\hline & PGM5 & 5239 & phosphoglucomutase 5 & -1.17 \\
\hline \multirow{3}{*}{$\begin{array}{l}\text { Vascular function / } \\
\text { coagulation }\end{array}$} & $\mathrm{APOH}$ & 350 & apolipoprotein $\mathrm{H}$ & 1.14 \\
\hline & F10 & 2159 & coagulation factor $\mathrm{X}$ & -1.16 \\
\hline & MMP2 & 4313 & matrix metalloproteinase 2 & -1.16 \\
\hline
\end{tabular}

Overlap between fenofibrate and fish oil treatment, ${ }^{2}$ Shared regulation with muscle, ${ }^{3}$ Shared regulation with PBMCs

\section{Discussion}

Six weeks of treatment with fenofibrate exerted only very minor effects on PPAR target genes in PBMCs, white adipose tissue or muscle. Serum triglyceride concentrations, however, were decreased. This may indicate that fenofibrate exerts most of its effects in the liver. Fenofibrate can be considered as a prodrug, which is rapidly absorbed in the gastrointestinal tract ${ }^{21}$. During absorption, 
fenofibrate undergoes rapid hydrolysis and is converted into its pharmacologically active form, fenofibric acid. After that, fenofibric acid is quickly distributed and cleared by the intestine, kidney and liver ${ }^{21}$. This may explain the lack of direct effects on PPAR $\alpha$ target gene expression in PBMCs, muscle and adipose tissue. Fish oil supplementation increases the EPA and DHA content of plasma and tissues and may therefore influence gene expression in larger variety of tissues $^{22}$. However, there was also a lack of effect on the expression of PPAR $\alpha$ target genes after fish oil treatment. In a 26-weeks study conducted in elderly subjects, fish oil treatment (1.8 g EPA+DHA per day) even decreased PPAR $\alpha$ target genes ${ }^{23}$. A postprandial study with a $33 \mathrm{~g} \mathrm{n}-3$ LCPUFA-containing high fat shake in healthy subjects increased only a small number of PPAR $\alpha$ target genes in $\mathrm{PBMCs}^{24}$. In contrast to nutritional interventions, $24 \mathrm{~h}$ fasting resulted in pronounced increases in PPAR $\alpha$ target gene expression in PBMCs, possibly due to tremendous increases in plasma endogenous free fatty acids ${ }^{25}$. Thus, the effect of $n-3$ LCPUFAs on PPAR $\alpha$ gene expression in PBMC seems to be largely influenced by plasma concentrations of FFA. Based on these previous studies, the changes in gene expression we observed upon fenofibrate and fish oil treatments are probably indirect and the result of longer term adaptation of the body and systemic changes. Furthermore, other transcription factors than PPAR $\alpha$ that are also involved in various metabolic processes can be influenced by both treatments, such as LXR by fenofibrate ${ }^{26}$ and PPAR $\gamma$, PPAR $\delta$, LXR, FXR, SREBPS, HNF $4 \alpha$ and NFKB by n-3 LCPUFA ${ }^{27}$. Indeed, we observed that fenofibrate treatment upregulated LXR-alpha expression and its target gene ABCA1 in PBMCs. Fish oil treatment did not change the expression of transcription factors in PBMCs, WAT and muscle.

Clearly, muscle tissue and WAT are no primary target tissues for fenofibrate, since in these tissues almost no biological, as defined by GSEA, were changed after fenofibrate treatment. The predominant target organ for fenofibrate is the liver, where PPAR $\alpha$ is also more abundantly present as compared to muscle and WAT $^{8}$. Fish oil exerted only very minor effects in muscle and exerted its strongest effects in WAT. The majority (18 out of 25) of downregulated pathways in WAT were comparable to the pathways downregulated in PBMCs after fish oil. These pathways were mainly related to lipid metabolism (synthesis and oxidation of fatty acids, biosynthesis of cholesterol and triglyceride synthesis) and amino acid metabolism (degradation branched chain aminoacids (BCAA)). The decrease in lipogenic pathways may suggest that $n-3$ LCPUFAs shift the balance in adipose tissue from fat storage towards mobilization of fatty acids for oxidation in muscle and liver, as reported by other studies ${ }^{28-30}$. However, we did not find any changes in the regulation of pathways involved in lipid mobilization. Also, pathways involved in lipid oxidation in muscle were not changed. The precise mechanisms of lipid metabolism in human adipose tissue is very complex and remains to be further elucidated. The apolipoprotein C3 (APOC3) gene, a natural and strong inhibitor of adipose tissue lipoprotein lipase (LPL) activity, was upregulated upon fish oil and fenofibrate treatment in WAT. LPL enhances fatty acid uptake from triglyceride in 
adipose tissue. In mice studies, presence of APOC3 has been proposed to be an interesting target to reduce excessive triglyceride storage, diet-induced obesity, and insulin resistance ${ }^{31,32}$. On the contrary, polymorphism studies revealed that deficiency of the APOC3 gene in humans was associated with reduced triglyceride levels and reduced arterial plaque formation ${ }^{31}$. Therefore, it is uncertain if the effect of fish oil and fenofibrate on APOC3 expression in WAT can be regarded as beneficial. Surprisingly, fish oil regulated pathways involved in amino acid metabolism in WAT. This is a less recognized role of adipose tissue compared to its role in lipid metabolism. Fish oil decreased the expression of genes involved in the degradation of BCAA. This suggest a reduced degradation of BCAA in the fasting state to preserve BCAA for glucose production and ketogenesis and prevent their irreversible conversion into lipids for storage $\mathrm{e}^{33,34}$.

Fish oil and fenofibrate treatment regulated 32 common pathways in PBMCs, of which 17 downregulated after both treatments and 15 were regulated in a different direction. However, there was almost no overlap between the treatments in regulated genes. This indicates that fenofibrate and fish oil treatment affect different target genes, which may result in commonly regulated metabolic pathways. Pathways with a shared downregulation were mainly involved in lipid metabolism, cell cycle, tissue turn-over and amino acid metabolism. Shared pathways, which were upregulated by fenofibrate treatment and downregulated by fish oil treatment, were mainly involved in cell adhesion, tissue morphogenesis and inflammation. Surprisingly, fenofibrate treatment upregulated pathways and several genes involved in eicosanoid metabolism and coagulation. This seems to contrast the reported anti-thrombotic and anti-platelet activities of fenofibrate ${ }^{35}$.

Since PPAR $\alpha$ is involved in the regulation of multiple metabolic pathways, fish oil and fenofibrate treatment may be a way to alleviate metabolic disturbances often seen in subjects with the metabolic syndrome. Our results show that only 9 similar genes relevant for the metabolic syndrome were regulated by fenofibrate and fish oil in PBMCs. Among those overlapping genes, the LDL receptor (LDLR) was downregulated by both treatments. Studies with lipid lowering interventions have indeed shown that PBMCs change the expression of the LDLR gene ${ }^{36,37}$. The decreased LDLR expression we observed upon fish oil treatment is in line with results from the study from Bouwens et al. ${ }^{23}$. Reduced LDLR expression could be a reaction to the increased serum and probably also increased intracellular cholesterol concentration upon fish oil treatment ${ }^{38}$. In contrast, the decreased LDLR expression upon fenofibrate was unexpected, since plasma cholesterol concentrations were significantly reduced. The other overlapping genes between fish oil and fenofibrate treatment were interleukin 25 (IL25), toll-like receptor adaptor molecule 1 (TICAM1), PTGS1 and peroxiredoxin-2 (PRDX2) involved in inflammation and oxidative stress; acyl glycerol kinase (AGK) and farnesyl diphosphate synthase (FDPS) involved in lipid metabolism and transport; and troponin I type 3 (TNNI3), lectin-mannose binding 1 (LMAN1) and PTGS1 involved in vascular function and coagulation.

Gene expression profiling can be an interesting tool to examine the metabolic 
state of a target tissue or to study changes reflected by external stimuli, such as nutrition. In humans, the inaccessibility of most target tissues complicates such a study. Therefore, PBMCs may be of interest to serve as surrogate cells as they are more readily accessible. In this respect, it has been shown that these cells are able to reflect changes caused by diet $^{39}$, medicine ${ }^{40}$, toxic exposure ${ }^{41}$ and exercise ${ }^{42}$. Our study showed that PBMCs are indeed able to respond to interventions as shown by specific gene expression profiles of fish oil and fenofibrate treatment compared to placebo. Although some common pathways were regulated, there was however only very little overlap in gene expression changes between PBMCs and muscle or WAT, which clearly indicates that gene expression is tissue and organ specific. Only a very limited number of studies reported single gene expression changes simultaneously in PBMCs and another (target) tissue. In humans, gene expression in PBMCs have been compared to liver, focussing on LDL receptor ${ }^{43}, \mathrm{HMG}-\mathrm{Co}$ A expression ${ }^{43}, 44, \mathrm{ABC}$ transporters ${ }^{45}$ correlated between liver and PBMCs. It seems that in PBMCs, expression levels of these genes involved in lipid metabolism correlate with those in liver. PBMCs might be good surrogate cells for these genes. In our study, the genes encoding for insulin-induced gene 1 (INSIG1) and FDPS were both downregulated in PBMCs and WAT after fish oil treatment. It has been suggested that INSIG1 contributes to the triglyceride lowering effect of PPAR $\alpha$ activation by inhibition of sterol-regulatory binding element 1c (SREBP1c) activation ${ }^{46}$. The downregulation of this gene may reflect a feedback mechanism to the decreased triglyceride concentrations by fish oil and fenofibrate treatment. FDPS, a SREBP-responsive gene, has been associated with decreased cholesterol and TG levels in animal studies ${ }^{47,48}$. In addition, the lipolytic GK gene was upregulated in both PBMCs and muscle after fenofibrate treatment, a key enzyme in regulating glycerol uptake and metabolism.

Overall, 6-weeks treatment with n-3 LCPUFAs and fenofibrate hardly affected PPAR $\alpha$ target genes in overweight and obese subjects. Pathway analysis, however, suggested that gene expression profiles in PBMCs can provide information about regulated metabolic processes by fish oil and fenofibrate in WAT, but not muscle. Expression of the individual genes, however, hardly overlapped between the tissues.

\section{Acknowledgements}

This study was funded by the Nutrigenomics Consortium (NGC) of Top Institute Food and Nutrition (TIFN). We would like to thank Martine Hulsbosch and Carla Langejan for their assistance in executing the study and performing laboratory analyses, Mechteld Grootte Bromhaar and Jenny Jansen for their help in processing of microarrays and Guido Hooiveld for his help with microarray data processing and management. 


\section{References}

1 Delerive $\mathrm{P}$, Fruchart $\mathrm{J}$ and Staels B. Peroxisome proliferator-activated receptors in inflammation control. J Endocrinol, 2001; 169: 453-459.

2 Evans RM, Barish GD and Wang YX. PPARs and the complex journey to obesity. Nat Med, 2004; 10: 355-361.

3 Martens FM, Visseren FL, Lemay J, et al. Metabolic and additional vascular effects of thiazolidinediones. Drugs, 2002; 62: 1463-1480.

4 Desvergne B and Wahli W. Peroxisome proliferator-activated receptors: nuclear control of metabolism. Endocr Rev, 1999; 20: 649-688.

5 Delerive $\mathrm{P}, \mathrm{De}$ Bosscher $\mathrm{K}$, Besnard S, et al. Peroxisome proliferator-activated receptor alpha negatively regulates the vascular inflammatory gene response by negative cross-talk with transcription factors NFkappaB and AP-1. The Journal of biological chemistry, 1999; 274: 32048-32054.

6 Grimaldi PA. Lipid sensing and lipid sensors: Peroxisome Proliferator-Activated Receptors as sensors of fatty acids and derivatives. Cell Mol Life Sci, 2007; 64: 2459-2464.

7 Krey G, Braissant O, L'Horset F, et al. Fatty acids, eicosanoids, and hypolipidemic agents identified as ligands of peroxisome proliferator-activated receptors by coactivator-dependent receptor ligand assay. Mol Endocrinol, 1997; 11: 779-791.

8 Auboeuf D, Rieusset J, Fajas L, et al. Tissue distribution and quantification of the expression of mRNAs of peroxisome proliferator-activated receptors and liver $\mathrm{X}$ receptor-alpha in humans: no alteration in adipose tissue of obese and NIDDM patients. Diabetes, 1997; 46: 1319-1327.

9 Sonnenberg GE, Krakower GR and Kissebah AH. A novel pathway to the manifestations of metabolic syndrome. Obes Res, 2004; 12: 180-186.

10 Plat $\mathrm{J}$ and Mensink RP. Vegetable oil based versus wood based stanol ester mixtures: effects on serum lipids and hemostatic factors in non-hypercholesterolemic subjects. Atherosclerosis, 2000; 148: 101-112.

11 Friedewald WT, Levy RI and Fredrickson DS. Estimation of the concentration of low-density lipoprotein cholesterol in plasma, without use of the preparative ultracentrifuge. Clin Chem, 1972; 18: 499-502.

12 Wopereis $\mathrm{S}$, Rubingh $\mathrm{CM}$, van Erk MJ, et al. Metabolic profiling of the response to an oral glucose tolerance test detects subtle metabolic changes. PLoS ONE, 2009; 4: e4525.

13 Bergstrom J, Hermansen L, Hultman E, et al. Diet, muscle glycogen and physical performance. Acta Physiol Scand, 1967; 71: 140-150.

14 Bolstad BM, Irizarry RA, Astrand $\mathrm{M}$, et al. A comparison of normalization methods for high density oligonucleotide array data based on variance and bias. Bioinformatics, 2003; 19: 185-193.

15 Irizarry RA, Bolstad BM, Collin F, et al. Summaries of Affymetrix GeneChip probe level data. Nucleic Acids Res, 2003; 31: e15.

16 Smyth GK. Linear models and empirical bayes methods for assessing differential expression in microarray experiments. Stat Appl Genet Mol Biol, 2004; 3: Article3.

17 Sartor MA, Tomlinson CR, Wesselkamper SC, et al. Intensity-based hierarchical Bayes method improves testing for differentially expressed genes in microarray experiments. BMC Bioinformatics, 2006; 7: 538.

18 Subramanian A, Tamayo P, Mootha VK, et al. Gene set enrichment analysis: a knowledge-based approach for interpreting genome-wide expression profiles. Proc Natl Acad Sci U S A, 2005; 102: 15545-15550.

19 Mootha VK, Lindgren CM, Eriksson KF, et al. PGC-1alpha-responsive genes involved in oxidative phosphorylation are coordinately downregulated in human diabetes. Nat Genet, 2003; 34: 267-273.

20 Phillips CM, Tierney AC and Roche HM. Gene-nutrient interactions in the metabolic syndrome. J Nutrigenet Nutrigenomics, 2008; 1: 136-151.

21 Chapman MJ. Pharmacology of fenofibrate. Am J Med, 1987; 83: 21-25.

22 Arterburn LM, Hall EB and Oken H. Distribution, interconversion, and dose response of $n-3$ fatty acids in humans. The American journal of clinical nutrition, 2006; 83: 1467S-1476S.

23 Bouwens $M$, van de Rest $\mathrm{O}$, Dellschaft $\mathrm{N}$, et al. Fish-oil supplementation induces antiinflammatory gene expression profiles in human blood mononuclear cells. The American journal of clinical nutrition, 2009; 90: 415-424.

24 Bouwens M, Grootte Bromhaar M, Jansen J, et al. Postprandial dietary lipid-specific effects on human peripheral blood mononuclear cell gene expression profiles. The American journal of clinical nutrition, 2010; 91: 208-217. 
25 Bouwens M, Afman LA and Muller M. Fasting induces changes in peripheral blood mononuclear cell gene expression profiles related to increases in fatty acid beta-oxidation: functional role of peroxisome proliferator activated receptor alpha in human peripheral blood mononuclear cells. The American journal of clinical nutrition, 2007; 86: 1515-1523.

26 Thomas J, Bramlett KS, Montrose C, et al. A chemical switch regulates fibrate specificity for peroxisome proliferator-activated receptor alpha (PPARalpha ) versus liver $\mathrm{X}$ receptor. The Journal of biological chemistry, 2003; 278: 2403-2410.

27 Jump DB. Dietary polyunsaturated fatty acids and regulation of gene transcription. Curr Opin Lipidol, 2002; 13: 155-164.

28 Couet C, Delarue J, Ritz P, et al. Effect of dietary fish oil on body fat mass and basal fat oxidation in healthy adults. Int J Obes Relat Metab Disord, 1997; 21: 637-643.

29 Price PT, Nelson CM and Clarke SD. Omega-3 polyunsaturated fatty acid regulation of gene expression. Curr Opin Lipidol, 2000; 11: 3-7.

30 Raclot T and Oudart H. Selectivity of fatty acids on lipid metabolism and gene expression. Proc Nutr Soc, 1999; 58: 633-646.

31 Hofker M. APOC3 deficiency: from mice to man. Eur J Human Gen, 2010; 18: 1-2.

32 Duivenvoorden I, Teusink B, Rensen PC, et al. Apolipoprotein C3 deficiency results in diet-induced obesity and aggravated insulin resistance in mice. Diabetes, 2005; 54: 664-671.

33 Herman MA, She P, Peroni OD, et al. Adipose tissue branched chain amino acid (BCAA) metabolism modulates circulating BCAA levels. The Journal of biological chemistry, 2010; 285: 11348-11356.

34 Odessey R, In: Odessey R (ed), Problems and Potential of Branched Chain Amino

Acids in Physiology and Medicine, New York, Elsevier, 1986: 49-79.

35 Lee JJ, Jin YR, Yu JY, et al. Antithrombotic and antiplatelet activities of fenofibrate, a lipid-lowering drug. Atherosclerosis, 2009; 206: 375-382.

36 Plat $\mathrm{J}$ and Mensink RP. Effects of plant stanol esters on LDL receptor protein expression and on LDL receptor and HMG-CoA reductase mRNA expression in mononuclear blood cells of healthy men and women. FASEB J, 2002; 16: 258-260.

37 Applebaum-Bowden D, Haffner S, Hartsook E, et al. Down-regulation of the low-density lipoprotein receptor bu dietary cholesterol. The American journal of clinical nutrition, 1984; 39: 360-367.

38 Issandou M. Pharmacological regulation of low density lipoprotein receptor expression: current status and future developments. Pharmacol Ther, 2006; 111: 424-433.

39 van Erk MJ, Blom WA, van Ommen B, et al. High-protein and high-carbohydrate breakfasts differentially change the transcriptome of human blood cells. The American journal of clinical nutrition, 2006; 84: 12331241.

40 Wibaut-Berlaimont V, Randi AM, Mandryko V, et al. Atorvastatin affects leukocyte gene expression in dyslipidemia patients: in vivo regulation of hemostasis, inflammation and apoptosis. $\mathrm{J}$ Thromb Haemost, 2005; 3: 677-685.

41 van Leeuwen DM, Gottschalk RW, van Herwijnen MH, et al. Differential gene expression in human peripheral blood mononuclear cells induced by cigarette smoke and its constituents. Toxicol Sci, 2005; 86: 200-210.

42 Connolly $\mathrm{PH}$, Caiozzo VJ, Zaldivar F, et al. Effects of exercise on gene expression in human peripheral blood mononuclear cells. J Appl Physiol, 2004; 97: 1461-1469.

43 Powell E and Kroon P. Low density lipoprotein receptor and 3-hydroxy-3-methylglutaryl coenzyme A reductase gene expression in human mononuclear leukocytes is regulated coodinately and parallels gene expression in human liver. J Clin Invest, 1994; 93: 2168-2174.

44 Harwood H, Bridge D and Stracpoole P. In vivo regulation of human mononuclear leukocyte 3-hydroxy-3methylglutaryl coenzyme A reductase. J Clin Invest, 1987; 79: 1125-1132.

45 Moustafa MA, Ogino D, Nishimura M, et al. Comparative analysis of ATP-binding cassette (ABC) transporter gene expression levels in peripheral blood leukocytes and in liver with hepatocellular carcinoma. Cancer Sci, 2004; 95: 530-536.

46 Konig B, Koch A, Spielmann J, et al. Activation of PPARalpha and PPARgamma reduces triacylglycerol synthesis in rat hepatoma cells by reduction of nuclear SREBP-1. Eur J Pharmacol, 2009; 605: 23-30. 
47 Jackson SM, Ericsson J, Metherall JE, et al. Role for sterol regulatory element binding protein in the regulation of farnesyl diphosphate synthase and in the control of cellular levels of cholesterol and triglyceride: evidence from sterol regulation-defective cells. J Lipid Res, 1996; 37: 1712-1721.

48 Le Jossic-Corcos C, Gonthier C, Zaghini l, et al. Hepatic farnesyl diphosphate synthase expression is suppressed by polyunsaturated fatty acids. Biochem J, 2005; 385: 787-794. 



\section{Сhapter 6}

\section{Differential effects of fenofibrate and fatty acids on $\mathrm{NF} \kappa \mathrm{B}$ activity in HepG2 cells}

Marjolijn C.E. Bragt-van Wijngaarden,1,2, Herman P. Popeijus ${ }^{1,2}$, Jogchum Plat $^{2}$, Ronald P. Mensink,

1 Dutch Nutrigenomics Consortium, Top Institute Food and Nutrition, Wageningen, the Netherlands.

2 NUTRIM School for Nutrition, Toxicology and Metabolism, Department of Human Biology, Maastricht University Medical Centre+, Maastricht, the Netherlands. 


\section{Abstract}

Peroxisome proliferator-activated receptor $\alpha$ (PPAR $\alpha)$ is known as a lipid sensor and can inhibit the pro-inflammatory transcription factor nuclear factor $\mathrm{B}(\mathrm{NF} \kappa \mathrm{B})$. Therefore, targeting PPAR $\alpha$ with fatty acids is of interest to reduce hepatic manifestations of the metabolic syndrome in which low grade-inflammation plays an important role. For this reason, we evaluated the effects of different fatty acids (palmitic acid (C16:0), stearic acid (C18:0), oleic acid (C18:1, n-9), linoleic acid (C18:2, n-6), $\alpha$-linolenic acid (C18:3, n-3), eicosapentaenoic acid (EPA; C20:5, $\mathrm{n}-3)$ and docosahexaenoic acid (DHA; $222: 6, n-3)$ ) and fenofibric acid, a synthetic PPAR $\alpha$ agonist, on the interrelationships between PPAR $\alpha$ and NF $\kappa B$ activities a human liver cell model in vitro. We showed that overexpression of PPAR $\alpha$ in human liver cells reduced basal NFKB expression in a dose-dependent manner. Fenofibric acid, C18 fatty acids stearic acid, oleic acid, linoleic acid and $\alpha$-linolenic acid, and EPA could increase PPAR $\alpha$ activity. In contrast, palmitic acid hardly affected and DHA decreased PPAR $\alpha$ activity at 50 and $100 \mu \mathrm{M}$. Fenofibric acid inhibited NF $\kappa B$ activity, and this effect requires the presence of PPAR $\alpha$. However, almost all fatty acids inhibited $N F \kappa B$ activity independent of PPAR $\alpha$. Exceptions were oleic acid at 1 and $10 \mu \mathrm{M}$ and $\alpha$-linolenic acid at $1 \mu \mathrm{M}$, showing NFKB activation in the absence of PPAR $\alpha$ and NF $\kappa B$ inhibition in the presence of PPAR $\alpha$. In conclusion, activation of PPAR $\alpha$ by fenofibrate in liver cells can inhibit NFKB activity. In addition, the modulation of $\mathrm{NF \kappa B}$ activity by fatty acids is fatty acid specific, where PPAR $\alpha$ counteracted the activation of $\mathrm{NF} \kappa \mathrm{B}$ by oleic and $\alpha$-linolenic acid. In contrast, the NF $\kappa B$ inhibitory effect of palmitic acid, stearic acid, linoleic acid, EPA and DHA in liver cells did not depend on PPAR $\alpha$. 


\section{Introduction}

Low-grade systemic inflammation is often present in overweight and obese subjects and contributes to an increased risk for developing the metabolic syndrome and associated diseases ${ }^{1}$. A potential molecular target to counteract this low-grade pro-inflammatory state is peroxisome proliferator activated receptor $\alpha$ (PPAR $\alpha$ ). PPAR $\alpha$ is a member of the nuclear receptor super family of ligand-activated receptors and well-known for its role in the expression of genes involved in lipid metabolism². However, PPAR $\alpha$ may also modulate inflammatory responses by physically interacting with the pro-inflammatory transcription factor nuclear factor $\kappa B(N F \kappa B)$, thereby forming inactive complexes ${ }^{3}$. $N F \kappa B$ activation is a crucial step in the inflammatory response and regulates the expression of pro-inflammatory cytokines, chemokines and adhesion molecules. Furthermore, PPAR $\alpha$ can indirectly control inflammatory responses by increasing the expression of $I \kappa B \alpha$ and IkB kinase (IKK), which are known to inhibit NFKB signaling ${ }^{4,5} . I_{\kappa} \mathrm{B} \alpha$ is a protein that binds to $\mathrm{NF} \kappa \mathrm{B}$ and prevents its translocation to the nucleus, whereas IKK prevents degradation of $I_{\kappa} B \alpha$.

PPAR $\alpha$ can be activated by synthetic ligands, such as drugs of the fibrate class. However, dietary fatty acids can also activate PPAR $\alpha$, which is illustrated by the fact that PPARs are frequently described as lipid sensors ${ }^{6}$. It has been suggested that especially polyunsaturated fatty acids (PUFAs) with 18-20 carbon atoms and 3-5 double bonds such as $\alpha$-linolenic acid (a-LA) and eicosapentaenoic acid (EPA), as well as monounsaturated fatty acids (MUFAs) bind to and activate PPARs $^{7,8}$. Docosahexaenoic acid (DHA) was found to be a less potent PPAR $\alpha$ activator. The effects of different fatty acids on NFKB activation and the role of PPAR $\alpha$ herein have not been studied before. Therefore, the aim of the present study was to explore in vitro in human liver cells the effects of fenofibric acid and different fatty acids on the interrelationships between PPAR $\alpha$, and NF $\kappa B$ activities. Oleic acid, linoleic acid, $\alpha$-linoleic acid were used to examine varying degrees of unsaturation, palmitic acid for its described pro-inflammatory effect, and the fish fatty acids EPA and DHA for their suggested anti-inflammatory properties.

\section{Material and methods}

\subsection{Reagents}

Bovine serum albumine (BSA; endotoxin and fatty acid free), palmitic acid (C16:0), stearic acid (C18:0), oleic acid (C18:1, n-9), linoleic acid (C18:2, n-6), $\alpha$-linolenic acid (C18:3, n-3), eicosapentaenoic acid (EPA; C20:5, n-3) and docosahexaenoic acid (DHA; C22:6, n-3) were purchased from Sigma Chemical Company (St. Louis, MO, USA). Fenofibric acid (FeAc) was kindly provided by Fournier Laboratories (Dijon, France). Minimal Essential Medium (MEM), trypsin, penicillin streptomycin (PS), sodium pyruvate (SP) and non-essential amino acids (NEAA) were obtained 
from Invitrogen Corporation (Paisley, UK), and Fetal Calf Serum (FCS; SouthAmerican) from Greiner Bio-one (Frickenhausen, Germany).

\subsection{HepG2 cell culture, transfection, fatty acid experiments and luciferase assay}

HEPG2 cells were kindly provided by Mabtech (Nacka Strand, Sweden). Cells were cultured in MEM containing glucose and L-glutamine, which was further supplemented with 10\% heat-inactivated FCS (v/v), 1\% PS (v/v), 1\% SP (v/v), and $1 \%$ NEAA (v/v). Cells were cultured at $37{ }^{\circ} \mathrm{C}$ in a 5\% CO2/95\% $02(\mathrm{v} / \mathrm{v})$ humidified atmosphere and separated twice a week, when they had reached $80 \%$ confluency. For passage, cells were first washed with phosphate buffered saline (PBS), followed by addition of trypsin-0.03\% ethylenediaminetetraacetic acid (EDTA) $(\mathrm{v} / \mathrm{v})$. For each experiment, HepG2 cells were seeded in 24-well plates with a density of $0.2 \times 10^{6} \times$ cells per well in a total volume of $1 \mathrm{~mL}$ MEM. Twenty-four hours after seeding, at $\pm 40 \%$ confluency, cells were transiently transfected with the appropriate plasmids using Fugene 6 Transfection Reagent according to the user manual (Roche Diagnostics, Basel, Switzerland). To study the effects of PPAR $\alpha$ agonists on $\mathrm{NF} \kappa \mathrm{B}$ transactivation, cells were transfected with a $4 \kappa \mathrm{B}-\mathrm{TK}$-luciferase (NFkB luciferase reporter) plasmid, which was kindly provided by Dr. David Gius (Radiation National Oncology Section, National Cancer Institute, Bethesda, MD, USA). To measure PPAR transcriptional activity, cells were transfected with a luciferase reporter $\mathrm{pGL} 3$ vector containing PPAR response elements (PPREs) as described by Gilde et al. ${ }^{9}$ In addition, all cells were co-transfected with a human PPAR $\alpha$ (hPPAR $\alpha$ ) expression construct. After 5 hours, FCS-free MEM containing the fatty acids was added to the cells, which were subsequently incubated for 24 hours. Fatty acids were dissolved in dimethylsulfoxide (DMSO). The final concentration of DMSO in the medium did not exceed $0.33 \%(\mathrm{v} / \mathrm{v})$. Fatty acids $(1$, 10,50 and $100 \mu \mathrm{M}$ ) were added to MEM with $0.1 \%$ BSA and pre-incubated at $37^{\circ} \mathrm{C}$ for 45 minutes to enable coupling of fatty acids to BSA. FeAc $(300 \mu \mathrm{M})$ was added and incubated for 24 hours as a positive control for PPAR $\alpha$ transactivation. A condition with only BSA served as a negative control. Each compound was tested in quadruplicate. After 24 hours, cells were lysed on ice with $100 \mu \mathrm{L}$ reporter lysis buffer per well (Promega, Madison, WI, USA) and stored at $-80^{\circ} \mathrm{C}$. Luciferase activity was measured according to the manufacturer's instruction (Promega) and expressed relative to protein content (Bio-rad assay, Bio-rad, Hercules, CA, USA).

\subsection{Statistics}

Values for PPAR $\alpha$ and NFKB reporter activity were analyzed by one-way ANOVA. If significant, the effects for each fatty acid were compared at each concentration to the negative control using the post hoc Bonferroni test. Statistical analysis was performed using SPSS 15.0 for Windows (SPSS, Chicago, IL, USA). $P$-values $<0.05$ were regarded to be statistical significant. 


\section{Results}

\subsection{Effects of PPAR $\alpha$ on $N F K B$ transactivation}

A PPRE-luciferase reporter construct was used to determine the activity of PPAR $\alpha$. HepG2 cells transfected with only the PPRE-luciferase reporter showed almost no PPRE-mediated luciferase activity, even not after incubation with the strong PPAR $\alpha$ agonist FeAc (figure 1). Co-transfection of HepG2 cells with the PPAR $\alpha$ expression construct resulted in a 4-fold increase in PPRE-mediated luciferase activity compared to basal PPRE activity. PPAR $\alpha$ activation could be enhanced 12 -fold by the addition of the PPAR $\alpha$ agonist FeAc (figure 1).

Figure 2 shows that increasing the transfected amount of the PPAR $\alpha$ construct dose-dependently decreased NFKB luciferase activity (Figure 2). This decrease became statistically significant at PPAR $\alpha$ concentrations of $0.06 \mu \mathrm{g}$ and more, and NFKB luciferase activity was almost completely abolished at a concentration of $0.1 \mu \mathrm{g}$ PPAR $\alpha$.
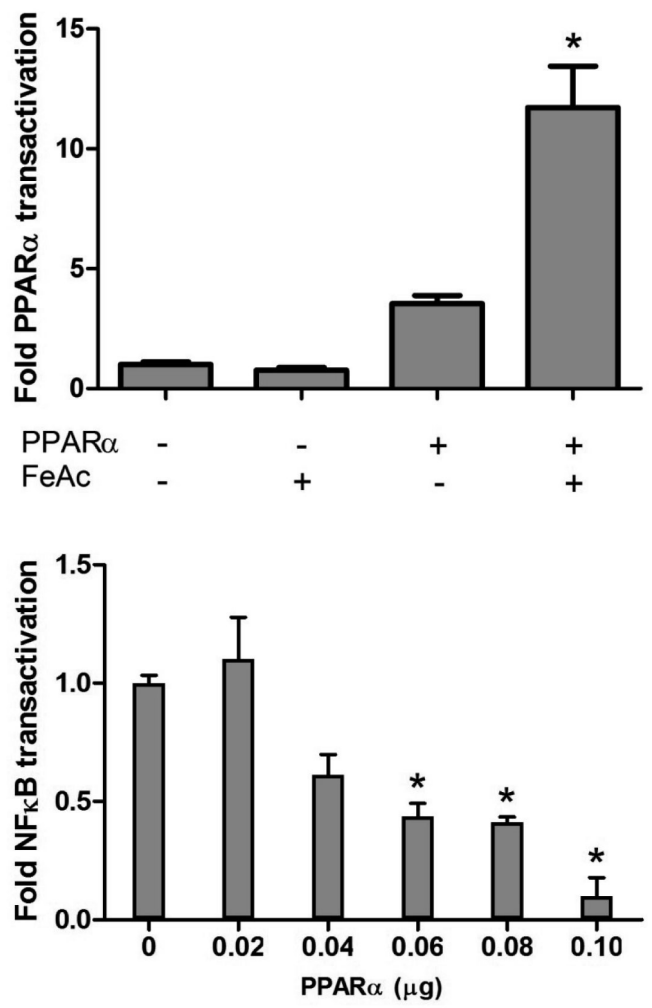

Figure 1. Effect of FeAc $(300 \mu \mathrm{M})$ in HepG2 cells transfected with the PPRE luciferase reporter with and without co-transfection with the PPAR $\alpha$ expression construct. The control without PPAR $\alpha$ and without FeAc was set to 1 . Values significantly different from control $(p<0.05)$ are indicated with an asterisk $(*)$.

Figure 2. Dose response curve of hPPAR $\alpha(0.02,0.04,0.06,0.08$ and $0.10 \mu \mathrm{g}$ ) using the PPRE luciferase reporter construct. The control condition without PPAR $\alpha$ was set to 1. Values significantly different from control $(P<0.05)$ are indicated with an asterisk (*). 


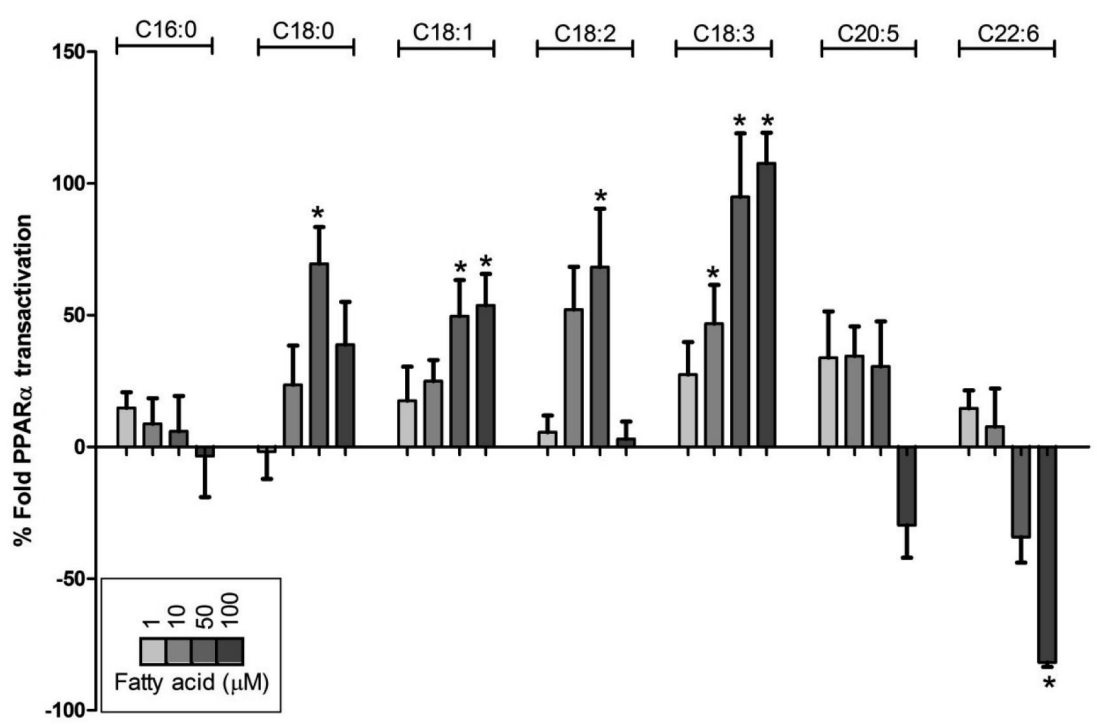

Figure 3. The effect of fatty acids C16:0, C18:0, C18:1, C18:2, C18:3, C20:5 and C22:6 in a concentration ranging from $1-100 \mu \mathrm{M}$, on PPAR $\alpha$ transactivation.

The transactivation properties of fatty acids are shown relative to the transactivation of PPAR $\alpha$ alone. The condition with BSA (negative control) is set at zero \% activation. Values significantly different from $\mathrm{P}<0.05$ are indicated with an asterisk (*).

\subsection{Effects of fatty acids on PPAR $\alpha$ transactivation}

None of the tested concentrations of palmitic acid (C16:0) was able to transactivate PPAR $\alpha$ (figure 3). In contrast, stearic acid (C18:0), oleic acid (C18:1), linoleic acid (C18:2) and $\alpha$-linolenic acid (C18:3) activated PPAR $\alpha$ at $50 \mu \mathrm{M}$ and oleic acid also at $100 \mu \mathrm{M}$. The long-chain fish fatty acids EPA (C20:5) and DHA (C22:6) hardly influenced PPAR $\alpha$ activity, except for a significantly reduced PPAR $\alpha$ activity at $100 \mu \mathrm{M}$ of DHA.

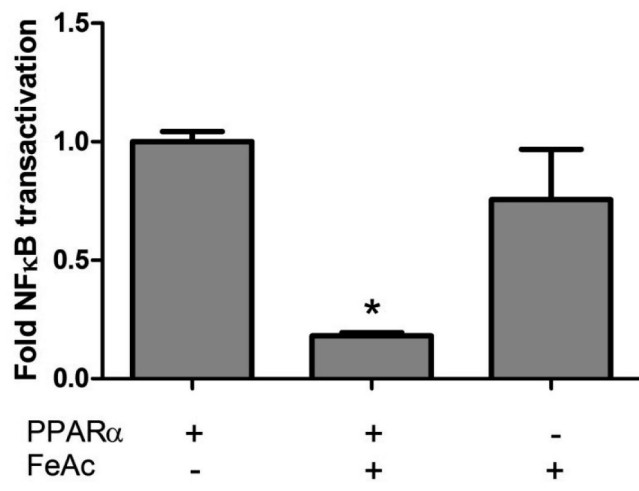

Figure 4. Effect of FeAc $(300 \mu \mathrm{M})$ on $\mathrm{NF} \kappa \mathrm{B}$ transactivation in presence and absence of PPAR $\alpha$. The control condition with PPAR $\alpha$ and without FeAc was set to 1 . Values significantly different from control $(p<0.05)$ are indicated with an asterisk $(*)$. 


\subsection{Effects of $F e A c$ and fatty acids on $N F \kappa B$ transactivation in absence and} presence of a PPAR $\alpha$

In the absence of the PPAR $\alpha$ construct, FeAc did not influence NFkB transactivation. Interestingly, after co-transfection of the PPAR $\alpha$ construct, FeAc significantly inhibited $N F \kappa B$ transactivation by $82 \%$ (figure 4 ).

To test the effects of different fatty acids, HepG2 were transfected with the $\mathrm{NF \kappa B}$ luciferase reporter, first in the absence of the PPAR $\alpha$ expression construct. Palmitic acid significantly inhibited NFKB activity at concentrations of 10,50 and $100 \mu \mathrm{M}$, whereas stearic acid had no effect (figure $5 \mathrm{a}$ ). The activity of the NFkB reporter also increased at 1 and $10 \mu \mathrm{M}$ of oleic acid, whereas $\mathrm{NF} \kappa \mathrm{B}$ activation was shown for linoleic acid at 50 and $100 \mu \mathrm{M}$, and for $\alpha$-linolenic acid at $1 \mu \mathrm{M}$. For the fish fatty acids, EPA significantly inhibited NFkB activity at 50 and $100 \mu \mathrm{M}$ and DHA at $100 \mu \mathrm{M}$. After co-transfection with PPAR $\alpha$, the NF $\kappa$ B stimulating effect of oleic acid at 1 and $10 \mu \mathrm{M}$ was completely abolished (figure $5 \mathrm{~b}$ ), as was also seen for $1 \mu \mathrm{M} \alpha$-linolenic acid. Furthermore, stearic acid significantly inhibited $N F \kappa B$ activity at 50 and $100 \mu \mathrm{M}$. For the other fatty acids in combination with PPAR $\alpha$, there were only marginal differences in the $\mathrm{NFKB}$ modulating effects when compared to the situation without PPAR $\alpha$ co-transfection. Correlations between the effects of the fatty acids on PPAR $\alpha$ activity with effects on NFKB activity did not reach statistical significance 


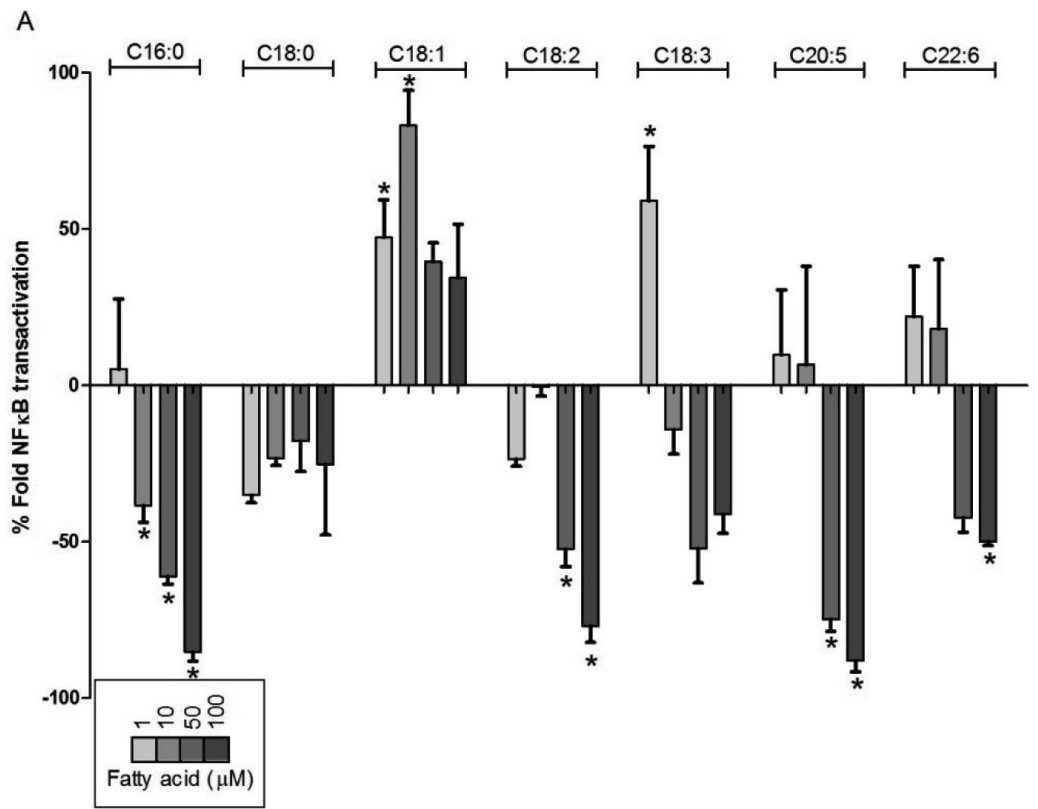

B

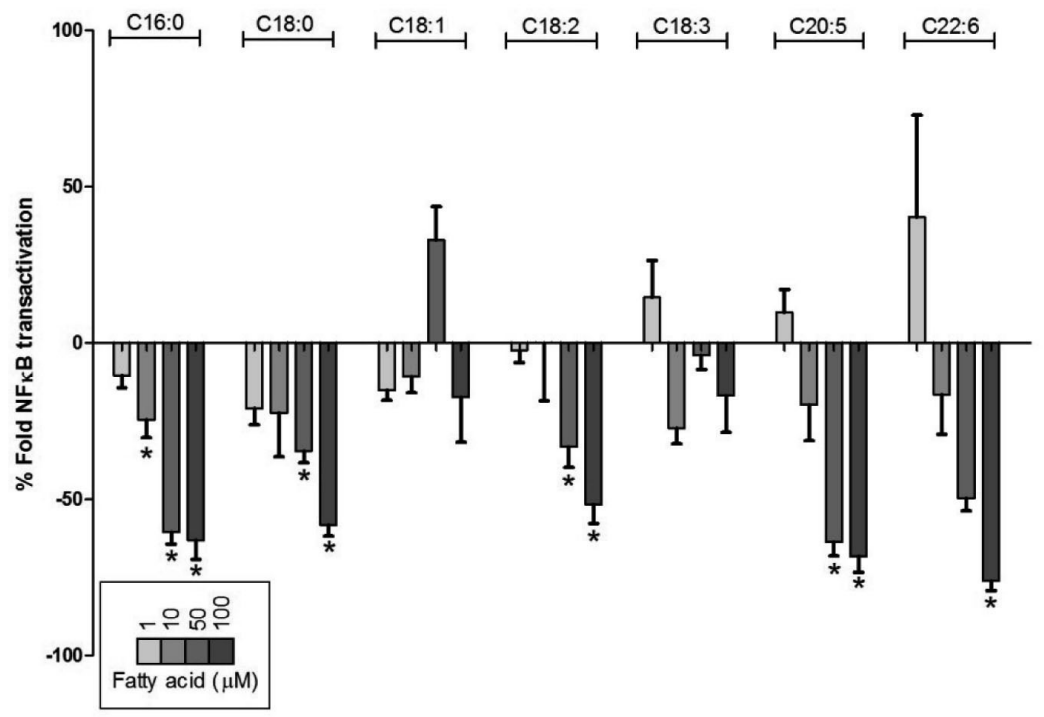

Figure 5. The effect of fatty acids C16:0, C18:0, C18:1, C18:2, C18:3, C20:5 and C22:6 in a concentration ranging from $1-100 \mu \mathrm{M}$, on NF $\kappa B$ transactivation in the absence $(A)$ and presence (B) of PPAR $\alpha$. The condition with BSA (negative control) was set at zero \% activation. Values significantly different from the negative control $(P<0.05)$ are indicated with an asterisk $(*)$. 


\section{Discussion}

Low-grade inflammation is often present in subjects with the metabolic syndrome. This pro-inflammatory state can contribute to hepatic manifestations related to this syndrome, such as non-alcoholic fatty liver disease (NAFLD) and steatohepatitis (NASH), 10, 11. There is evidence from in vitro experiments in aortic smooth muscle cells that PPAR $\alpha$ can dampen the inflammatory response by preventing NFKB translocation to the nucleus ${ }^{4,5}$. We have extended these findings by showing for the first time cells that in HepG 2 cells activation of PPAR $\alpha$ by

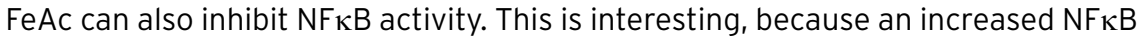
activity is a characteristic of patients with $\mathrm{NASH}^{12,13}$. In contrast to fenofibrate, the effects of PPAR $\alpha$ in HepG2 cells on NFKB by fatty acids was, if anything at all, marginal.

It is thought that PPAR $\alpha$ can be activated by natural ligands, such as fatty acids. So far, activation of PPAR $\alpha$ by fatty acids has almost exclusively been studied with ligand binding assays or by using only a GAL4-fused ligand binding domain of PPAR $\alpha^{7,8}$. However, to detect true fatty acid ligands and activators of PPAR $\alpha$, it may be preferred to use the fully functional transcription factor. Using this approach, we here show that fatty acids with 18 carbon atoms are activators of PPAR $\alpha$ in HepG2 cells. In contrast, palmitic acid and the fish oil fatty acids EPA and DHA were poor PPAR $\alpha$ activators. These results are largely in agreement with the findings of Mochizuki et al., who examined the effects of fatty acids on PPAR $\alpha$ binding and activity in a GAL-4 fused PPAR $\alpha$ luciferase system in a colon cell line $(\mathrm{CaCo} 2)^{8}$. They found that especially linoleic acid, $\alpha$-linolenic acid, $\gamma$-linolenic acid, arachidonic acid and EPA stimulated PPAR $\alpha$. Less activity was seen after incubation with palmitic acid and oleic acid. In addition, DHA hardly affected PPAR $\alpha$ transcriptional activity in that study, although there was an increased binding of DHA to PPAR $\alpha^{8}$.

In contrast to fenofibrate, PPAR $\alpha$ seems to play only a limited role in NFKB inhibition by fatty acids in HepG2 cells. The fatty acids palmitic, stearic and linoleic acids, EPA and DHA inhibited NF $\kappa$ B activity in the absence of PPAR $\alpha$. Remarkably, palmitic acid dose-dependently reduced NFKB activity, while oleic and $\alpha$-linolenic acids were the only fatty acids capable of activating NFKB. Joshi-Barve et al. reported an increased expression and production of neutrophil chemoattractant interleukin-8 in combination with an increased DNA binding activity of the proinflammatory transcription factors $\mathrm{NF} \kappa \mathrm{B}$ and $\mathrm{AP}-1$ after stimulation of HepG2 cells with $300 \mu \mathrm{M}$ palmitic acid ${ }^{14}$. It was not reported if this increased DNA binding was also followed by an increased transactivation of NFKB by palmitic acid.

From in vitro studies in muscle cell lines, it is known that the saturated fatty acid palmitic acid stimulates NF $\kappa B$ activity and consequently the production of the pro-inflammatory cytokines IL6 and TNF $\alpha^{15-17}$. Thus, the effects we observed may be liver-specific. It has been hypothesized by Pasparakis et al. that NFKB can have distinct roles in different tissues, illustrated by contrasting responses of tissues to $\mathrm{NF} \kappa \mathrm{B}$ inhibition ${ }^{18}$. The inhibition (or activation) of NFKB in skin, intestinal epithelial cells and liver parenchymal cells forms the trigger for an immune response, and 
$\mathrm{NF} \kappa \mathrm{B}$-competent immune cells will further drive the inflammatory response ${ }^{18}$. Contrasting, inhibition of $\mathrm{NF \kappa B}$ in central nervous system cells, pancreas and skeletal muscle cells did not inflict an inflammatory response18. The reason for potential tissue-specific effects of fatty acids on activation of NF $\kappa B$ could relate to differences in expression of toll-like receptor (TRL) types ${ }^{19,20}$. TRLs can be activated by fatty acids and play an important role in the regulation of NF $\kappa B$ activity. TRLS can be differentially modulated by the different fatty acids in various tissues ${ }^{21,22}$. How this can explain our observed NFKB activating capacity of oleic acid and low dose $\alpha$-linoleic acid in liver cells warrants further investigation. For macrophages and human embryonic kidney cells, it has been reported that unsaturated fatty acids (including oleic acid) inhibited TRL and subsequent NFKB activation ${ }^{23}$.

DHA and EPA are n-3 LCPUFAs from fish oil and are known to reduce inflammation and to exert cardioprotective effects ${ }^{24}$. However, the mechanisms behind these effects are not clear. It is suggested that these effects arise from inhibition of $\mathrm{NF}_{\kappa} \mathrm{B}^{25}$. We have shown that EPA and DHA may reduce $N F \kappa B$ activation, at least in liver cells. These effects were independent of PPAR $\alpha$. Also for the other fatty acids, with the exception of oleic acid and low dose $\alpha$-linoleic acid, the presence of PPAR $\alpha$ had only minor influences on NF $\kappa B$ activity. It could be that the NFKB-suppressing effects of these fatty acids are PPAR $\alpha$-independent. Since fatty acids are non-specific PPAR ligands, modulation of NFKB expression could possibly also occur via PPAR ${ }^{26,27}$ instead of PPAR $\alpha$. However, it is not likely that anti-inflammatory effects of PPAR $\gamma$ agonists can simply be attributed to PPAR activation ${ }^{28}$. Research with the specific PPAR $\gamma$ agonist rosiglitazone failed to demonstrate NFKB-related inflammatory gene expression in peripheral blood mononuclear cells of diabetes patients ${ }^{29}$ or showed only an effect in a study with a dose beyond the pharmacological level ${ }^{4}$. Fatty acids, especially EPA and DHA, may also influence inflammation via the earlier mentioned TRLs, modulation of liver $X$ receptor (LXR) $\alpha$ or $\beta$, hepatic nuclear factor $\alpha$ (HNF $4 \alpha$ ) or nod-like receptors (NRLs) ${ }^{28,30}$. Hypothetically, it could also be that fatty acids act more directly on the NFKB signaling cascade. These direct effects may involve reduced IKB phosphorylation via decreased mitogen activated protein kinases (MAPKs) or reduced IKK activity ${ }^{25,31-33}$. Alternatively, PPAR $\alpha$-mediated inhibition of NFKB via PPAR $\alpha$ is masked in our experiments by counteracting factors or mechanisms. More in vitro experiments and in vivo research with tissue-specific knock-out models are therefore necessary to elucidate the molecular mechanisms behind the NFKB-mediated anti-inflammatory effects of fatty acids.

In conclusion, the presence and activation of PPAR $\alpha$ by fenofibrate in liver cells can inhibit the activation NFKB. In addition, the modulation of NFKB activity by fatty acids is fatty acid specific, where PPAR $\alpha$ counteracted the activation of $N F \kappa B$ by oleic and $\alpha$-linolenic acid. In contrast, the NFKB inhibitory effect of palmitic, stearic, linoleic acid, EPA and DHA in liver cells seem independent of PPAR $\alpha$ and involve other biological relevant pathways or potential counteracting mechanisms. 


\section{References}

1 Fantuzzi $G$ and Mazzone T. Adipose tissue and atherosclerosis: exploring the connection. Arterioscler Thromb Vasc Biol, 2007; 27: 996-1003.

2 Bragt MC and Popeijus HE. Peroxisome proliferator-activated receptors and the metabolic syndrome. Physiol Behav, 2008; 94: 187-197.

3 Delerive $\mathrm{P}$, De Bosscher K, Besnard S, et al. Peroxisome proliferator-activated receptor alpha negatively regulates the vascular inflammatory gene response by negative cross-talk with transcription factors NFkappaB and AP-1. The Journal of biological chemistry, 1999; 274: 32048-32054.

4 Delerive $\mathrm{P}$, Fruchart $\mathrm{J}$ and Staels B. Peroxisome proliferator-activated receptors in inflammation control. J Endocrinol, 2001; 169: 453-459.

5 Delerive P, Gervois P, Fruchart JC, et al. Induction of IkappaBalpha expression as a mechanism contributing to the anti-inflammatory activities of peroxisome proliferator-activated receptor-alpha activators. The Journal of biological chemistry, 2000; 275: 36703-36707.

6 Grimaldi PA. Lipid sensing and lipid sensors : Peroxisome Proliferator-Activated Receptors as sensors of fatty acids and derivatives. Cell Mol Life Sci, 2007; 64: 2459-2464.

7 Krey G, Braissant O, L'Horset F, et al. Fatty acids, eicosanoids, and hypolipidemic agents identified as ligands of peroxisome proliferator-activated receptors by coactivator-dependent receptor ligand assay. Mol Endocrinol, 1997; 11: 779-791.

8 Mochizuki K, Suruga K, Fukami H, et al. Selectivity of fatty acid ligands for PPARalpha which correlates both with binding to cis-element and DNA binding-independent transactivity in Caco-2 cells. Life Sci, 2006; 80: 140-145.

9 Gilde AJ, van der Lee KA, Willemsen PH, et al. Peroxisome proliferator-activated receptor (PPAR) alpha and PPARbeta/delta, but not PPARgamma, modulate the expression of genes involved in cardiac lipid metabolism. Circ Res, 2003; 92: 518-524.

10 Marchesini $G$ and Babini M. Nonalcoholic fatty liver disease and the metabolic syndrome. Minerva Cardioangiol, 2006; 54: 229-239.

11 Adams LA, Angulo P and Lindor KD. Nonalcoholic fatty liver disease. Cmaj, 2005; 172: 899-905.

12 Marra F, Gastaldelli A, Svegliati Baroni G, et al. Molecular basis and mechanisms of progression of nonalcoholic steatohepatitis. Trends Mol Med, 2008; 14: 72-81.

13 Ribeiro PS, Cortez-Pinto H, Sola S, et al. Hepatocyte apoptosis, expression of death receptors, and activation of NF-kappaB in the liver of nonalcoholic and alcoholic steatohepatitis patients. Am J Gastroenterol, 2004; 99 : 1708-1717.

14 Joshi-Barve S, Barve SS, Amancherla K, et al. Palmitic acid induces production of proinflammatory cytokine interleukin-8 from hepatocytes. Hepatology, 2007; 46: 823-830.

15 Hommelberg PP, Plat J, Langen RC, et al. Fatty acid-induced NF-kappaB activation and insulin resistance in skeletal muscle are chain length dependent. American journal of physiology, 2009; 296: E114-120.

16 Jove M, Planavila A, Laguna JC, et al. Palmitate-induced interleukin 6 production is mediated by protein kinase $\mathrm{C}$ and nuclear-factor kappaB activation and leads to glucose transporter 4 down-regulation in skeletal muscle cells. Endocrinology, 2005; 146: 3087-3095.

17 Jove M, Planavila A, Sanchez RM, et al. Palmitate induces tumor necrosis factor-alpha expression in C2C12 skeletal muscle cells by a mechanism involving protein kinase $\mathrm{C}$ and nuclear factor-kappaB activation. Endocrinology, 2006; 147: 552-561.

18 Pasparakis M. Regulation of tissue homeostasis by NF-kappaB signalling: implications for inflammatory diseases. Nat Rev Immunol, 2009; 9: 778-788.

19 Frost RA, Nystrom GJ and Lang CH. Multiple Toll-like receptor ligands induce an IL-6 transcriptional response in skeletal myocytes. Am J Physiol Regul Integr Comp Physiol, 2006; 290: R773-784.

20 Nishimura $\mathrm{M}$ and Naito $\mathrm{S}$. Tissue-specific mRNA expression profiles of human toll-like receptors and related genes. Biol Pharm Bull, 2005; 28: 886-892.

21 Chait A and Kim F. Saturated fatty acids and inflammation: who pays the toll? Arterioscler Thromb Vasc Biol, 2010; 30: 692-693.

22 Lee JY, Zhao L, Youn HS, et al. Saturated fatty acid activates but polyunsaturated fatty acid inhibits Toll-like receptor 2 dimerized with Toll-like receptor 6 or 1 . The Journal of biological chemistry, 2004; 279: 16971-16979. 
23 Lee J, Plakidas A, Lee $\mathrm{W}$, et al. Differential modulation of Toll-like receptors by fatty acids: preferential inhibition by $n-3$ polyunsaturated fatty acids. J Lipid Res, 2003; 44: 479-486.

24 Tziomalos K, Athyros VG and Mikhailidis DP. Fish oils and vascular disease prevention: an update. Curr Med Chem, 2007; 14: 2622-2628.

25 Zhao Y, Joshi-Barve S, Barve S, et al. Eicosapentaenoic acid prevents LPS-induced TNF-alpha expression by preventing NF-kappaB activation. J Am Coll Nutr, 2004; 23: 71-78.

$26 \mathrm{Li} \mathrm{H}$, Ruan XZ, Powis SH, et al. EPA and DHA reduce LPS-induced inflammation responses in HK-2 cells: evidence for a PPAR-gamma-dependent mechanism. Kidney Int, 2005; 67: 867-874.

27 Zhao G, Etherton TD, Martin KR, et al. Anti-inflammatory effects of polyunsaturated fatty acids in THP-1 cells. Biochem Biophys Res Commun, 2005; 336: 909-917.

28 Stulnig TM. Immunomodulation by polyunsaturated fatty acids: mechanisms and effects. Int Arch Allergy Immunol, 2003; 132: 310-321.

29 Bragt MC, Plat J, Mensink M, et al. Anti-inflammatory effect of rosiglitazone is not reflected in expression of NFkappaB-related genes in peripheral blood mononuclear cells of patients with type 2 diabetes mellitus. BMC Endocr Disord, 2009; 9: 8.

30 Chapkin RS, Kim W, Lupton JR, et al. Dietary docosahexaenoic and eicosapentaenoic acid: emerging mediators of inflammation. Prostaglandins Leukot Essent Fatty Acids, 2009; 81: 187-191.

31 Chen W, Esselman WJ, Jump DB, et al. Anti-inflammatory effect of docosahexaenoic acid on cytokine-induced adhesion molecule expression in human retinal vascular endothelial cells. Invest Ophthalmol Vis Sci, 2005; 46: 4342-4347.

32 Lo CJ, Chiu KC, Fu M, et al. Fish oil modulates macrophage P44/P42 mitogen-activated protein kinase activity induced by lipopolysaccharide. JPEN J Parenter Enteral Nutr, 2000; 24: 159-163.

33 Novak TE, Babcock TA, Jho DH, et al. NF-kappa B inhibition by omega -3 fatty acids modulates LPS-stimulated macrophage TNF-alpha transcription. Am J Physiol Lung Cell Mol Physiol, 2003; 284: L84-89. 


\section{Chapter 7}

General discussion 
The incidence of the metabolic syndrome is rapidly increasing world-wide among adults and also among adolescents and children ${ }^{1,2}$. This syndrome is characterized by a cluster of metabolic abnormalities, such as obesity, disturbed lipid and glucose metabolism and hypertension, which predisposes to the development of type 2 diabetes (T2D) and cardiovascular diseases (CVD) ${ }^{3}$. Therefore, there is an urge to prevent or reverse the metabolic abnormalities associated with the metabolic syndrome and to prevent the development of these chronic diseases.

Nutrition can play a pivotal role in disease prevention. Dietary interventions mainly focus on the very early phase of disease development, when there is a predisease state with metabolic stress, but no clinical manifestations of the disease, as in case of the metabolic syndrome (figure 1). In this way, early symptoms can be reversed to normalize metabolic homeostasis. Nutrition and pharmacological approaches to prevent or ameliorate metabolic stress and the metabolic syndrome can be complementary. However, drugs are more often applied at a later stage when clinical symptoms already occur.

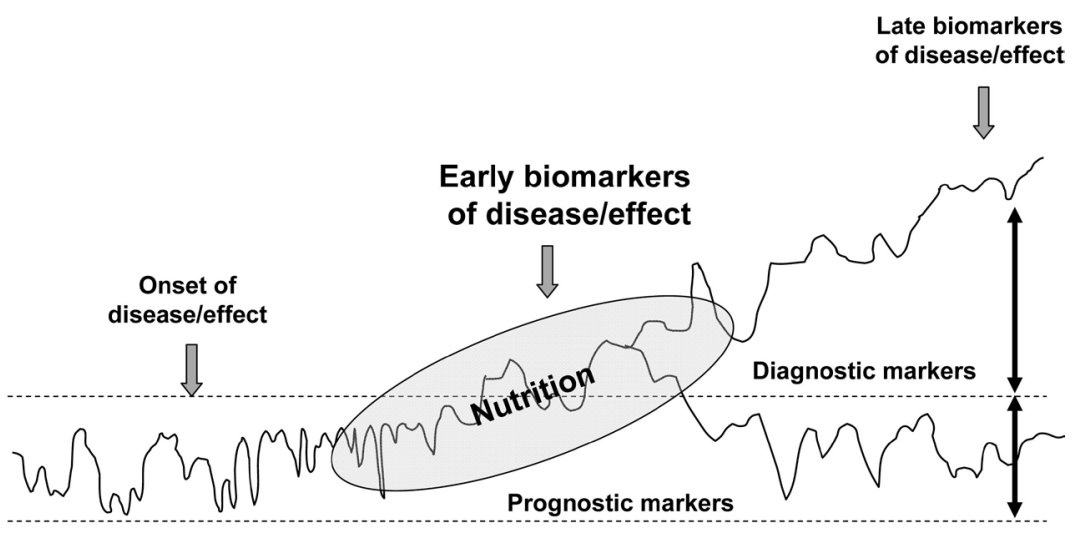

Figure 1. Development of the metabolic syndrome (adapted from Van der Greef et al. ${ }^{4}$ ). A nutritional approach can be applied to prevent the metabolic syndrome and normalize metabolic homeostasis. A pharmacological approach is more often applied after the onset of disease in order to treat the disease. Dietary intervention studies using a nutrigenomics approach may reveal early biomarkers of disease in order to define better dietary strategies for disease prevention. Interesting targets for prevention of the metabolic syndrome are PPARs, which can be activated by pharmacological as well as dietary interventions.

Unfortunately, the underlying molecular mechanisms of the metabolic syndrome are largely unknown, which makes it difficult to develop effective prevention strategies. Dietary intervention studies using a nutrigenomics approach to study the effects of a diet or dietary compound at the gene, protein and metabolite level may reveal early biomarkers of effect. This will be helpful in determining and applying effective intervention strategies to prevent the 
metabolic syndrome by reversing metabolic stress back into normal homeostasis. The search for these molecular biomarkers is complicated due to the relative inaccessibility of target tissues. Therefore, it is also important to elucidate if the readily accessible peripheral blood mononuclear cells (PBMCs) can be used as a surrogate.

There is an interesting and considerable overlap in molecular targets between nutritional and pharmacological intervention strategies. In this light, peroxisome proliferator activated receptors (PPARs), such as PPAR $\alpha$ and PPAR $\gamma$, deserve attention. These transcription factors can be activated by pharmacological ligands, such as fibrates and thiazolidinediones, respectively, but also by dietary fatty acids. Most often, pharmacological approaches are more powerful and dietary interventions lead to more subtle molecular changes. Comparing a pharmacological and a nutritional approach to target PPARs may therefore reveal how gene expression effects exerted by a drug relate to those achieved by a dietary intervention. In this way, dietary intervention strategies can be explored for prevention of the metabolic syndrome or as an alternative to drugs to improve metabolic abnormalities associated with the metabolic syndrome.

The major objective of the studies described in this thesis was to examine the role of PPARs in various metabolic processes and to identify a potential role for nutrition in modulating these transcription factors. A second objective was to evaluate the suitability of PBMCs as surrogate cells for target tissues to reflect PPAR-related gene expression and gene expression in general. For this, we studied the effects of both synthetic PPAR agonists and natural PPAR agonists on a wide range of metabolic risk markers. As synthetic ligands we used rosiglitazone (PPAR $\gamma$ ) and a micronized form of fenofibrate (PPAR $\alpha$ ), which are commonly used, potent agonists. We used n-3 fatty acids from fish oil as natural non-selective dietary ligands of PPARs. Except for the effects on serum lipids and lipoproteins, we were particularly interested in the effects on inflammation markers and markers of vascular activity. In addition, we investigated if effects on these parameters were reflected by changes in gene expression. This chapter will provide a comprehensive overview of the main results of the conducted studies, which will be discussed and put into a broader perspective.

\section{Targeting PPARs to modulate lipid and glucose metabolism}

The first PPAR, PPAR ${ }^{5}$, was discovered in 1990, followed by the discovery of the existence of 3 isotypes, PPAR $\alpha$, PPAR $\gamma$ and PPAR $\delta^{6}$. Since then, numerous studies have been conducted and PPARs received widespread attention as therapeutic targets in T2D and CVD. PPAR $\alpha, \gamma$ and $\delta$ are key regulators of lipid and glucose metabolism. The research in this thesis focuses on PPAR $\alpha$ and PPAR $\gamma$. Synthetic ligands of PPAR $\alpha$ and PPAR $\gamma$ are already used in the clinical practice. Fibrates have been used for a long time to treat hyperlipidemia, due to their potent triglyceride (TG) lowering action via PPAR $\alpha$. Thiazolidinediones, synthetic ligands 
for PPAR $\gamma$, have been used to treat T2D patients by improving their insulin sensitivity. Interestingly, it was also discovered that PPARs can be activated by natural dietary ligands 7 . Fatty acids and their metabolites can act as metabolic regulators by controlling the activity of these lipid-sensing transcription factors. Therefore, the research described in this thesis was conducted to examine the role of PPAR $\alpha$ and PPAR $\gamma$ in various metabolic processes and to identify a potential role for nutrition in modulating these transcription factors.

\subsection{Effects of PPAR agonists on circulating metabolic parameters}

The majority of the effects we found on lipid and glucose metabolism for the studied PPAR ligands (figure 2 ) were consistent with the existing literature. In our study, 8 weeks rosiglitazone treatment $(8 \mathrm{mg} / \mathrm{d})$ improved insulin sensitivity in T2D making these patients again as insulin sensitive as healthy reference subjects (chapter 3). The mechanism underlying this effect is related to an increased glucose uptake and a stimulation of adipocyte differentiation, which creates an increased number of smaller and more insulin sensitive adipocytes. This latter way leads to a preferential shuttling of free fatty acids (FFA) to subcutaneous tissue, which reduces the lipid load in muscle and liver, making these tissues more insulin sensitive. This was also shown by an increased insulin-mediated reduction in FFA and TG. A consequence of the promotion of adipocyte differentiation by rosiglitazone can be an expansion of subcutaneous adipose tissue and subsequent weight gain ${ }^{8}$. Weight gain, however, was not apparent in our study after 8 weeks of rosiglitazone treatment in $\mathrm{T} 2 \mathrm{D}$ patients. Rosiglitazone treatment improved serum lipids, by increasing high-density lipoprotein (HDL) cholesterol and by reducing concentrations of FFA and TG. Most likely, the increase in HDL cholesterol is a result of non-selective or indirect effects of rosiglitazone. It is possible that this agonist can also weakly activate PPAR $\alpha$, increase the expression of transcription factor Hepatic Nuclear Factor $4 \alpha$ (HNF $4 \alpha$ ), or decrease inflammation followed by an elevated ApoA2 production responsible for the increase in HDL cholesterol'. 


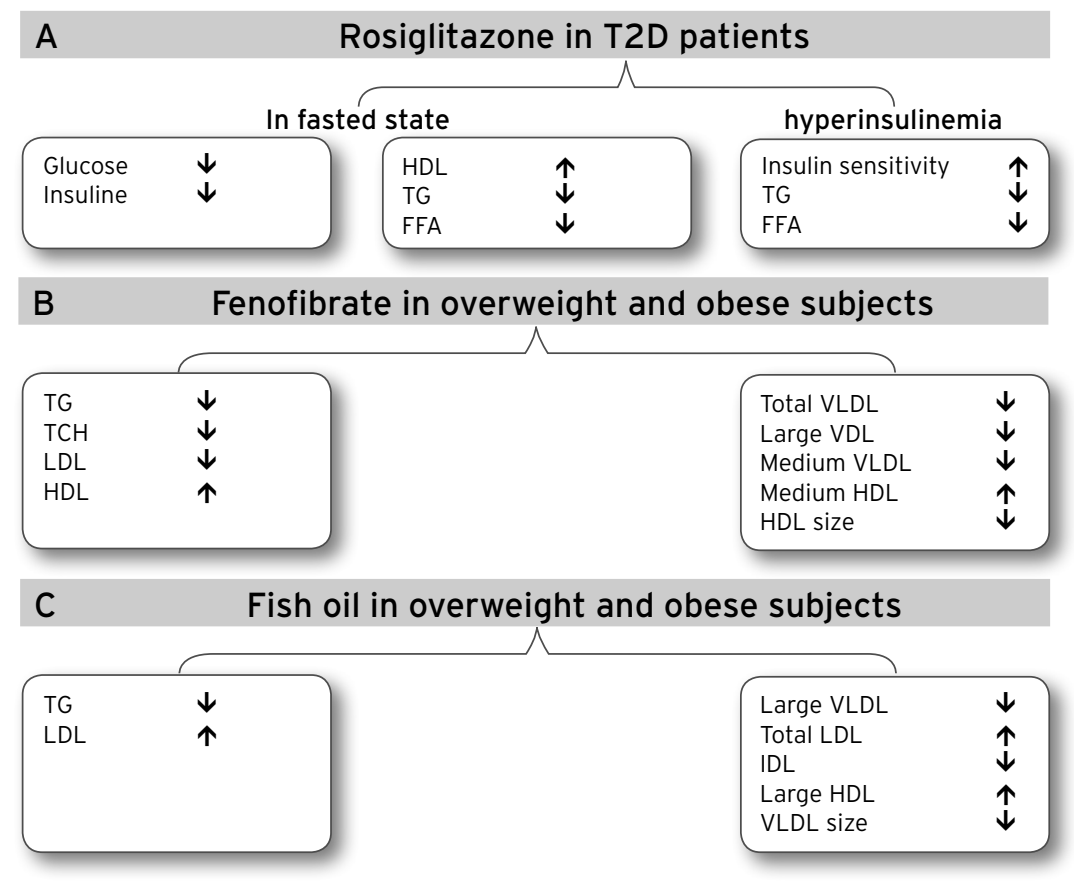

Figure 2. Summary of the effects on serum lipids and lipoprotein particles, plasma glucose and insulin of A) PPAR $\gamma$ agonist rosiglitazone in type 2 diabetic (T2D) subjects, B) PPAR $\alpha$ agonist fenofibrate in overweight and obese subjects and $C$ ) n-3 fatty acids from fish oil as natural, non-specific PPAR ligands in overweight and obese subjects. FFA: free fatty acids, HDL: high-density lipoprotein, IDL: intermediate-density lipoprotein, LDL: low-density lipoprotein, TCH: total cholesterol, TG: triglycerides, VLDL: very low-density lipoproteins.

Consistent with clinical studies with pre-diabetic and diabetic subjects, we did not detect an effect of the synthetic PPAR $\alpha$ agonist fenofibrate on plasma glucose and insulin levels in overweight and obese subjects. This clearly illustrates the isotype-specific functions of PPARs. PPAR $\alpha$ predominantly regulates lipid metabolism and has potent hypotriglyceridemic effects. Indeed, our study showed that fenofibrate treatment $(200 \mathrm{mg} / \mathrm{d})$ for 6 weeks effectively improved the serum lipid profile in overweight and obese subjects (chapter 4 and figure 2 ). The mechanisms underlying these effects are related to an increased clearance of lipids from the circulation. This increased clearance is due to lowering of hepatic ApoCIII production and stimulation of lipoprotein-lipase mediated lipolysis via PPAR $\alpha^{10}$. The combination of increased uptake and catabolism of fatty acids and TG, and reduced TG synthesis will lower serum TG and large TG-rich very low density lipoprotein (VLDL) particles ${ }^{11,12}$. There are multiple proposed mechanisms for the increase in HDL upon fenofibrate, including an increased production of apolipoproteins $A 1$ ( $A p o A 1)$ and $A 2$, and the induction of cholesterol transporter $A B C A 1^{9,13,14}$. Normally when the number of large VLDL particles is reduced, the 
proportion of small atherogenic low density lipoprotein (LDL) is expected to be reduced and that of large HDL increased ${ }^{15}$. However, we could not demonstrate this in our study and showed even a slight decrease in HDL size upon fenofibrate. We do not have an explanation for this discrepancy in findings, but the substantial decrease in number of LDL particles will in this case most likely outweigh the lack of beneficial effect on LDL particle size. Overall, fenofibrate effectively improved the serum lipid profile in overweight and obese subjects.

The main well established effect of fish oil is its TG lowering effect. Many studies have reported that this action of fish oil is mediated via the same PPAR $\alpha$ dependent mechanism as described for fenofibrate ${ }^{16-18}$. On the contrary, there are also studies showing TG lowering in fish oil fed PPAR $\alpha$-deficient mice and mice on PPAR $\alpha$ antagonists and fish-oil diet fed mice, suggesting the presence of a PPAR $\alpha$ independent pathway in lipid metabolism ${ }^{19,20}$. Regardless of the exact mechanism, our study also confirmed that fish-oil treatment $(1.2 \mathrm{~g} / \mathrm{d}$ docosahexaenoic acid $(\mathrm{DHA})$ and $1.7 \mathrm{~g} / \mathrm{d}$ eicosapentaenoic acid (EPA)) for 6 weeks resulted in a marked $13 \%$ decrease in TG in obese and overweight subjects compared to the placebo group on high oleic sunflower oil (HOSO) (chapter 4). However, this TG-lowering effect was accompanied by a significant increase in LDL cholesterol of $10 \%$. Although the effects of fish oil on LDL cholesterol are inconsistent between the many studies, meta-analyses have shown that LDL cholesterol can indeed increase by $5-10 \%$ in normolipidemic and hyperlipidemic subjects at high dosages of EPA and DHA ${ }^{21,22}$. The impact of fish oil on lipoprotein subclasses has been less extensively studied, but a shift in size distribution from smaller dense to more buoyant and less atherogenic LDL particles has been reported ${ }^{23,24}$. However, we did not find a change in LDL particle size distribution upon fish oil treatment. The reported effects of fish oil on glucose metabolism are inconsistent. We saw a tendency towards increased fasting plasma glucose levels. This may be due to stimulation of hepatic glucose production or to decreasing hepatic insulin secretion by fish oil ${ }^{25}$. Overall, fish oil has beneficial effects on TG levels. However, since fish oil increased LDL cholesterol without improving the quality of LDL particles, caution should be taken using extreme dosages of fish oil in subgroups susceptible for developing CVD.

\subsection{Metabolic genes and pathways affected by PPAR agonists}

Microarray analyses were performed on PBMCs, muscle and white adipose tissue (WAT) samples from eleven subjects who received 6-week treatments with placebo, fish oil and fenofibrate treatment (chapter 5). These tissues are relevant in the multi-factorial etiology of the metabolic syndrome and studying gene expression in these tissues could reveal important (PPAR $\alpha$-regulated) genes and pathways implicated in metabolic risk reduction by pharmacological and dietary treatment. Muscle and white adipose tissue are clearly no primary target tissues of PPAR $\alpha$, given the tissue distribution of PPAR $\alpha^{26}$ and the fact fenofibrate hardly affected any pathways in these tissues. In PBMCs, fenofibrate and fish oil downregulated the pathway involved in fatty acid synthesis, in 
line with the (non-significant) reduction in plasma FFA and reduction in TG. Furthermore, fenofibrate downregulated cholesterol biosynthesis, which is in correspondence with the observed reduction in plasma LDL cholesterol. Yet, some lipid metabolic pathways changed in another direction than expected, such as the downregulation of pathways involved in lipid oxidation.

Although fasting serum TGs were reduced by fenofibrate and fish oil treatment, this did not correspond to a change in expression of the PPAR $\alpha$ target gene lipoprotein lipase, which codes for the enzyme involved in the TG-lowering effects of fibrates ${ }^{27}$. Furthermore, other PPAR $\alpha$ target genes hardly changed in PBMCs, muscle, and WAT. It was at least expected that the well known lipid-related PPAR $\alpha$ target genes, such as fatty acid transporter protein (FATP), AcylCoA synthase and carnitine palmitoyltransferase (CPT) I and II would have been upregulated by fenofibrate and fish oil treatment ${ }^{10,28-30}$. To speculate, these PPAR $\alpha$ target genes may still be involved to explain the TG lowering effect observed after fish oil and fenofibrate treatment, although not in the tissues and cells measured. In this case, these effects are probably almost exclusively mediated by modulating PPAR $\alpha$ target genes in the liver. However, the relevance of the intestine should not be underestimated considering the emerging role of this organ in cholesterol metabolism ${ }^{31-33}$. It may also be possible that changes in gene expression we observed in PBMCs are less related to a direct effect of fenofibrate on these cells, but are secondary to changes in plasma metabolites originating from the liver. For fish oil, human long-term and postprandial studies with fish oil also showed no or hardly any changes in PPAR $\alpha$ target genes ${ }^{34,35}$. In contrast, high levels of FFA resulting from 24-hour fasting did change PPAR $\alpha$ target genes ${ }^{36}$. There is a possibility that TG-lowering by fish oil treatment is regulated by PPAR $\alpha$ independent mechanisms as PPAR $\alpha$ antagonists were not able to influence the lipid-lowering by fish oil in diet-induced obese mice mice ${ }^{20}$.

In addition to lipid metabolic pathways, fenofibrate and fish oil downregulated certain mitochondrial metabolic pathways in PBMC and WAT, including oxidative phosphorylation, branched chain amino acid (BCAA) degradation and Krebs cycle (figure 3 ). The decrease in mitochondrial bioenergetics after fenofibrate treatment seems in line with that in rodent studies ${ }^{37-40}$. This effect is probably caused by a direct interference of fenofibrate with mitochondrial respiration ${ }^{39}$. This may result in the inhibition of oxidative phosphorylation and production of energy in the form of adenosine triphosphate (ATP). Subsequent accumulation of fatty acids and the induction of fatty acylCoA oxidase activity may provide a means to trigger the proliferation of peroxisomes. Substantial increased peroxisome-proliferation in the liver has been implicated in hepatocarcinoma in rodents. Probably, this effect is independent of PPAR $\alpha$. Studies in liver biopsies from humans on fibrate therapy for 2-156 months showed an inconclusive increase in peroxisome proliferation ( $<1.5$ fold), which indicates that humans are not susceptible to PPAR $\alpha$-mediated cancer of liver ${ }^{41}$. On the other hand, the effects of fish oil and fenofibrate on mitochondrial metabolic pathways have been rarely studied in human cell lines or humans. It is not valid to directly translate gene expression data to physiological 
outcomes, especially when measured in PBMCs as surrogate cells, but it may be worthwhile to further investigate the effects of fish oil and fenofibrate on mitochondrial metabolic pathways in humans or human cell lines.

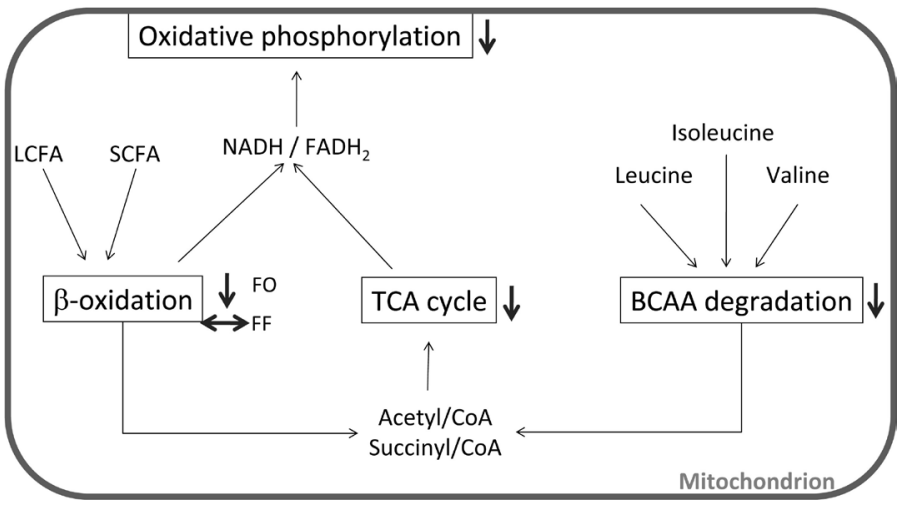

Figure 3. Inter-linked mitochondrial metabolic pathways are downregulated by fish oil and fenofibrate in PBMCs and by fish oil in WAT in overweight and obese subjects. BCAA: branched chain amino acids, FF: fenofibrate, FO: fish oil, LCFA: long-chain fatty acids, SCFA: short chain fatty acids, TCA: tricarboxylic acid.

\section{Inflammation and metabolic diseases: role for PPARs?}

\subsection{PPAR agonists and inflammation control}

Atherosclerosis is a process in which lipid and fibrous material is deposited in the arterial wall in the setting of a low-grade inflammatory state ${ }^{42}$. The metabolic syndrome is also characterized by a chronic state of low-grade inflammation and associated with an increased CVD risk ${ }^{43,44}$. PPARs have been shown to play a role in critical CVD-related processes, but the impact of and the mechanism behind PPAR agonists treatment and CVD outcomes remains under debate ${ }^{45}$. It has been reported that PPAR agonists are able to inhibit pro-inflammatory transcription factors, such as $N F \kappa B$, leading to a downregulation of pro-inflammatory genes and reduction of circulating markers of inflammation ${ }^{46}$. Indeed, we showed in a mechanistic in vitro study in human liver cells that fenofibrate and different fatty acids are able to inhibit NF $\kappa B$ activity, although the effect of fatty acids seems to be independent of PPAR $\alpha$ (chapter 6). Despite the potency of PPAR agonists to inhibit NFKB activity, we did not observe potent anti-inflammatory effects of PPAR agonists that can be linked with CDV reduction in our human intervention studies (figure 4). Only a very few inflammatory markers were inconsistently affected by rosiglitazone (chapter 3 ) and fenofibrate (chapters 4 and 5) treatment, showing both pro- as anti-inflammatory effects. If there is a role for synthetic PPAR agonists in CVD risk reduction, this is probably mainly due to their insulin-sensitizing and/or hypolipidemic effects. The $n-3$ fatty acids EPA 
and DHA have been reported to reduce TG levels at higher dosages (EPA+DHA $3 \mathrm{~g} / \mathrm{d}$ ), similar as given in our study. For cardiovascular risk reduction, however, a lower dosage (EPA+DHA: $1 \mathrm{~g} / \mathrm{d}$ ) that hardly affects serum TGs is advised. This recommendation was based on an observed 20-30\% reduction of CVD mortality in long-term secondary prevention trials. Despite the high dosage of EPA and DHA that we used and the large hypotriglyceridemic effect that was shown, we did not demonstrate in overweight and obese subjects any improvements in any measure of circulating marker of inflammation after 6-weeks fish oil supplementation (chapter 4 ). These results are in correspondence with findings from other studies with dosages ranging from 1.1 and $6.6 \mathrm{~g} / \mathrm{d}$ of $n-3$ LCPUFAs ${ }^{47-51}$. In line, a recent study by Skulas-Ray et al. did not show any effects of a 8-weeks treatment low $(0.85 \mathrm{~g} / \mathrm{d})$ and high $(3.5 \mathrm{~g} / \mathrm{d})$ dosage of EPA+DHA on inflammation, endothelial function in healthy persons with moderate hypertriglyceridemia in a placebo-controlled, randomized double-blind cross-over trial, despite the $27 \%$ TG-lowering by the high dosage ${ }^{52}$. Furthermore, they found no changes in expression of inflammatory cytokine genes in PBMCs of these patients. Except for a downregulation of the TNF-NFKB pathway, we could also not show any changes in inflammatory pathways or individual inflammatory genes in PBMCs after a 6-weeks treatment with $2.9 \mathrm{~g} / \mathrm{d}$ of EPA+DHA treatment in overweight and obese subjects. Evidence that n-3 LCPUFAs from fish oil reduce the risk of CVD is strong, but it is becoming more and more clear that this is not mediated by an improvement of systemic markers of inflammation and vascular activity. Instead, other mechanisms, such as anti-arrhythmic and anti-coagulant properties, are more likely to underlie the CVD protective effect of n-3 LCPUFAs from fish oil. Furthermore, the effect of fish oil also depends on the dose $e^{53-55}$. 


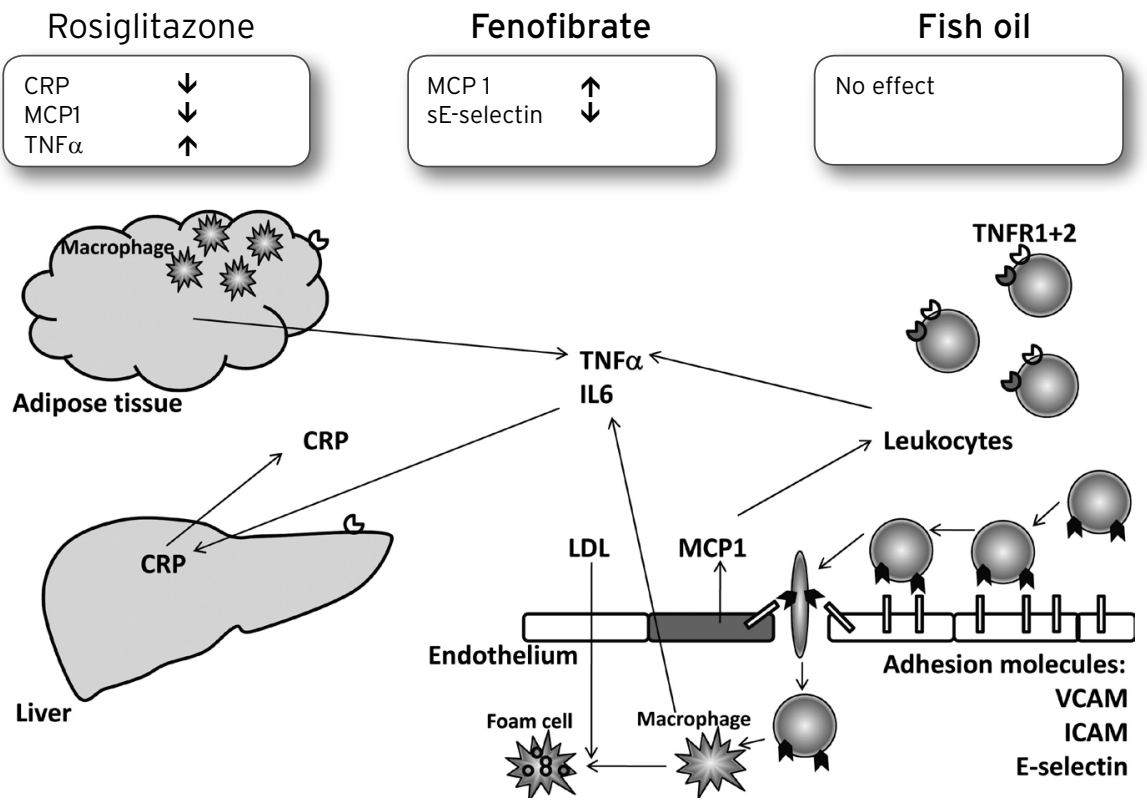

Figure 4. Summary of effects on fasting markers of inflammation and vascular activity of rosiglitazone in T2D patients and of fenofibrate and fish oil in overweight and obese subjects.

Illustrated is the link between the measured markers in relation to the atherosclerotic process. CRP: C-Reactive protein, E-selectin: endothelial selectin, ICAM: intracellular adhesion molecule 1, IL6: interleukin 6, LDL: low-density lipoprotein, MCP1: macrophage chemoattractant protein 1, VCAM: vascular cellular adhesion molecule.

\subsection{Hyperinsulinemia and inflammation}

The question about the role of elevated insulin levels becomes relevant in light of the low-grade pro-inflammatory state associated with insulin resistance, the metabolic syndrome and T2D. Both hyperinsulinemia ${ }^{56-58}$ and hyperglycemia ${ }^{59-61}$ have been held responsible for promoting inflammation. Elevated blood glucose levels have been shown to trigger inflammation markers, including IL6, TNF $\alpha$, and $\mathrm{CRP}^{62}$. This response is more pronounced in diabetic patients compared to non-diabetic controls. Furthermore, the increase of these markers seems to be independent of insulin production. It has even been shown that insulin has the potency to exert anti-inflammatory effects via inhibition of $\mathrm{NF}_{\kappa} \mathrm{B}^{63}$. Indeed, our study also showed that a supra-physiological concentration of insulin during the hyperinsulinemic clamp is not per se related to an increase in inflammatory markers, and even to lowered MCP1 levels in T2D patients and healthy controls (chapter 3 ). Therefore, it is likely that hyperglycemia and not hyperinsulinemia is responsible for the pro-inflammatory state seen in insulin resistant and T2D subjects. 


\subsection{Inflammation and PPARs: a gut feeling?}

There is no doubt that obesity is associated with a subclinical inflammatory state and predisposes to T2D and CVD. However, the factors responsible for the initiation and maintenance of chronic inflammation are not yet clear. More and more evidence points towards an important role of the intestinal environment in metabolic diseases. Besides an altered lipid and glucose metabolism, obesity and T2D are also characterized by changes in gut permeability and changes in intestinal microbiota. Disruption of the gut barrier may lead to bacterial translocation and enhanced uptake of endotoxins (lipopolysaccharides (LPS)) originating from gram-negative bacteria from the lumen. Furthermore, obesity is characterized by a shift in the quantity and proportion of two dominant gut bacteria: Bacteroides and Firmicutes. In the course of obesity, the number of Firmicutes increases over the number of Bacteroides ${ }^{64}$. Although the most favorable gut microflora composition and causality has not yet been defined, changes in microbiota may be important, because it can determine endogenous LPS absorption from gram-negative bacteria in the gut. Endotoxins follow the route of dietary fat, as they are absorbed along with lipids ${ }^{65}$. This is a way in which a chronic high-fat diet can contribute to the development of endotoxemia, leading to a low-grade systemic inflammatory state ${ }^{66}$. LPS can trigger certain receptors, such as NFKB and TLR 4, inducing a signaling cascade leading to the release of pro-inflammatory cytokines. Thereby, low-grade inflammation is maintained and can even be worsened. This metabolic endotoxemia can increase the risk of diabetes and atherosclerosis. Indeed, it has been shown that T2D patients have higher LPS levels than controls ${ }^{67}$.

Striving for a beneficial gut microbiota composition and optimal gut integrity could provide alternative and interesting ways for metabolic risk management in light of the metabolic syndrome. However, more (long-term) clinical trials will be needed to unravel the complex relationship between the intestinal environment and the development of obesity, T2D and CVD. Although evidence is limited, PPARs could also play a potential role herein. It has been shown that rodents subjected to restrained stress show an increase in intestinal permeability, a decrease the absorption capacity, and an increase the level of inflammatory markers ${ }^{68,69}$. There are indications from rodent studies that PPAR $\alpha$ and PPAR $\gamma$ can control intestinal barrier function ${ }^{70}$, and prevent intestinal inflammation and dysfunction ${ }^{68,69}$.

\section{Nutritional versus pharmacological approach to target PPARs}

\subsection{Can a nutritional approach compete with pharmacological approach?}

Fish oil $(2.9 \mathrm{~g} / \mathrm{d}$ EPA+DHA) and fenofibrate $(200 \mathrm{mg} / \mathrm{d})$ exerted similar hypotriglyceridemic effects after 6-weeks supplementation in overweight and obese subjects (chapter 4). It is likely that this effect is mediated via a comparable mechanism of PPAR $\alpha$ activation ${ }^{71}, 72$, but PPAR $\alpha$-independent effects cannot be excluded ${ }^{19}$. In contrast to fish oil, fenofibrate exerted also significant beneficial 
effects on LDL- and HDL-cholesterol concentrations. However, it should be noted that fenofibrate is also able to raise LDL cholesterol levels in a situation of severe hypertriglyceridemia ${ }^{73}$. Fenofibrate and fish oil both lacked consistent beneficial effects on markers of inflammation, questioning their uses as anti-inflammatory agents. However, fenofibrate can potentially ameliorate vascular activity as we showed a decreased sE-selectin concentration. To our knowledge, there are four other studies that have compared the pharmacological intervention with fibrate and a nutritional intervention with fish oil treatment side-by-side. In hyperlipidemic T2D patients, it was shown that a greater hypolipidemic efficacy was achieved by 2 -weeks treatment with the fibrate gemfibrozil $(900 \mathrm{mg} / \mathrm{d}$ ) compared to $\mathrm{n}-3$ LCPUFAs $(4.6 \mathrm{~g} / \mathrm{d})$ and that neither of the treatments affected carbohydrate metabolism ${ }^{74}$. Another study comparing the effects of gemfibrozil $(1200 \mathrm{mg} / \mathrm{d})$ and $\mathrm{n}-3$ fatty acids $(3.2 \mathrm{~g} / \mathrm{d}$ of EPA+DHA) in hypertriglyceridemic patients showed favorable effects of both treatments on lipid and lipoprotein concentrations and the LDL-subfraction profile ${ }^{75}$. However, treatment with n-3 LCPUFAs did increase susceptibility of LDL to oxidation ${ }^{75}$. In HIV-infected patients with moderate hypertriglyceridemia, 18-months of gemfibrozil treatment and n-3 LCPUFA treatment both lowered TG levels, but gemfibrozil with a higher efficacy ${ }^{76}$. A study making the comparison between fenofibrate treatment and n-3 fatty acid treatment for 8 weeks in patients with familial dysbetalipoproteinemia (FDL) and familial hypertriglyceridemia, also included hemorrheological parameters in addition to lipid parameters ${ }^{77}$. This study also showed that both treatments had comparable effects on lipid parameters in both patient groups, but fenofibrate exerted additional beneficial effects on fibrinogen levels and blood viscosity in FDL patients ${ }^{77}$. In line with other studies, we showed that $n-3$ fatty acids from fish oil could compete with fenofibrate with respect to TG lowering in healthy overweight and obese subjects. However, pharmacological dosages of fish oil (2-4 $\mathrm{g} / \mathrm{d}$ ) are needed to obtain this effect ${ }^{21}$, which also exert unbeneficial effects on LDL cholesterol, especially in patients with hypertriglyceridemia.

\subsection{Targeting PPARs: risky business?}

The metabolic characteristics of PPARs and their involvement in metabolic diseases, may make it worthwhile to invest in the therapeutic potential of targeting PPAR activity. This can help in the development of new effective PPARbased therapies to prevent or treat metabolic abnormalities associated with the metabolic syndrome. However, due to the versatile actions of PPARs, it is difficult to reach specific preventive or therapeutic effects without increasing the risk of undesirable side-effects. In our study, we measured specific enzymes and components derived from liver and kidney as safety markers. We showed that a 6-week treatment with fenofibrate in overweight and obese subjects significantly elevated alanine aminotransferase (ALAT) and aspartate aminotransferase (ASAT) (chapter 4), although these markers remained in the normal ranges. On the contrary, fish oil did not negatively influence these markers. As already discussed, we found both beneficial and unbeneficial changes on cardiovascular 
risk markers after fenofibrate and rosiglitazone treatments (chapters 3 and 4).

There is still a gap between pre-clinical data indicating a protective effect of PPAR ligands on cardiovascular disease risk and the effects shown by clinical trials $^{78}$. The great majority of clinical trials with fibrates as PPAR $\alpha$ ligands indeed indicate a reduced risk of cardiovascular events ${ }^{79}$. The effect of thiazolidinediones, especially rosiglitazone, is heavily debated. A meta-analysis by Nissen and Wolfski in 2007 covering 42 clinical trials has shown that rosiglitazone treatment in T2D subjects was associated with a significantly increased risk of myocardial infarction and there was a trend towards an increase in fatal events with cardiovascular cause $^{80}$. After the publication, the accuracy of the methodology used for this meta-analysis was challenged ${ }^{81}$. Results of a large follow-up study on long-term cardiovascular outcome with rosiglitazone treatment (Rosiglitazone Evaluated for Cardiovascular Outcomes in Oral Agent Combination Therapy for Type 2 Diabetes (RECORD) showed inconclusive results with respect to $C V D^{82}$. Nissen and Wolfski updated their meta-analysis, including the RECORD study, and they still showed an increased risk for myocardial infarction, but not for cardiovascular mortality ${ }^{83}$. The debate concerning the safety of TZDs and rosiglitazone is still ongoing, but the European Medicine Agency's (EMA) scientific committee, the Committee for Medicinal Products for Human Use (CHMP) concluded that the benefits of rosiglitazone did not outweigh the risk and that placing these products on market for sale should be stopped ${ }^{81}$.

Synthetic PPAR agonists are also able to modulate the expression of a large number of genes, some of which produce unknown effects. It can be questioned if more selective and more powerful drugs would not result in more robust beneficial effects. This is probably a tough challenge, as two multicenter trials with a far more powerful new synthetic PPAR $\alpha$ agonist did not produce more favorable effects on lipid parameters compared to fenofibrate ${ }^{84}$. The controversy that still exists around safety of synthetic PPAR agonists does not automatically imply that there is no need to look for nutritional modulators of these transcription factors for disease prevention. PPARs did not evolve merely as drug targets, but as lipid targets. A nutritional approach can provide a more subtle strategy to obtain beneficial effects with less side-effects.

\section{Biomarkers for cardiovascular risk prediction}

Over the last decade, many attempts have been made to predict the risk for developing CVD in individuals. The major risk factors identified included age, sex tobacco use, systolic blood pressure, need for anti-hypertensive medication use, diabetes mellitus, and LDL-cholesterol85. Exposure to one or more of these risk factors already associate with $70-80 \%$ of CVD events ${ }^{85}$. The Framingham Risk Score (FRS) is a good and frequently used model to estimates a person's risk of a CHD event over the next 10 years, based on an algorithm that incorporates these traditional risk factors ${ }^{86}$. For many years now, there has been a consensus that a causal relationship exists between high levels of LDL-cholesterol with 
cardiovascular diseases ${ }^{87-90}$. However, this consensus is currently a hot topic of debate, like the role of HDL-cholesterol as a risk factor for CVD ${ }^{91-93}$.

The discovery that inflammation clearly plays a role in type 2 diabetes and $C_{V D}{ }^{42,44}$, has opened a new field of research to establish if inflammation markers can contribute to risk assessment for CVD, which may increase the sensitivity and specificity of risk scores. We measured a wide range of inflammatory markers and markers of vascular activity in the studies described in this thesis, but changes were inconsistent. For example, rosiglitazone treatment in T2D patients reduced CRP and elevated TNF $\alpha$ (chapter 3 ). In overweight and obese subjects, fenofibrate treatment reduced sE-selectin and increased MCP1 (chapter 4). Another approach we used was to study molecular markers of immune function, such as expression the pro-inflammatory transcription factor NFKB and is related genes, as we studied after rosiglitazone treatment in PBMCs of T2D patients (chapter 3). Hardly any gene changed upon treatment and the sparse molecular effects did not reflect the changes in plasma inflammatory markers. Therefore, it is very hard and probably even impossible to say how these changes in molecular and plasma immune function markers can be translated to a biologically meaning in relation to prediction of (cardiovascular) health outcome. Whole genome expression studies for discovering predictive molecular biomarkers have had modest success in the field of oncology ${ }^{94}$, but not yet in the field of CVD. For an inflammatory biomarker to become widely accepted, it needs multiple studies in various populations showing that it predicts a part of the CVD risk that is not already captured by traditional markers, such as LDL cholesterol. And even then, the applicability for a large population and cost-effectiveness will probably limit the routine use in clinical practice. CRP is such a non-traditional candidate biomarker, which use in clinical practice is expanding ${ }^{95}$. The addition of CRP to the FRS can provide additional prognostic information when evaluating intermediate-risk patients ${ }^{85}$, 96, 97. Although more research is required ${ }^{98}$, CRP may improve classification of subjects with intermediate risk by $12 \%{ }^{97,99}$. Continuous and active research in this field will probably lead to the identification and/or validation of more markers of inflammation, vascular function and thrombosis contributing to and predicting CVD risk that is not yet captured by traditional markers.

\section{Nutrigenomics research and PBMCs}

Functional genomics provided a revolution in science with the sequencing of the entire human genome (Human Genome Project) in the 1990's and the development of high-throughput methods to profile genes (transcriptomics), proteins (proteomics), and metabolites (metabolomics). These techniques were incorporated into nutritional sciences, and nutrigenomics came into existence. This enabled researchers to study responses to diets or single nutrients in relation to health. Expectations of nutrigenomics were very high, predicting effective dietary intervention strategies to restore homeostasis and prevent diet-related diseases, providing a basis for personalized diets ${ }^{100-102}$. Now in 2011, it must be 
concluded that it is still in its infancy and still needs a substantial amount of time to deliver its promises. Applying microarray techniques in studies will generate huge amounts of data, since numerous genes, proteins or metabolites can be measured simultaneously. A caveat of generating enormous datasets is the difficulty in translating the data to a biological meaning, especially considering the complex inter-relationships between genes, gene regulation, proteins and metabolites.

The current status of nutrigenomics in human intervention studies has been comprehensively reviewed by Wittwer et al. ${ }^{103}$. This review indicates that most published human nutrigenomics studies are descriptive of nature and show that dietary components can indeed affect genes, proteins and/or metabolites without providing a comprehensive and detailed interpretation of biological meaning. As for this thesis, interpretation difficulties were also experienced when studying huge gene expression datasets after fenofibrate and fish oil in PBMC, muscle and adipose tissue samples of overweight and obese subjects (chapter 5). Although sophisticated pathway analysis tools are available and used to analyze transcriptomic data, interpretation of the acquired results in relation to expression of genes and subsequent prediction of health outcomes remains very complex ${ }^{104}$.

A drawback of studying whole genome expression is the limited accessibility of human tissue. This is especially the case for the metabolic syndrome, involving many tissues, like liver, muscle and adipose tissue. It has already been shown that PBMCs have an active metabolism ${ }^{105}$ and respond to nutritional interventions, but it is not clear if they as well serve as good surrogate cells reflecting the condition of specific target tissues. As PBMCs also express PPARs, it was worthwhile to study if PBMCs are applicable surrogate with respect to the molecular effects of PPAR agonists (chapter 3 and 5). PBMCs of overweight subjects were found to respond to a nutritional (fish oil) and pharmacological intervention (fenofibrate) by changing their gene expression profile. Especially, lipid metabolic pathways were affected by fenofibrate and fish oil treatment. Reviewing literature on PBMCs as surrogate cells (chapter 2 ) indeed consistently shows the capability of PBMCs to reflect lipid metabolic genes and expression changes in these genes upon hypolipidemic dietary and pharmacological interventions (chapter 2). This seems not the case for inflammation, as changes in inflammation-related genes did not correspond with changes in plasma parameters, or vice versa (chapter $3,4,5)$. This also shows the limitation of transcriptomics that gene expression changes are not necessarily reflected in protein levels and/or protein function ${ }^{103}$.

Despite the several physiological effects we observed after treatment with PPAR $\alpha$ or PPAR $\gamma$ agonists, these effects were not or only very marginal reflected by an increased expression of PPAR target genes in PBMCs. This is in correspondence to another study providing $1.8 \mathrm{~g} / \mathrm{d}$ of EPA/DHA for 26 weeks to healthy Dutch elderly ${ }^{35}$. The lack of effect on PPAR target genes is most probably related to treatment duration, because fasting or postprandial effects of PPAR agonists on PPAR target genes are much more pronounced ${ }^{34,36}$. Results on shortterm exposure may therefore be somewhat misleading, as secondary effects of 
longer-term exposure can mask the direct effect on PPAR target genes. Also of relevance is that PBMCs consist of a heterogeneous cell population, with each population having its own function and its own specific transcriptome. It has also been shown that PPARs influence these distinct cell types in different ways ${ }^{45,106}$. However, the isolation of subpopulations is less feasible, as it requires a larger amount of blood and a substantial longer isolation procedure.

Transcriptomics in PBMCs is still in its infancy, especially with respect to the suitability of PBMCs reflecting other inaccessible tissues ${ }^{107}$. From literature, PBMCs seems most promising in reflecting the liver on a molecular level with respect to lipid metabolic pathways (chapter 2). Recently, it was also reported that PBMCs express a large proportion of transcripts at comparable levels that are found in smooth muscle cells after n-3 PUFA supplementation ${ }^{108}$. However, this study had no control group or baseline samples to investigate the response to n-3 PUFAs. We showed only very little overlap in gene expression changes between WAT, muscle and PBMCs (chapter 5). However, there might be a possible role for PBMCs as surrogate cells for WAT, due to the large resemblance in altered pathways after fish oil treatment.

Certainly, nutrigenomics brought nutritional research to a higher level, but is not yet fully exploited. Hopefully, scientists will manage to overcome existing technical and biological problems and improve evaluation and interpretation of datasets. Using a combination of complementary nutrigenomic techniques in human studies, namely transcriptomics, proteomics and metabolomics, together with functional measurements may provide a better understanding of the complex human biological system, how this system is disturbed at the onset of disease, and how it can be modulated by nutrition.

\section{Conclusions and recommendations}

The studies described in this thesis show that PPAR $\alpha$ and $\gamma$ agonists are able to exert beneficial modulate metabolic risk factors in type 2 diabetic and overweight subjects. In some instances, nutritional PPAR $\alpha$ agonists may provide an alternative for synthetic agonists, as we show that both fish oil as fenofibrate can exert a comparable TG lowering effect. However, the comparison does not go beyond this effect and high pharmacological dosages of fish oil are needed for this effect. Lower dosages are recommended, as it seems that the cardioprotective effects are more likely mediated via anti-arrhythmic and anticoagulant properties. A low-grade inflammatory state is often associated with the metabolic syndrome and in vitro studies showed the ability of PPAR agonists to block pro-inflammatory transcription factor NFKB. Nevertheless, rosiglitazone, fenofibrate and fish oil treatment hardly and inconsistently affected markers of inflammation in humans. PPAR agonists are able to induce gene expression changes in PBMCs, although these changes seem not to be a reflection of direct effects of PPAR activation. Furthermore, there is only very little overlap in gene expression changes between PBMCs, WAT, and muscle after fish oil and fenofibrate treatment. Nevertheless, PBMCs might have potency to serve as 


\section{surrogate cells for WAT for gene expression analysis, since they showed a large overlap in regulated pathways.}

\section{References}

1 Balkau B, Vernay $M$, Mhamdi $L$, et al. The incidence and persistence of the NCEP (National Cholesterol Education Program) metabolic syndrome. The French D.E.S.I.R. study. Diabetes Metab, 2003; 29: 526-532.

2 Weiss R, Dziura J, Burgert TS, et al. Obesity and the metabolic syndrome in children and adolescents. N Engl J Med, 2004; 350: 2362-2374.

3 Salmenniemi U, Ruotsalainen E, Pihlajamaki J, et al. Multiple abnormalities in glucose and energy metabolism and coordinated changes in levels of adiponectin, cytokines, and adhesion molecules in subjects with metabolic syndrome. Circulation, 2004; 110: 3842-3848.

4 van der Greef J, Stroobant P and van der Heijden R. The role of analytical sciences in medical systems biology. Curr Opin Chem Biol, 2004; 8: 559-565.

5 Issemann I and Green S. Activation of a member of the steroid hormone receptor superfamily by peroxisome proliferators. Nature, 1990; 347: 645-650.

6 Dreyer $\mathrm{C}$, Krey $\mathrm{G}$, Keller $\mathrm{H}$, et al. Control of the peroxisomal beta-oxidation pathway by a novel family of nuclear hormone receptors. Cell, 1992; 68: 879-887.

7 Krey G, Braissant O, L'Horset F, et al. Fatty acids, eicosanoids, and hypolipidemic agents identified as ligands of peroxisome proliferator-activated receptors by coactivator-dependent receptor ligand assay. Mol Endocrinol, 1997; 11: 779-791.

8 Carey DG, Cowin GJ, Galloway GJ, et al. Effect of rosiglitazone on insulin sensitivity and body composition in type 2 diabetic patients [corrected]. Obes Res, 2002; 10: 1008-1015.

9 Millar JS, Ikewaki K, Bloedon LT, et al. The effect of rosiglitazone on HDL metabolismin subjects with metabolic syndrome and low HDL. J Lipid Res, 2011; 52: 136-142.

10 Staels B, Dallongeville J, Auwerx J, et al. Mechanism of action of fibrates on lipid and lipoprotein metabolism. Circulation, 1998; 98: 2088-2093.

11 Forcheron F, Cachefo A, Thevenon S, et al. Mechanisms of the triglyceride- and cholesterol-lowering effect of fenofibrate in hyperlipidemic type 2 diabetic patients. Diabetes, 2002; 51: 3486-3491.

12 Harris WS and Bulchandani D. Why do omega-3 fatty acids lower serum triglycerides? Curr Opin Lipidol, 2006; 17: 387-393.

13 Chinetti G, Lestavel S, Bocher V, et al. PPAR-alpha and PPAR-gamma activators induce cholesterol removal from human macrophage foam cells through stimulation of the ABCA1 pathway. Nat Med, 2001; 7: 53-58.

14 Staels B and Auwerx J. Regulation of apo A-I gene expression by fibrates. Atherosclerosis, 1998; 137 Suppl: S19-23.

15 Deckelbaum RJ, Granot E, Oschry Y, et al. Plasma triglyceride determines structure-composition in low and high density lipoproteins. Arteriosclerosis, 1984; 4: 225-231.

16 Deckelbaum RJ, Worgall TS and Seo T. n-3 fatty acids and gene expression. The American journal of clinical nutrition, 2006; 83: 1520S-1525S.

17 Gani OA. Are fish oil omega-3 long-chain fatty acids and their derivatives peroxisome proliferator-activated receptor agonists? Cardiovasc Diabetol, 2008; 7: 6.

18 Jump DB. N-3 polyunsaturated fatty acid regulation of hepatic gene transcription. Curr Opin Lipidol, 2008; 19: 242-247.

19 Dallongeville J, Bauge E, Tailleux A, et al. Peroxisome proliferator-activated receptor alpha is not rate-limiting for the lipoprotein-lowering action of fish oil. The Journal of biological chemistry, 2001; 276: 4634-4639.

20 Wakutsu M, Tsunoda N, Shiba S, et al. Peroxisome proliferator-activated receptors (PPARs)-independent functions of fish oil on glucose and lipid metabolism in diet-induced obese mice. Lipids Health Dis, 2010; 9: 101.

21 Harris WS. n-3 fatty acids and serum lipoproteins: human studies. The American journal of clinical nutrition, 1997; 65: 1645S-1654S.

22 Balk EM, Lichtenstein $\mathrm{AH}$, Chung $\mathrm{M}$, et al. Effects of omega-3 fatty acids on serum markers of cardiovascular disease risk: A systematic review. Atherosclerosis, 2006. 
23 Bjornheden T, Babyi A, Bondjers G, et al. Accumulation of lipoprotein fractions and subfractions in the arterial wall, determined in an in vitro perfusion system. Atherosclerosis, 1996; 123: 43-56.

24 Tribble DL, Rizzo M, Chait A, et al. Enhanced oxidative susceptibility and reduced antioxidant content of metabolic precursors of small, dense low-density lipoproteins. Am J Med, 2001; 110: 103-110.

25 Glauber $\mathrm{H}$, Wallace $\mathrm{P}$, Griver K, et al. Adverse metabolic effect of omega-3 fatty acids in non-insulin-dependent diabetes mellitus. Annals of internal medicine, 1988; 108: 663-668.

26 Auboeuf $D$, Rieusset $J$, Fajas $L$, et al. Tissue distribution and quantification of the expression of mRNAs of peroxisome proliferator-activated receptors and liver $X$ receptor-alpha in humans: no alteration in adipose tissue of obese and NIDDM patients. Diabetes, 1997; 46: 1319-1327.

27 Heller $\mathrm{F}$ and Harvengt $\mathrm{C}$. Effects of clofibrate, bezafibrate, fenofibrate and probucol on plasma lipolytic enzymes in normolipaemic subjects. Eur J Clin Pharmacol, 1983; 25: 57-63.

28 Fruchart JC. Peroxisome proliferator-activated receptor-alpha activation and high-density lipoprotein metabolism. Am J Cardiol, 2001; 88: 24N-29N.

29 Schoonjans K, Staels B and Auwerx J. Role of the peroxisome proliferator-activated receptor (PPAR) in mediating the effects of fibrates and fatty acids on gene expression. J Lipid Res, 1996; 37: 907-925.

30 Schoonjans $\mathrm{K}$, Watanabe $\mathrm{M}$, Suzuki $\mathrm{H}$, et al. Induction of the acyl-coenzyme A synthetase gene by fibrates and fatty acids is mediated by a peroxisome proliferator response element in the $\mathrm{C}$ promoter. The Journal of biological chemistry, 1995; 270: 19269-19276.

31 Kruit JK, Groen AK, van Berkel TJ, et al. Emerging roles of the intestine in control of cholesterol metabolism. World J Gastroenterol, 2006; 12: 6429-6439.

32 Chapman MJ. Pharmacology of fenofibrate. Am J Med, 1987; 83: 21-25.

33 Dullens SP, Mensink RP, Mariman EC, et al. Differentiated CaCo-2 cells as an in-vitro model to evaluate de-novo apolipoprotein A-I production in the small intestine. Eur J Gastroenterol Hepatol, 2009; 21: 642-649.

34 Bouwens M, Grootte Bromhaar M, Jansen J, et al. Postprandial dietary lipid-specific effects on human peripheral blood mononuclear cell gene expression profiles. The American journal of clinical nutrition, 2010; 91: 208-217.

35 Bouwens $\mathrm{M}$, van de Rest $\mathrm{O}$, Dellschaft $\mathrm{N}$, et al. Fish-oil supplementation induces antiinflammatory gene expression profiles in human blood mononuclear cells. The American journal of clinical nutrition, 2009; 90: 415-424.

36 Bouwens M, Afman LA and Muller M. Fasting induces changes in peripheral blood mononuclear cell gene expression profiles related to increases in fatty acid beta-oxidation: functional role of peroxisome proliferator activated receptor alpha in human peripheral blood mononuclear cells. The American journal of clinical nutrition, 2007; 86: 1515-1523.

37 Brunmair B, Lest A, Staniek K, et al. Fenofibrate impairs rat mitochondrial function by inhibition of respiratory complex I. J Pharmacol Exp Ther, 2004; 311: 109-114.

38 Nadanaciva S, Dykens JA, Bernal A, et al. Mitochondrial impairment by PPAR agonists and statins identified via immunocaptured OXPHOS complex activities and respiration. Toxicol Appl Pharmacol, 2007; 223: $277-287$.

39 Zhou S and Wallace KB. The effect of peroxisome proliferators on mitochondrial bioenergetics. Toxicol Sci, 1999; 48: 82-89.

40 Zungu M, Felix R and Essop MF. Wy-14,643 and fenofibrate inhibit mitochondrial respiration in isolated rat cardiac mitochondria. Mitochondrion, 2006; 6: 315-322.

41 Fidaleo M. Human health risk assessment for peroxisome proliferators: more than 30 years of research. Exp Toxicol Pathol, 2009; 61: 215-221.

42 Ross R. Atherosclerosis is an inflammatory disease. Am Heart J, 1999; 138: S419-420.

43 Esposito K and Giugliano D. The metabolic syndrome and inflammation: association or causation? Nutr Metab Cardiovasc Dis, 2004; 14: 228-232.

44 Libby P. Inflammation and cardiovascular disease mechanisms. The American journal of clinical nutrition, 2006; 83: 456S-460S.

45 Zandbergen F and Plutzky J. PPARalpha in atherosclerosis and inflammation. Biochim Biophys Acta, 2007; 1771: 972-982.

46 Delerive $\mathrm{P}$, Fruchart $\mathrm{J}$ and Staels B. Peroxisome proliferator-activated receptors in inflammation control. J Endocrinol, 2001; 169: 453-459. 
47 Egert S and Stehle P. Impact of $\mathrm{n}-3$ fatty acids on endothelial function: results from human interventions studies. Curr Opin Clin Nutr Metab Care, 2011; 14: 121-131.

48 Chan DC, Watts GF, Barrett PH, et al. Effect of atorvastatin and fish oil on plasma high-sensitivity C-reactive protein concentrations in individuals with visceral obesity. Clin Chem, 2002; 48: 877-883.

49 Jellema A, Plat J and Mensink RP. Weight reduction, but not a moderate intake of fish oil, lowers concentrations of inflammatory markers and PAI-1 antigen in obese men during the fasting and postprandial state. European journal of clinical investigation, 2004; 34: 766-773.

50 Madsen T, Christensen JH, Blom M, et al. The effect of dietary n-3 fatty acids on serum concentrations of C-reactive protein: a dose-response study. $\mathrm{Br} \mathrm{J}$ Nutr, 2003; 89: 517-522.

51 Yusof HM, Miles EA and Calder P. Influence of very long-chain n-3 fatty acids on plasma markers of inflammation in middle-aged men. Prostaglandins Leukot Essent Fatty Acids, 2008; 78: 219-228.

52 Skulas-Ray AC, Kris-Etherton PM, Harris WS, et al. Dose-response effects of omega-3 fatty acids on triglycerides, inflammation, and endothelial function in healthy persons with moderate hypertriglyceridemia. The American journal of clinical nutrition, 2011; 93: 243-252.

53 de Goede J, Geleijnse JM, Boer JM, et al. Marine (n-3) fatty acids, fish consumption, and the 10-year risk of fatal and nonfatal coronary heart disease in a large population of Dutch adults with low fish intake. J Nutr, 2010; 140: 1023-1028.

54 He K, Song Y, Daviglus ML, et al. Accumulated evidence on fish consumption and coronary heart disease mortality: a meta-analysis of cohort studies. Circulation, 2004; 109: 2705-2711.

55 Iso H, Kobayashi M, Ishihara J, et al. Intake of fish and $\mathrm{n} 3$ fatty acids and risk of coronary heart disease among Japanese: the Japan Public Health Center-Based (JPHC) Study Cohort I. Circulation, 2006; 113: 195-202.

56 Fishel MA, Watson GS, Montine TJ, et al. Hyperinsulinemia provokes synchronous increases in central inflammation and beta-amyloid in normal adults. Arch Neurol, 2005; 62: 1539-1544.

57 Krogh-Madsen R, Plomgaard P, Keller $\mathrm{P}$, et al. Insulin stimulates interleukin- 6 and tumor necrosis factor-alpha gene expression in human subcutaneous adipose tissue. American journal of physiology, 2004; 286: E234238.

58 Setola E, Monti LD, Lucotti P, et al. Fasting hyperinsulinemia associates with increased sub-clinical inflammation in first-degree relatives normal glucose tolerant women independently of the metabolic syndrome. Diabetes Metab Res Rev, 2009; 25: 639-646.

59 Chaudhuri A, Janicke D, Wilson MF, et al. Anti-inflammatory and profibrinolytic effect of insulin in acute STsegment-elevation myocardial infarction. Circulation, 2004; 109: 849-854.

60 Dandona P, Aljada A and Mohanty P. The anti-inflammatory and potential anti-atherogenic effect of insulin: a new paradigm. Diabetologia, 2002; 45: 924-930.

61 Dandona P, Chaudhuri A, Ghanim H, et al. Anti-inflammatory effects of insulin and the pro-inflammatory effects of glucose. Seminars in thoracic and cardiovascular surgery, 2006; 18: 293-301.

62 Esposito K, Nappo F, Marfella R, et al. Inflammatory cytokine concentrations are acutely increased by hyperglycemia in humans: role of oxidative stress. Circulation, 2002; 106: 2067-2072.

63 Dandona P, Aljada A, Mohanty $\mathrm{P}$, et al. Insulin inhibits intranuclear nuclear factor kappaB and stimulates IkappaB in mononuclear cells in obese subjects: evidence for an anti-inflammatory effect? J Clin Endocrinol Metab, 2001; 86: 3257-3265.

64 Ley RE, Turnbaugh PJ, Klein S, et al. Microbial ecology: human gut microbes associated with obesity. Nature, 2006; 444: 1022-1023.

65 Amar J, Burcelin R, Ruidavets JB, et al. Energy intake is associated with endotoxemia in apparently healthy men. The American journal of clinical nutrition, 2008; 87: 1219-1223.

66 Cani PD, Bibiloni R, Knauf $\mathrm{C}$, et al. Changes in gut microbiota control metabolic endotoxemia-induced inflammation in high-fat diet-induced obesity and diabetes in mice. Diabetes, 2008; 57: 1470-1481.

67 Creely SJ, McTernan PG, Kusminski CM, et al. Lipopolysaccharide activates an innate immune system response in human adipose tissue in obesity and type 2 diabetes. American journal of physiology, 2007; 292: E740-747.

68 Mazzon E, Crisafulli C, Galuppo M, et al. Role of peroxisome proliferator-activated receptor-alpha in ileum tight junction alteration in mouse model of restraint stress. Am J Physiol Gastrointest Liver Physiol, 2009; 297 : G488-505.

69 Ponferrada A, Caso JR, Alou L, et al. The role of PPARgamma on restoration of colonic homeostasis after experimental stress-induced inflammation and dysfunction. Gastroenterology, 2007; 132: 1791-1803. 
70 de Vogel-van den Bosch HM, Bunger M, de Groot PJ, et al. PPARalpha-mediated effects of dietary lipids on intestinal barrier gene expression. BMC genomics, 2008; 9: 231.

71 Gerber JG, Kitch DW, Fichtenbaum CJ, et al. Fish oil and fenofibrate for the treatment of hypertriglyceridemia in HIV-infected subjects on antiretroviral therapy: results of ACTG A5186. J Acquir Immune Defic Syndr, 2008; 47: 459-466.

72 Roth EM, Bays HE, Forker AD, et al. Prescription omega-3 fatty acid as an adjunct to fenofibrate therapy in hypertriglyceridemic subjects. J Cardiovasc Pharmacol, 2009; 54: 196-203.

73 Bays HE, Tighe AP, Sadovsky R, et al. Prescription omega-3 fatty acids and their lipid effects: physiologic mechanisms of action and clinical implications. Expert Rev Cardiovasc Ther, 2008; 6: 391-409.

74 Fasching $\mathrm{P}$, Rohac M, Liener K, et al. Fish oil supplementation versus gemfibrozil treatment in hyperlipidemic NIDDM. A randomized crossover study. Horm Metab Res, 1996; 28: 230-236.

75 Stalenhoef AF, de Graaf J, Wittekoek ME, et al. The effect of concentrated n-3 fatty acids versus gemfibrozil on plasma lipoproteins, low density lipoprotein heterogeneity and oxidizability in patients with hypertriglyceridemia. Atherosclerosis, 2000; 153: 129-138.

76 Manfredi R, Calza L and Chiodo F. Polyunsaturated ethyl esters of n-3 fatty acids in HIV-infected patients with moderate hypertriglyceridemia: comparison with dietary and lifestyle changes, and fibrate therapy. J Acquir Immune Defic Syndr, 2004; 36: 878-880.

77 Otto C, Ritter MM, Soennichsen AC, et al. Effects of n-3 fatty acids and fenofibrate on lipid and hemorrheological parameters in familial dysbetalipoproteinemia and familial hypertriglyceridemia. Metabolism, 1996; 45: 13051311.

78 van Bilsen $\mathrm{M}$ and van Nieuwenhoven FA. PPARs as therapeutic targets in cardiovascular disease. Expert Opin Ther Targets, 2010; 14: 1029-1045.

79 Remick J, Weintraub H, Setton R, et al. Fibrate therapy: an update. Cardiol Rev, 2008; 16: 129-141.

80 Nissen SE and Wolski K. Effect of rosiglitazone on the risk of myocardial infarction and death from cardiovascular causes. N Engl J Med, 2007; 356: 2457-2471.

81 Blind E, Dunder K, de Graeff PA, et al. Rosiglitazone: a European regulatory perspective. Diabetologia, 2011; 54: 213-218.

82 Home PD, Pocock SJ, Beck-Nielsen H, et al. Rosiglitazone evaluated for cardiovascular outcomes in oral agent combination therapy for type 2 diabetes (RECORD): a multicentre, randomised, open-label trial. Lancet, 2009; 373: 2125-2135.

83 Nissen SE and Wolski K. Rosiglitazone Revisited: An Updated Meta-analysis of Risk for Myocardial Infarction and Cardiovascular Mortality. Arch Intern Med, 2010.

84 Nissen SE, Nicholls SJ, Wolski K, et al. Effects of a potent and selective PPAR-alpha agonist in patients with atherogenic dyslipidemia or hypercholesterolemia: two randomized controlled trials. Jama, 2007; 297: 13621373.

85 Wilkins JT and Lloyd-Jones DM. Biomarkers for coronary heart disease clinical risk prediction: a critical appraisal. Counterpoint. Prev Cardiol, 2010; 13: 160-165.

86 Wilson PW, D'Agostino RB, Levy D, et al. Prediction of coronary heart disease using risk factor categories. Circulation, 1998; 97: 1837-1847.

87 Hausenloy DJ and Yellon DM. Enhancing cardiovascular disease risk reduction: raising high-density lipoprotein levels. Curr Opin Cardiol, 2009; 24: 473-482.

88 Jakobsen MU, O'Reilly EJ, Heitmann BL, et al. Major types of dietary fat and risk of coronary heart disease: a pooled analysis of 11 cohort studies. The American journal of clinical nutrition, 2009; 89: 1425-1432.

89 Sacks FM and Katan M. Randomized clinical trials on the effects of dietary fat and carbohydrate on plasma lipoproteins and cardiovascular disease. Am J Med, 2002; 113 Suppl 9B: 13S-24S.

90 Astrup A, Dyerberg J, Elwood P, et al. The role of reducing intakes of saturated fat in the prevention of cardiovascular disease: where does the evidence stand in 2010? The American journal of clinical nutrition, 2011.

91 Siri-Tarino PW, Sun Q, Hu FB, et al. Meta-analysis of prospective cohort studies evaluating the association of saturated fat with cardiovascular disease. The American journal of clinical nutrition, 2010; 91: 535-546.

92 Robinson JG. Low high-density lipoprotein cholesterol and chronic disease risk. Marker or causal? J Am Coll Cardiol, 2010; 55: 2855-2857. 
93 Mensink RP. Dietary Fatty Acids and Cardiovascular Health - An Ongoing Controversy. Ann Nutr Metab; 58 : 66-67.

94 Mehta R, Jain RK and Badve S. Personalized medicine: the road ahead. Clin Breast Cancer, 2011; 11: 20-26.

95 Windgassen $E$, Funtowics $L$, Lunsford $T$, et al. C-reactive protein and high sensitive c-reactive protein: an update for clinicians. Postgrad Med, 2011; 123: 114-119.

96 Cushman M, Arnold AM, Psaty BM, et al. C-reactive protein and the 10-year incidence of coronary heart disease in older men and women: the cardiovascular health study. Circulation, 2005; 112: 25-31.

97 Rana JS, Cote M, Despres JP, et al. Inflammatory biomarkers and the prediction of coronary events among people at intermediate risk: the EPIC-Norfolk prospective population study. Heart, 2009; 95: 1682-1687.

98 Targher G. High-Sensitivity C-Reactive Protein, Obesity, and Subclinical Atherosclerosis: Implications of JUPITER From the MESA Study. Arterioscler Thromb Vasc Biol, 2011; 31: 1251-1252.

99 Wilson PW, Pencina M, Jacques $\mathrm{P}$, et al. C-reactive protein and reclassification of cardiovascular risk in the Framingham Heart Study. Circ Cardiovasc Qual Outcomes, 2008; 1: 92-97.

100 Muller M and Kersten S. Nutrigenomics: goals and strategies. Nat Rev Genet, 2003; 4: 315-322.

101 Kaput J. Diet-disease gene interactions. Nutrition, 2004; 20: 26-31.

102 Ordovas JM and Mooser V. Nutrigenomics and nutrigenetics. Curr Opin Lipidol, 2004; 15: 101-108.

103 Wittwer J, Rubio-Aliaga I, Hoeft B, et al. Nutrigenomics in human intervention studies: Current status, lessons learned and future perspectives. Mol Nutr Food Res, 2011; 55: 341-358.

104 Shi L, Perkins RG, Fang H, et al. Reproducible and reliable microarray results through quality control: good laboratory proficiency and appropriate data analysis practices are essential. Curr Opin Biotechnol, 2008; 19: 10-18.

105 Kussmann M, Raymond F and Affolter M. OMICS-driven biomarker discovery in nutrition and health. J Biotechnol, 2006; 124: 758-787.

106 Szeles L, Torocsik D and Nagy L. PPARgamma in immunity and inflammation: cell types and diseases. Biochim Biophys Acta, 2007; 1771: 1014-1030.

107 Hofmann T, Klenow S, Borowicki A, et al. Gene expression profiles in human peripheral blood mononuclear cells as biomarkers for nutritional in vitro and in vivo investigations. Genes Nutr, 2010; 5: 309-319.

108 Rudkowska I, Raymond C, Ponton A, et al. Validation of the use of peripheral blood mononuclear cells as surrogate model for skeletal muscle tissue in nutrigenomic studies. Omics, 2011; 15: 1-7. 

Additional files 

Additional file 1 - NF $\kappa B$-related genes measured with the NFKB RT ${ }^{2}$ Profiler PCR array

\begin{tabular}{|c|c|c|}
\hline Gene name & Gene function & Unigene code \\
\hline AGT & Angiotensinogen (serpin peptidase inhibitor, clade $A$, member 8) & Hs.19383 \\
\hline AKT1 & V-akt murine thymoma viral oncogene homolog 1 & Hs.525622 \\
\hline ATF1 & Activating transcription factor 1 & Hs. 435267 \\
\hline BCL10 & B-cell CLL/lymphoma 10 & Hs.567382 \\
\hline $\mathrm{BCL3}$ & B-cell CLL/lymphoma 3 & Hs. 31210 \\
\hline $\mathrm{BF}$ & B-factor, properdin & Hs.69771 \\
\hline BIRC2 & Baculoviral IAP repeat-containing 2 & Hs.503704 \\
\hline CARD4 & Caspase recruitment domain family, member 4 & Hs.405153 \\
\hline CASP1 & Caspase 1 , apoptosis-related cysteine peptidase (interleukin 1, beta, convertase) & Hs.2490 \\
\hline CASP8 & Caspase 8 , apoptosis-related cysteine peptidase & Hs.369736 \\
\hline CCL2 & Chemokine (C-C motif) ligand 2 & Hs.303649 \\
\hline CD40 & CD40 antigen (TNF receptor superfamily member 5 ) & Hs. 472860 \\
\hline CFLAR & CASP8 and FADD-like apoptosis regulator & Hs.390736 \\
\hline CHUK & Conserved helix-loop-helix ubiquitous kinase & Hs.198998 \\
\hline CSF2\# & Colony stimulating factor 2 (granulocyte-macrophage) & Hs.1349 \\
\hline $\mathrm{CSF}^{\#}$ & Colony stimulating factor 3 (granulocyte) & Hs.2233 \\
\hline SLC44A2 & Solute carrier family 44 , member 2 & Hs.515134 \\
\hline EDARADD & EDAR-associated death domain & Hs.352224 \\
\hline EDG2 & Endothelial differentiation, Iysophosphatidic acid G-protein-coupled receptor, 2 & Hs.126667 \\
\hline $\mathrm{EGR}^{\#}$ & Early growth response 1 & Hs.326035 \\
\hline ELK1" & ELK1, member of ETS oncogene family & Hs.181128 \\
\hline $\mathrm{F} 2 \mathrm{R}$ & Coagulation factor II (thrombin) receptor & Hs.482562 \\
\hline FADD & Fas (TNFRSF6)-associated via death domain & Hs.86131 \\
\hline FASLG & Fas ligand (TNF superfamily, member 6 ) & Hs.2007 \\
\hline FOS & V-fos FBJ murine osteosarcoma viral oncogene homolog & Hs.25647 \\
\hline GJA1 & Gap junction protein, alpha 1, 43kDa (connexin 43) & Hs.74471 \\
\hline HMOX1 & Heme oxygenase (decycling) 1 & Hs.517581 \\
\hline HTR2B & 5-hydroxytryptamine (serotonin) receptor $2 \mathrm{~B}$ & Hs.421649 \\
\hline ICAM1 & Intercellular adhesion molecule 1 (CD54), human rhinovirus receptor & Hs.515126 \\
\hline IFNA1 ${ }^{\#}$ & Interferon, alpha 1 & Hs.37026 \\
\hline IFNB1 & Interferon, beta 1, fibroblast & Hs.93177 \\
\hline IFNG & Interferon, gamma & Hs.856 \\
\hline IKBKB & Inhibitor of kappa light polypeptide gene enhancer in B-cells, kinase beta & Hs. 413513 \\
\hline IKBKE & Inhibitor of kappa light polypeptide gene enhancer in B-cells, kinase epsilon & Hs.321045 \\
\hline IKBKG & Inhibitor of kappa light polypeptide gene enhancer in B-cells, kinase gamma & Hs.43505 \\
\hline IL10\# & Interleukin 10 & Hs.193717 \\
\hline IL1A & Interleukin 1, alpha & Hs.1722 \\
\hline IL1B & Interleukin 1, beta & Hs.126256 \\
\hline IL1R1 & Interleukin 1 receptor, type I & Hs.557403 \\
\hline IL6 & Interleukin 6 (interferon, beta 2) & Hs. 512234 \\
\hline IL8 & Interleukin 8 & Hs.624 \\
\hline IRAK1 & Interleukin-1 receptor-associated kinase 1 & Hs.522819 \\
\hline IRAK2 & Interleukin-1 receptor-associated kinase 2 & Hs.449207 \\
\hline JUN & V-jun sarcoma virus 17 oncogene homolog (avian) & Hs.525704 \\
\hline
\end{tabular}




\begin{tabular}{|c|c|c|}
\hline Gene name & Gene function & Unigene code \\
\hline LTA & Lymphotoxin alpha (TNF superfamily, member 1) & Hs.36 \\
\hline LTBR & Lymphotoxin beta receptor (TNFR superfamily, member 3) & Hs.1116 \\
\hline MALT1 & Mucosa associated lymphoid tissue lymphoma translocation gene 1 & Hs.180566 \\
\hline MAP3K1 & Mitogen-activated protein kinase kinase kinase 1 & Hs. 508461 \\
\hline MYD88 & Myeloid differentiation primary response gene (88) & Hs.82116 \\
\hline NALP12 & NACHT, leucine rich repeat and PYD containing 12 & Hs.367965 \\
\hline NFKB1 & Nuclear factor of kappa light polypeptide gene enhancer in B-cells 1 (p105) & Hs.431926 \\
\hline NFKB2 & Nuclear factor of kappa light polypeptide gene enhancer in B-cells 2 (p49/p100) & Hs.73090 \\
\hline NFKBIA & Nuclear factor of kappa light polypeptide gene enhancer in B-cells inhibitor, alpha & Hs.81328 \\
\hline PPM1A & Protein phosphatase $1 \mathrm{~A}$ (formerly $2 \mathrm{C}$ ), magnesium-dependent, alpha isoform & Hs.130036 \\
\hline RAF1 & V-raf-1 murine leukemia viral oncogene homolog 1 & Hs.159130 \\
\hline REL & V-rel reticuloendotheliosis viral oncogene homolog (avian) & Hs.370620 \\
\hline RELA & $\begin{array}{l}\text { V-rel reticuloendotheliosis viral oncogene homolog A, nuclear factor of kappa light } \\
\text { polypeptide gene enhancer in B-cells 3, p65 (avian) }\end{array}$ & Hs.502875 \\
\hline RELB & $\begin{array}{l}\text { V-rel reticuloendotheliosis viral oncogene homolog B, nuclear factor of kappa light } \\
\text { polypeptide gene enhancer in B-cells } 3 \text { (avian) }\end{array}$ & Hs.307905 \\
\hline RFP2 & Ret finger protein 2 & Hs.436922 \\
\hline $\mathrm{RHOA}$ & Ras homolog gene family, member $\mathrm{A}$ & Hs.247077 \\
\hline RIPK1 & Receptor (TNFRSF)-interacting serine-threonine kinase 1 & Hs. 519842 \\
\hline SLC20A1 & Solute carrier family 20 (phosphate transporter), member 1 & Hs.187946 \\
\hline STAT1 & Signal transducer and activator of transcription $1,91 \mathrm{kDa}$ & Hs.470943 \\
\hline TBK1 & TANK-binding kinase 1 & Hs. 505874 \\
\hline TICAM2 & Toll-like receptor adaptor molecule 2 & Hs.278391 \\
\hline TLR1 & Toll-like receptor 1 & Hs.111805 \\
\hline TLR2 & Toll-like receptor 2 & Hs.519033 \\
\hline TLR3 & Toll-like receptor 3 & Hs.29499 \\
\hline TLR4 & Toll-like receptor 4 & Hs.174312 \\
\hline TLR6 & Toll-like receptor 6 & Hs.366986 \\
\hline TLR7 & Toll-like receptor 7 & Hs.443036 \\
\hline TLR8 & Toll-like receptor 8 & Hs. 272410 \\
\hline TLR9 & Toll-like receptor 9 & Hs.87968 \\
\hline TMED4 & Transmembrane emp24 protein transport domain containing 4 & Hs. 510745 \\
\hline TNF & Tumor necrosis factor (TNF superfamily, member 2) & Hs.241570 \\
\hline TNFAIP3 & Tumor necrosis factor, alpha-induced protein 3 & Hs.211600 \\
\hline TNFRSF10A & Tumor necrosis factor receptor superfamily, member 10a & Hs.401745 \\
\hline TNFRSF10B & Tumor necrosis factor receptor superfamily, member $10 \mathrm{~b}$ & Hs.521456 \\
\hline TNFRSF1A & Tumor necrosis factor receptor superfamily, member $1 \mathrm{~A}$ & Hs.279594 \\
\hline TNFRSF7 & Tumor necrosis factor receptor superfamily, member 7 & Hs. 355307 \\
\hline TNFSF10 & Tumor necrosis factor (ligand) superfamily, member 10 & Hs. 478275 \\
\hline TNFSF14\# & Tumor necrosis factor (ligand) superfamily, member 14 & Hs.129708 \\
\hline TRADD & TNFRSF1A-associated via death domain & Hs.460996 \\
\hline TICAM1 & Toll-like receptor adaptor molecule 1 & Hs.29344 \\
\hline
\end{tabular}


Additional file 2 List of measured PPAR $\alpha$ target genes

\begin{tabular}{|c|c|c|}
\hline Gene & Entrez ID & Gene description \\
\hline ACADL & 33 & acyl-Coenzyme A dehydrogenase, long chain \\
\hline ACADM & 34 & acyl-Coenzyme A dehydrogenase, C-4 to C-12 straight chain \\
\hline ACOX1 & 51 & acyl-Coenzyme A oxidase 1, palmitoyl \\
\hline $\mathrm{ACOX} 2$ & 8309 & acyl-Coenzyme A oxidase 2 , branched chain \\
\hline $\mathrm{ACOX} 3$ & 8310 & acyl-Coenzyme A oxidase 3, pristanoyl \\
\hline ACSL1 & 2180 & acyl-CoA synthetase long-chain family member 1 \\
\hline ACSL3 & 2181 & acyl-CoA synthetase long-chain family member 3 \\
\hline ACSL5 & 51703 & acyl-CoA synthetase long-chain family member 5 \\
\hline ACSL6 & 23305 & acyl-CoA synthetase long-chain family member 6 \\
\hline ADIPOQ & 9730 & adiponectin, $\mathrm{C} 1 \mathrm{Q}$ and collagen domain containing \\
\hline ANGPTL4 & $51120=9$ & angiopoietin-like 4 \\
\hline APOA1 & 335 & apolipoprotein A-I \\
\hline APOA2 & 336 & apolipoprotein A-II \\
\hline APOA5 & 116519 & apolipoprotein A-V \\
\hline APOC3 & 345 & apolipoprotein C-III \\
\hline AQP7 & 364 & aquaporin 7 \\
\hline CD36 & 948 & CD36 molecule (thrombospondin receptor) \\
\hline CPT1A & 1374 & carnitine palmitoyltransferase 1 A (liver) \\
\hline CPT1B & 1375 & carnitine palmitoyltransferase 1B (muscle) \\
\hline CPT1C & 126129 & carnitine palmitoyltransferase $1 \mathrm{C}$ \\
\hline CPT2 & 1376 & carnitine palmitoyltransferase II \\
\hline CYP27A1 & 1593 & cytochrome $\mathrm{P} 450$, family 27 , subfamily $A$, polypeptide 1 \\
\hline CYP7A1 & 1581 & cytochrome P450, family 7, subfamily A, polypeptide 1 \\
\hline CYP8B1 & 1582 & cytochrome P450, family 8, subfamily B, polypeptide 1 \\
\hline $\mathrm{DBI}$ & 1622 & diazepam binding inhibitor (GABA receptor modulator, acyl-Coenzyme A binding protein) \\
\hline EHHADH & 1962 & enoyl-Coenzyme A, hydratase/3-hydroxyacyl Coenzyme A dehydrogenase \\
\hline FABP1 & 2168 & fatty acid binding protein 1 , liver \\
\hline FABP2 & 2169 & fatty acid binding protein 2 , intestinal \\
\hline FABP4 & 2167 & fatty acid binding protein 4 , adipocyte \\
\hline FABP6 & 2172 & fatty acid binding protein 6 , ileal (gastrotropin) \\
\hline FABP7 & 2173 & fatty acid binding protein 7 , brain \\
\hline FADS2 & 9415 & fatty acid desaturase 2 \\
\hline GK2 & 2712 & glycerol kinase 2 \\
\hline HMGCS2 & 3158 & 3-hydroxy-3-methylglutaryl-Coenzyme A synthase 2 (mitochondrial) \\
\hline ILK & 3611 & integrin-linked kinase \\
\hline LPL & 4023 & lipoprotein lipase \\
\hline NR1H3 & 10062 & nuclear receptor subfamily 1 , group $\mathrm{H}$, member 3 \\
\hline OLR1 & 4973 & oxidized low density lipoprotein (lectin-like) receptor 1 \\
\hline PCK1 & 5105 & phosphoenolpyruvate carboxykinase 1 (soluble) \\
\hline PCK2 & 5106 & phosphoenolpyruvate carboxykinase 2 (mitochondrial) \\
\hline PDPK1 & 5170 & 3-phosphoinositide dependent protein kinase-1 \\
\hline PLTP & 5360 & phospholipid transfer protein \\
\hline PPARA & 5465 & peroxisome proliferator-activated receptor alpha \\
\hline PPARD & 5467 & peroxisome proliferator-activated receptor delta \\
\hline PPARG & 5468 & peroxisome proliferator-activated receptor gamma \\
\hline RXRA & 6256 & retinoid $\mathrm{X}$ receptor, alpha \\
\hline RXRB & 6257 & retinoid $X$ receptor, beta \\
\hline RXRG & 6258 & retinoid $\mathrm{X}$ receptor, gamma \\
\hline SLC27A1 & 376497 & solute carrier family 27 (fatty acid transporter), member 1 \\
\hline SLC27A2 & 11001 & solute carrier family 27 (fatty acid transporter), member 2 \\
\hline SLC27A4 & 10999 & solute carrier family 27 (fatty acid transporter), member 4 \\
\hline SLC27A5 & 10998 & solute carrier family 27 (fatty acid transporter), member 5 \\
\hline SLC27A6 & 28965 & solute carrier family 27 (fatty acid transporter), member 6 \\
\hline SORBS1 & 10580 & sorbin and $\mathrm{SH} 3$ domain containing 1 \\
\hline$\overline{U B C}$ & 7316 & ubiquitin $\mathrm{C}$ \\
\hline UCP1 & 7350 & uncoupling protein 1 (mitochondrial, proton carrier) \\
\hline
\end{tabular}





\section{SuMmary}





\section{Summary}

The incidence of the metabolic syndrome is rapidly increasing world-wide and predisposes to the development of type 2 diabetes (T2D) and cardiovascular diseases (CVD). Obesity is often associated with various risk factors characterizing the metabolic syndrome, such as abnormal lipid and carbohydrate metabolism and a pro-inflammatory state of the body. Peroxisome proliferator activated receptors (PPARs) $\alpha$ and $\gamma$ are interesting molecular targets in metabolic risk management, as these receptors are involved in many metabolic pathways and present in various tissues. They can be activated by drugs and dietary fatty acids. Comparing a pharmacological and a nutritional approach to target PPARs may reveal a potential role for nutrition in modulating these transcription factors to ameliorate metabolic disturbances. Applying a nutrigenomics approach is an interesting way to explore the molecular effects of pharmacological and nutritional challenges on the metabolic state or condition of specific target tissues. However, access to specific metabolically relevant target tissues, such as muscle and adipose tissue, is complicated in humans. Therefore, it would be advantageous to be able to use the ready accessible peripheral blood mononuclear cells (PBMCs). PBMCs also express PPARs, making them of interest to study the molecular effects of these transcription factors.

The major objective of the studies described in this thesis was to examine the physiological and molecular effects of PPARs in various metabolic processes and to identify a potential role for nutritional fatty acids in modulating these transcription factors. The second objective was to evaluate the suitability of PBMCs as surrogate cells for tissues to reflect PPAR-related gene expression and gene expression in general.

\section{Lipid, lipoprotein and glucose metabolism}

PPAR $\alpha$ predominantly regulates lipid metabolism and effectively lowers blood triglyceride concentration. This hypotriglyceridemic effect is ascribed to a PPARmediated increase in activity of the enzyme lipoprotein lipase (LPL) and subsequent breakdown of triglycerides. In our 6-week intervention with fish oil (3.7 g/d n-3 long chain polyunsaturated fatty acids) and fenofibrate $(200 \mathrm{mg} / \mathrm{d})$ in overweight and obese subjects, we indeed found strong hypotriglyceridemic effects for both treatments. This was accompanied by reductions in large very low density lipoprotein (VLDL) particles. Fenofibrate further improved the serum lipid profile, as also low density lipoprotein (LDL) cholesterol concentrations decreased and high density lipopreitein (HDL) cholesterol increased. In contrast to fenofibrate, fish oil increased LDL cholesterol concentrations. For fish oil and fenofibrate treatment, it was expected that the LDL particle size would change to a more buoyant and less atherogenic type, but we could not confirm this in our study. Neither fenofibrate nor fish oil exerted effects on plasma glucose concentrations.

PPAR $\gamma$ is mainly known for its insulin-sensitizing effects, which is related to an increased glucose uptake and stimulation of adipocyte differentiation to create more smaller and insulin sensitive adipocytes. Indeed, our intervention study of an 8-week treatment with the synthetic PPAR $\gamma$ agonist rosiglitazone $(8 \mathrm{mg} / \mathrm{d})$ improved insulin sensitivity in type 2 diabetic patients, making these patients as insulin sensitive as healthy reference subjects. Furthermore, rosiglitazone also improved the serum lipid 
profile, as shown by reduced serum triglycerides and free fatty acids and by increased HDL cholesterol concentrations.

\section{Markers of inflammation and vascular activity}

The metabolic syndrome is also characterized by a state of low-grade inflammation, although this is not part of its official diagnostic criteria. Since inflammation has been implicated in the development of type 2 diabetes and cardiovascular diseases, it is of relevance to prevent this. It has been reported that PPAR $\alpha$ and $\gamma$ agonists are able to inhibit proinflammatory transcription factors, such as nuclear factor $\kappa B(N F \kappa B)$. The cardioprotective effect of fish oil has also been partly described to a reduction in markers of low-grade inflammation. In our mechanistic in vitro study in human liver (HepG2) cells, we showed that fenofibrate and different fatty acids were indeed able to inhibit NFKB activation, although the effects of fatty acids seemed to be largely independent of PPAR $\alpha$. Despite this finding, we did not observe potent anti-inflammatory effects of PPAR agonists that can be linked with CVD reduction in our human intervention studies. Only very few plasma inflammatory and vascular activity markers were, inconsistently, affected by rosiglitazone, fenofibrate and fish oil, showing both pro- and anti-inflammatory effects. Rosiglitazone decreased macrophage chemoattractant protein 1 (MCP1) and C-reactive protein (CRP), but increased tumor necrosis factor $\alpha$ (TNF $\alpha$ ) in type 2 diabetic patients. Fenofibrate reduced soluble endothelial selectin (sE-selectin), but increased MCP1 in overweight and obese subjects and no changes were seen upon fish oil treatment.

\section{Gene expression}

PBMCs can be seen as sentinels that travel trough the body and pick up physiological signals. It has been shown that PBMCs have an active metabolism, express PPARs and are able to respond to nutritional interventions. However, it is not clear if these cells are adequate surrogate cells reflecting the condition of relatively inaccessible target tissues. Reviewing the literature on this topic showed that PBMCs have the capability to reflect lipid metabolic genes and expression changes in these genes upon dietary or pharmacological hypolipidemic treatment. PBMCs could therefore potentially be surrogate cells to reflect the liver with respect to lipid metabolism. We performed whole genome microarray analysis on PBMCs, muscle and white adipose tissue (WAT) samples from eleven subjects who received 6-week treatments with placebo, fish oil (3.7 $\mathrm{g} / \mathrm{d} \mathrm{n}-3$ LCPUFA) and fenofibrate $(200 \mathrm{mg} / \mathrm{d})$. These tissues are relevant in the etiology of the metabolic syndrome and could reveal important (PPAR $\alpha$-regulated) genes implicated in metabolic risk reduction. Despite the several physiological effects we observed after PPAR $\alpha$ or $\gamma$ agonists in our intervention studies, these effects were not, or only very marginally, reflected by changes in (PPAR-) related genes. Especially, lipid metabolic gene expression pathways were downregulated after fish oil and fenofibrate treatment in PBMCs. In addition, mitochondrial metabolic pathways were downregulated in both treatments, which may be related to peroxisome proliferation. Fenofibrate hardly affected gene expression in muscle and adipose tissue, showing that these tissues are not primary 
PPAR $\alpha$ target tissues. There was hardly any overlap in gene expression changes between all three tissues. However, there might be a role for PBMCs to serve as surrogate for adipose tissue, due to the large resemblance in altered pathways upon fish oil treatment. These pathways were mainly involved in lipid and amino acid metabolism.

\section{Conclusion}

The studies described in this thesis show that PPAR $\alpha$ and $\gamma$ agonists are able to beneficially modulate metabolic risk factors in type 2 diabetic and overweight subjects. In some instances, nutritional PPAR $\alpha$ agonists may provide an alternative for synthetic agonists, as we show that both fish oil as fenofibrate can exert a comparable TG lowering effect. However, the comparison does not go beyond this and high dosages of fish oil are needed to obtain this effect. Despite their in vitro capability to block pro-inflammatory transcription factor $N F_{K B}$, the PPAR agonists rosiglitazone, fenofibrate and fish oil inconsistently affected markers of inflammation in humans, if at all. The studies in this thesis also show that PPAR agonists are able to induce gene expression changes in PBMCs, although these changes seem not to be a reflection of direct effects of PPAR activation. Despite the very little overlap in gene expression changes between PBMCs, WAT, and muscle after fish oil and fenofibrate treatment, PBMCs might have potency to serve as surrogate cells for WAT for gene expression analysis, since these two cell types showed a large overlap in regulated pathways after fish oil treatment. 

SAmenvatting

145 


\section{Samenvatting}

De incidentie van het metabool syndroom neemt wereldwijd snel toe en vergroot het risico op het ontwikkelen van type 2 diabetes (T2D) en hart- en vaatziekten (HVZ). Overgewicht en obesitas zijn vaak geassocieerd met verschillende risicofactoren die het metabool syndroom karakteriseren, waaronder een abnormaal vet- en koolhydraatmetabolisme en een laag-grade ontstekingsstatus van het lichaam. Peroxisoom prolifererence receptoren (PPARs) $\alpha$ en $\gamma$ zijn interessante moleculaire doelwitten voor management van metabole risico's, omdat deze receptoren bij veel metabole processen betrokken zijn en in diverse weefsels tot expressie komen. Ze kunnen geactiveerd worden door medicijnen en vetzuren uit de voeding. Door een vergelijking te maken tussen een farmacologische en voedingskundige benadering om PPARs te beïnvloeden, kan een mogelijke rol van voeding ontrafeld worden ter voorkoming van metabole verstoringen. Een interessante manier om de moleculaire effecten van een farmacologische en voedingsinterventie op de metabole conditie van specifieke weefsels, zoals vet- en spierweefsel, te onderzoeken is door middel van nutrigenomics. Echter, deze specifieke weefsels zijn in mensen moeilijk beschikbaar voor onderzoek. Het zou daarom gunstig zijn als de eenvoudig bereikbare perifere mononucleaire bloedcellen (PBMC) hiervoor gebruikt zouden kunnen worden. Deze bloedcellen brengen immers ook PPARs tot expressie, waardoor ze interessante surrogaatcellen kunnen zijn om de moleculaire effecten van deze transcriptiefactoren te onderzoeken.

De hoofddoelstelling van de studies beschreven in dit proefschrift was om de fysiologische en moleculaire effecten te onderzoeken van PPARs in diverse metabole processen en om daarbij de rol van vetzuren uit de voeding te identificeren voor het moduleren van deze transcriptiefactoren. De secundaire doelstelling was om de geschiktheid van PBMCs te evalueren als surrogaatcellen voor andere lichaamsweefsels om (PPAR-gerelateerde) genexpressie te reflecteren.

\section{Lipide-, lipoproteine- en glucosemetabolisme}

PPAR $\alpha$ reguleert voornamelijk het vetmetabolisme en activatie van deze receptor leidt tot verlaging van de triglyceride concentratie in het bloed. Dit hypotryglyceridemische effect is toe te schrijven aan een toename van lipoproteine lipase activiteit via PPAR $\alpha$. In onze zesweekse interventie met visolie $(3.7 \mathrm{~g} / \mathrm{d} \mathrm{n}-3$ lange keten meervouding onverzadigde vetzuren ( $n-3$ LCPUFA)) en fenofibraat $(200 \mathrm{mg} / \mathrm{d})$ in mensen met overgewicht en obesitas vonden we inderdaad sterke triglyceride-verlagende effecten na beide interventies. Dit ging samen met verlagingen in VLDL vetdeeltjes. Fenofibraat verbeterde het serumvetprofiel effectief, door ook een verlaging van het LDL cholesterol en verhoging van het HDL cholesterol te bewerkstelligen. Dit in tegenstelling tot visolie, waarbij een stijging van het LDL cholesterol werd waargenomen. Er werd verwacht dat de visolie- en fenofibraatinterventie de LDL deeltjes groter zouden worden met een lagere dichtheid, waardoor ook minder atherogeen. Dit konden we met onze studie echter niet bevestigen. Daarnaast leidde een interventie met fenofibraat of visolie niet tot veranderingen in plasmaglucoseconcentraties.

PPAR $\gamma$ staat bekend om het insuline-gevoeliger maken van het lichaam, 
wat gerelateerd is aan een toename van glucoseopname en een stimulering van vetceldifferentiatie, waarbij meer kleine, insulinegevoeligere vetcellen worden gevormd. Inderdaad liet onze achtweekse interventie met de synthetische PPAR $\gamma$ agonist rosiglitazone zien dat de insuline-gevoeligheid toenam in patiënten met type 2 diabeten. Deze mensen werden zelfs weer net zo insulinegevoelig als de gezonde personen die als referentiegroep dienden. Verder verbeterde rosiglitazone ook het serumvetprofiel, door triglyceriden en vrije vetzuurconcentraties te verlagen en door HDLcholesterolconcentraties te verhogen.

\section{Markers voor laag-grade ontsteking en vasculaire activiteit}

Het metabool wordt ook gekarakteriseerd door een staat van laag-grade ontsteking, al hoort dit niet tot de officiële criteria om het metabool syndroom te diagnostiseren. Het is belangrijk dit te voorkomen, omdat laag-grade ontsteking betrokken is bij het ontstaan van T2D en HVZ. Van PPAR $\alpha$ en $\gamma$ activatoren is gerapporteerd dat ze pro-inflammatoire transcriptiefactoren kunnen remmen, zoals de transcriptiefactor nucleaire factor kappa bèta $(N F \kappa B)$. De beschermende werking van visolie op het ontstaan van HVZ wordt ook gedeeltelijk toegeschreven aan de verlaging van laag-grade ontstekingsmarkers. In onze mechanistische in vitro studie in humane levercellen (HepG2), laten we zien dan fenofibraat en verschillende vetzuren de transcriptiefactor $N F \kappa B$ inderdaad kunnen remmen, al leek dit effect van vetzuren grotendeels onafhankelijk van PPAR $\alpha$ te zijn. Ondanks deze observatie zagen we in onze humane studie geen sterke ontstekingsremmende effecten van PPAR agonisten die gelinkt zouden kunnen worden aan een verminderd risico op het ontwikkelen van HVZ. Zeer weinig laag-grade ontstekingsmarkers en markers van vasculaire activiteit werden beïnvloed door rosiglitazone, fenofibraat en visolie. De veranderingen die werden waargenomen waren ook inconsistent, dus zowel mogelijk anti- als pro-inflammatoire effecten. Rosiglitazone zorgde er voor dat de concentraties van monocyt chemotactisch eiwit 1 (MCP1) en C-reactief proteïne (CRP) daalden, maar deed de concentratie van tumor necrosefactor a (TNF $\alpha$ ) stijgen in patiënten met T2D. Door fenofibraat daalde oplosbaar endotheliaal selectine (E-selectin), maar het deed MCP1 stijgen in mensen met overgewicht en obesitas. Door visolie veranderde zelfs geen van de markers voor laag-grade ontsteking en vasculaire activiteit.

\section{Genexpressie}

PBMCs kunnen gezien worden als schildwachten die door het lichaam surveilleren en fysiologische signalen kunnen oppikken. Het is gerapporteerd dat PBMCs een actief metabolisme hebben, PPARs tot expressie brengen en reageren op voedingsinterventies. Echter, het is niet duidelijk of deze cellen goede surrogaatcellen zijn om de status van relatief onbereikbare doelweefsels weer te geven. De literatuur over dit onderwerp laat zien dat PBMCs de eigenschap bezitten om genen betrokken bij het vetmetabolisme te reflecteren en de expressie van deze genen te laten veranderen op een vetverlagende farmacologische of voedingsinterventie. PBMCs zouden om deze reden interessante surrogaatcellen kunnen vormen voor de lever wat betreft vetmetabolisme. We 
hebben microarray-analyse gedaan op het volledige genoom van PBMCs, spier- en vetweefselmonsters van elf proefpersonen die zesweekse behandelingen ondergingen met placebo, visolie (3.7 g/d n-3 LCPUFA) en fenofibraat (200 mg/d) capsules. De onderzochte weefsels zijn relevant in de etiologie van het metabool syndroom en kunnen belangrijke (PPAR $\alpha$-gereguleerde) genen onthullen die betrokken zijn bij risicoverlaging.

Ondanks de verschillende fysiologische effecten na behandeling met PPAR $\alpha$ en $\gamma$ agonisten in onze interventiestudies, werden deze effecten, als ze al optraden, maar marginaal gereflecteerd door veranderingen in (PPAR-) gerelateerde genen. In PBMCs werden voornamelijk genexpressieroutes betrokken bij vetmetabolisme naar beneden gereguleerd als reactie op visolie en fenofibraatbehandeling. Ook mitochondriale metabole routes werden naar beneden gereguleerd, wat te maken kan hebben met een toegenomen peroxisoomproliferatie. Fenofibraat had maar erg marginaal invloed op genexpressie in spier- en vetweefsel, wat laat zien dat deze weefsels geen primaire doelweefsels zijn voor PPAR $\alpha$. Er was haast geen overlap in genexpressieveranderingen tussen alle drie de weefsels. Echter, PBMCs zouden een rol kunnen spelen als surrogaatcellen voor vetweefsel, omdat er een grote overeenkomst was in veranderde genexpressieroutes na visoliebehandeling. Deze routes waren met name betrokken bij lipide en aminozuurmetabolisme.

\section{Conclusion}

De studies die in dit proefschrift worden beschreven, laten zien dat PPAR $\alpha$ en $\gamma$ agonisten in staat zijn om metabole risicofactoren gunstig te beïnvloeden in mensen met type 2 diabetes en mensen met overgewicht. In sommige gevallen zou een natuurlijke PPAR $\alpha$ agonist een alternatief kunnen zijn voor een synthetische agonist, omdat we hebben laten zien dat zowel visolie- als fenofibraatbehandeling een vergelijkbaar triglycerideverlagend effect kan bewerkstelligen. Echter, de vergelijking gaat niet verder dan dit overeenkomstige effect en er is een hoge dosering visolie nodig om dit effect te bereiken. Ondanks de eigenschap van PPAR agonisten rosiglitazone, fenofibraat en visolie om in vitro de pro-inflammatoire transcriptiefactor $N F \kappa B$ af te remmen, wordt dit nauwelijks en inconsistent gereflecteerd in veranderingen van plasma-ontstekingsmarkers in mensen. De studies beschreven in dit proefschrift laten ook zien dat PPAR agonisten genexpressieveranderingen in PBMCs kunnen induceren, al lijken deze veranderingen niet het directe resultaat te zijn van PPAR activering. Ondanks de zeer marginale overlap in genexpressieveranderingen na PBMCs, vetweefsel en spier na visolie en fenofibraat behandeling, zouden PBMCs wel de potentie kunnen hebben om als surrogaatcellen voor vetweefsel te dienen, omdat deze twee celtypen grote overlap in gereguleerde routes laten zien na visoliebehandeling. 



\section{DANKWOORD}

\section{Publications}

Curriculum Vitae 



\section{Dankwoord}

Promotieonderzoek was voor mij als een lange, boeiende en leerzame treinreis..... De trein reed met wisselende snelheden, van stoptrein tot hogesnelheidstrein en met vertragingen inbegrepen. Soms stapte ik per ongeluk in de verkeerde trein, waardoor ik ongewenste of juist onverwacht verrassende bestemmingen bereikte. Mijn proefschrift is nu echt af, het eindstation van deze treinreis is bereikt!

Deze treinreis heb ik natuurlijk niet in mijn eentje afgelegd. Daarom wil ik iedereen bedanken die heeft bijgedragen aan dit proefschrift en de fijne samenwerking bij de vakgroep Humane Biologie en TI Food \& Nutrition.

Allereerst wil ik mijn promotor Ronald Mensink bedanken. Beste Ronald, als de trein dreigde te ontsporen was je er om bij te sturen. Je kritische, wetenschappelijke vragen en opmerkingen hebben me gestimuleerd om altijd net dat stapje extra te zetten bij het doorgronden van de onderzoeksresultaten. Onze samenwerking en je begeleiding hebben me niet alleen veel geleerd over voedingswetenschap, maar hebben me ook gesterkt in mijn persoonlijke ontwikkeling. Heel veel dank daarvoor.

Verder gaat mijn dank uit naar de beoordelingscommissie, onder voorzitterschap van Prof. Edwin Mariman en verder bestaande uit Prof. Ellen Blaak, Prof. Matthijs Hesselink, Prof. Sander Kersten en Prof. Annemie Schols. Hartelijk dank voor het kritisch doorlezen en beoordelen van mijn proefschrift

Beste proefpersonen, zonder jullie had dit proefschrift nooit tot stand kunnen komen, zeker omdat ongeveer 1260 capsules door ieder van jullie zijn weggeslikt! Hartelijk bedankt voor jullie deelname, alle leuke gesprekken, gezelligheid en jullie oprechte interesse in wetenschappelijk onderzoek.

Beste Jogchum, door jou ben ik er als stagiaire bij Humane Biologie achter gekomen hoe interessant en leuk voedingsonderzoek is. Ik wil je bedanken voor je enthousiasme, onze wetenschappelijke discussies, je hulp bij snelle en interessante verklaringen van resultaten en je opbeurende woorden voor als het even tegen zat.

Beste Herman, je introduceerde me in de wereld van constructen, transfecties, luciferase-metingen en lange labdagen ;-). Mijn begrip hiervan is sterk vergroot, heel erg bedankt daarvoor! De vlinderstruik uit Sittard doet het trouwens ook goed in het hoge noorden!

Een treinreis stelt niets voor, zonder heel veel gezellige medepassagiers! Ik ken inmiddels meer dan 1 generatie ;-) en heb dus helaas niet de ruimte om tot iedereen een persoonlijk woordje te richten. Graag wil ik daarom iedereen bedanken voor de fijne tijd bij het hoofdstation Humane Biologie met veel gezelligheid, lol, koffiemomenten en ondersteuning waar nodig.

Julian, Elke, Leonie en Chris, jullie zijn fantastische kamergenootjes geweest! Ik vond bij jullie altijd een luisterend oor. Bedankt voor het delen van o.a. alle onderzoeksgerelateerde problemen en oplossingen, de geweldige werksfeer, vakantiefoto's als computerachtergrond om bij weg te dromen, de nieuwste mode en haartrends (inclusief kleuradviezen), huis- en interieurontwerpen en veel meer! Ariënne, 
ik heb als stagiaire de fijne kneepjes van het doen van humaan-interventieonderzoek van je mogen leren. Ik heb het geweldig gevonden om je in Milaan te kunnen bezoeken. Zo kon ik genieten van een op en top Italiaans rustmoment om de hectiek van het promoveren te doorbreken. Julia, we hebben elkaar leren kennen in het bestuur van SV Helix. Heel leuk dat je later, 1 uur na mij, ook AiO werd bij Humane Biologie! Bedankt voor de fijne gesprekken, de leuke uitjes buiten werktijd en het openstellen van "Hotel Julia"! Pascal, vaak letterlijk mijn medepassagier op de treinreis. Met onze slaapdronken hoofden konden we de verkeerde trein instappen, om weer in Bunde terecht te komen in plaats van in Maastricht Randwyck! Bedankt voor de relativerende evaluaties van onze promotietrajecten. Florence, ik maakte het je als student niet altijd makkelijk;-). Ik bewonder je gedrevenheid in het doen van onderzoek. Bedankt voor de goede, leuke gesprekken en de logeermogelijkheden, ook na mijn vertrek bij Humane Biologie. Stan, heel erg bedankt voor je gezonde dosis humor! Door jou heb ik heel wat geleerd over bioinformatica en computers, al denk ik wel dat er een positieve correlatie is tussen hoeveel je van computers weet en de kans op crashen ;-). Martine en Carla, dank voor de (gezellige) hulp bij de studie en analyses. Mijn dank gaat ook uit naar al mijn TIFN collega's op diverse tussenstations voor de leuke gesprekken en (praktische) ondersteuning.

Een tijd geleden ben ik aan een nieuwe, avontuurlijke treinreis begonnen die me voerde naar het verre, noordelijke Leeuwarden. Daarom natuurlijk ook nog een woord van dank voor al mijn 'nieuwe' collega's bij FrieslandCampina. Door jullie voelde ik me al heel erg snel thuis in deze nieuwe geografische- en werkomgeving. Anne, André, Eiko, Ilse, Miriam en Olga bedankt voor de fijne werksfeer op onze afdeling!

Dan wil ik nu het woord richten aan mijn lieve (schoon)familie en vrienden, die ervoor hebben gezorgd dat ik deze reis heb kunnen starten en het eindstation heb kunnen bereiken. Dat promoveren leek voor sommigen van jullie een haast onbegrijpelijk en eindeloos traject, maar nu kan ik dan eindelijk de vraag "is je proefschrift al klaar?" met een volle "ja" beantwoorden! Dank voor al jullie steun!

Lieve Esther, in onze kansloze flat in Tilburg verklaarde je me voor gek dat ik echt helemaal in het verre Maastricht ging promoveren en met de trein op en neer ging reizen. Het was daarom een extra verrassing dat je me daarna gewoon naar Maastricht volgde! Het is bijzonder hoe onze levens zo parallel gingen lopen; verhuizen, promoveren, trouwen, moeder worden. Ik ben heel blij dat ik ook dit proces van promoveren met je heb kunnen delen. Lieve Anke, we werden vriendinnen in Maastricht tijdens onze studietijd. Bedankt voor je vriendschap en de gezellige momenten! Esther en Anke, fijn dat jullie mijn paranimfen zijn! Met 2 psychologen achter me moet die verdediging toch zeker wel goed komen!

Anne, Annette, Ellen, Karin en Saskia, bedankt voor jullie steun wanneer nodig en voor de leuke momenten als welkome afleiding tijdens mijn promotietraject. Ik kijk elk jaar weer uit naar vrijwel jaarlijks terugkerende tradities: beachvolleyballen met mannen en kids, het vieren van Sinterklaas en weekendjes weg.

Bernadette, mijn lieve 'zusje', nu we allebei in de voedingsmiddelenindustrie terecht zijn gekomen is het leuk dat we daar alle ins en outs over kunnen delen! 
Papa en mama, het is mede aan jullie te danken dat ik sta waar ik nu sta. Dank voor jullie liefde, onvoorwaardelijke steun, interesse en ruimte om mezelf te kunnen ontwikkelen. De leuke discussies aan de keukentafel met papa, met name over voedselveiligheid ;-), hebben zeker een basis gevormd voor mijn interesse in voeding.

Als laatste richt ik me tot de belangrijkste persoon in mijn leven. Paul, het is eigenlijk niet in woorden uit te drukken wat je voor me betekent. Bedankt voor je steun, het opbrengen van bergen geduld, maar bovenal bedankt voor je liefde. Daarbij was het bijzonder om mee te maken dat onze liefde nog eens vermenigvuldigde toen we het konden delen met Noah, ons prachtige, lieve en grappige ventje. Dit werkte erg relativerend op het haast onbegrijpelijke proces van promoveren. Ik kijk erg uit naar onze verdere toekomst samen! Ik hou van je. 



\section{Publications}

\section{Full papers}

- Bragt MCE, Mensink RP. Comparison of the effects of n-3 long chain polyunsaturated fatty acids and fenofibrate on markers of inflammation and vascular function, and on the serum lipoprotein profile in overweight and obese subjects. Nutr Metab Cardiovasc Dis 2011; doi10.1016/j.numecd.2010.12.010.

- Bragt MCE, Plat J, Mensink M, Schrauwen P, Mensink R. Anti-inflammatory effect of rosiglitazone is not reflected in expression of NFKB-related genes in peripheral blood mononuclear cells of patients with type 2 diabetes mellitus. BMC Endocr Disord 2009; 25(9):8

- Bragt MCE, Popeijus H.E. Peroxisome proliferator-activated receptors and the metabolic syndrome. J Physiol Behav, 2008; 94(2): 187-197

- Dullens PJ, Mensink RP, Bragt MCE, Kies AK, Plat J. Effects of emulsified policosanols with different chain-lengths on cholesterol metabolism. J Lipid Res, 2008; 49(4): 790-796

- Plat J, Bragt MCE, Mensink RP. Common sequence variations in ABCG8 are related to plant sterol metabolism in healthy volunteers. J Lipid Res, 2005; 46(1): 68-75.

\section{Abstracts and poster presentations}

- Bragt MCE, Plat J, Mensink M, Schrauwen P, Mensink RP. The effects of rosiglitazone on inflammation markers and expression of $\mathrm{NF} \kappa \mathrm{B}$-related genes in type II diabetic subjects. Keystone Symposium 2008 "Diabetes, insulin action and resistance", Breckenridge, Colorado, USA

- Bragt MCE, Plat J, Greve J-W, Mensink RP. Correlations of molecular signatures between peripheral blood mononuclear cells and other specified tissues. NuGO week 2005, Tuscany, Italy. This poster was awarded with the NuGO poster prize for excellence in communication

- Plat J, de Jong A, Bragt MCE, Mensink RP. Plant sterol and stanol esters do not influence markers for endothelial function and inflammation in subjects on statin treatment despite a significant LDL reduction. Atherosclerosis 2004; 5 (Suppl 1): 34. EAS 2004, Seville, Spain. 



\section{Curriculum vitae}

Marjolijn Bragt was born on January 101981 in Roosendaal, the Netherlands. In 1999, she completed her secondary school at "Norbertus College" in Roosendaal. Subsequently, she started her academic education and studied Health Sciences with a specialization in Biological Health Sciences and molecular biology at the Faculty of Health Medicine and Life Sciences of Maastricht University. Her internship was spent at the department of Human Biology, Maastricht University to study the effects of plant sterols and stanols on inflammation and endothelial function in statin-treated patients. She graduated

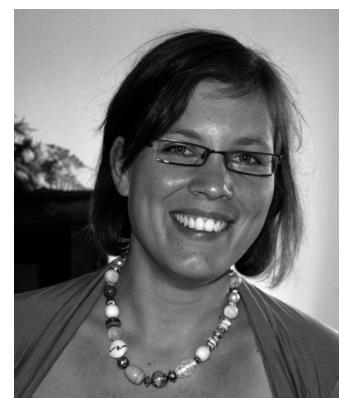
in 2003. Her master's thesis was awarded with the Unilever Research Prize 2004. In October 2003, Marjolijn was appointed as a research assistant at the department of Human Biology, Maastricht University to study the effects of policosanols on ApoA1 expression in liver and intestinal cells. From September 2004 to December 2008, she worked as a PhD-fellow in the same department on a project from Top Institute Food \& Nutrition under supervision of prof. dr. ir. Ronald P. Mensink. In this research project, she studied the role of peroxisome-proliferator-activated receptors (PPARs) in metabolic risk management, using a pharmacological and nutritional approach. Since September 2009, Marjolijn works as a nutritionist in the field of immunity at FrieslandCampina Innovation Infant \& Toddler Nutrition in Leeuwarden, the Netherlands. 
